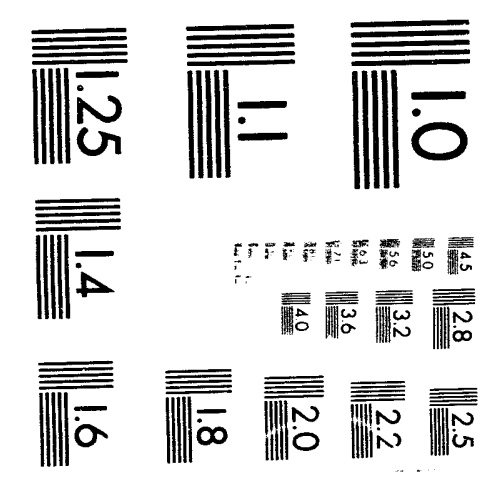



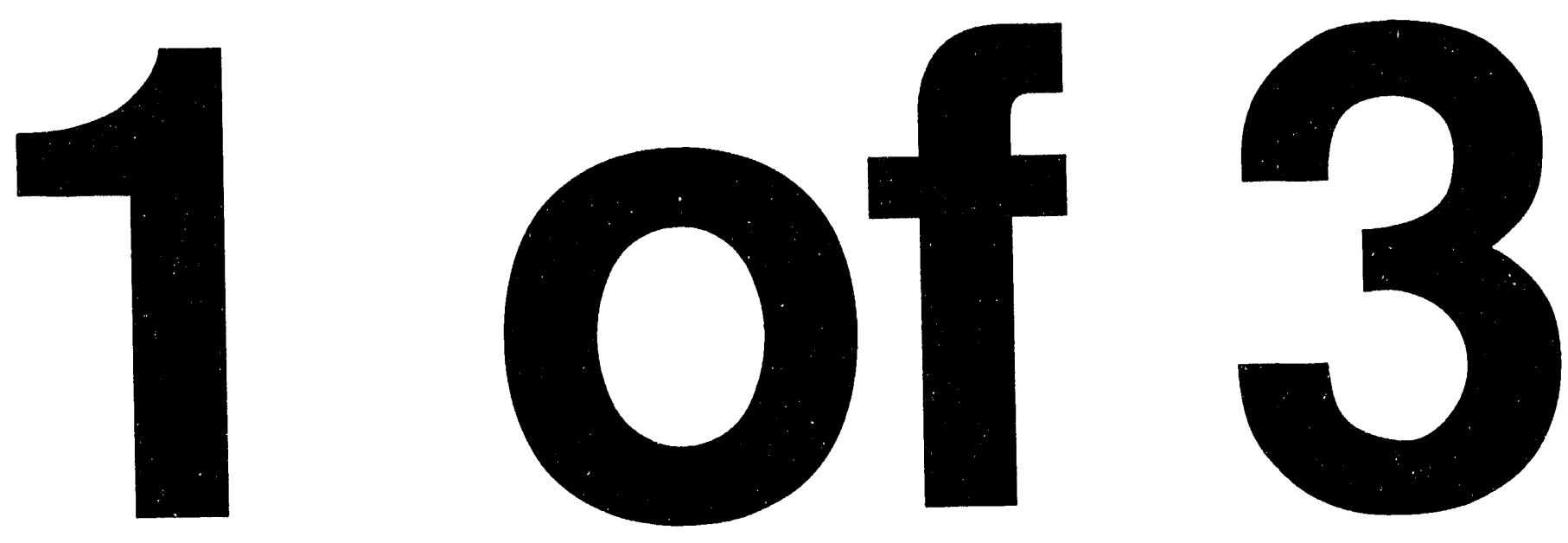


\title{
INVESTIGATION OF FORCED AND ISOTHERMAL CHEMICAL VAPOR INFILTRATED SiC/SiC CERAMIC MATRIX COMPOSITES
}

\author{
Final Report
}

J. Sankar, A. D. Kelkar, and R. Vaidyanathan

Date Published : September 1993

\begin{abstract}
Research sponsored by the U. S. Department of Energy, Fossil Energy

Advanced Research and Technology Development Materials Program
\end{abstract}

\author{
Report Prepared by \\ Department of Mechanical Engineering \\ North Carolina A \& T State University \\ Greensboro, North Carolina 27411 \\ under \\ Subcontract No. 19X-SC423C \\ for \\ OAK RIDGE NATIONAL LABORATORY \\ Oak Ridge, Tennessee 37831 \\ managed by \\ MARTIN MARIETTA ENERGY SYSTEMS, INC. \\ for the \\ U. S. Department of Energy \\ under Contract No. DE-AC05-84OR21400
}

\section{MASTER}


TABLE OF CONTENTS

Page No.

List of Tables

List of Figures $\quad$ vi

Abstract $x$

CHAPTER

1. Introduction 1

2. Theoretical background for CVI composites 12

2.1. Chemical vapor infiltration process 12

2.2. Chemical vapor infiltration of $\mathrm{SiC} / \mathrm{SiC}$ composites 17

2.2.1. Isothermal CVI process for $\mathrm{SiC} / \mathrm{SiC}$ composites 19

2.2.2. Forced flow/thermal gradient CVI process for 23 $\mathrm{SiC} / \mathrm{SiC}$ composites

2.3. Interfacial modification in $\mathrm{SiC} / \mathrm{SiC}$ composites for 26 improved toughness

2.4. Effect of interfaces on the properties of fiber 28 reinforced ceramics

2.5. Basic mechanisms of toughening in ceramic matrix 33 composites

2.5.1. Load Transfer 39

2.5.2. Prestressing 39

2.5.3. Crack Impediment 40

2.5.4. Crack deflection or multiplication/fiber 41 pullout

2.5.5. Microcracking 42

2.5.6. Phase transformation toughening 44

2.5.7. High temperature aspects of toughening 45 mechanisms

2.5.8. Combined mechanisms of toughening 45

2.5.9. Combination with the modulus load transfer 46 mechanism

2.5.10.Combination with prestressing and line tension 47 mechanisms

2.5.11.Combination with pullout and microcracking $\quad 47$ mechanisms

2.6 Mechanical properties of $\mathrm{SiC} / \mathrm{SiC}$ composites 48

2.7 Characterization with electron microscopy 54

2.8 Relevance of the current thesis 57 
Page No.

3. Experimental set up, materials, and procedures 60

3.1. Materials systems 60

3.1.1. Specimen configuration 63

3.2. Experimental set up $\quad 67$

3.2.1. Testing machine and controls 67

3.3. Calibration of laser extensometer 73

3.4. Microstructural characterization 74

3.5. Calculation of initial modulus from the stress-strain 76 curves

4. Experimental results 78

4.1. Results of the characterization of the laser extensometer 78

4.2. Stress-strain behavior of $\mathrm{SiC} / \mathrm{SiC}$ composites 78

4.3. Scanning electron microscopy/transmission electron 82 microscopy of $\mathrm{SiC} / \mathrm{SiC}$ composites

5. Analytical modeling procedures and resuits 144

5.1. The analytical model 145

5.1.1. Plain weave-classical laminate theory (PWCLT) 148

5.1.2. Volume fraction and undulation length 149 computation

5.1.3. Boundary conditions for fill and warp fibers $\quad 149$

5.2. Results of the analytical model 152

6. Discussion 160

6.1. Experimental 160

6.1.1. Characterization of the laser extensometer 160

6.1.2. Mechanical behavior of FCVI and ICVI SiC/SiC 161 composites

6.1.3. Mechanical behavior vs microscopy of FCVI and 165 ICVI SiC/SiC composites

6.2. Analytical

173

6.2.1. Graphite/Epoxy system 173

6.2.2. $\mathrm{SiC} / \mathrm{SiC}$ system 174

7. Conclusions and Recommendations 177

7.1. Conclusions 177

7.1.1. Experimental 177

7.1.2. Analytical 178

$\begin{array}{ll}\text { 7.2. Recommendations } & 179\end{array}$

8. References 181 
TABLE

\section{LIST OF TABLES}

Page No.

1.1. Mechanical and physical properties of reinforcement components for 4 silicon carbide

2.1. Ceramic matrix composite toughening concepts

2.2. Possible combinations of toughening mechanisms in ceramic matrix composites

3.1. Comparison of materials investigated

4.1. Calibration results for Zygo laser extensometer at room temperature

4.2. Calibration results for Zygo laser extensometer at $500 \mathrm{deg}$. C

4.3. Calibration results for Zygo laser extensometer at $800 \mathrm{deg}$. C

4.4. Calibration results for Zygo laser extensometer at $1000 \mathrm{deg}$. C

4.5. Maximum difference between micrometer and laser extensometer readings

82

4.6 Test conditions, tensile strength, and initial modulus results for $\mathrm{SiC} / \mathrm{SiC}$ ceramic matrix composites

5.1. Constituent material properties

5.2. Equivalent fiber properties as a function of coating thickness

5.3. Input/output format for program PWCLT

5.4. Comparison of PWCLT model results with experimental results for graphite/epoxy fabric composite

5.5. Comparison of PWCLT model results with experimental results for $\mathrm{SiC} / \mathrm{SiC}$ fabric composite

6.1. General mechanical behavior under various test conditions (RT, $\mathrm{RT} / \mathrm{TS}, \mathrm{RT} / \mathrm{OX}, 1000 \mathrm{deg}$. C) for $\mathrm{SiC} / \mathrm{SiC}$ composites

6.2. General fracture surface investigation under various test conditions (RT, RT/TS, RT/OX, $1000 \mathrm{deg}$. C) for $\mathrm{SiC} / \mathrm{SiC}$ composites 
6.3. Effect of interfacial coating under various test conditions 168 (RT, RT/TS, RT/OX, 1000 deg. C) for $\mathrm{SiC} / \mathrm{SiC}$ composites

6.5. Factors controlling failure processes in CVI composites 


\section{LIST OF FIGURES}

FIGURE

Page No.

2.1. Equipment for CVD and CVI 14

$\begin{array}{ll}\text { 2.2. Five types of CVI processes } & 14\end{array}$

2.3. Schematic representation of the isothermal CVI process 21

2.4. Schematic representation of the forced flow-thermal gradient 24 CVI process

2.5. Typical debonding and sliding processes in ceramic matrix composites 30

2.6. A typical stress-strain curve for a ceramic matrix composite 30

2.7. A schematic drawing explaining the initial debonding/no bonding 32 behavior in ceramic matrix composites

2.8. The cubic, zinc-blende structure of $\beta$-SiC 56

2.9. Projections of the $3 \mathrm{C}, 6 \mathrm{H}$, and $15 \mathrm{R}$ structures of $\mathrm{SiC} 56$

3.1. A quasi-isotropic layup for $\mathrm{SiC} / \mathrm{SiC}$ composite material 62

3.2. Schematic drawing of the sample design 65

3.3. Tensile sample design 66

3.4. Test-set up used for tensile characterization of the $\mathrm{SiC} / \mathrm{SiC} \quad 68$ composite system

3.5. Self-aligning hydraulic grip system for gripping composite specimens 70

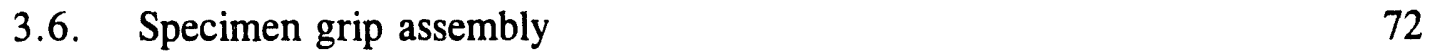

$\begin{array}{lll}\text { 3.7. Specimen with attached tabs and flags } & 73\end{array}$

3.8. Close-up view of the calibration set-up 75

4.1. Laser extensometer characterization, $25 \mathrm{deg}$. C 83

4.2. Laser extensometer characterization, $800 \mathrm{deg}$. C 84 
4.3. Laser extensometer characterization, 1000 deg. C 85

4.4. Stress-strain ; FCVI ; 0/30/60 86

4.5. Stress-strain ; RT ; RT/TS ; $1000 \mathrm{C}$; FCVI ; 0/30/60 88

4.6. Stress-strain ; RT ; RT/OX ; $1000 \mathrm{C}$; FCVI ; 0/30/60 89

4.7. Stress-strain ; RT ; RT/TS ; $1000 \mathrm{C}$; FCVI ; 0/45 90

4.8. Stress-strain ; RT ; RT/OX ; $1000 \mathrm{C}$; FCVI ; 0/45 91

4.9. RT stress-strain ; FCVI ; 0/30/60 and 0/45 92

4.10. 1000 C stress-strain ; FCVI ; 0/30/60 and 0/45 93

4.11. Stress-strain ; RT ; RT/TS ; RT/OX ; ICVI ; 0/45 94

4.12. Stress-strain ; RT ; RT/TS ; $1000 \mathrm{C}$; ICVI ; 0/90 95

4.13. Stress-strain ; RT ; RT/OX ; 1000 C ; ICVI ; 0/90 96

4.14. RT stress-strain ; ICVI ; 0/90 and 0/45 97

4.15. RT stress-strain after TS ; ICVI ; 0/90 and 0/45 98

4.16. RT stress-strain ; ICVI and FCVI ; 0/45 99

4.17. RT stress-strain after TS ; ICVI and FCVI ; 0/45 100

4.18. Volume effect on RT stress-strain ; ICVI ; 0/90 101

4.19. Tensiie strength vs treatment conditions ; FCVI 0/30/60 layup 102

4.20. Tensile strength vs treatment conditions ; FCVI 0/45 layup 103

4.21. Tensile strength vs treatment conditions ; ICVI 0/45 layup 104

4.22. Tensile strength vs treatment conditions ; ICVI 0/90 layup 105

4.23. Tensile strength vs treatment conditions ; Average strength ; 106 $\mathrm{SiC} / \mathrm{SiC}$ composites 
4.25. Average initial modulus vs treatment conditions ; $\mathrm{SiC} / \mathrm{SiC}$ composites 108

4.26. Typical failure pattern in $\mathrm{SiC} / \mathrm{SiC}$ tensile specimens

4.27. Fractography of FCVI SiC/SiC composites ; 0/45; RT

4.28. Fractography of FCVI SiC/SiC composites ; 0/45; RT

4.29. Fractography of FCVI SiC/SiC composites ; 0/45; RT

4.30. Fractography of FCVI SiC/SiC composites ; 0/45; RT

4.31. Fractography of FCVI SiC/SiC composites ; 0/45; RT

4.32. Fractography of FCVI SiC/SiC composites ; 0/30/60 ; $1000 \mathrm{C}$

4.33. Fractography of FCVI SiC/SiC composites ; 0/30/60; $1000 \mathrm{C}$

4.34. Fractography of FCVI SiC/SiC composites ; 0/30/60 ; $1000 \mathrm{C}$

4.35. Fractography of FCVI SiC/SiC composites ; 0/30/60 ; RT/TS

4.36. Fractography of FCVI SiC/SiC composites ; 0/30/60 ; RT/TS

4.37. Fractography of FCVI SiC/SiC composites ; 0/30/60 ; RT/OX

4.38. Fractography of FCVI SiC/SiC composites ; 0/30/60 ; RT/OX

4.39. Fractography of ICVI SiC/SiC composites ; 0/45; RT

4.40. Fractography of ICVI $\mathrm{SiC} / \mathrm{SiC}$ composites ; 0/45; RT/TS

4.41. Fractography of ICVI SiC/SiC composites ; 0/45; RT/OX

4.42. Fractography of ICVI $\mathrm{SiC} / \mathrm{SiC}$ composites ; $0 / 45$; RT/OX

4.43. Fractography of ICVI SiC/SiC composites ; 0/45;1000 C 
FIGURE

Page No.

4.45. Fractography of ICVI SiC/SiC composites ; 0/90;1000 C

131

4.46. Fractography of ICVI SiC/SiC composites ; 0/90 at RT and $0 / 45$ at $1000 \mathrm{C}$

4.47. TEM of FCVI SiC/SiC composites ; 0/30/60 ; RT/OX ;

Bulk material

4.48. TEM of FCVI SiC/SiC composites ; 0/30/60 ; RT/OX ;

134

Bulk material

4.49. TEM of FCVI SiC/SiC composites ; 0/30/60 ; RT/OX ; Bulk material

4.50. TEM of ICVI SiC/SiC composites ; 0/45 ; RT ; Bulk material

136

4.51. TEM of ICVI SiC/SiC composites ; 0/45 ; RT ; Bulk material

4.52. TEM of ICVI SiC/SiC composites ; 0/45 ; RT ; Bulk material

138

4.53. TEM of ICVI SiC/SiC composites ; 0/45 ; RT ; Bulk material

4.54. TEM of FCVI SiC/SiC composites ; 0/30/60 ; RT/OX ;

140 Bulk material

4.55. TEM of FCVI SiC/SiC composites ; 0/30/60 ; RT/OX ; Fracture surface

4.56. TEM of FCVI SiC/SiC composites ; 0/30/60;1000 C ; Fracture surface

4.57. TEM of ICVI SiC/SiC composites ; 0/45 ; RT ; Fracture surface

5.1. Common interlacing patterns used in various fabric composites

5.2. Unit cell representation of the plain weave pattern 148

5.3. Predicted single lamina properties of $\mathrm{CVI} \mathrm{SiC/SiC} \mathrm{composites}$ vs fiber coating thickness using program PWCLT

5.4. Predicted Poisson's ratios of CVI SiC/SiC composites vs fiber 159 coating thickness using program PWCI.T 


\title{
INVESTIGATION OF FORCED AND ISOTHERMAL CHEMICAL VAPOR INFILTRATED SiC/SiC CERAMIC MATRIX COMPOSITES*
}

\author{
J. Sankar, A. D. Kelkar, and R. Vaidyanathan
}

\begin{abstract}
Ceramic fiber reinforced ceramic matrix composites fabricated by chemical vapor infiltration (CVI) have recently received a lot of attention for use in high temperature structural applications because of their high strength and toughness, especially at elevated temperatures. The aim of this research was to study the mechanical properties of woven ceramic matrix composites fabricated by forced CVI (FCVI) and isothermal CVI (ICVI) processes, and in particular, $\mathrm{SiC}$ fiber reinforced $\mathrm{SiC}$ matrix systems.

The mechanical properties of two different layups for each of the FCVI (41 specimens) and ICVI (36 specimens) materials were investigated in air at room temperature (RT), $1000^{\circ} \mathrm{C}(1000 \mathrm{C})$, and at room temperature after thermal shock (RT/TS) and exposure to oxidation (RT/OX). The FCVI specimens had a nominal interfacial coating thickness of $0.3 \mu \mathrm{m}$ of pyrolytic carbon, while the ICVI specimens had a coating thickness of $0.1 \mu \mathrm{m}$. The effect of the reinforcement and the interfacial bond on the mechanical properties of the composite were investigated. Scanning electron microscopy (SEM) and transmission electron microscopy (TEM) were employed to analyze the fiber-matrix interface and the toughening mechanisms in this ceramic composite system.

$\mathrm{SiC} / \mathrm{SiC}$ CVI ceramic composites were observed to exhibit a tensile behavior showing both a linear elastic range and a non-linear region with a smooth slope change at the test conditions (RT, $1000 \mathrm{C}, \mathrm{RT} / \mathrm{TS}$, and RT/OX). The stress-strain and toughening behavior of these composites were found to be strongly influenced by the interfacial coating thickness, operating temperature, environmental conditions, density of infiltration, and the layup sequence. The extent of fiber pull-out was found to be controlled by the interfacial coating thickness. The toughness in these composites was found to be controlled through combinations of matrix cracking/partial fiber-matrix debonding, crack bridging, crack deflection, fiber pull-out and crack blunting mechanisms. Both the SEM and TEM studies conducted supported the above conclusions. The average tensile strength at $\mathrm{RT}$ of the $\mathrm{SiC} / \mathrm{SiC}$ system for both FCVI and ICVI materials were retained under all test conditions. Thermal shock and exposure to oxidizing conditions were found to be detrimental to the composite interfacial properties.

Three (3) ICVI specimens with a higher testing volume were also tested. These exhibited superior tensile properties as compared to the specimens with the lower testing volume which seems to indicate that there might be a specimen volume effect on the
\end{abstract}

"Research Sponsored by the U. S. Department of Energy, Fossil Energy AR \& TD Materials Program, DOE/FE AA 151010 0, Work Breakdown Structure Element NCAT-1 
strength of these materials but more effort has to be focussed in this area of research.

An analytical model was developed by considering a typical representative fabric element of the composite. A plain weave/classical laminate theory was used in this model to predict the mechanical properties such as Young's modulii, Poisson's ratio, and Shear modulus for ceramic matrix woven fabric composites, based upon the constituent material properties of the fiber and the matrix. Within the fabric element, a repeating unit, termed as a unit cell was identified. The developed model is capable of predicting both the modulii and Poisson's ratio for CMC systems. The predicted values using the model matched well with the experimental values for the $\mathrm{SiC} / \mathrm{SiC}$ system.

Key words : Fiber reinforced ceramic matrix composites, chemical vapor infiltration, mechanical properties, ceramic toughening mechanisms, fractography, interfacial properties, plain weave/classical laminate theory. 


\section{CHAPTER 1}

\section{INTRODUCTION}

There has been a great interest among scientists to develop new materials for potential high temperature applications in several areas. These include advanced heat engines, power engineering, chemical and petrochemical processing, coal conversion, and aerospace etc. These have led to the use of structural ceramics in a variety of applications, because of their good retention of strength and excellent oxidation resistance at high temperatures. The nonductile behavior of structural ceramics over a wide temperature range require that candidate ceramics have : i) a low coefficient of thermal expansion, ii) low elastic modulus, iii) retention of high strength at high temperature, iv) high thermal conductivity, and, v) good oxidation resistance. Ceramics based on either silicon nitride or silicon carbide are the prime candidates to meet these property requirements at temperatures above $800^{\circ} \mathrm{C}$ (Kingery et al., 1976, Neil 1984).

Silicon carbide is a promising high temperature material because of its excellent chemical and physical properties. The chemical stability of silicon carbide is based on the growth of a protective glassy or partially crystallized $\mathrm{SiO}_{2}$ layer at the surface of the material (Schlichting 1979). Good high temperature strength, thermal shock resistance, low thermal expansion coefficient, good heat conductivity, hardness, abrasion resistance, low density, are possessed by silicon carbide (Fitzer et al., 1986). However, silicon carbide is a highly refractory and hard material. Consequently, it is difficult to make it 
into a fine grained, dense ceramic. Silicon carbide materials are currently made by three principal methods, namely, i) Reaction bonded $\mathrm{SiC}$ ii) Hot pressed $\mathrm{SiC}$, and iii) Sintered SiC (Morrel, 1985).

Of the above forms, the highest strengths are obtained by hot pressing. However, the reaction bonded type is most suitable for industrial production. The strength of reaction bonded type $\mathrm{SiC}$ is only moderate, when compared to the hot pressed type of $\mathrm{SiC}$, while its fracture toughness is insufficient for most uses (Fitzer and Gadow, 1986). Therefore, researchers have tried to increase these critical mechanical properties by the use of fiber reinforcement.

The main aim of fiber reinforcement is to strengthen and toughen the material which forms the matrix of the composite material. The major factors which influence the properties of the composite material are : i) the mechanical properties of the individual components themselves, ii) the degree of interaction between the fiber and the matrix (geometrical, adhesion, chemical, and physical) (Fitzer and Gadow, 1986).

For the reinforcement of a brittle material like silicon carbide, Günther (1978) has proposed two basic models. In the first model, it is assumed that the brittle matrix is reinforced by high modulus fibers, with complete adhesion between the fibers and the matrix. Here, the strain to failure of the composite will be controlled by the strain to failure of the matrix. Simple brittle fracture will occur, and the tensile strength of the fiber will not contribute to either the toughness or the strength of the composite, even though the initial strain to failure of the fiber may exceed that of the matrix. In the second case, it is assumed that there is imperfect bonding between the fiber and the 
matrix, and the interface will cause the cracks to be deflected and blunted. In these cases, there is a critical fiber volume fraction $\theta_{\mathrm{F}}$, above which multiple matrix fracture is favored over single matrix fracture. Here, the strength of the composite is dependent only on the fiber strength.

The choice of the fibers to be used for the reinforcement of the $\mathrm{SiC}$ matrix is dependent on i) compatibility of the fibers to the matrix, ii) the ability of the fibers to withstand the temperatures experienced during processing and service. The mechanical and physical properties of some reinforcement components that are considered for $\mathrm{SiC}$, are given in Table 1.1 (Fitzer and Gadow, 1986). Fitzer and Gadow during their research, observed that carbon and $\mathrm{SiC}$ fibers, and $\mathrm{SiC}$ whiskers were the best reinforcement materials. They observed that at processing temperatures above $1300^{\circ} \mathrm{K}$, the best tensile strength was obtained from carbon fibers, while polycarbosilane derived $\mathrm{SiC}$ fibers exhibited a significant decrease in strength above $1000^{\circ} \mathrm{C}$. It was also observed that in the case of chemical vapor infiltration or impregnation of $\mathrm{SiC}$ into a fibrous preform of fibers, $\mathrm{SiC}$ fibers showed resistance to chemical attack by the gaseous reactants during the infiltration.

Ideally, sintering or hot pressing could be used to fabricate $\mathrm{SiC}$ fiber or whisker reinforced SiC composites. However, Fitzer and Gadow (1986) report that there is hardly any published research in which the processing temperature and pressure did not exceed critical values to recrystallize or shear the fibers. Therefore, researchers concentrated their interest on CVD based, reaction-bonded, and organosilicon based SiC composites. Chemical vapor infiltration (CVI) has been reported to be a successful method to 
Table 1.1 Mechanical and Physical Properties of Reinforcement Components for Silicon Carbide (Fitzer and Gadow, 1986)

\begin{tabular}{|c|c|c|c|c|c|c|c|}
\hline \multirow[b]{2}{*}{ Property } & \multicolumn{4}{|c|}{ Fibers } & \multicolumn{2}{|c|}{ Whiskers } & \multirow[b]{2}{*}{$\alpha-\mathrm{Si}_{3} \mathrm{~N}_{4}$} \\
\hline & Carbon(HM) $^{*}$ & $\mathrm{PCS}-S i C^{* *}$ & CVD-SiC ${ }^{* * *}$ & $\mathrm{Al}_{2} \mathrm{O}_{3}$ & $\alpha-\mathrm{SiC}$ & $\beta-\mathrm{SiC}$ & \\
\hline $\begin{array}{l}\text { Filament diameter } \\
\qquad(\mu \mathrm{m})\end{array}$ & $\begin{array}{l}\text { 6.5-7.5(Pan) } \\
\text { 10-14 (Pitch) }\end{array}$ & $9-15$ & $100-140$ & $15-25$ & $5-20$ & $0.05-1.5$ & $0.1-1.6$ \\
\hline $\begin{array}{l}\text { Filament length } \\
\text { (mm) }\end{array}$ & Endless & Endless & Endless & 1000 & $2-20$ & $0.02-0.2$ & $0.02-0.2$ \\
\hline $\begin{array}{l}\text { Tensile Strength } \\
\left(10^{3} \mathrm{MPa}\right)\end{array}$ & $\begin{array}{l}2.5-3.5 \\
(1.4-2.3 \text { coate }\end{array}$ & ed) & $2.5-3.7$ & $1.2-1.4$ & $8-21$ & $3-21$ & $3-14$ \\
\hline $\begin{array}{l}\text { Young's Modulus } \\
\text { (GPa) }\end{array}$ & $320-390$ & $180-200$ & $380-420$ & $340-400$ & $450-490$ & $400-490$ & 385 \\
\hline Density $\left(\mathrm{g} / \mathrm{cm}^{3}\right)$ & $1.8-1.9$ & $2.55-2.58$ & $3.4-3.5$ & $3.90-3.95$ & 3.21 & $3.18-3.19$ & 3.18 \\
\hline $\begin{array}{l}\text { Thermal Expansion } \\
\text { Coeff. }\left(10^{-6} \mathrm{~K}^{-1}\right)\end{array}$ & $-0.5-0.2$ & 3.1 & $4.2-4.5$ & $7.0-8.6$ & $4.4-4.6$ & $4.4-4.7$ & $2.4-2.5$ \\
\hline $\begin{array}{l}\text { Parallel } \\
\text { Perpendicular }\end{array}$ & $10-15$ & $\begin{array}{l}3.1 \\
7.0-8.6\end{array}$ & $\begin{array}{l}4.2-5.2 \\
4.4-4.6\end{array}$ & & & $\begin{array}{l}4.1-4.7 \\
2.4-2.5\end{array}$ & \\
\hline
\end{tabular}

* High Modulus

** Polycarbosilane derived

*** Chemically vapor deposited 
infiltrate and densify SiC ceramics (Fitzer and Gadow 1986, Stinton et al., 1986). The matrix is created in this process by the thermal decomposition of $\mathrm{CH}_{3} \mathrm{SiCl}_{3}$ (Methyltrichlorosilane) to $\mathrm{SiC}$ at 1200 to $1400^{\circ} \mathrm{K}$ in a hot wall tubular reactor. The theory of CVI and experimental conditions are discussed later in another chapter.

Fitzer and Gadow (1986) have identified the properties of several types of fiber reinforced $\mathrm{SiC}$ composites. They report that the CVD-SiC fiber reinforced $\mathrm{SiC}$ composite showed the highest absolute strength compared with all $\mathrm{SiC}$ composites, but exhibited brittle behavior. They believed this to be due to the adhesion between the fiber and the matrix, which prevented the matrix cracks from being deflected. However, high modulus Carbon fiber reinforced $\mathrm{SiC}$ composites did exhibit a small range of inelastic behavior at the maximum stress range, due to the incomplete adhesion between the carbon fibers and the CVI SiC matrix. Naslain et al., (1980) investigated the effect of infiltrating multidirectional preforms of carbon fibers with CVD SiC. They were able to create high modulus composites in this manner, with almost identical results being obtained by Fitzer and Gadow (1986). Société Européenne de Propulsion introduced the use of two dimensional fiber reinforcement with layers of woven fabrics of polycarbosilane based $\mathrm{SiC}$ fibers. These were used to manufacture SiC fiber reinforced CVD SiC composites, in 1983 (reference 36 in Fitzer and Gadow, 1986). However, it was observed that there was a strong decrease in the bend strength of the composite at temperatures above $1300^{\circ}$ $\mathrm{K}$. It was also found that the $\mathrm{SiC} / \mathrm{SiC}$ composites exhibited quasi-isotropic thermal expansion behavior. However, a major limitation for this material was the long processing times required for the fabrication. 
Lamicq et al., (1986) have presented the results of several tests done on Isothermal CVI SiC/SiC composite, conducted at Société Européenne de Propulsion, France. A typical tensile test curve for this material (Lamicq et al., 1986) exhibited two distinct parts, with two slopes. In the first portion, the fibers and the matrix are both undamaged. In the second part, the matrix gradually cracks, and the matrix and fibers debond partly. Once the fibers that hold the fractured matrix portions (which is strongly cracked) break, the composite undergoes final fracture. The strain to failure is quite high compared to a monolithic ceramic ( $\mathrm{SiC})$, and is as high as $0.8 \%$. Thermal conductivity and diffusivity values are reported to be low, compared to a monolithic ceramic, possibly due to the pores acting as thermal barriers and the fibers which contain oxygen and carbon.

Lamicq et al., (1986) also performed environmental tests on $\mathrm{SiC} / \mathrm{SiC}$ composites using a 4 point bend fixture. They reported that these composites exhibit a slight increase in bending strength from room temperature to $1300^{\circ} \mathrm{C}$, with some strength remaining at temperatures of 2000 to $2200^{\circ} \mathrm{C}$. It has been reported that this material exhibits no sharp loss in strength at high temperatures, enhancing its ability to sustain temporary overheating without catastrophic failure. These materials also have been reported to have excellent oxidation resistance even after $500 \mathrm{~h}$ exposure to $1100^{\circ} \mathrm{C}$ in air, with no loss in bend strength after the exposure. $\mathrm{SiC} / \mathrm{SiC}$ composites are also reported (Lamicq et al., 1986) to have excellent thermal shock as well as thermal fatigue resistance. In the thermal shock tests, the composite samples were heated to a certain temperature and quenched into cold water. It was observed that there was a slight decrease in the bend 
strength for temperatures above $300^{\circ} \mathrm{C}$, with no catastrophic failure observed up to $1200^{\circ}$ C. The increase in strength at elevated temperatures may he explained as follows. Due to the difference in thermal expansion characteristics of the fiber and matrix, the composite at room temperature may have the fiber in tension, while the matrix is in compression. However, at elevated temperatures, these differences are expected to be negligible. Therefore, a composite at room temperature may exhibit slightly lower strength than at elevated temperatures.

Lamicq et al., (1986) examined the fracture behavior and the resulting damage. Fracture toughness was measured on notched samples, with values as high as $25 \mathrm{MPa}$ $\mathrm{m}^{1 / 2}$ remaining constant up to $1400^{\circ} \mathrm{C}$. However, due to the inherent non linear behavior of these materials, it is not possible to accept these values without circumspection, though, the fracture toughness values may be used for comparison purposes. A more suitable test for composites is the slow crack growth test, performed on notched compact tension samples, several samples with different initial lengths of the notch tested to give similar R curves. In comparison to sintered ceramics which exhibit a constant energy of propagation, $\mathrm{SiC} / \mathrm{SiC}$ start out with a higher energy of propagation for an initial notch, which then grows as the crack propagates, up to more than $10,000 \mathrm{~J} / \mathrm{m}^{2}$, which is at least two orders of magnitude more than sintered ceramics. Lamicq et al., postulate that this high fracture energy is possibly due to the multiple branching of cracks in the composite. The multiple branching of cracks causes the amount of energy required to propagate them also, which in turn generates and propagates a damaged region in front of the initial notch tip. It is inaccurate to discuss a mode I propagation or a $\mathrm{K}_{\mathrm{lc}}$ for these materials, 
but for rough comparison purposes, it is possible to derive a stress intensity factor for rupture, from the maximum of energy measured. This proves that $\mathrm{SiC} / \mathrm{SiC}$ composites are damage tolerant materials.

Danforth (1989) has presented an overview of existing manufacturing methods for ceramic matrix composites, which generally involves two stages : a) the incorporation of the reinforcement into the unconsolidated ceramic matrix material, followed by final densification. Several researchers have reported that the incorporation of second phase particles or fibers into inherently brittle matrices can toughen the brittle material. The mechanisms by which such increases in toughness are made possible have been reviewed by Rice $(1981,1985)$. These depend upon the nature and orientation of the reinforcing phase and include : transformation toughening, crack deflection, bridging, pinning, microcracking, and fiber/whisker pull out, and depend on the reinforcement geometry. If ceramic composites are to be used in place of monolithic ceramic materials, it is to be expected that the advantages in mechanical properties and performance must outweigh the difficulties introduced due to the processing. In general, the difficulties in processing increase as the reinforcements change from particulate, to whiskers (randomly oriented fibers/whiskers), and to continuous fibers (Danforth, 1989). Moreover, many conventional ceramic fabrication processes tend to mechanically, thermally, or chemically damage the fibers during the processing stage, which effectively reduce the properties of the resulting composite. Therefore, a process that forms the ceramic matrix around a preform of fibers without affecting the properties of the fiber adversely, is the necessary or desirable manufacturing route. 
Chemical Vapor Infiltration (CVI) is increasingly receiving attention as a practical process for the manufacture of ceramic matrix composites (Fitzer et al., 1979, Heraud et al., 1984, Dauchier et al., 1985, Fitzer and Gadow, 1986, Lamicq et al., 1986, Stinton et al., 1986, Caputo et al., 1987). In the CVI process, a matrix is chemically vapor deposited(CVD) within a porous preform, which is made of fibers, to produce a composite material (Lackey and Starr, 1990). Thus, CVI is a specialized form of CVD. In the CVI process, it is desired to deposit a matrix on the surfaces of the fibers located within the preform, while, in the CVD process, the desired result is to deposit a matrix on the surface of a substrate.

The great potential use of CVI based ceramic matrix composites has prompted indepth investigations of these materials (Stinton et al., 1990, 1990a; Lowden and James, 1991; Nair and Wang, 1992; Navarre et al., 1990; Lowden and More, 1990; Stinton et al., 1986; Caputo et al., 1987; Yang et al., 1988; Abbé et al., 1989, 1990; Akimune et al., 1991; Headinger et al., 1991, 1991a, 1992; Yang et al., 1991; Lamicq et al., 1986; Fitzer and Gadow, 1986; Veltri et al., 1989). An examination of the papers presented at the recent 16th Annual Conference on Composites, Materials, and Structures that took place at Cocoa Beach, Florida during 7-10 January 1992 (open sessions) indicate the extraordinary interest in these materials (Singh et al., 1992; Ellingson et al., 1992; Headinger et al., 1992; Hembree et al., 1992; Steiffer, 1992; Nair and Wang, 1992). However, fundamental understanding of details of the failure mode and toughening mechanisms of these composites at both ambient and elevated temperatures are still very limited (Lamicq et al., 1986; Yang et al., 1991; Navarre et al., 1990), especially for 
both the forced CVI and isothermal CVI composites under the same conditions. In addition, the effect of tensile loads at both the ambient and elevated temperatures (being the worst loading scenarios) on the failure modes has not been investigated in detail. The effect of thermal shock, oxidizing atmosphere, and cyclic tensile loading on the failure modes and toughening mechanisms has also not been investigated in detail. Motivated by the results in the references cited above, two layups each of forced CVI and isothermal $\mathrm{CVI} \mathrm{SiC/SiC} \mathrm{composites} \mathrm{were} \mathrm{chosen} \mathrm{for} \mathrm{understanding} \mathrm{their} \mathrm{mechanical} \mathrm{behavior} \mathrm{and}$ basic failure process at ambient and elevated temperatures. The details of the layups, and the number of specimens tested will be listed in later chapters.

The objective of this thesis was to investigate and analyze the mechanical properties of $\mathrm{SiC} / \mathrm{SiC}$ ceramic matrix composites manufactured by the isothermal and forced flow/thermal gradient CVI processes. The properties studied include uniaxial tensile strength, cyclic tensile strength, thermal shock resistance, and oxidation resistance. An analytical model was also developed, based on the plain weave composite theory/classical laminate analysis, to predict the mechanical properties of these ceramic matrix composites.

The thesis is divided into seven sections. Chapter I introduces the thesis work. The theoretical background to the current study on CVI composites is presented in Chapter II. The effect of interfacial properties and how it influences the mechanical properties and failure mechanisms in ceramic composites is also given in this chapter. The basic mechanisms of toughening followed by the discussion of available data in literature on the mechanical properties of these materials in view of the mechanisms of 
toughening is also discussed here. The discussion is focussed on, a) tensile strength, b) cyclic strength/toughness, c) thermal shock resistance, d) oxidation resistance, and e) analytical modeling for composite properties, based on the individual fiber and matrix properties. Chapter III lists the Experimental materials, procedures and set up. Chapter IV presents the experimental results. Chapter V presents the procedures and results from an Analytical Model for the prediction of Mechanical Properties of Ceramic Matrix Composites. Chapter VI discusses both the experimental and analytical results. Chapter VII presents the conclusions and the recommendations from the thesis work. The references are listed at the end of the thesis. Related informations such as the computer program used for the data acquisition, pertinent to the current work, are listed in the appendices. 


\section{CHAPTER 2}

\section{THEORETICAL BACKGROUND FOR CVI COMPOSITES}

\subsection{CHEMICAL VAPOR INFILTRATION PROCESS}

The CVI process to produce a ceramic matrix composite can be described as follows (Lackey and Starr, 1990). The preform, which consists of the fibers, is kept inside a high temperature furnace. The gaseous CVD reagents are passed into the preform, and deposit as a solid coating on the fibers, after reacting at the high temperature inside the furnace. As the deposited coatings get larger, they interlock, thus holding the fibers together. This forms the final composite. Lackey and Starr (1990) have presented an excellent overview of the CVI process including its development over the years. CVI is one of only a few processes that is capable of incorporating continuous fibers in a ceramic matrix without damaging the fibers mechanically, thermally, or chemically (Stinton, 1987). CVI is also capable of producing composites which are strong and tough, and is ideal to produce composites that are resistant to corrosion, erosion, and wear (Lackey and Starr 1990). 
In general, a Chemical Vapor Deposition system consists of three subsystems : reactant supply, the reactor (consisting of the preform), and the effluent gas handling system. The equipment for the CVD and CVI process is shown schematically shown in Figure 2.1 (Lackey and Starr, 1990). The different CVI processes can be classified into five types as shown in Figure 2.2 (Lackey and Starr, 1990). The basis for this classification is based on :

1) whether the preform is uniformly heated (isothermal), or contains a thermal gradient, and 2) the manner in which the gaseous reagents contact or flow through the preform. A brief description of the processes are given below.

I. Isothermal CVI : In the type I Isothermal process (Figure 2.2), the preform or preforms are kept at a constant temperature, and the reacting gases flow through the furnace, enter the preform through chemical diffusion, and react to form the matrix inside the preform. The gaseous products also diffuse out of the preforms. The product gases are carried out of the furnace by the flowing gas stream. In this case, the deposition of the matrix tends to occur preferentially near the outer surface of the preform. Since the process is dependent on diffusion, the infiltration times are as long as few weeks (Lackey and Starr, 1990). Despite these problems, the isothermal process has been used extensively as a commercial process, since a wide variety of shapes and sizes of preforms could be infiltrated using this process.

Type II. Thermal Gradient : In the thermal gradient CVI (Figure 2.2), there is a steep thermal gradient through the thickness of the preform. The gaseous reagents enter the preform through the cold side, move through the preform by chemical diffusion, and 


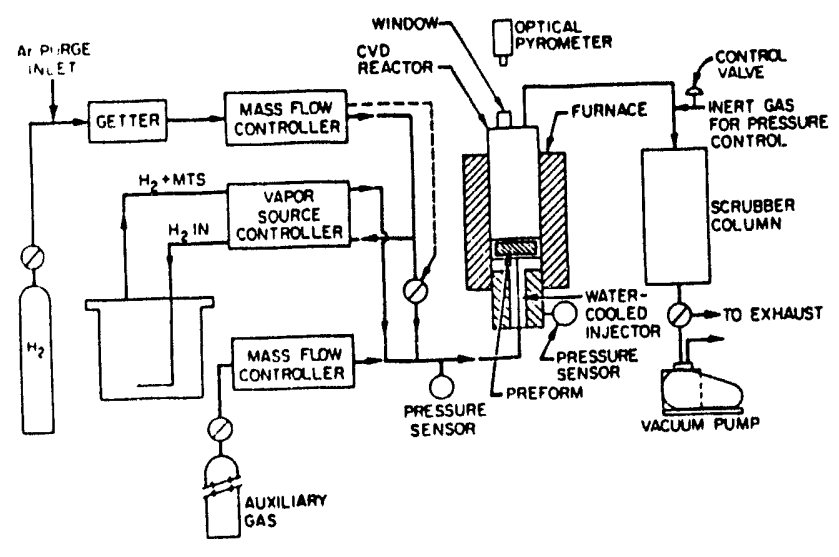

Figure 2.1. Equipment for CVD and CVI consists of three subsystems : reactant supply, furnace and effluent gas handling (after Lackey and Starr, 1990).

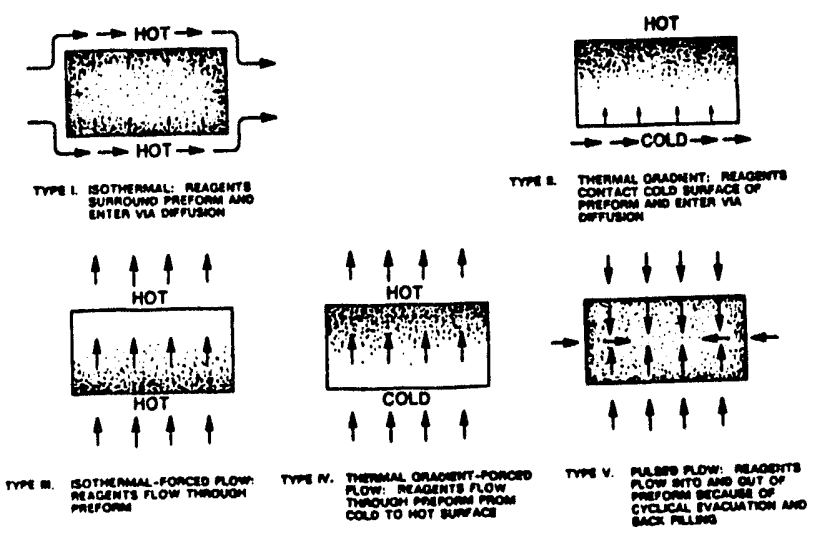

Figure 2.2. CVI processes can be classified into five general types depending on whether the preform is uniformly heated or not and how the reagents contact the preform. The long arrows represent flowing reagent ; the short arrows show reagent diffusion. The progression of densification is indicated by shading ; the heavier shading shows more deposition (after Lackey and Starr, 1990). 
deposit the matrix near the hot side, thus reducing the porosity near the hot side. This in turn causes the thermal conductivity of the infiltrated preform to increase, causing the preform to be heated more uniformly. Thus, the infiltration progresses uniformly from the hot side to the cold side. Infiltration times are typically long (several weeks) due to the diffusive nature of the reaction.

III. Isothermal-Forced Flow CVI : This process (Figure 2.2) relies on the forced flow of reagents through a uniformly heated (isothermal) preform. Reaction of the gases takes place throughout the preform, due to the forced flow. The process continues until some portion of the preform reaches a sufficiently high density, essentially causing it to be impermeable. This terminates the process, even though other regions of the preform may be of much lower density. The process tends to deposit more matrix near the preform surface where the reagent gases enter, since the reagent concentration is the maximum there. Moreover, if an inner region is appreciably warmer or denser than any other region, this inner region may become impermeable.

IV. Thermal Gradient-Forced Flow : This process (Figure 2.2) takes advantage of both a thermal gradient as well as forced flow of the reacting gases through the preform. In this case, the reacting gases enter frol 2 the cold side of the preform and the matrix is deposited within regions of the preform where the preform is sufficiently hot. The preform gets densified from the hot side to the cold side, depending on the changing thermal conductivity of the preform, or the changes in the heating and cooling. In an improved thermal gradient-forced flow process suggested by Caputo et al., (1984, 1985), alternative flow paths are provided to give continuous forced flow of the reagents through 
the preform even after some portions of the preform have become densified and impermeable. The major advantage of this process is in the considerable reduction in infiltration time, as compared to the processes explained before. Infiltration times of the order of 10-24 hours have been reported even for parts that are one inch thick (Lackey and Starr, 1990). The advantages of this process over the other processes are : a) reduced infiltration times b) high deposition efficiency c) uniform infiltration density, and, d) ease of manufacturing process.

V. Pulsed Flow : This process (Figure 2.2) is based on the pulsed flow of reagents into and out of the preform. This is caused by the cyclical evacuation of the reaction chamber and filling the reagent gases back into the reaction chamber. Conmercialization of this process has still not been achieved to the same degree as to that of the processes described earlier, as the practicality of large commercial furnaces for this process remains to be determined.

Although numerous composite systems have been fabricated using the various CVI processes, our discussion here will be limited to $\mathrm{SiC} / \mathrm{SiC}$ composites. As mentioned earlier, several researchers have helped develop an extensive data base (Stinton and Lackey 1978, Fitzer et al., 1979, Christin et al., 1979, Heraud et al., 1984, Caputo et al., 1984, 1985, Fisher et al., 1985, Stinton et al., 1986, Fitzer et al., 1986, Lamicq et al., 1986, Naslain et al., 1986, Caputo et al., 1987, Moeller et al., 1987, Stinton, 1987) for the $\mathrm{SiC}$ fiber - SiC matrix composites. Of the infiltration processes used, the isothermal and forced flow/thermal gradient processes appear to be the most popular, and both these processes have now been commercialized. As explained in the introduction, 
though extensive data exists for composites manufactured by either of these processes, no data currently exists to compare the composites from the above two processes under identical conditions. Literature survey also indicated that very scant data exists to correlate the damage patterns obtained for these composites to known damage theories for ceramic matrix composites. The current work addresses all these issues.

\subsection{CHEMICAL VAPOR INFILTRATION OF SiC/SiC COMPOSITES}

$\mathrm{SiC} / \mathrm{SiC}$ composites are typically made by the thermal decomposition of silicon carbide from methyltrichlorosilane (MTS) from the following reaction (Stinton 1987, Lackey and Starr 1990):

$$
\mathrm{CH}_{3} \mathrm{Cl}_{3} \mathrm{Si}+\text { excess } \mathrm{H}_{2}=\mathrm{SiC}+3 \mathrm{HCl}+\text { excess } \mathrm{H}_{2}
$$

The deposition of stoichiometric silicon carbide is promoted by this reactant because of the 1:1 gram-atomic ratio of silicon and carbon (Stinton and Lackey 1978). Though process conditions may vary from one process to another, generally, deposition temperatures of about $1473 \mathrm{~K}$ and furnace pressures of about $3 \mathrm{kPa}$ have been used. Typically, densities approaching $90 \%$ have been reported (Stinton 1987), with the 10 \% porosity affecting properties very minimally. 
As explained above, Methyltrichlorosilane $\left(\mathrm{CH}_{3} \mathrm{Cl}_{3} \mathrm{Si}\right)$ (MTS) and hydrogen mixtures are used in the CVD and CVI of $\mathrm{SiC}$. $\mathrm{SiC}$ is commonly observed in five different polytypes (Stinton et al., 1990), which are designated $2 \mathrm{H}, 3 \mathrm{C}, 4 \mathrm{H}, 6 \mathrm{H}$, and $15 \mathrm{R}$ where $\mathrm{C}, \mathrm{H}$, and $\mathrm{R}$ refer to Cubic, Hexagonal, and Rhombohedral polytypes respectively. The number preceding the notation refers to the number of close packed planes in the 'c' direction before the stacking cycle is repeated. The cubic structure is referred to as the $\beta$-SiC, while all the hexagonal and rhombohedral polytypes put together are referred to as $\alpha$-SiC. Stinton and co-workers (1990) have studied the structure of the $\mathrm{SiC}$ matrix as a function of the distance from the fibers in this composite material. They found that the structure of the deposited matrix was a mixture of small regions of $\beta-\mathrm{SiC}$ along with regions of one or more of the $\alpha-\mathrm{SiC}$. The random distribution of the $\alpha-\mathrm{SiC}$ was found to have been generated by random rotational twinning. TEM studies also supported the above findings.

In addition, process conditions such as temperature, pressure, and hydrogen to MTS ratio influence the stoichiometry, structure and morphology of the SiC deposited (Lackey and Starr 1990). Low deposition temperatures $\left(\approx 1100^{\circ} \mathrm{C}\right.$ ) and very high hydrogen to MTS ratios ( $\geq 100$ ) have been reported to yield deposits containing metallic silicon (Christin et al., 1979, Stinton and Lackey 1978), while deposits at temperatures above $1700^{\circ} \mathrm{C}$ and low hydrogen to MTS ratios $(\approx 15)$ can lead to deposits (Christin et al., 1979, Stinton and Lackey 1978) containing free carbon. The deposit density can increase with hydrogen to MTS ratios in the range of 10 to 25 , and is very strongly influenced by temperature (Fisher et al., 1985) and pressure (Fitzer and Gadow 1986). 
Thermodynamic calculations also indicate that reducing the pressure broaden the range of hydrogen to MTS which can lead to single phase SiC deposits (Christin et al., 1979).

Both the Isothermal CVI and forced flow thermal gradient CVI processes have been used to make $\mathrm{SiC} / \mathrm{SiC}$ composites. The isothermal process, though very slow, has been used to make thin-walled and complex shapes. The faster forced flow thermal gradient process has been used comparatively simpler and thicker shapes. However, in the forced flow thermal gradient process, only one composite part can be made at one time.

\subsubsection{ISOTHERMAL CVI PROCESS FOR SiC/SiC COMPOSITES}

The isothermal process for the $\mathrm{SiC} / \mathrm{SiC}$ composites was a natural extension of the efforts taken by several researchers in the area of carbon-carbon composites (Theis 1972 , Gebhart et al., 1976, Dacic et al., 1980). An overview of the work done in the area of carbon-carbon composites has been given by Buckley (1988). Though the process conditions for the isothermal CVI process for $\mathrm{SiC} / \mathrm{SiC}$ composites can vary considerably, the optimum conditions have been determined by Fitzer and Gadow (1986) to be , infiltration temperature of $1320 \mathrm{~K}, \mathrm{P}_{\mathrm{tot}}=3 \mathrm{kPa}$, and a total infiltration time of 14 days. This was for a Nicalon ${ }^{\mathrm{a}}$ preform size of 4 X 5 X $50 \mathrm{~mm}$ and containing $40-50$ vol \%

\footnotetext{
a Nippon Carbon Company Ltd.
} 
fibers. The isothermal CVI process has led to the largest commercial effort in the area of ceramic matrix composites by Société Européanne de Propulsion (SEP) of France in the development of carbon and $\mathrm{SiC}$ matrix composites. In 1987, this technology was licensed to DuPont Company, Wilmington, DE, who made a major investment in this technology by late 1989 (Strife et al., 1990). DuPont constructed the facility for manufacturing $\mathrm{SiC} / \mathrm{SiC}$ composites in 1988 and the initial $\mathrm{CMC}$ (ceramic matrix composites) parts were manufactured in 1990 . The processing conditions for this process at DuPont remain proprietary. The schematic of a CVD furnace for the isothermal CVI process is shown in Figure 2.3.

Despite the long time period required to obtain satisfactory results, the isothermal CVI process is the most used commercially, due to its ability to make a large number of complex shaped parts simultaneously (Lackey and Starr 1990). Large CVD furnaces measuring $6 \mathrm{ft}$. in diameter have already been reported to be operational at DuPont (Strife et al., 1990) for this process, proving the commercial viability of this technique. The major disadvantage with isothermal CVI technique is the long infiltration times required, since the process requires a combination of low temperature, low reactant concentration, and low pressures to avoid coating and sealing the outer surface of the preform and depleting the reactants before they reach the inner volume (Kotlensky 1973, in his work on carbon-carbon composites). Such a combination of process parameters would render the process uneconomically slow, and therefore, commercial processes are forced to maintain significant temperatures, reactant concentrations and pressures to obtain a sufficient rate of densification (Stinton, 1987). The deposition conditions also 


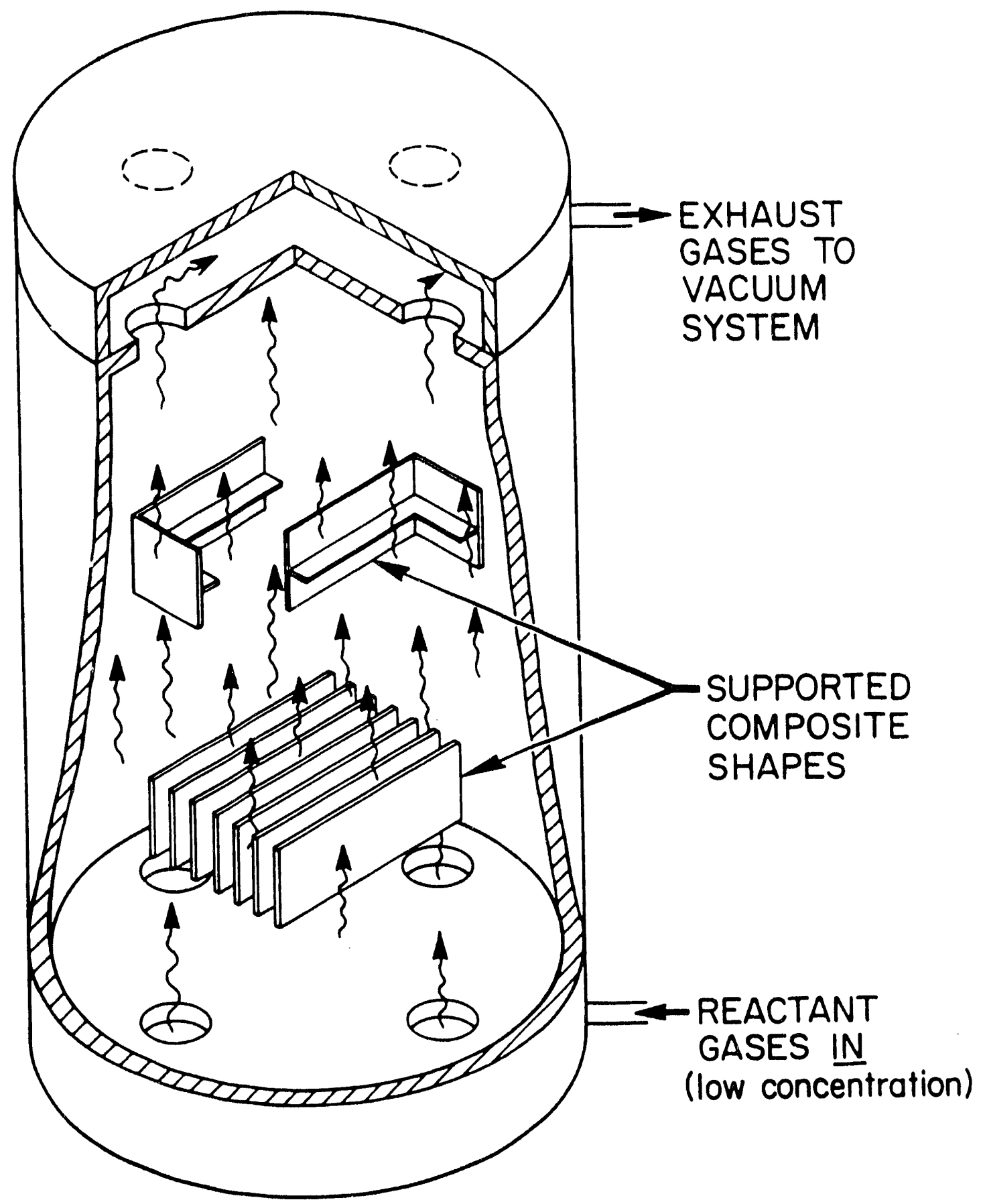

Figure 2.3. Schematic representation of the isothermal CVI process. Reactant gases, as they flow through the furnace at a reduced pressure, diffuse into fibrous preforms and effluents diffuse back to the preform surface. 
causes the deposition to take place more on the fibers on the surface of the preforms rather than on fibers inside the preform. Eventually, the porosity on the surfaces are closed by the deposition, causing density gradients from the surface to the interior of the preforms.

In order to reduce the density gradients, it may be necessary to interrupt the deposition process itself, and perform diamond machining operations on the surface, to open up passageways to the interior of the preform (Stinton 1987). This also helps prolong the actual process, which can take anywhere between 3 weeks to several months to complete. Inspite of these precautions, the use of only very thin preforms $(\approx 0.3-$ $1.0 \mathrm{~cm}$ ) is required, in order to avoid density gradients from the surface to the interior of the finished composite (Stinton 1987). In addition, free standing preforms are required to maximize the surface area preforms exposed to the reactant gases. It may be necessary to use binders to retain the shape of the preform till adequate infiltration has taken place, to stabilize the form, and could place a limitation on the amount of fiber volume in the preforms (Stinton 1987). Moreover, once the binder is used, it is necessary to remove the binder after the infiltration process. The details of the infiltration process as well as the fiber coating conditions are proprietary (Headinger, E. I. DuPont Co., 1992a). 


\subsubsection{FORCED FLOW THERMAL GRADIENT CVI PROCESS FOR SiC/SiC COMPOSITES}

This process which has been developed by the Oak Ridge National Laboratory (ORNL), simultaneously uses a thermal gradient and a pressure gradient and has been under development for a number of years (Caputo and Lackey 1984, Stinton et al., 1986, Caputo et al., 1987, Stinton 1987). It has also undergone several process changes as far as the fiber preform pretreatments are concerned (Stinton et al., 1986, Rawlins et al., 1987, Stinton 1987, Lowden and More 1988, Stinton et al., 1990, Lowden and More 1990), for the sake of obtaining strong and tough composites.

The ORNL process briefly can be described as follows (Stinton et al., 1986, Caputo et al., 1987). A schematic of the ORNL process is given in Figure 2.4. Fibrous preforms in the form of disks are retained in a graphite holder that contacts a water cooled metal gas distributor. The disk is fabricated by alternatively stacking multiple layers of a plain weave Nicalon $\mathrm{SiC}$ cloth. The stacking sequences used are described elsewhere in this thesis. It is desired that the final fabricated composite have about $40 \mathrm{vol}$ $\%$ fibers. The fibers in the preforms are then precoated with a thin layer of pyrolytic carbon coating, to obtain uniform fiber pull out and to weaken the fiber matrix bonding, thus enhancing the toughness of the composite. The carbon is deposited by infiltrating the preform with propylene at $1100^{\circ} \mathrm{C}$ for about $2 \mathrm{~h}$ at $\approx 3 \mathrm{kPa}$. Isothermal conditions are used for pyrolytic carbon infiltration, since a uniform coating is desired. 


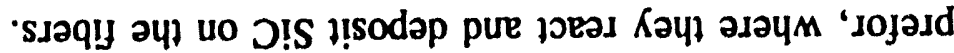

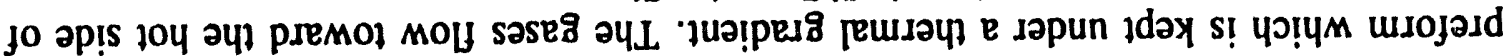

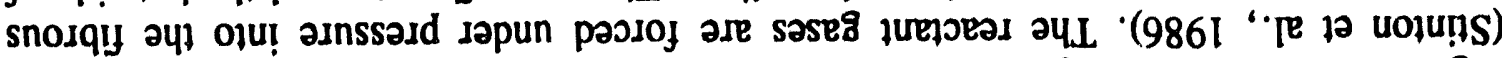

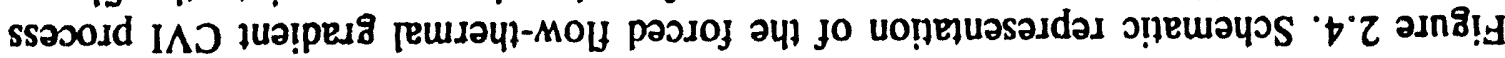

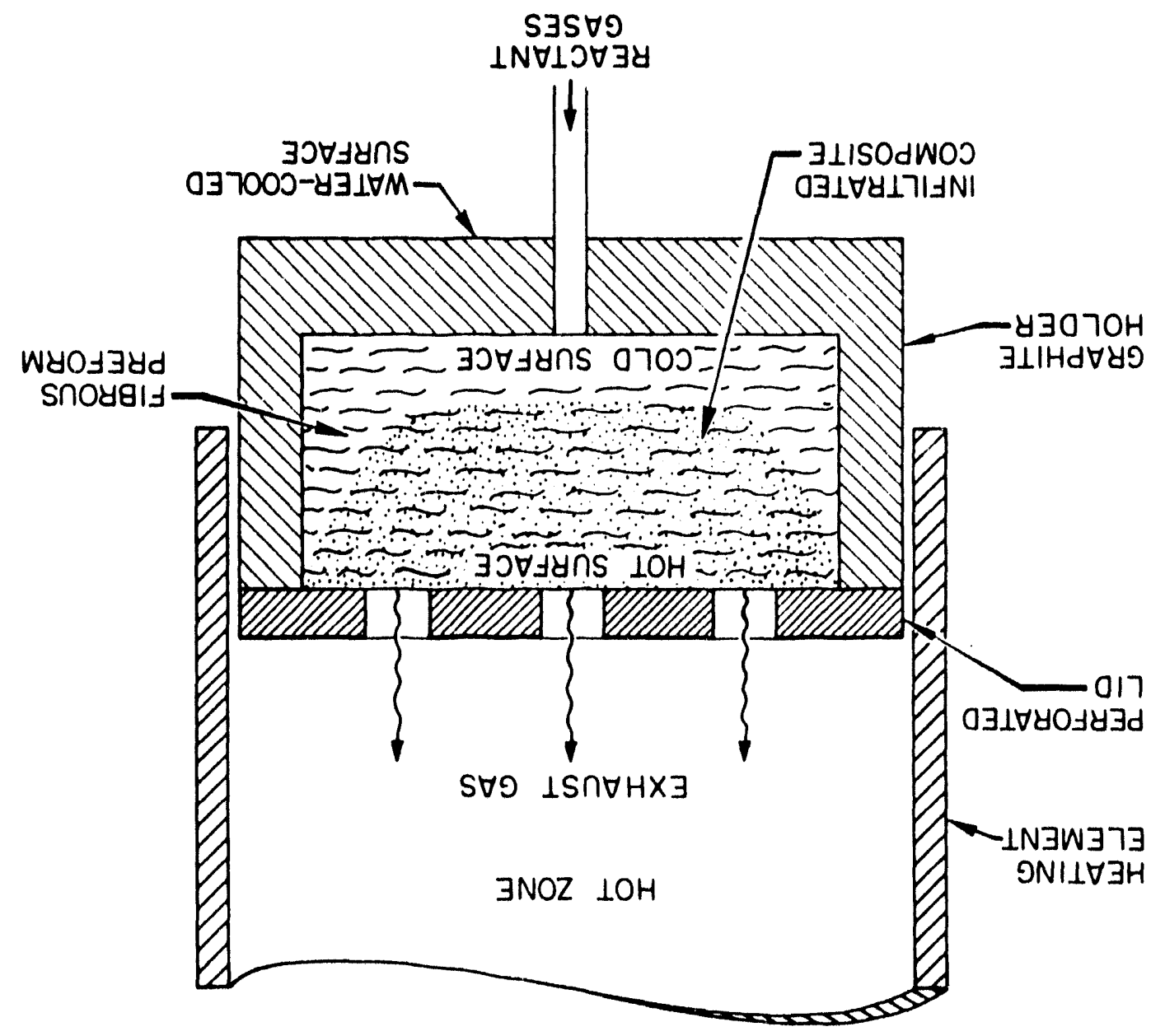


The water cooling of the graphite holder cools the sides and the bottom of the graphite holder, while the top of the preform is exposed to the hot furnace, which effectively creates a very steep thermal gradient across the preform. The reactant gases pass through the fibrous preform from the bottom to the top (which is at a higher temperature than the bottom of the preform). The reactant gases do not react at the bottom of the preform due to the low temperature, but react, decompose, and deposit on and around the fibers in the preform (Stinton et al., 1986). As the matrix gets deposited from the hot portion towards the cold portion, the density and thermal conductivity of the preform is increased, so that the hot region can move progressively from the top of the preform toward the bottom. However, as $\mathrm{SiC}$ is deposited on the fibers within the preform, due to the poisoning effect of $\mathrm{HCl}$ that is generated, the reaction rate is reduced by a factor of 100 . This could cause $\mathrm{SiC}$ to be deposited in the center of the preform, while little additional $\mathrm{SiC}$ is being deposited on the hot face. Furnace temperatures close to $1200^{\circ} \mathrm{C}$ are used for the decomposition of methyltrichlorosilane, since higher temperatures would degrade the fiber and reduce its strength. Typical process parameters used (Stinton et al., 1986) are, $\mathrm{CH}_{3} \mathrm{Cl}_{3} \mathrm{Si}$ flow rate of $50 \mathrm{~cm}^{3}$ gas $/ \mathrm{min}$, a $\mathrm{H}_{2} / \mathrm{CH}_{3} \mathrm{Cl}_{3} \mathrm{Si}$ ratio of 10 , and a pressure of $0.2 \mathrm{MPa}(2 \mathrm{Atm})$.

Relatively simple and thick shapes can be fabricated using the ORNL CVI process. This process has several attractive advantages over the SEP isothermal process. The primary advantage is the reduced processing time, with increased efficiency of infiltration. In addition, the preforms are held in place by the graphite holder which simplifies the process, whereas in the isothermal process, it is necessary to use a binder 
to hold the preforms in place. Thirdly, gentle pressure can be applied to the graphite holder, which can increase the fiber volume content of the composite. Finally, very thick composites can be fabricated using the Forced CVI process. Stinton et al., (1988) have reported that specimens upto $50 \mathrm{~mm}$ thick, as well as $50 \mathrm{~mm}$ diameter tubes with wall thicknesses as much as $10 \mathrm{~mm}$ have been fabricated using the Forced CVI (FCVI) process.

\subsection{INTERFACIAL MODIFICATION IN SIC/SIC COMPOSITES FOR IMPROVED TOUGHNESS}

One of the most significant problems reported by earlier researchers (Caputo et al., 1987, Stinton et al., 1986, 1986a) was the observation of both brittle and ductile fracture in specimens produced under the same conditions. This was correlated to inconsistencies in fracture behavior in the same specimen, which showed regions of brittle fracture as well as regions with good fiber pull out (Rawlins et al., 1987). This lack of reproducibility of the mechanical properties between specimens was investigated by the chemical and microstructural characterization of the fiber surfaces and the fiber matrix interface (Rawlins et al., 1987).

In an attempt to improve the reproducibility in mechanical properties, researchers have attempted to modify the interface between the fiber and the matrix by coating the 
fibers with a thin coating of either pyrolytic carbon or boron nitride (Lowden and More, 1990). Stinton et al., (1986a), in their initial work on CVI SiC/SiC composites, examined the interface region between the fibers and the matrix. The areas with fiber pull out were observed to contain a thin carbon rich layer, while in the areas with brittle fracture, no such intermediate layers were found. In specimens with uncoated fibers, it was observed by the Lowden and Stinton (1988) that there was a thin layer of silica on the fiber surfaces, which tended to bond the fibers and matrix, resulting in brittle behavior. In these specimens, it was also observed that there was a higher amount of chlorine in the fibers in the matrix, perhaps due to the chemical degradation of the fibers by the byproduct gases in the infiltration process. Rawlins et al., (1987) compared the effect of coating of pyrolytic carbon versus no prior coating on the fibers of these composites. They observed that the carbon coating greatly enhanced the composite toughness and also improved the reproducibility of the mechanical properties. In addition, it was also observed that the carbon coatings protected the fiber reinforcements from the harsh processing environments. Lowden and More (1990) have reported that the thickness of carbon coating required for optimum frictional stress and resultant strength is between 0.1 and $0.2 \mu \mathrm{m}$.

Though coatings with carbon were observed to improve the fracture toughness, the usefulness of these coatings are limited by its low resistance to oxidation at temperatures above $1000^{\circ} \mathrm{C}$. Lowden and More (1990) have examined other types of fiber coatings with similar mechanical properties but improved oxidation resistance. They 
have reported that boron nitride coatings provided comparable toughening and fracture strength, with improved oxidation resistance.

In light of the above information, it might be useful to understand the effect of interfacial properties and how it influences the strength of the composite material. This is treated in the next section.

\subsection{EFFECT OF INTERFACES ON THE PROPERTIES OF FIBER-REINFORCED CERAMICS}

Thouless and Evans (1988), Charalambides and Evans (1989), and Thouless and coworkers (1989) have performed some classical analyses on the relationship between the interface mechanical properties on the mechanical properties of ceramic matrix composites. Among these papers, the work by Thouless and coworkers is most noteworthy for its detailed analysis of the correlation of interface mechanical properties to the mechanical properties including pullout. Though Thouless and coworkers have used the example of a unidirectional fiber reinforced composite for the analysis, it is still relevant in the case of multidirectional fiber reinforced composites such as in the present research. It might be useful therefore, to list the known effects of interface mechanical properties on composite properties. 
In a ceramic composite that exhibits a high toughness, fibers typically fail at appreciable distances from the crack plane. The toughness of the composite is enhanced by the fiber sliding and bridging mechanisms which resist the crack opening. Thouless and Evans (1988) have derived the factors that control the fiber fracture location. These are, i) the location of the fiber fracture site with respect to the crack plane, 'h', and ii) the interfacial sliding resistance, ' $\tau$ '. According to Thouless and Evans (1988), the most important variables controlling the toughening behavior are : $\tau$, and the statistical parameters that control the fiber strength. Figure 2.5 is a schematic diagram showing the debonding and sliding processes in fiber reinforced composites. It could be observed that debonding is a prerequisite for toughening, and sliding governs the behavior and extent of toughening (Thouless et al., 1989).

From the experiments performed on Lithium Aluminosilicate/SiC fiber reinforced composite, Thouless et al. (1989) try to explain the effect of sliding stress on fiber failure. The two different cases are, the case of large sliding stress, and, the case of small sliding stress. The toughening behavior and the pullout lengths are controlled by the fiber sliding stress. In the case of a high sliding stress, the most probable fiber failure site is close to the crack plane, since the axial stress in the fiber tends to drop rapidly with ' $z$ '. In the case of small sliding stress, stress transfer from intact fiber to the matrix tends to occur gradually, and the axial stress decreases slowly with ' $z$ '. Therefore, in this case, the fiber failure site would tend to be remote from the crack plane (Thouless et al., 1989). In other words, the failure site in the fiber is strongly controlled by the sliding stress $\tau$. 
A schematic stress strain curve for ceramic matrix composites is given in Figure 2.6. Thouless and Evans (1988) have determined that $\sigma_{0}$, the matrix cracking stress increases as $\tau$ increases. If the ultimate failure stress is given by $\sigma_{u}$, and if $\sigma_{0}>\sigma_{u}$, then

Debonding and Sliding Processes

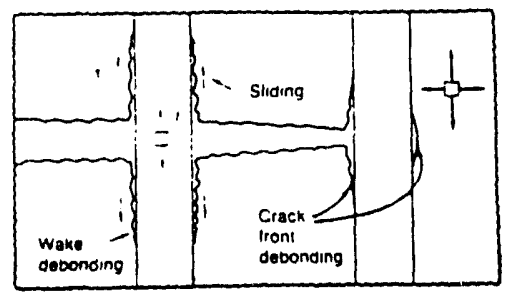

- Debonding is a prerequisite for toughening.

- Sliding governs toughening.

Figure 2.5. Typical debonding and sliding processes in ceramic matrix composites (Thouless et al., 1989).

Stress-Strain Curve for Composite

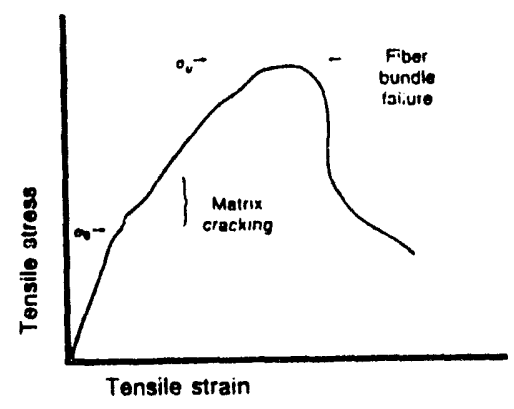

Figure 2.6. A typical stress strain curve for a ceramic matrix composite. 
the material can be brittle. Such a brittle behavior is promoted when the interfacial sliding resistance is high. Therefore, it is to be expected that the composite stress strain behavior can be explained in terms of the interfacial sliding resistance. As explained above, toughening is promoted by the initial debonding at the fiber matrix interface near the crack tip. This condition is satisfied provided the fracture energy of the interface $G_{i c}$ is sufficiently small compared to the fracture energy of the fiber $G_{f c}$ (reference 9 cited in Evans, 1990), which is given by $\mathrm{G}_{\mathrm{ic}} / \mathrm{G}_{\mathrm{fc}}<1 / 4$. However, there is no experimental verification available for this condition. The schematic drawing explaining the initial debonding/no debonding behavior, based on the inidividual fracture energies is given in Figure 2.7.

As the interfacial layer is decreased by exposure to elevated temperature and oxidation, the interfacial coating of carbon on the fibers is gradually replaced by a layer of $\mathrm{SiO}_{2}$. This drastically tends to increase the sliding resistance, and also tend to make the composite brittle. The toughening behavior due to pullout may be explained as follows (Thouless et al., 1989) :

a. The composite tends to become brittle as the sliding stress increases.

b. This could happen as a result of the carbon layer on the fiber surfaces being replaced by a layer of $\mathrm{SiO}_{2}$ at the interface.

c. The contribution to toughening from frictional sliding is quite considerable, and is proportional to $\tau h^{2} / R$, where, $h$ is the pullout distance, and $R$ is the radius of the fiber.

d. Frictional sliding causes energy dissipation in the form of heat. 
Initial Debonding

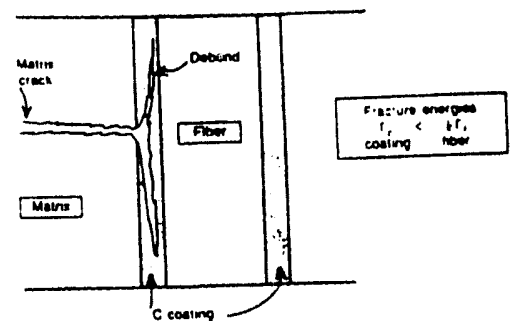

Carbon Coatings on Nicalon

Debond

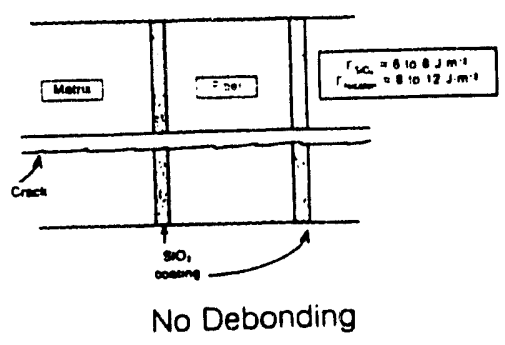

Figure 2.7. A schematic drawing explaining the initial debonding/no debonding behavior in ceramic matrix composites, based on the individual fracture energies (Thouless et al., 1989).

e. As the frictional stress decreases, the pullout distances increase and also increases the toughness.

Therefore, in the current research, it is important to recognize the role of frictional sliding stress in the stress strain behavior and the role temperature and oxidation exposure play in determining the same. 


\subsection{BASIC MECHANISMS OF TOUGHENING IN CERAMIC MATRIX COMPOSITES}

A thorough understanding of the basic mechanisms of toughening in ceramic matrix composites (CMC) is necessary to correlate the failure behavior to the mechanical properties and structure. An initial review of these mechanisms was provided by Rice (1981). Rice (1985) has also updated the previous review (1981). Another major review of microstructural design of toughened ceramics has been provided by Becher and coworkers $(1988,1991)$. An attempt will be made in this chapter to review the current understanding of these mechanisms and the efforts by the manufacturers of CMC to incorporate these techniques into the composites. The applicability of current theories will later be correlated to the observed phenomena in the actual composites.

The effectiveness of reinforcing brittle matrices such as glass and glass-ceramic matrices was demonstrated by Prewo and Brennan $(1980,1982)$ in the early eighties. These composites were reportedly more resistant to high temperature oxidation than carbon fiber reinforced composites. In addition, these composites were also "tougher" than then available monolithic ceramics (Prewo and Brennan 1980, 1982; Marshall and Evans 1985). Several interesting theories and analyses were put forth by Evans and co workers for understanding the basic mechanisms of toughening and failure in ceramic matrix composites (Evans :1988, 1989, 1990; Evans and Marshall : 1988, 1989; Thouless and Marshall : 1988; Evans and McMeeking : 1986; Marshall and Evans : 
1985). Most of the work presented by these researchers were solely related to theories based upon unidirectionally reinforced composites. However, it is reasonable to predict that similar mechanical behavior could be expected from ceramic composites reinforced with multidirectional fibers, as far as toughening mechanisms (fiber pull out, matrix cracking, crack deflection etc.) are concerned.

It is generally well known that the most important method to improve the mechanical reliability of structural ceramics is by increasing the fracture toughness. It is also generally accepted that most ceramic composites have more than one toughening mechanism which is responsible for the ultimate toughness of ceramic composites. Table 2.1 is a list of toughening mechanisms in continuous fiber reinforced ceramic composites.

In resin matrix composites, typically, the fiber modulus and strength are much higher than that of the matrix. Therefore, the fiber provides stiffness and load bearing capacity, while the matrix serves to distribute the load among the fibers. Most often, as is the case of epoxy matrix materials, the transverse tensile strength is sought to be increased by improving the adhesion between the fiber and the matrix, which increases the load transfer capability from the matrix to the fiber (Hurwitz, 1987). The strain capability of the matrix typically exceeds that of the fiber, and therefore, fracture initiation takes place from either a fiber or a group of fibers. Once a few fibers fail, the total load is shared between the remaining fibers, till the additional fibers break.

In contrast, in ceramic matrix composites, the modulus of the fibers and matrix are typically similar. Therefore, the fibers do not act as a source of stiffness or strength in ceramic matrix composites (CMC). In ceramic matrix composites, the incorporation 
of fibers is for the bridging and deflection of cracks rather than load bearing (Rice 1981). A higher population of processing induced flaws and microcracks are also expected to be present in CMC's than the case of resin matrix composites. In addition, the fibers are expected to have a higher strain to failure than the matrix (Aveston et al., 1971), which will cause the matrix cracking to precede fiber cracking. Non catastrophic failure is promoted by the debonding at the fiber matrix interface (Aveston et al., 1971, Hurwitz 1987). If the ultimate matrix strain were greater than the ultimate fiber strain, it would lead to a brittle failure in the composite. Therefore, the fundamental role of the fibers in a $\mathrm{CMC}$ is crack bridging and toughening by blunting and deflecting the matrix cracks, and the promotion of non catastrophic failure.

The fundamental factors that control the formation of cracks in a composite are:

a) Fiber or particle diameters

b) Fiber or particle spacing

Fiber or particle diameter: The mismatches between fibers or particles and the matrix in elastic modulus or thermal expansion or both, can lead to stress mismatches and subsequent formation of either of two types of flaws. A larger thermal expansion or a lower Young's modulus for the fihers can cause a partial or complete peripheral crack on cooling after processing (Rice 1981). If the fibers or particles have a lower thermal expansion coefficient or higher Young's modulus than the matrix, this could lead to cracks propagating into the matrix, either parallel or perpendicular to the fiber axis (Rice 1981). 
The formation of spontaneous peripheral cracks has been derived to be dependent on a critical fiber or particle diameter $D_{c}$ :

$$
D_{c} \approx \frac{\alpha \gamma_{B}}{E_{c}(\Delta \varepsilon)^{2}}
$$

Here, $\alpha$ is a proportionality constant ( $\approx 9$ for particle and $\approx 6$ for fibers), $\gamma_{\mathrm{B}}$ is the interfacial or grain boundary fracture energy. $\mathrm{E}_{\mathrm{c}}$ is the Young's modulus of the composite, and $\Delta \epsilon$ is the strain difference that would exist if neither the matrix nor the fibers were constraining the other. A poor $\gamma_{B}$ ennances the chances of cracks around the fibers. A similar fiber/particle diameter dependence is expected for the formation of cracks spontaneously extending into the matrix, even though the analysis is difficult (Rice 1981). The presence of applied stresses and prior cracks and pores are expected to increase the chances of cracks, especially near high significant stress concentrations. Significant differences in elastic properties between the fibers and the matrix can also contribute to the formation of cracks.

Fiber or particle spacing : A fiber or particle spacing larger than the typical strength controlling factors in ceramic materials of reasonable strength can limit the strength of the material because of the distances the cracks can propagate before they encounter a fiber or particle. This means that the fracture toughness of the matrix just ahead of the advancing crack must increase considerably in order to be able to arrest the crack (Rice 1981). Since such increases in fracture toughness does not take place, the cracks will propagate without any deflection, leading to catastrophic failure. This 
problem is significantly increased if the flaws or cracks initiate from the fibers or particles themselves, since the crack can propagate a distance equivalent to the average fiber/particle spacing before encountering another fiber or particle. In contrast to this situation, a random flaw (either due to machining or processing) can advance only for half of the fiber/particle spacing before encountering another fiber or particle (Rice 1981).

The above effects can get accentuated if they are combined. In order to assure that the fiber/particle spacing is less than the typical flaw size, there has to be an upper limit to the density of fibers or particles (Rice 1981). When the distance between elastic discontinuities such as pores or particles is approximately equal to their diameters, the interactions between them become significant. This condition requires that the volume fractions of reinforcing fibers/particles be $40-60 \%$ for uniform distributions and less than this for other distributions such as particles mainly along the grain boundaries. The requirement of a small fiber/particle size is again reinforced by the above condition. 
Table 2.1. Ceramic Matrix Composite Toughening Concepts (Rice, 1981)

\begin{tabular}{|c|c|c|}
\hline Concept & Basic Requirements & Status \\
\hline $\begin{array}{l}\text { 1. Transfer of load from } \\
\text { matrix to fibers }\end{array}$ & $\begin{array}{l}E_{f}>E_{m}, \text { preferably by } \\
\text { a factor }>2\end{array}$ & $\begin{array}{l}\text { Fairly well verified, } \\
\text { reasonable modeling }\end{array}$ \\
\hline $\begin{array}{l}\text { 2. Prestressing of fibers } \\
\text { and matrix }\end{array}$ & $\begin{array}{l}\text { Axial tensile stresses in } \\
\text { fibers and compressive } \\
\text { stresses in matrix }\end{array}$ & \\
\hline $\begin{array}{l}\text { 3. Crack impeding second } \\
\text { phases }\end{array}$ & $\begin{array}{l}\text { Fracture toughness of } \\
\text { fibers }>\text { matrix, so } \\
\text { crack is either arrested } \\
\text { or bows out with line } \\
\text { tension effects between } \\
\text { fibers }\end{array}$ & $\begin{array}{l}\text { Crack Arrest is } \\
\text { impractical. Model } \\
\text { exists for line tension } \\
\text { but no verification }\end{array}$ \\
\hline $\begin{array}{l}\text { 4. Crack deflection or } \\
\text { multiplication, fiber } \\
\text { pullout }\end{array}$ & $\begin{array}{l}\text { Particles or fibers } \\
\text { deflecting the cracks so } \\
\text { that the cracks move } \\
\text { along the fiber-matrix } \\
\text { or particle interface }\end{array}$ & \\
\hline 5. Microcracking & $\begin{array}{l}\text { Appropriate mismatch } \\
\text { of properties, especially } \\
\text { thermal expansions } \\
\text { between matrix and } \\
\text { fibers and suitable sizes }\end{array}$ & \\
\hline $\begin{array}{l}\text { 6. Phase transformation } \\
\text { toughening }\end{array}$ & $\begin{array}{l}\text { Second phase particles } \\
\text { increase one or more } \\
\text { dimensions }\end{array}$ & \\
\hline
\end{tabular}




\subsubsection{Load Transfer}

The first mechanism of load transfer from a matrix of low strength to the fibers of high strength due to the Young's modulus of the fiber $\left(E_{f}\right)$ being greater than the Young's modulus of the matrix $\left(\mathrm{E}_{\mathrm{m}}\right)$ is the most fundamental concept of toughening in polymeric and metal matrix composites. The extent of toughening increases as the ratio of $E_{f} / E_{m}$ increases and as the volume fraction of fibers increases (Prewo and Brennan, 1980). However, this principle is of limited use in the case of ceramic matrix composites, since the Young's modulus of the fibers and matrix are essentially similar (Rice 1981). In addition, the Young's modulus of fibers reduce with temperature compared to the matrix, and therefore, the benefits of load transfer from the matrix to the fibers is limited (Rice 1981).

\subsubsection{Prestressing}

Toughening by prestressing the composite due to differences in thermal expansion coefficients of the fibers and the matrix (Rice 1981) is also a known toughening mechanism, though the exact theory and verification of this theory as a valid mechanism is yet to be done. When the thermal expansion coefficient $\left(\alpha_{f}\right)$ of the fibers are less than the thermal expansion coefficient $\left(\alpha_{\mathrm{m}}\right)$ of the matrix, cooling after processing can introduce tensile stresses in the fibers, while introducing compressive stresses in the matrix. Though Rice (1981) has provided no references to this concept, he has postulated 
that realistic and useful levels of compressive stresses are of the order of $350 \mathrm{MPa}$ in the matrix. For this, a fiber volume fraction of 0.25 is required, coupled with about 700 MPa tensile loads on the fibers. It is thought that the compressive stresses in the matrix can hold up the cracks till they can be relaxed by the combination of the applied stress ahead of the crack and the tensile stresses applied on the fibers. The compressive stresses in the matrix decreases as a power of the cube of the distance from the fiber surface. Radial tension in the fibers can lead to peripheral cracks around the fibers, while radial compression in the fibers can lead to cracks propagating into the matrix and parallel to the fiber axis.

\subsubsection{Crack Impediment}

The extreme case of crack impediment is to have fibers or second phase particles, which possess enough fracture toughness that they can hold the bodies together, and arrest the cracks. A less extreme case is to have fibers which are tougher than the matrix, so that the cracks are temporarily impeded by the fibers. This results in a crack bowing out between the fibers or second phase particles, until a suitable breaking stress has to be applied before the crack can break away (Lange 1970, Evans 1972). The toughening due to this effect does not take place until the fiber or particle spacing is

much less than the average size (Lange 1970). Since the average flaw size in high strength ceramics is typically $20-50 \mu \mathrm{m}$, this toughening mechanism requires a very high fiber volume density or particle content (Rice 1981). 
Toughening due to line tension with unidirectional fibers would be directional in nature. To obtain isotropic toughening, the best bet would be to use particles. However, the amount of toughening would be substantially lesser, since the cracks could go around the particles. A strengthening with short length fibers or elongated particles in three dimensions would be a compromise between the case of strengthening with unidirectional fibers and particles (Rice 1981).

\subsubsection{Crack Deflection or Multiplication/Fiber Pullout}

Crack deflection, or multiplication is related closely to both crack impediment as well as microcracking. The process of crack deflection or multiplication can also occur by other mechanisms also. The most important mechanism of this type is the deflection of cracks along the fiber-matrix interface (Rice 1981). However, it is impossible to distinguish between a crack directly branching along the fiber-matrix interface and a crack generating microcracks along the interface and branching due to interactions with the microcracks. Another form of crack deflection is the crack splitting into two around or through a particle or fiber due to orientation of the preferred fracture surfaces (Rice 1981).

The effect of pull out in composite materials is to ultimately increase the work of fracture, and is applicable at any temperature (Rice 1981). Lange (1979) has shown that the same equation for pull out in polymeric composites could be applied to ceramics also. 
This is given by :

$$
K_{c}=\left[K_{0}{ }^{2}+\left(\frac{\tau}{2}\right) V_{f} D E(l a)^{2}\right]^{1 / 2}
$$

where, $\mathrm{K}_{\mathrm{c}}$ and $\mathrm{K}_{0}$ are the fracture toughness of the composite and matrix respectively, $\tau$ is the shear stress to pull the fiber out of the matrix, $V_{f}$ is the volume fraction of fibers, $\mathrm{D}=$ fiber diameter, la $=$ average fiber aspect ratio after fracture, and $\mathrm{E}=$ Young's modulus. Significant crack deflection and the resultant increased fracture area also can contribute to the increase in fracture toughness of the composite.

The toughness and the crack deflection contribution is controlled by the type of bonding between the fibers and the matrix. An optimum bonding between the fibers and the matrix is required so that pull out is promoted. However, a poor bonding can degrade the overall composite properties, and the improvement in toughness may be of limited value.

\subsubsection{Microcracking}

The mechanism of microcracking can also influence the preceding mechanism of crack deflection. This mechanism is mainly due to property mismatches (Equation 3.1) in thermal properties, phase transformation ( to a lesser extent), and differences in elastic modulus (to a much lesser extent). The generation of microcracks near or at the tip of a stressed crack because of the interaction of the crack-tip stress fields with the property 
mismatches between the matrix and the fibers is of interest currently (Rice 1981). The increase in toughening occurs because the microcracking process increases the amount of energy for fracture. In addition, the system is designed in such a way that the amount of strength limitation that microcracking may impose can be kept small, allowing this to be a mechanism of toughening with good strengths. However, it may be difficult to control the size and spacing of the microcracks sufficiently so that a composite of higher strength than the matrix itself may be produced.

Rice (1981) has derived the increase in fracture energy $\Delta$, due to microcracking per unit area of advance of the main crack, to be

$$
\Delta \gamma=\frac{\Gamma}{2 L}=\frac{2 \pi \alpha \gamma_{B} V_{f} L}{t}
$$

where, $\mathrm{L}$ and $\alpha \mathrm{L}$ are the major and minor axes of an elliptical process zone around a "through the thickness" crack, $\gamma_{B}$ is the interfacial fracture energy, $V_{f}$ is the volume of particles with cracks, and $t$ is the thickness of the platelets. $V_{f}$ is derived to be equal to

$$
V_{f}=\frac{N l^{2} t}{\pi \alpha L^{2}}
$$

where, $\mathrm{N}$ is the number of particles, and 1 and $\mathrm{t}$ are the length and thickness of the particles. However, this is assuming the reinforcements to be platelets, and will be modified accordingly for fiber reinforcements. Thus, the increase in fracture energy $\gamma$ is directly proportional to the boundary fracture energy, the volume fraction of particles or reinforcements which develop cracks, the process zone size, and inversely proportional to the particle dimensions ( diameter in the case of fiber reinforcements). 
The above equation could clearly overestimate the increase in fracture energy, since a single crack will not remain stationary and will generate multiple cracks. However, the trends in materials which exhibit multiple cracking, could be expected to be similar, with $\gamma_{\mathrm{B}}$ being replaced with a crack size dependent local fracture energy. However, in reality, the linking up of microcracks to form and propagate a macrocrack seems highly likely. This could then lead to some mixed mode crack propagation and reduction in stress intensity since more than one macrocrack could be present. This could be denoted by crack multiplication and deflection on the fracture surface, as may be evidenced from SEM studies. Overall increases in fracture energy of about two to four times appear feasible with this toughening mechanism (Rice, 1981).

\subsubsection{Phase Transformation Toughening}

In this mechanism, fine particles of an unstable crystal structure, are transformed to a stable structure in the presence of high stresses near a crack tip under high stress. Due to the transformation, there is usually a volume change, that leads to partial relaxation of matrix stresses near the crack surface. The strain energy absorbed by the transformation process thus absorbs energy otherwise available for crack propagation (Rice, 1981). 


\subsubsection{High Temperature Aspects of Toughening Mechanisms}

The toughening mechanisms discussed above are appropriate for the matrix which is continuous in nature, such as glass matrix composites or fiber reinforced composites. However, the toughening mechanisms operative at moderate or room temperature, may not be effective to the same extent at elevated temperature, due to the changes taking place at those temperatures (Rice, 1981). The load transfer due to $E_{f}>E_{m}$ could also work at elevated temperatures, though not to the same degree, since the ratio of $E_{f} / E_{m}$ could change with change in temperature. The changes in the interface between the fiber and matrix could also determine the bonding that could take place between the fiber and the matrix, which could in turn affect the amount of fiber pull out effects. The effects of prestressing of the fibers and matrix also will decrease at elevated temperatures, especially close to the processing temperature. Microcracking will generally reduce at elevated temperatures, and could be considered less effective as a toughening mechanism at those temperatures (Rice 1981).

\subsubsection{Combined Mechanisms of Toughening}

In ceramic matrix composites, typically, one might find that more than one mechanism is responsible for the toughening behavior. It is also possible that one toughening mechanism may not be the dominant mechanism, suggesting that it is possible to take advantage of the multiple mechanisms operative in a single composite. However, 
it may be difficult to quantify the individual contributions of each mechanism to the total toughness of the composite. Table 2.2 (Rice 1981) gives a brief idea of the possible combinations of toughening mechanisms in ceramic matrix composites.

Table 2.2. Possible combinations of toughening mechanisms in ceramic matrix composites

\begin{tabular}{||l|l|c|c|c|c|c||}
\hline & & Prestress & $\begin{array}{c}\text { Line } \\
\text { Tension }\end{array}$ & Pullout & $\begin{array}{c}\text { Micro- } \\
\text { Cracking }\end{array}$ & $\begin{array}{c}\text { Trans- } \\
\text { formation }\end{array}$ \\
\hline Fibers & $\begin{array}{l}\text { Modulus } \\
\text { load } \\
\text { Transfer }\end{array}$ & $\mathrm{C}, \mathrm{I}$ & $\mathrm{C}, \mathrm{I}$ & $\mathrm{C}, \mathrm{I}$ & $\mathrm{C}^{*}$ & $\mathrm{~N}$ \\
\cline { 2 - 7 } & Prestress & $\mathrm{I}$ & $\mathrm{C}(\mathrm{I} ?)$ & $\mathrm{N}$ & $\mathrm{N}$ \\
\cline { 2 - 7 } $\begin{array}{l}\text { Fibers } \\
\text { or } \\
\text { Particles }\end{array}$ & Line Tension & $\mathrm{C}(\mathrm{I} ?)$ & $\mathrm{C}$ & $\mathrm{C}$ \\
\cline { 2 - 7 } & Pullout & $\mathrm{C}$ & $\mathrm{I}$ \\
\hline Particles & Microcracking & & $\mathrm{C}^{*}$ \\
\hline
\end{tabular}

C : Combinable; $\mathrm{N}$ : Not Combinable

I : Inherent combination

* : Combinations that may be interesting

?: Indicates that there may be uncertainties in the designation

\subsubsection{Combination with the Modulus Load Transfer Mechanism}

This mechanism can be used in combination with prestressing, line tension, and fiber pullout singly, and possibly a combination of two or all of the above mechanisms. If a fiber with a higher Young's modulus as well as thermal expansion than the matrix is chosen, then the requirement of load transfer as well as prestress could be satisfied. 
A fiber tougher than the matrix could aid in line tension, while sufficiently tough fibers along with an appropriate bond between the fiber and the matrix, can aid in significant pullout. This mechanism also may be combined along with microcrackinig, if a single type with anisotropic fibers, matrix, or both is used (Rice 1981, 1985).

Due to microcracking, at the local level, the modulus of the matrix may decrease, thus increasing the $\mathrm{E}_{\mathrm{f}} / \mathrm{E}_{\mathrm{m}}$ ratio locally, and improving the effectiveness of load transfer in the crack tip region. Therefore, it might be possible to use fibers whose modulus is close to that of the matrix. The fibers could then limit the loss of strength due to microcracking, and might even improve the fracture toughness for crack propagation normal to the fibers.

\subsubsection{Combination with Prestressing and Line Tension Mechanisms}

The above two mechanisms may appear to be inherently combined, since we need a strong, tough fiber for the prestress mechanism, which could also inhibit a crack. Pull out effects also could be combined with the above mechanism, with proper control of the fiber-matrix bonding (Rice, 1981, 1985).

\subsubsection{Combination with Pullout and Microcracking Mechanisms}

The above two mechanisms are clearly combinable, since microcracking and fiber pullout may be achieved with one single fiber reinforcement (Rice, 1981). 


\subsection{MECHANICAL PROPERTIES OF SiC/SiC COMPOSITES}

The advantages of $\mathrm{SiC} / \mathrm{SiC}$ ceramic matrix composites has been described in the previous sections. Fitzer et al., (1983), Naslain et al., (1980), Heraud et al., (1984), Dauchier et al., (1985), Fitzer and Gadow (1986), Lamicq et al., (1986), Stinton et al., (1986), Caputo et al., (1987), Stinton (1987), Yang et al., (1988), Lowden and Stinton (1988), Veltri et al., (1989), Abbé et al., (1990), Lowden and More (1990), Stinton et al., (1990), Rawlins et al., (1987), Moeller et al., (1986, 1987), Headinger et al., (1991, 1991a, 1992), Kmetz et al., (1990), Akimune et al., (1991) have reported on various aspects of the mechanical properties of CVI based composite materials. These researchers have reported on the properties of both Isothermal CVI based and Forced CVI based $\mathrm{SiC} / \mathrm{SiC}$ composites. Veltri et al., (1989) have reported on the properties of CVI based composites prepared from methyldichlorosilane gas as a precursor for the $\mathrm{SiC}$ matrix. It is also worth noting that most of the mechanical properties have been reported based on bending tests, due to the simple and inexpensive nature of the tests. Lamicq et al., (1986), and Headinger et al., (1991) did report some of the properties based on uniaxial tension tests, though they did not use any self aligning grips to eliminate the bending on the specimens. Caputo et al., (1987) did report the result of one tensile test conducted using a self aligning grip for the $\mathrm{SiC} / \mathrm{SiC}$ composite.

For the sake of comparison to the results obtained in the current thesis, the mechanical properties obtained and reported for the $\mathrm{SiC} / \mathrm{SiC}$ system by the above 
researchers is listed below. Heraud et al., (1984) have reported on the mechanical properties of $\mathrm{C} / \mathrm{C}-\mathrm{SiC}, \mathrm{C}-\mathrm{SiC}$, and $\mathrm{SiC}-\mathrm{SiC}$ composites prepared by the ICVI process. These samples were prepared in a Société Européenne de Propulsion (SEP) pilot plant having a CVI furnace. Ultimate compression strength, shear strength, Young's modulus, and thermal shock resistance were investigated. The SiC-SiC were reinforced with unidirectional SiC fibers, with a fiber volume fraction of about 0.40 and a residual porosity of 15 to $20 \%$. Heraud et al., have reported that when these composites were tested at $1400^{\circ} \mathrm{C}$ under vacuum, they retained as much as $50 \%$ of their room temperature strength. The Young's modulus of these composites were however, found to be lesser than usually measured on sintered silicon carbide, while the thermal expansion coefficients, measured in the fiber direction, were quite similar.

Heraud et al., (1984) used a formula for thermal shock resistance given below :

$$
\text { Thermal Shock resistance }=\frac{\lambda \cdot \sigma}{E \cdot \alpha}
$$

where, $\lambda$ is the thermal conductivity, $\sigma$ the strength to failure, $E$ the Young's modulus, and $\alpha$ the thermal linear expansion coefficient. The thermal shock resistance of these unidirectionally reinforced composites has been reported to be about $50,000 \mathrm{w} \mathrm{m}^{-1}$, which is twice that of the sintered silicon carbides.

Dauchier et al., (1985) have reported on the mechanical properties of SiC based ceramics reinforced with 2 dimensional woven fibers, which includes $\mathrm{SiC}$ fiber reinforced $\mathrm{SiC}$ composites. These researchers have reported that the bend strength of $\mathrm{SiC} / \mathrm{SiC}$ composites is much higher than expected at $1300^{\circ} \mathrm{C}$, with a high amount of deformation/ 
strain. This was thought to be due to the fiber pull-out phenomenon, which led to a very high amount of fracture energy. The stress-strain curve of these composites showed three typical zones, with a linear zone, a non linear zone, and a zone where the direction of the curve changes, up to the ultimate strength. An ultimate strength of about $190 \mathrm{MPa}$ and a strain of about $0.6 \%$ was reported. Dauchier et al., (1985) have also reported that these composites possess excellent toughness and thermal shock resistance.

Lamicq et al., (1986) have presented the results of several tests done on Isothermal CVI $\mathrm{SiC} / \mathrm{SiC}$ composite, conducted at Société Européenne de Propulsion, France. The typical curve exhibited two distinct parts, with two slopes (Lamicq, et al., 1986). In the first portion, the fibers and the matrix are both undamaged. In the second part, the matrix gradually cracks, and the matrix and fibers debond partly. Once the fibers that hold the fractured matrix portions (which is strongly cracked) break, the composite undergoes final fracture. The strain to failure is quite high compared to a monolithic ceramic $(\mathrm{SiC})$, and is as high as $0.8 \%$. Thermal conductivity and diffusivity values are reported to be low, compared to a monolithic ceramic, possibly due to the pores acting as thermal barriers and the fibers which contain oxygen and carbon.

Lamicq et al., (1986) also performed environmental tests on $\mathrm{SiC} / \mathrm{SiC}$ composites using a 4 point bend fixture. They reported that these composites exhibit a slight increase in bending strength from room temperature to $1300^{\circ} \mathrm{C}$, with some strength remaining at temperatures of 2000 to $2200^{\circ} \mathrm{C}$. It has been reported that this material exhibits no sharp loss in strength at high temperatures, enhancing its ability to sustain temporary overheating without catastrophic failure. These materials also have been reported to have 
excellent oxidation resistance even after $500 \mathrm{~h}$ exposure to $1100^{\circ} \mathrm{C}$ in air, with no loss in bend strength after the exposure. $\mathrm{SiC} / \mathrm{SiC}$ composites are also reported (Lamicq et al., 1986) to have excellent thermal shock as well as thermal fatigue resistance. In the thermal shock tests, the composite samples were heated to a certain temperature and quenched into cold water. It was observed that there was a slight decrease in the bend strength for temperatures above $300^{\circ} \mathrm{C}$, with no catastrophic failure observed up to $1200^{\circ}$ C.

Lamicq et al., (1986) examined the fracture behavior and the resulting damage. Fracture toughness was measured on notched samples, with values as high as $25 \mathrm{MPa}$ $\mathrm{m}^{1 / 2}$ remaining constant up to $1400^{\circ} \mathrm{C}$. However, due to the inherent non linear behavior of these materials, it is not possible to accept these values without circumspection, though, the fracture toughness values may be used for comparison purposes. A more suitable test for composites is the slow crack growth test, performed on notched compact tension samples, several samples with different initial lengths of the notch tested to give similar R curves. In comparison to sintered ceramics which exhibit a constant energy of propagation, $\mathrm{SiC} / \mathrm{SiC}$ start out with a higher energy of propagation for an initial notch, which then grows as the crack propagates, up to more than $10,000 \mathrm{~J} / \mathrm{m}^{2}$, which is at least two orders of magnitude more than sintered ceramics. Lamicq et al., postulate that this high fracture energy is possibly due to the multiple branching of cracks in the composite. The multiple branching of cracks causes the amount of energy required to propagate them also, which in turn generates and propagates a damaged region in front of the initial notch tip. It is inaccurate to discuss a mode I propagation or a $\mathrm{K}_{\mathrm{Ic}}$ for these materials, 
but for rough comparison purposes, it is possible to derive a stress intensity factor for rupture, from the maximum of energy measured. This proves that $\mathrm{SiC} / \mathrm{SiC}$ composites are damage tolerant materials.

Caputo et al., (1987) have reported bend strength values of 288 to $324 \mathrm{MPa}$ for room temperature tests, and bend strength values of 123 to $141 \mathrm{MPa}$ for the elevated temperatures, for $\mathrm{SiC} / \mathrm{SiC}$ composites. For 1 test conducted in tension at room temperature, a strength value of $217 \mathrm{MPa}$ was reported by Caputo et al., (1987). This was about $70 \%$ of the room temperature 4 point flexure strength. Lowden and Stinton (1988) have reported on the effect of interface modification with the help of pyrolytic carbon coatings on the mechanical strength of these composites. They have reported a strength of $262 \mathrm{MPa}$ for a coating thickness of $0.07 \mu \mathrm{m}$ and a strength of $390 \mathrm{MPa}$ for a coating thickness of $0.12 \mu \mathrm{m}$. All the above results were for the standard $(0 / 30 / 60)_{\text {repeat }}$ layup made at ORNL.

Yang et al., (1988) have reported on the mechanical properties of $\mathrm{SiC} / \mathrm{SiC}$ composites which were reinforced with 3-dimensional braided $\mathrm{SiC}$ fibers. These composites had a $35 \%$ fiber volume fraction, and a porosity level of $16.5 \%$. These researchers have reported on the fracture toughness, before and after a thermal shock treatment. Though the researchers quote an earlier paper for high temperature properties, unfortunately, it was impossible to obtain the same. The researchers have reported that these composites exhibited excellent thermal shock resistance.

Veltri et al., (1989) have investigated SiC fiber reinforced composites prepared by CVI using methyldichlorosilane (MDS) instead of methyltrichlorosilane (MTS) as in 
the current thesis. These researchers have reported a flexural strength level of about 450 MPa (65 ksı) with about $0.8 \%$ strain to failure, with a lot of fiber pull out being observed on the fracture surfaces. The composite was manufactured in this case by winding a mandrel with fibers and infiltrating with the $\mathrm{SiC}$ matrix (unidirectional fibers).

Ko (1989) has also reported on the flexural strength of $\mathrm{SiC} / \mathrm{SiC}$ composites prepared by the ICVI method. In this reference, he has reported a flexural strength level of about $345 \mathrm{MPa}$ for these composite specimens. Ko has also reported a modulus level of $240 \mathrm{GPa}$ and a shear modulus of $22 \mathrm{GPa}$. The layup investigated was $(0 / 90)_{\text {repeal }}$.

Lowden and More (1990) investigated the effect of both the coating type and the thickness of coating on the mechanical properties (flexural strength) of $\mathrm{SiC} / \mathrm{SiC}$ composites. They also investigated the interfacial stresses and correlated the same to the flexural strength. A fiber coating of carbon with coating thicknesses varying from 0.07 to $0.50 \mu \mathrm{m}$ produced flexural strengths ranging from $344 \mathrm{MPa}$ to $420 \mathrm{MPa}$. The effect of the carbon coating was to reduce the frictional stress from $49 \mathrm{MPa}$ (uncoated fibers) to $0.6 \mathrm{MPa}$ ( $0.28 \mu \mathrm{m}$ coating thickness). There was no interfacial stress determination reported for the carbon coating thickness of greater than $0.5 \mu \mathrm{m}$. One set of results were also reported for boron nitride fiber coating $(0.15 \mu \mathrm{m})$ which produced composites of flexural strength of about $350 \mathrm{MPa}$. The layup investigated was the standard ORNL layup of $(0 / 30 / 60)_{\text {repeal }}$.

Headinger et al., (1991) have examined the properties of ICVI $\mathrm{SiC} / \mathrm{SiC}$ composites for $0 / 90$ balanced Nicalon fabric as part of characterization by Du Pont. A tensile strength range of $200 \mathrm{MPa}$ (room temperature) to $150 \mathrm{MPa}\left(1400^{\circ} \mathrm{C}\right)$ has been 
reported. A strain range of $0.3 \%$ to $0.5 \%$ was also reported. A higher strength and strain ranges were also reported for this lay up after exposure at $2200^{\circ} \mathrm{F}$ for various times in inert atmospheres. Slightly lower tensile strength values and higher strain values were reported for $0 / \pm 45 / 90$ laminate lay ups.

Kmetz et al., (1990) prepared SiC/SiC specimens using CVI SiC as the matrix and Nicalon Yarn. At room temperature, they obtained strength values of about 228 $\mathrm{MPa}$. When the composite was heated in air at $1040^{\circ} \mathrm{C}$, the strength was maintained. The matrix cracking stress was found to be approximately $117 \mathrm{MPa}$. The composite was essentially reinforced with unidirectional fibers.

Akimune et al., (1991) also investigated the properties of $\mathrm{SiC} / \mathrm{SiC}$ composites manufactured by the ICVI process. They obtained tensile strength values of about 162 $\mathrm{MPa}$, and a Young's Modulus of $230 \mathrm{GPa}$. The layup investigated was a $(0 / 90)_{\text {repeat }}$ layup.

\subsection{CHARACTERIZATION WITH ELECTRON MICROSCOPY}

Stinton et al., (1990) have done detailed characterization of both the interface as well as the matrix in the case of FCVI SiC/SiC composites using TEM and Raman Spectroscopy. These researchers mainly characterized the microstructure and composition of the $\mathrm{SiC}$ matrix and determined the $\mathrm{SiC}$ polytype that was deposited. Veltri et al., (1989), Yang et al., (1988), Navarre et al., (1990), Abbé and Chermant (1990) have 
attempted to correlate the mechanical properties to the various microstructural properties such as fiber-matrix bond strength, effect of pyrolytic coating, fiber oullout, crack deflection etc. However, the current level of understanding in this area is still incomplete.

It has been reported that (references 5 and 6 in Stinton et al., 1990) though there are about 150 polytypes of $\mathrm{SiC}$, only about 5 types are commonly observed. Each carbon and silicon atom in every polytype is tetrahedrally coordinated to four atoms of the other type ( $\beta$ Zinc blende structure) to form a close packed structure. This is shown in Figure 2.8. It has also been reported (Stinton et al., 1990) that the plane containing the a and $\mathrm{b}$ directions of the unit cell are identical in all polytypes, while the stacking sequence in the $c$ direction of the unit cell is different, which gives the different polytypes. The different stacking sequences are created by the translation of the planes and $180^{\circ}$ rotational twins, and are designated as $2 \mathrm{H}, 3 \mathrm{C}, 4 \mathrm{H}, 6 \mathrm{H}$, and $15 \mathrm{R}$. The letters $\mathrm{C}, \mathrm{H}$, and $\mathrm{R}$ are used to signify Cubic, Hexagonal, and Rhombohedral respectively, while the numbers before the letters signify the number of close packed layers before the stacking cycle is repeated (Stinton et al., 1990). These projections are schematically given in Figure 2.9. The $3 \mathrm{C}$ stacking cycle is the simplest of the 5 polytypes. The other polytypes are collectively known as $\alpha-\mathrm{SiC}$.

Stinton et al., (1990) report that the CVI SiC matrix is found to have a columnar structure, with each columnar grain containing a high density of rotational twins. The specimens taken from the composite side closest to the hot side of the furnace contained larger columnar grains than the specimens taken from the composite side closest to the 

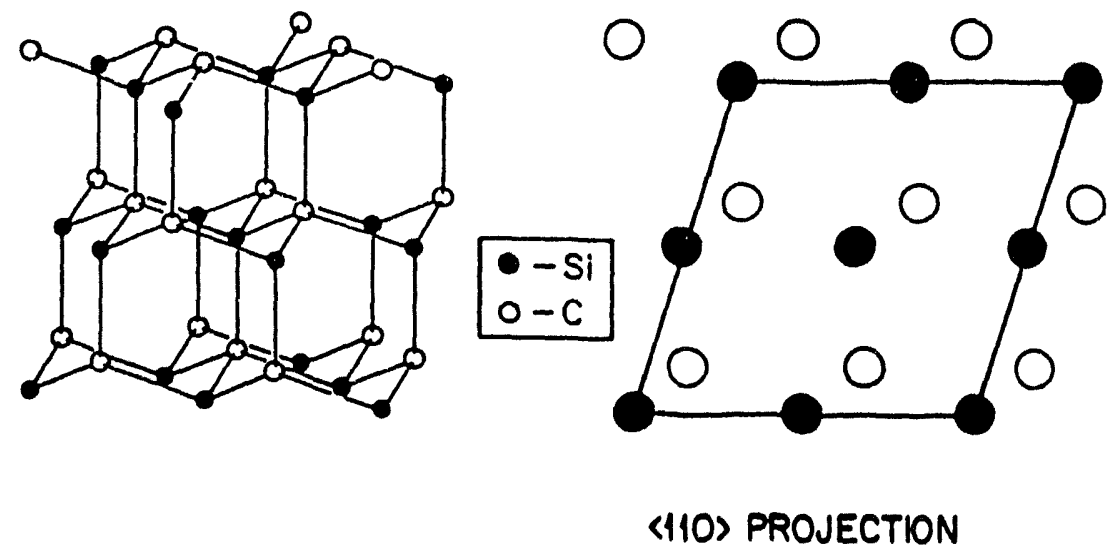

Figure 2.8. The cubic, zinc blende structure of $\beta$-SiC (Stinton et al., 1990).
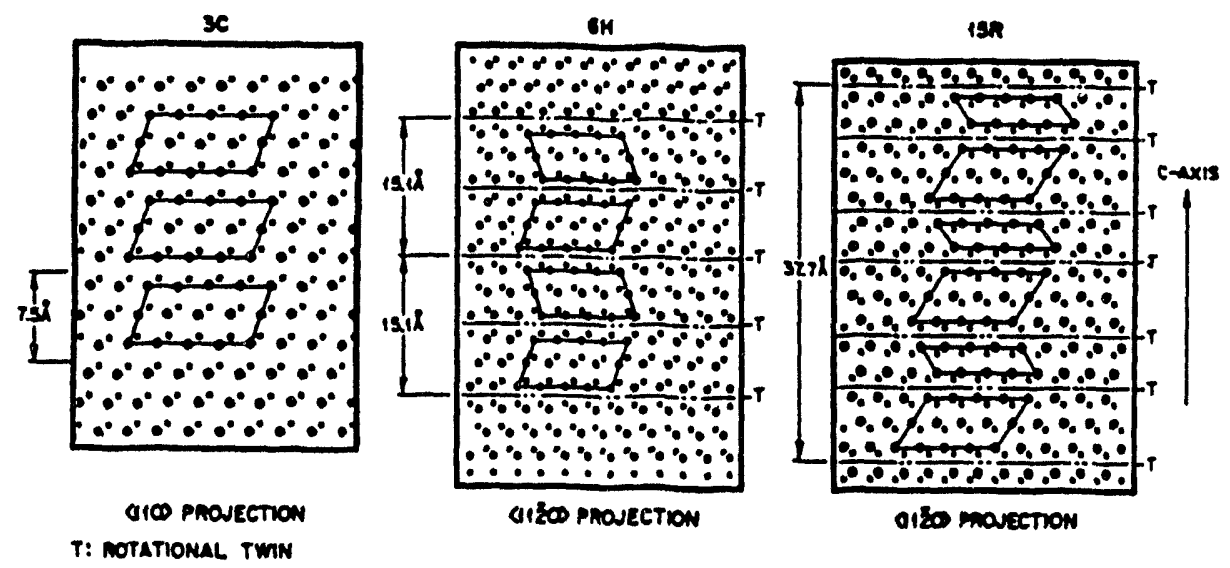

Figure 2.9. Projections of the 3C, 6H, and 15R structures of SiC (Stinton et al., 1990). 
cooler side of the furnace. It was observed that the $\mathrm{SiC}$ matrix away from the fiber had a structure which was a mixture of $\alpha$ polytypes commonly known as highly twinned $\mathrm{SiC}$. Regions of $\beta$-SiC were observed between the rotational twins.

\subsection{RELEVANCE OF THE CURRENT THESIS}

The mechanical properties reported so far for $\mathrm{SiC} / \mathrm{SiC}$ composites have mostly been determined using bend tests. Huwever, brittle ceramic materials are inherently weak in tension primarily due to latent defects. Ceramic matrix composites could also be included in this group, due to their latent and inherent defects. Therefore, tensile strength is of primary concern in the design of ceramic components including monolithic ceramics and ceramic matrix composites. Uniaxial tensile tests testing has the following advantages over bend testing (Govila 1982, 1983; Lange et al., 1979a; Kossowsky et al., 1975; Vaidyanathan et al., 1988).

a) The state of stress is simple and uniform over the gage cross-section of the tensile specimen.

b) The test volume under the maximum stress in tensile specimen is greater than that in a bend specimen having the equivalent cross-sectional area by a factor of 10 to 1000. 
c) Uniaxial tensile testing characterized the fracture behavior of both the internal and surface flaws.

d) The fracture in a tensile specimen is likely to initiate from the largest flaw.

e) Uniaxial tensile data is directly applicable to structural design and analysis use, whereas bend data are applied indirectly based on a theory. Drawbacks of the uniaxial testing are the high cost of test specimens and experimental difficulties associated with specimen gripping and alignment.

Due to the importance of tensile data as explained previously, it is important that test data be determined in the tensile mode for tensile strength, cyclic loading strength, thermal shock resistance, and oxidation resistance. Very scant data also exists for the comparison of the mechanical properties of $\mathrm{SiC} / \mathrm{SiC}$ composites manufactured by both the isothermal and forced CVI techniques. It is also important that the fracture/damage mechanisms be correlated to the mechanical properties obtained in tension. Therefore, it is the major thrust of this thesis to compare and understand the properties of both the isothermal and forced CVI composites as well as to determine the fracture/damage mechanisms for these properties. In addition, it will be useful to develop an analytical model for the prediction of mechanical properties. It will also be useful to compare the properties thus obtained to the data available so far.

Specifically the thesis objectives were :

\section{A. EXPERIMENTAL}

\section{MECHANICAL BEHAVIOR INVESTIGATION}


i. To design a test setup to grip and test the uniaxial properties up to $1000^{\circ} \mathrm{C}$ and to measure strain for $\mathrm{SiC} / \mathrm{SiC}$ systems.

ii. To understand the uniaxial tensile behavior of $\mathrm{SiC}-\mathrm{SiC}$ composites

iii. To determine the cyclic loading response of $\mathrm{SiC}-\mathrm{SiC}$ composites

iv. To investigate the thermal shock characteristics of SiC-SiC composites

v. To evaluate the oxidation resistance properties of $\mathrm{SiC}-\mathrm{SiC}$ composites

II. MICROSTRUCTURAL

i. Scanning Electron Microscopy : Fracture surface and failure process investigation.

ii. Transmission Electron Microscopy : Fiber-Matrix interface and matrix structure characterization.

\section{B. ANALYTICAL MODELING}

i. To develop a model for a plain weave ceramic matrix composite to determine the mechanical properties.

It is hoped that this thesis work will contribute to a better understanding of the mechanical properties of $\mathrm{SiC} / \mathrm{SiC}$ ceramic matrix composites, with a special emphasis on the correlation of damage/fracture patterns to known toughening theories. 


\section{CHAPTER 3}

\section{EXPERIMENTAL SET UP, MATERIALS AND PROCEDURES}

\subsection{MATERIAL SYSTEMS}

The ceramic fiber-ceramic matrix composite system of $\mathrm{SiC} / \mathrm{SiC}$ was chosen for in-depth study in this research since this system currently is one of the most popular and advantageous ceramic matrix composite systems being scrutinized most actively. The two different methods of manufacturing the composite system, i. e., the Forced CVI and Isothermal CVI processes were selected. Two different stacking layups from each system was chosen for this study $\left((0 / 30 / 60)_{\text {repeat }}\right.$ and $(0 / 45 / 45 / 0)_{\text {repeat }}$ layups for FCVI composites ; $(0 / 45 / 45 / 0)_{\text {repeat }}$ and $(0 / 90)_{\text {repeat }}$ layups for ICVI composites). The $(0 / 30 / 60)_{\text {repeat }}$ is the standard layup FCVI composite made by ORNL for best infiltration. The $(0 / 45 / 45 / 0)_{\text {repeat }}$ was a layup suggested to ORNL for its quasi-isotropic nature (from classical laminate theories). Similarly, the standard layup made by Du Pont is the $(0 / 90)_{\text {repeat }}$, while the $(0 / 45 / 45 / 0)_{\text {repeat }}$ layup was chosen in order to compare its properties with a FCVI composite with a similar stacking sequence. Each lamina is a plain weave, i. e., each lamina contains fibers woven in directions 90 degrees to each other. For example, a 0 degree in the layups described above contains fibers in both 0 (warp) and 90(fill) degree directions. 45 degree contains both 45 and -45 degree fibers, while 90 degree fibers contains both 90 degree as well as 0 degree fibers. The orientation of the fibers is 
specified with respect to the longitudinal direction ( 0 degree means that the fibers are parallel to the tensile direction). It is also to be noted that the cloth used by Du Pont is a plain weave with 500 filaments/tow and about 6 tows $/ \mathrm{cm}$, while that used by ORNL is a plain weave with 1000 filaments/tow and about 6.2 tows/cm (Stinton et al., 1990a). Efforts were made to identify a tensile specimen configuration for uniaxial tensile testing, emphasis being placed on a simple specimen geometry that allowed minimal volume of material, minimum machining, minimal cost, and ease of alignment in the testing grips. A comparison of the material systems investigated is given in Table 3.1. A model quasi-isotropic layup for $\mathrm{SiC} / \mathrm{SiC}$ composite material is shown in Figure 3.1. 


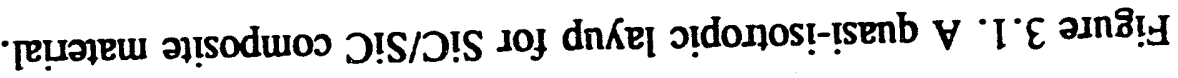

$$
d n k e \mid p d \varepsilon+2 \quad d n k e 147 t+1
$$

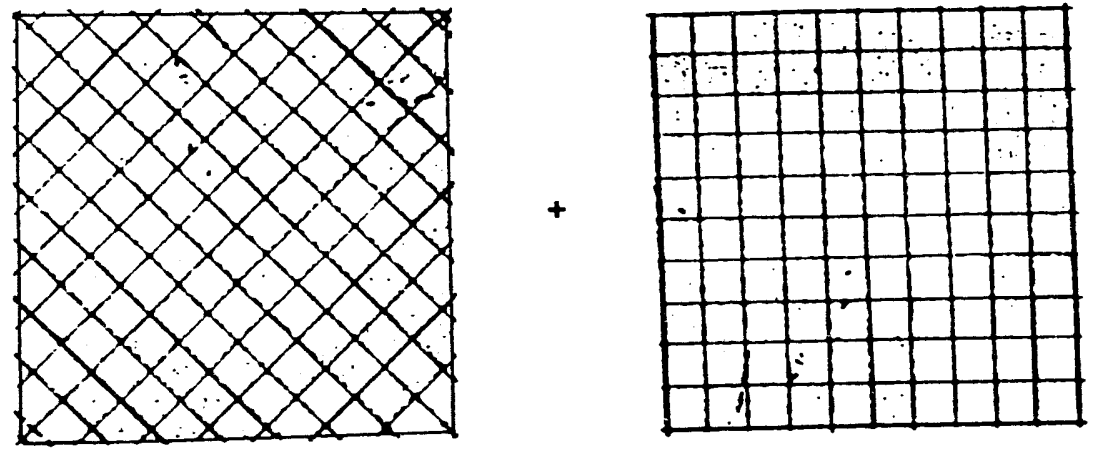


Table 3.1. Comparison of Materials Investigated

\begin{tabular}{||l|l||}
\hline \multicolumn{1}{|c|}{ FCVI (ORNL) } & \multicolumn{1}{|c|}{ ICVI (Du Pont) } \\
\hline \multicolumn{1}{|c|}{ SiC Matrix } & \multicolumn{1}{|c|}{ SiC Matrix } \\
\hline Nicalon Fibers & \multicolumn{1}{|c|}{ Nicalon Fibers } \\
\hline $\begin{array}{l}0.3 \mu \mathrm{m} \text { Pyrolytic carbon coating } \\
\text { on fibers }\end{array}$ & $\begin{array}{l}0.1 \mu \mathrm{m} \text { Pyrolytic carbon coating } \\
\text { on fibers }\end{array}$ \\
\hline $\begin{array}{l}\text { Flat specimen } \\
\text { Configuration used } \\
76 \mathrm{~mm} \times 11.8 \mathrm{~mm} \times 4 \mathrm{~mm} \\
\text { overall } \\
24.4 \times 6 \times 4 \text { gage section }\end{array}$ & $\begin{array}{l}\text { Flat specimen } \\
\text { Configurations used } \\
\text { a. } 76 \mathrm{~mm} \times 11.8 \mathrm{~mm} \times 4 \mathrm{~mm} \\
\text { overall } \\
24.4 \times 6 \times 4 \text { gage section }\end{array}$ \\
$\begin{array}{l}\text { b. } 120 \times 12 \times 4 \text { overall } \\
40 \times 8 \times 4 \text { gage section }\end{array}$ \\
\hline $\begin{array}{l}25-50 \mu \mathrm{m} \text { SiC overcoating after } \\
\text { machining to protect the interface }\end{array}$ & $\begin{array}{l}25-50 \mu \mathrm{m} \mathrm{SiC} \text { overcoating after } \\
\text { machining to protect the interface }\end{array}$ \\
\hline $\begin{array}{l}\text { Manufactured in } 76 \mathrm{~mm}(3 \\
\text { inches }) \text { dia "Hockey Puck" form }\end{array}$ & $\begin{array}{l}\text { Manufactured in plate form } \\
(200 \times 200 \times 4 \text { mm })\end{array}$ \\
\hline $\begin{array}{l}\text { Plain weave cloth with } 1000 \\
\text { filaments/tow and } 6.2 \text { tows } / \mathrm{cm}\end{array}$ & $\begin{array}{l}\text { Plain weave cloth with } 500 \\
\text { filaments/tow and } 6 \text { tows } / \mathrm{cm}\end{array}$ \\
\hline $\begin{array}{l}\text { Processing temperature } \approx 1473^{\circ} \\
\mathrm{K}\left(1200^{\circ} \mathrm{C}: \text { Furnace Hot zone }\right. \\
\text { temperature) }\end{array}$ & $\begin{array}{l}\text { Processing temperature } \approx 1273^{\circ} \mathrm{K} \\
\left(1000^{\circ} \mathrm{C}: \text { Specific processing }\right. \\
\text { conditions are proprietary })\end{array}$ \\
\hline Nominal fiber volume $=40 \%$ & Nominal fiber volume $=40 \%$ \\
\hline $\begin{array}{l}\text { Composite density } \approx 2.5 \mathrm{~g} / \mathrm{cc} \\
\text { Composite density } \geq 2.5 \mathrm{~g} / \mathrm{cc}\end{array}$ \\
\hline \hline
\end{tabular}

\subsubsection{SPECIMEN CONFIGURATION}

In the case of the specimens from FCVI layups, the specimens are machined out of 3" diameter block of FCVI material. 9 specimens could be obtained from each block of the material. The schematic of the sample design for the FCVI specimens is shown 
in Figure 3.2. In the case of ICVI material, the specimens were machined directly out of the plates of ICVI material. The specimen configuration used in a majority of tests is shown in Figure 3.3. In the case of specimens with a different test volume, the length of the specimen is $120 \mathrm{~mm}$ as compared to the specimen in Figure 3.3 which has a length of $76 \mathrm{~mm}$. 


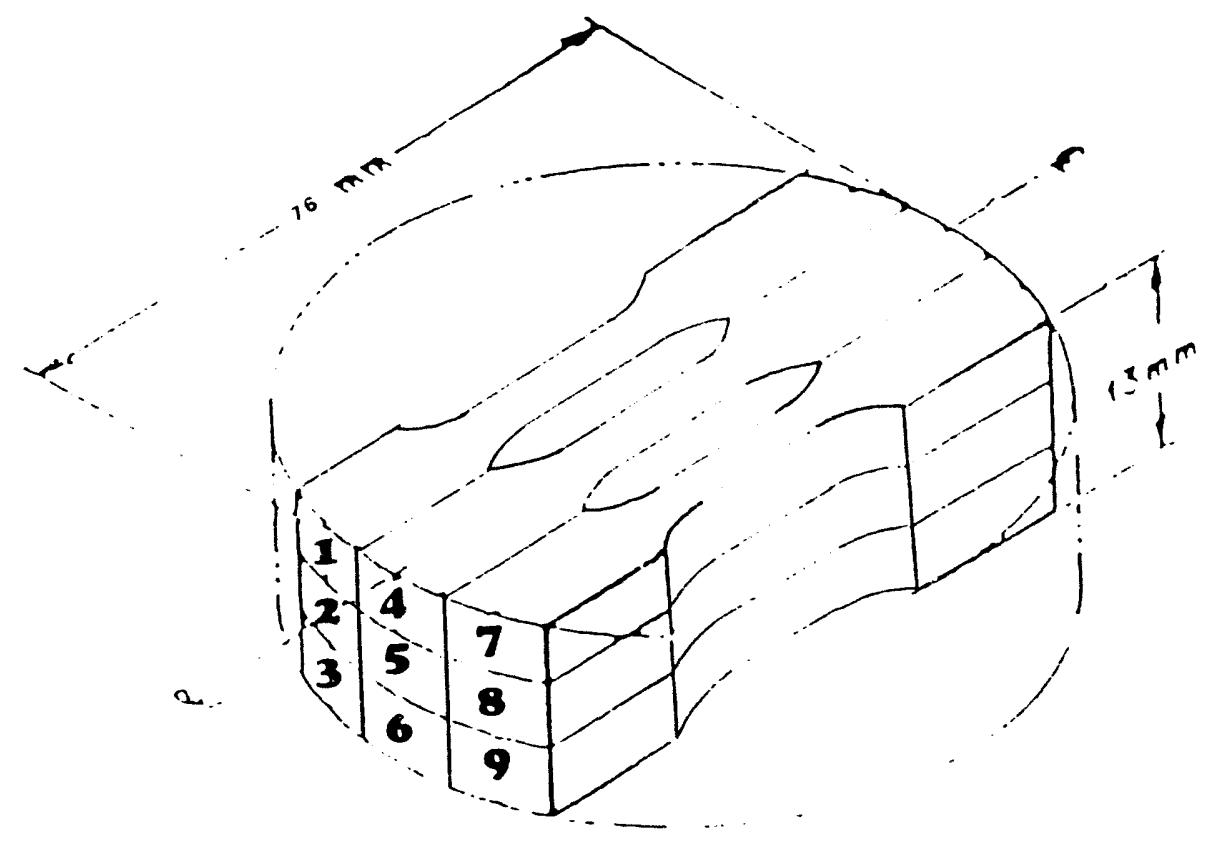

Figure 3.2. Schematic drawing of the sample design. 


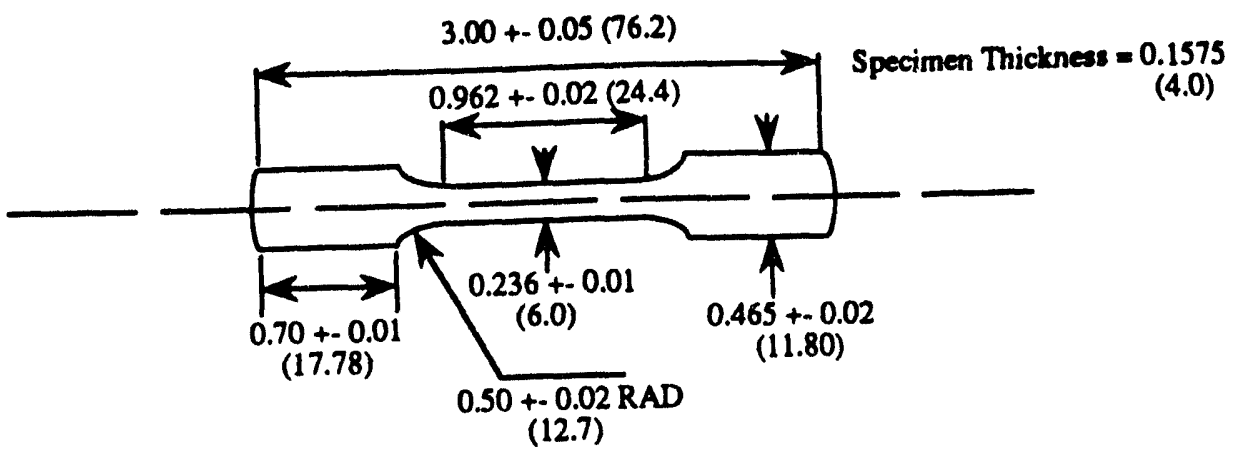

All Dimenoions in inches (mm)

Figure 3.3. Tensile Specimen Configuration for $\mathrm{SiC} / \mathrm{SiC}$ composites 


\subsection{EXPERIMENTAL SET UP}

The set up and procedures for the experiments in the current thesis are briefly described below. The set up and procedures are described on the basis of the nature of the thesis objectives.

\subsubsection{TESTING MACHINE AND CONTROLS}

An MTS 880 Model servo-hydraulic testing machine interfaced through a MicroPDP/11 computer for data acquisition and storage was used for investigating the mechanical behavior. Load control mode was used for controlling the mechanical tests. Ceramics and Ceramic composites being brittle materials, the amount of strain that these materials might be able to withstand is very low. It is therefore easier to control the tensile tests more easily in the load control mode rather than strain control mode. The testing machine and accompanying controls are shown in Figure 3.4.

Data acquisition was conducted using a computer program "CERTEN" (Ceramic composite testing program for tensile tests) written in MTS BASIC language for monitoring the load change during the course of the test. A stressing rate of 250 $\mathrm{MPa} / \mathrm{min}$ was used in the test program, though it was possible to change this rate as required. This stressing rate was used so that the specimen failure could be achieved in about a minute. The strain change in the specimen was monitored by a Laser telemetric 


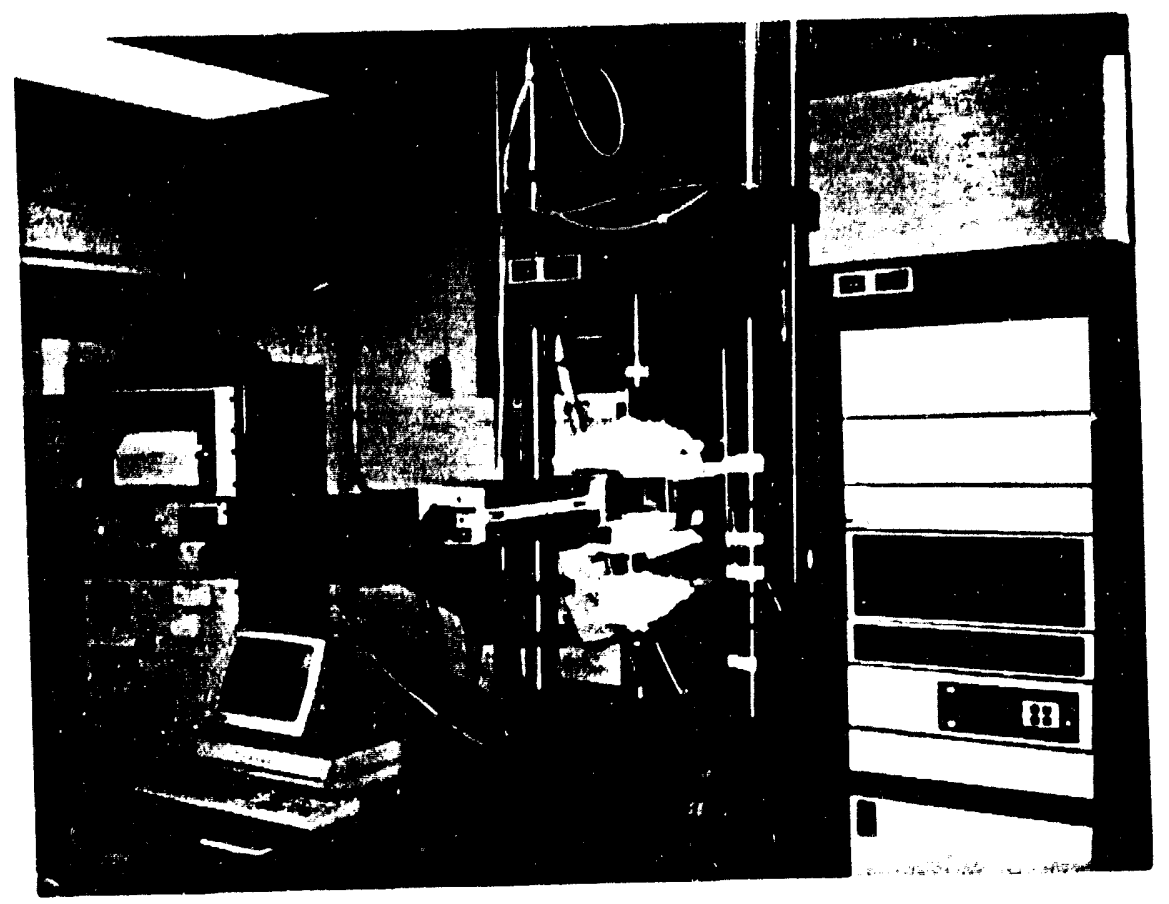

Figure 3.4. Test set up used for tensile characterization of $\mathrm{SiC}$ fiber - SiC matrix composite. 
system $^{a}$ which was very accurate and monitored the extension of the specimen with the help of two Inconel flags attached to the specimen. The Model 121 laser telemetric system also generates a voltage (in the range of -10 to 10 volts) corresponding to the extension of the flags, and is fed into an A/D channel through an RS-232C interface. The extension is thus accurately monitored along with the load. Thus, it is possible to monitor the change in stress and strain in the specimens under perfectly uniaxial tensile conditions. The maximum load and strain are also monitored and stored in the memory. Data acquisition is done through a Micro-PDP-11 computer which has an RT-11 operating system. A VT240 DEC terminal which is a graphics terminal was used for its graphics capabilities. However, it is also possible to use an IBM PC for the data acquisition and graphics capability. The program uses function generator commands to apply the load on the specimen.

The specimens were gripped using a wedge type gripa. This specimen assembly was then attached to a self aligning grip ${ }^{\mathrm{b}}$, which produces near zero bending moments during tensile testing. The wedge type grip was used to grip the very short flat composite specimens used in the current thesis. The self aligning grip has been described in detail elsewhere (Liu and Brinkman, 1986, Vaidyanathan et al., 1988). The schematic drawing of the gripping mechanism is given in Figure 3.5.

In order to prevent the crushing of the specimens as well as for proper gripping

${ }^{a}$ Model 121, Zygo Corporation, Middlefield, CT

${ }^{a}$ Model 4053, Applied Test Systems, Butler, PA

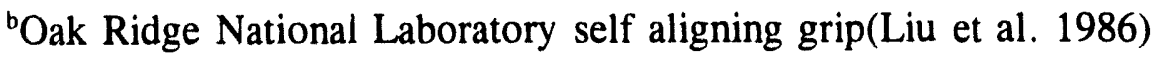




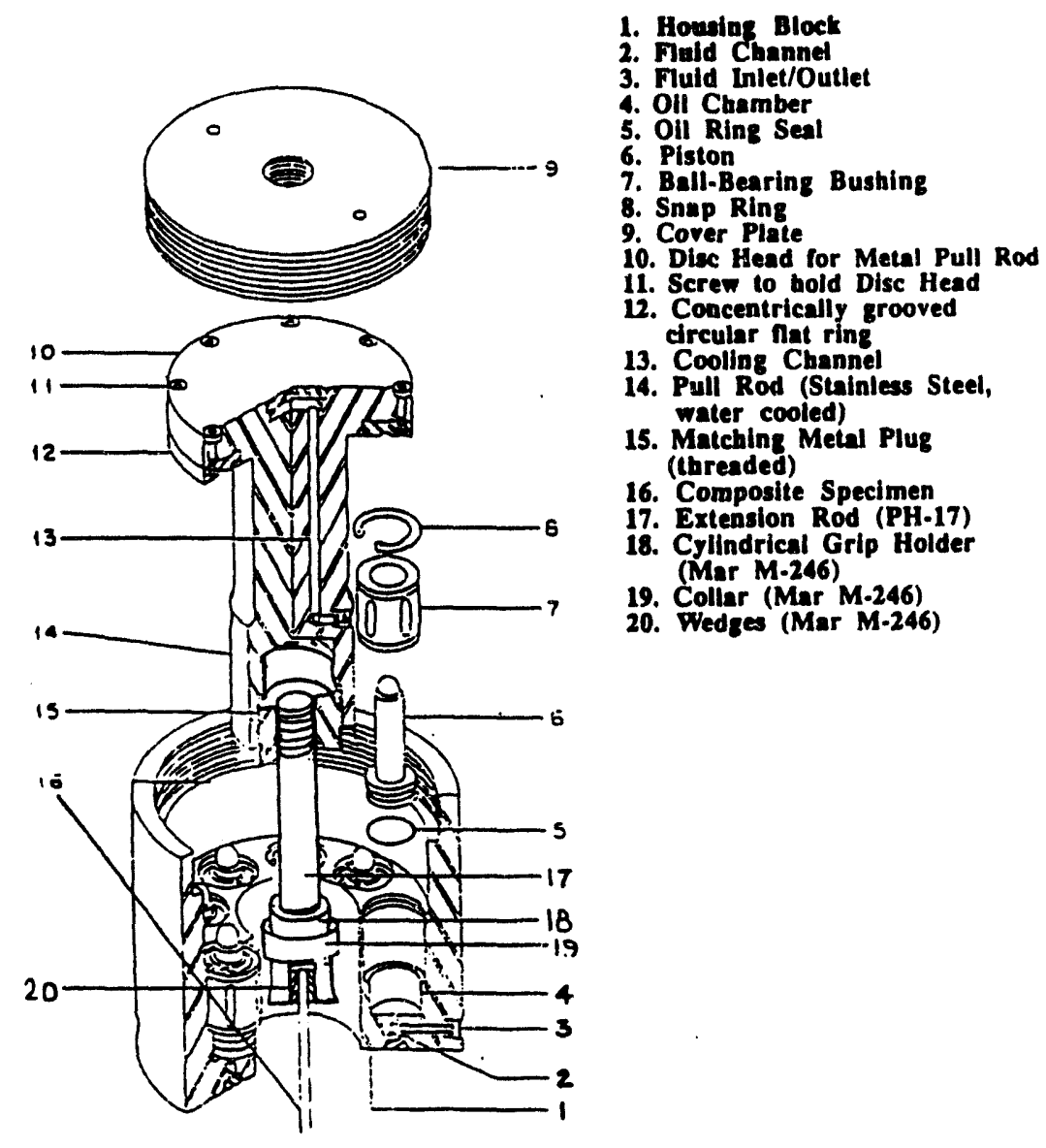

Figure 3.5. Self aligning hydraulic grip system for gripping composite specimens. 
without slippage, inconel tabs cut to the size of the ends of the specimen were glued to the specimen. For room temperature tests, superglue gel was used for attaching the tabs, while for high temperature tests, the tabs were glued with an alumina based high temperature adhesive ${ }^{a}$. The flags for monitoring the strain was also attached to the specimen using the same adhesive. The grip, wedges, and the specimen assembly is shown in Figure 3.6, while Figure 3.7 shows the specimen with attached flags.

The experiments were conducted at room temperature as well as at $1273^{\circ} \mathrm{K}$ $\left(1000^{\circ} \mathrm{C}\right)$. The specimen heating was achieved by a High temperature box furnace ${ }^{\mathrm{b}}$ with a heating zone of about $25 \mathrm{~mm}$ ( 1 inch). The heating elements are made of Silicon Carbide. The heating control was achieved with the help of a Model $2010^{c}$ automatic temperature controller.

The uniaxial tensile tests at room temperature (RT) were performed at a stressing rate of $250 \mathrm{MPa} / \mathrm{min}$. This stressing rate was $\mathrm{cl} \quad \mathrm{h}$ that specimen failure would occur in 1 minute or less. Uniaxial tensile tests were also performed after the specimens were exposed to thermal shock (RT/TS) as well as after exposure to oxidation (RT/OX). The thermal shock treatment consisted of 10 cycles of thermal shock. 1 cycle of thermal shock consisted of heating the composite specimens to $1273^{\circ} \mathrm{K}\left(1000^{\circ} \mathrm{C}\right)$ in air, holding for 30 minutes to uniformly heating the specimen, cooling to about $1273^{\circ} \mathrm{K}\left(100^{\circ} \mathrm{C}\right)$ using compressed air, and reheating to $1273^{\circ} \mathrm{K}\left(1000^{\circ} \mathrm{C}\right)$. Heating was accomplished by

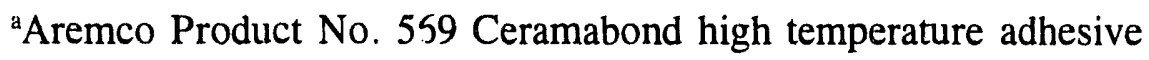

${ }^{b}$ Model 3450, ATS Corporation, Butler, PA

'LFE Corporation, Clinton, MA
} 
a box type laboratory muffle furnace. Oxidation exposure was accomplished by heating the composite specimens to $1273^{\circ} \mathrm{K}\left(1000^{\circ} \mathrm{C}\right)$ in air, holding at that temperature for 100 hours, and cooling to room temperature. The elevated temperature tests consisted of uniaxial tensile tests at $1273^{\circ} \mathrm{K}\left(1000^{\circ} \mathrm{C}\right)$.

A total of thirty three (33) FCVI samples and thirty three (33) ICVI samples were tested under different test conditions. Three (3) ICVI samples with a higher test specimen volume were also tested at room temperature.

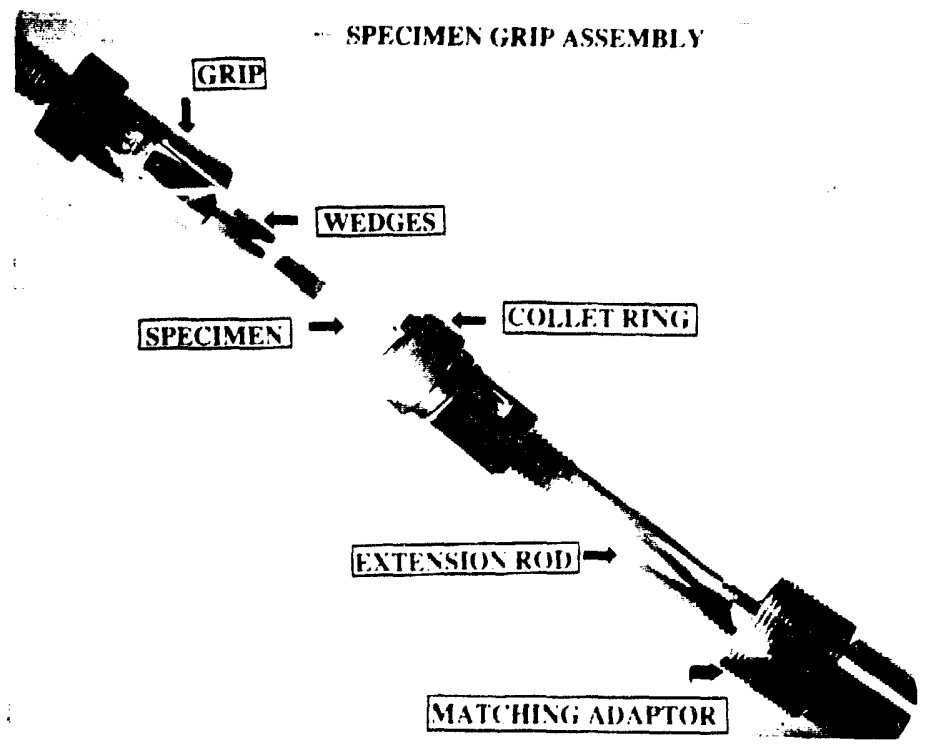

Figure 3.6. Specimen grip assembly. 


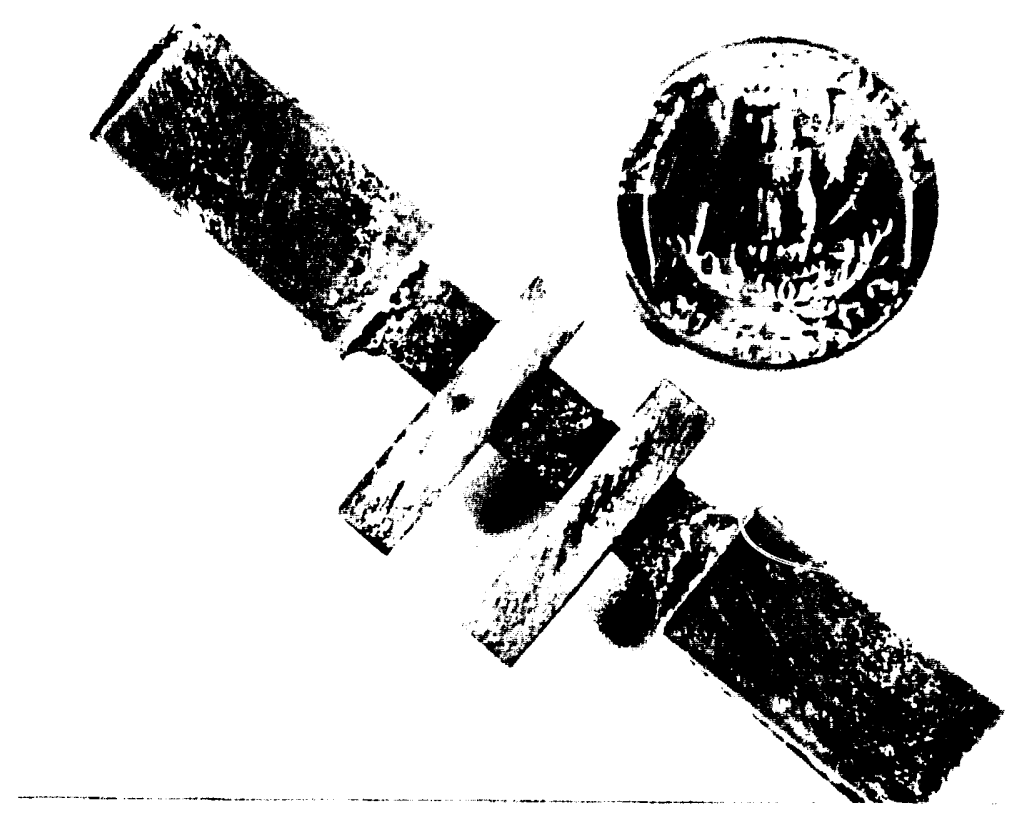

Figure 3.7. Specimen with attached tabs and flags.

\subsection{CALIBRATION OF LASER EXTENSOMETER}

It was necessary to study the accuracy of the Zygo laser extensometer before it could be applied to measure such low strains produced during the uniaxial tensile tests. This was done by comparing the gap measured by the laser extensometer against the same gap as measured by a standard micrometer located outside the setup. Figure 3.8 shows the close up view of the set up. A pair of alumina rods were used, one of which was held in a standard micrometer. The gap between the tips of the rods could be 
increased or decreased by turning the micrometer wheel. The time between each reading was approximately 2 to 3 minutes. The readings were taken after about 45 minutes of stabilization time at the test temperature. This helped to accommodate the thermal expansion of the alumina rods, if any, at these temperatures. Calibration of the Zygo laser extensometer was conducted at room temperature, 500,800 , and $1000^{\circ} \mathrm{C}$. This work was also done as a part of another research project carried out at North Carolina A \& T State University (Gao, 1990).

\subsection{MICROSTRUCTURAL CHARACTERIZATION}

Microstructural characterization consisted of both Scanning electron microscopy (SEM) as well as Transmission electron microscopy (TEM) for the characterization of the fracture surfaces and the fiber/matrix interface. A Scanning electron microscope ${ }^{a}$ was used for fracture surface characterization. A Transmission electron microscope ${ }^{b}$ was used to characterize the fiber matrix interface. A high resolution $\mathrm{TEM}^{\mathrm{c}}$ was also used to characterize the structure of the matrix away from the fiber matrix interface.

A low speed diamond saw was used to cut and prepare the samples for SEM. For TEM characterization, specimens from both the bulk of the specimen as well as the fracture surfaces were prepared (Stinton et al., 1990). This was done by cutting $\approx 300$

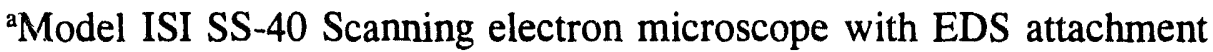

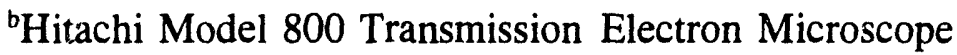

'Akas: Model 002B Transmission Electron Microscope
} 


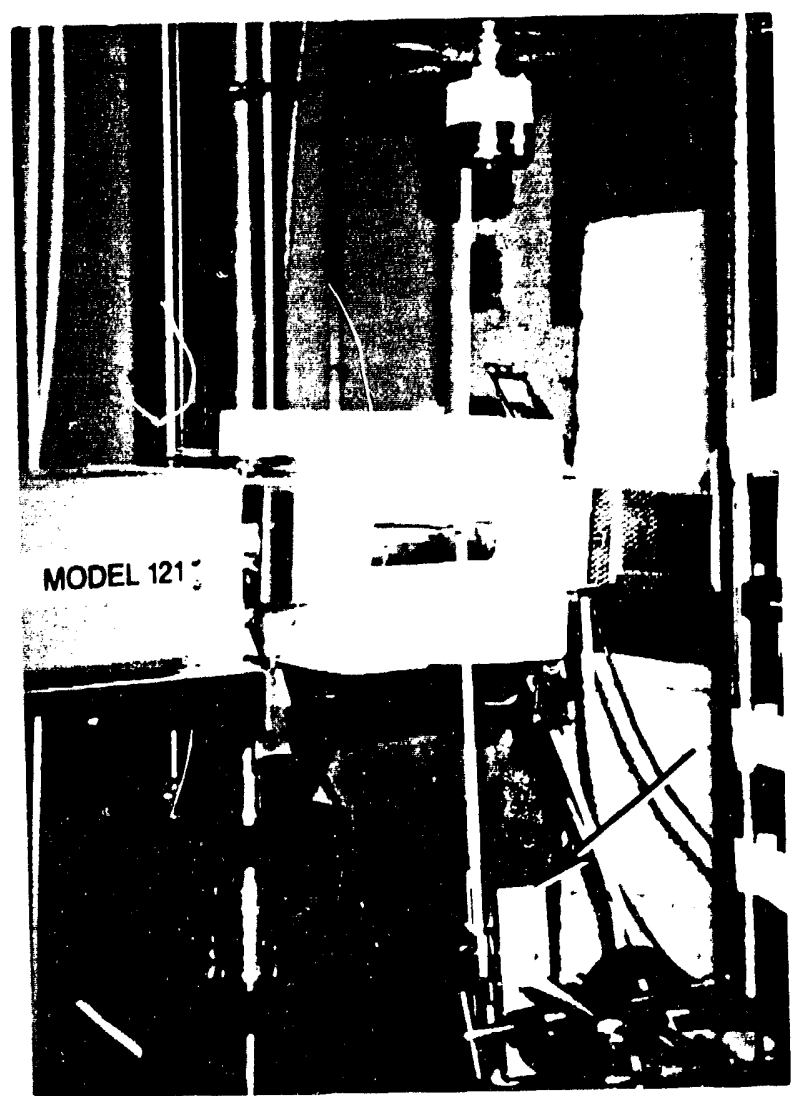

Figure 3.8. Close up view of calibration set up. 
$\mu \mathrm{m}$ thick, 2 by $2 \mathrm{~mm}$ samples using a low speed diamond saw. The small squares were then mechanically ground and polished to a thickness of $\approx 75-100 \mu \mathrm{m}$, dimpled to a center thickness of $\approx 20 \mu \mathrm{m}$. The thin foils were then ion-milled using $6-\mathrm{kV} \mathrm{Ar}{ }^{+}$ions at an incident angle of $15^{\circ}$ and total gun current of $1 \mathrm{Amp}$. The specimens were examined using an Akasi-002B high resolution (HR) TEM as well as a Hitachi-800 TEM which were operated at $200 \mathrm{kV}$. High resolution electron microscopy was primarily used to understand the results from the thesis and also to compare the present work with results available from the literature.

\subsection{CALCULATION OF INITIAL MODULUS FROM THE STRESS STRAIN CURVES}

To understand the effect of the testing conditions on CVI composites, stress-strain behavior of the individual composite lay-ups investigated under different testing conditions needed to be compared. A good measure of comparison in the current work was determined to be the initial modulus of the composite, determined from the individual stress-strain curves. However, this turned out to be a difficult task, since it was observed that the slope of some of the stress-strain curves tended to vary gradually from the initial stages of the test itself (possibly due to fiber pull-out occurring from the initial stages of the test itself), in turn affecting the initial elastic modulus. This necessitated the use of a percent offset strain for the calculation of the elastic modulus, similar to metals. After closer examination, a strain of 0.0005 (0.05\% strain) was 
chosen as the percent offset strain. In a majority of tests, it is observed that the change in the linear behavior of the material occurred after this limit. A least square fit was done for a straight line fit on approximately 25 data points between 0 and $0.05 \%$ strain for all the stress-strain curves. The slope of this straight line was calculated to be the initial elastic modulus for the composite specimen under the specific test condition. 


\section{CHAPTER 4}

\section{EXPERIMENTAL RESULTS}

\subsection{RESULTS OF THE CHARACTERIZATION OF THE LASER EXTENSOMETER}

The micrometer readings and those obtained by using the Zygo laser extensometer at room temperature are given in Table 4.1. Evaluation results at 500,800 and $1000^{\circ} \mathrm{C}$ are given in Tables 4.2. through 4.4. The corresponding curves are presented in Figures 4.1. through 4.3. $\delta_{\max }$ is the maximum deviation between the micrometer readings and the laser extensometer readings. The micrometer readings are used as the reference. The maximum $\delta_{\max }$ at each temperature is summarized in Table 4.5.

\subsection{STRESS-STRAIN BEHAVIOR OF SiC/SiC COMPOSITES}

Table 4.6 summarizes the tensile strength, strain, and initial modulus of the $\mathrm{SiC} / \mathrm{SiC}$ composites for all the test conditions for all the layups. A typical stress-strain plot for a FCVI $(0 / 30 / 60)_{\text {repeat }}$ layup is shown in Figure 4.4. To facilitate comparisons between the different layups as well as between the different test conditions for the same layup, the stress-strain behavior were plotted on the same graph. These plots are given 
in Figures 4.5 through 4.18.

Figures 4.5 through 4.10 compare the behavior of the FCVI composites under various test conditions. In Figure 4.5, the stress-strain behavior of 3 specimens of FCVI $(0 / 30 / 60)_{\text {repeat }}$ layup under test conditions of room temperature (RT), room temperature after exposure to thermal shock (RT/TS), as well as at $1000^{\circ} \mathrm{C}(1000 \mathrm{C})$ are compared. In Figure 4.6, the stress-strain behavior of the same layup at RT, room temperature after exposure to oxidation (RT/OX), and $1000 \mathrm{C}$ are compared. Similarly, the stress-strain behavior of the FCVI $(0 / 45 / 0 / 45)_{\text {repeat }}$ layup at RT, RT/TS, and $1000 \mathrm{C}$ are compared in Figure 4.7. Figure 4.8 compares the stress-strain behavior of the same layup under conditions of RT, RT/TS, and RT/OX. Figures 4.9 and 4.10 compare the stress-strain behavior of the FCVI $(0 / 30 / 60)_{\text {repeat }}$ layup and the $(0 / 45 / 0 / 45)_{\text {repeat }}$ layup at RT and 1000 C respectively.

Figures 4.11 through 4.15 compare the behavior of ICVI composites under various test conditions. Figure 4.11 compares the RT, RT/OX, and RT/Ts behavior of the $(0 / 45 / 0 / 45)_{\text {repeat }}$ layup. Figures 4.12 and 4.13 compare the behavior of the ICVI $(0 / 90)_{\text {repeat }}$ layup for different test conditions. The room temperature behavior of both these layups $(0 / 45 / 45 / 0$ and $0 / 90)$ are compared in Figure 4.14 , while the room temperature behavior after exposure to thermal shock for these layups are compared in Figure 4.15.

A comparison between the stress-strain behavior of the same type of layup for both the FCVI and ICVI layups at RT and RT/TS are made in Figures 4.16 and 4.17. The common layup compared was the $(0 / 45 / 0 / 45)_{\text {repeat }}$ layup. The effect of test specimen 
volume is given by Figure 4.18 which was carried out by having samples of different dimensions for the ICVI $(0 / 90)_{\text {referat }}$ layup.

Figures 4.19 through 4.22 are bar graphs of the tensile strength versus various tests conditions for the FCVI $(0 / 30 / 60)_{\text {repeat }}$ layup, FCVI $(0 / 45 / 0 / 45)_{\text {repeal }}$ ICVI $(0 / 45 / 0 / 45)_{\text {repeat }}$, and the ICVI $(0 / 90)_{\text {repeat }}$ layups respectively.

The average tensile strength, average strain to failure, and the average initial modulus for each of the layups investigated was also plotted as bar graphs. These are given in Figures 4.23 through 4.25 .

Table 4.1. Calibration results for Zygo laser extensometer at room temperature

\begin{tabular}{|c|c|c||}
\hline Reading \# & $\begin{array}{c}\text { Micrometer reading } \\
\text { (inches) }\end{array}$ & $\begin{array}{c}\text { Laser Extensometer } \\
\text { reading } \\
\text { (inches) }\end{array}$ \\
\hline 1 & 0.0340 & 0.0340078 \\
2 & 0.0350 & 0.0350073 \\
3 & 0.0360 & 0.0360068 \\
4 & 0.0370 & 0.0370144 \\
5 & 0.0380 & 0.0380096 \\
6 & 0.0390 & 0.0390121 \\
7 & 0.0400 & 0.0400136 \\
\hline$\delta_{\max }=1.44 \mathrm{e}-05$ inch $(0.3658 \mu \mathrm{m})$ &
\end{tabular}


Table 4.2. Calibration results for Zygo laser extensometer at $500 \mathrm{deg}$. C

\begin{tabular}{||l|c|l||}
\hline Reading \# & $\begin{array}{c}\text { Micrometer reading } \\
\text { (inches) }\end{array}$ & $\begin{array}{c}\text { Laser Extensometer } \\
\text { reading } \\
\text { (inches) }\end{array}$ \\
\hline 1 & 0.0378 & 0.0378091 \\
2 & 0.0383 & 0.0383063 \\
3 & 0.0388 & 0.0387744 \\
4 & 0.0393 & 0.0392199 \\
5 & 0.0398 & 0.0397115 \\
6 & 0.0403 & 0.0402148 \\
7 & 0.0408 & 0.0407113 \\
\hline
\end{tabular}

$\delta_{\max }=8.87 \mathrm{e}-05$ inch $(2.253 \mu \mathrm{m})$

Table 4.3. Calibration results for Zygo laser extensometer at $800 \mathrm{deg}$. C

\begin{tabular}{||c|c|c||}
\hline Reading \# & $\begin{array}{c}\text { Micrometer reading } \\
\text { (inches) }\end{array}$ & $\begin{array}{c}\text { Laser Extensometer } \\
\text { reading } \\
\text { (inches) }\end{array}$ \\
\hline 1 & 0.0349 & 0.0349579 \\
2 & 0.0354 & 0.0354075 \\
3 & 0.0359 & 0.0358474 \\
4 & 0.0364 & 0.0363099 \\
5 & 0.0369 & 0.0368342 \\
6 & 0.0374 & 0.0373114 \\
7 & 0.0379 & 0.0378063 \\
\hline$\delta_{\max }=9.38 \mathrm{e}-05$ inch $(2.382 \mu \mathrm{m})$ &
\end{tabular}


Table 4.4. Calibration results for Zygo laser extensometer at $1000 \mathrm{deg}$. C

\begin{tabular}{||c|c|c||}
\hline Reading \# & $\begin{array}{c}\text { Micrometer reading } \\
\text { (inches) }\end{array}$ & $\begin{array}{c}\text { Laser Extensometer } \\
\text { reading } \\
\text { (inches) }\end{array}$ \\
\hline 1 & 0.0349 & 0.0349914 \\
2 & 0.0354 & 0.0354079 \\
3 & 0.0359 & 0.0358812 \\
4 & 0.0364 & 0.0363293 \\
5 & 0.0369 & 0.0369077 \\
6 & 0.0374 & 0.0373103 \\
7 & 0.0379 & 0.0377991 \\
\hline$\delta_{\max }=1.01 \mathrm{e}-04$ inch $(2.565 \mu \mathrm{m})$ &
\end{tabular}

Table 4.5. Maximum difference between micrometer and laser extensometer readings

\begin{tabular}{||c|c|c|}
\hline \multirow{2}{*}{$\begin{array}{c}\text { Temperature } \\
\text { (deg. C) }\end{array}$} & \multicolumn{2}{|c|}{ Difference } \\
\cline { 2 - 3 } & In inches & In $\mu \mathrm{m}$ \\
\hline 25 & $1.44 \mathrm{e}-05$ & 0.366 \\
500 & $8.87 \mathrm{e}-05$ & 2.253 \\
800 & $9.38 \mathrm{e}-05$ & 2.382 \\
1000 & $1.01 \mathrm{e}-04$ & 2.565 \\
\hline
\end{tabular}

\subsection{SCANNING ELECTRON MICROSCOPY/TRANSMISSION ELECTRON MICROSCOPY OF SiC/SiC COMPOSITES}

Two typical failed samples of $\mathrm{SiC} / \mathrm{SiC}$ composites after tensile testing is shown in Figure 4.26. Figures 4.27 through 4.57 are the results of scanning electron microscopy (SEM) and transmission electron microscopy (TEM) of the fracture surfaces and the bulk composite. This was performed on a select number of specimens, since the behavior was 


$$
\text { 国 }
$$




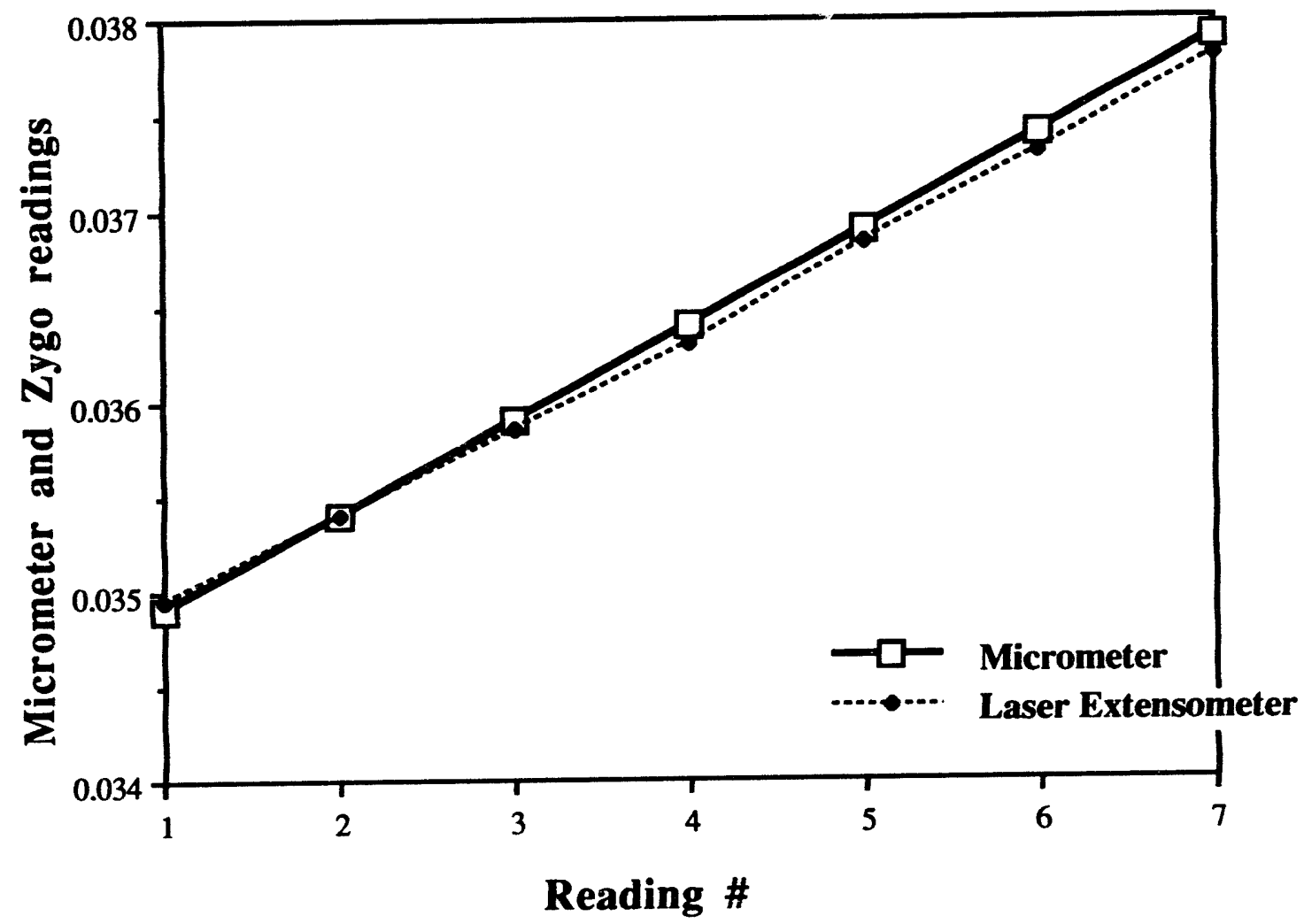

Figure 4.2. Laser Extensometer characterization, 800 deg. C 


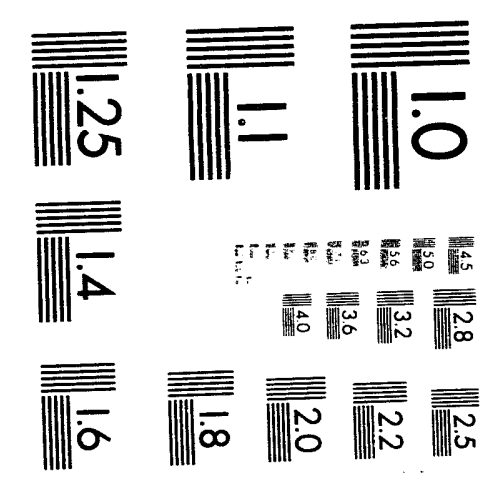



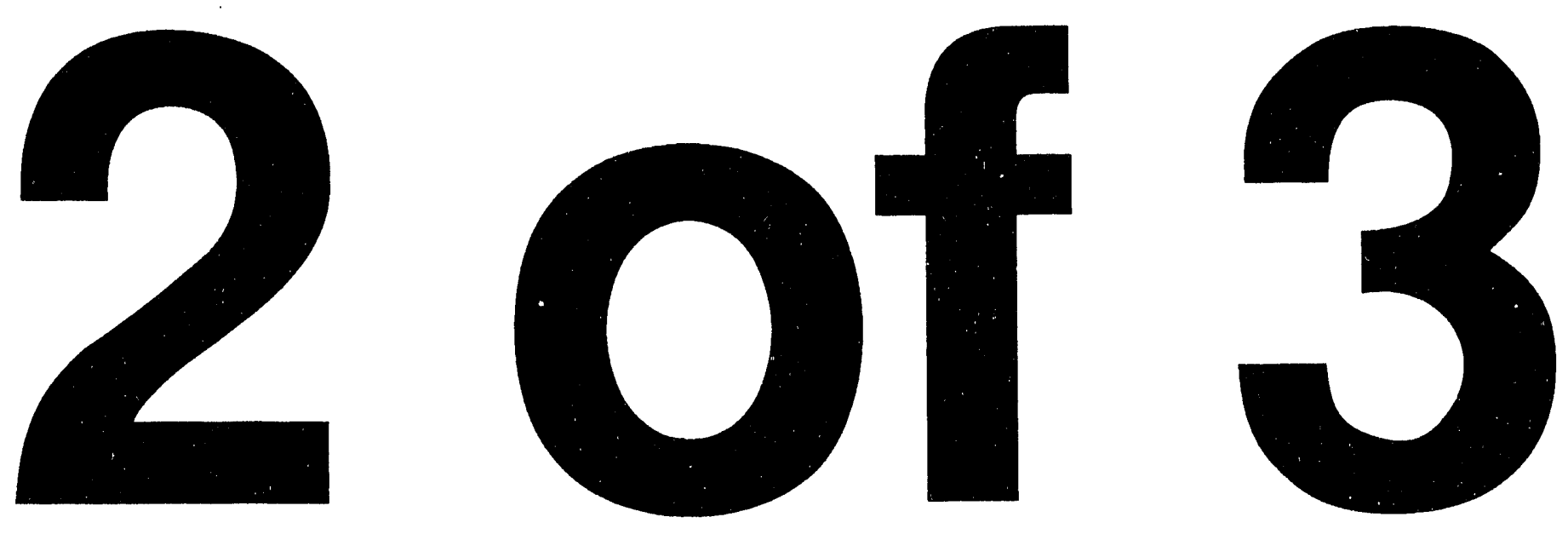


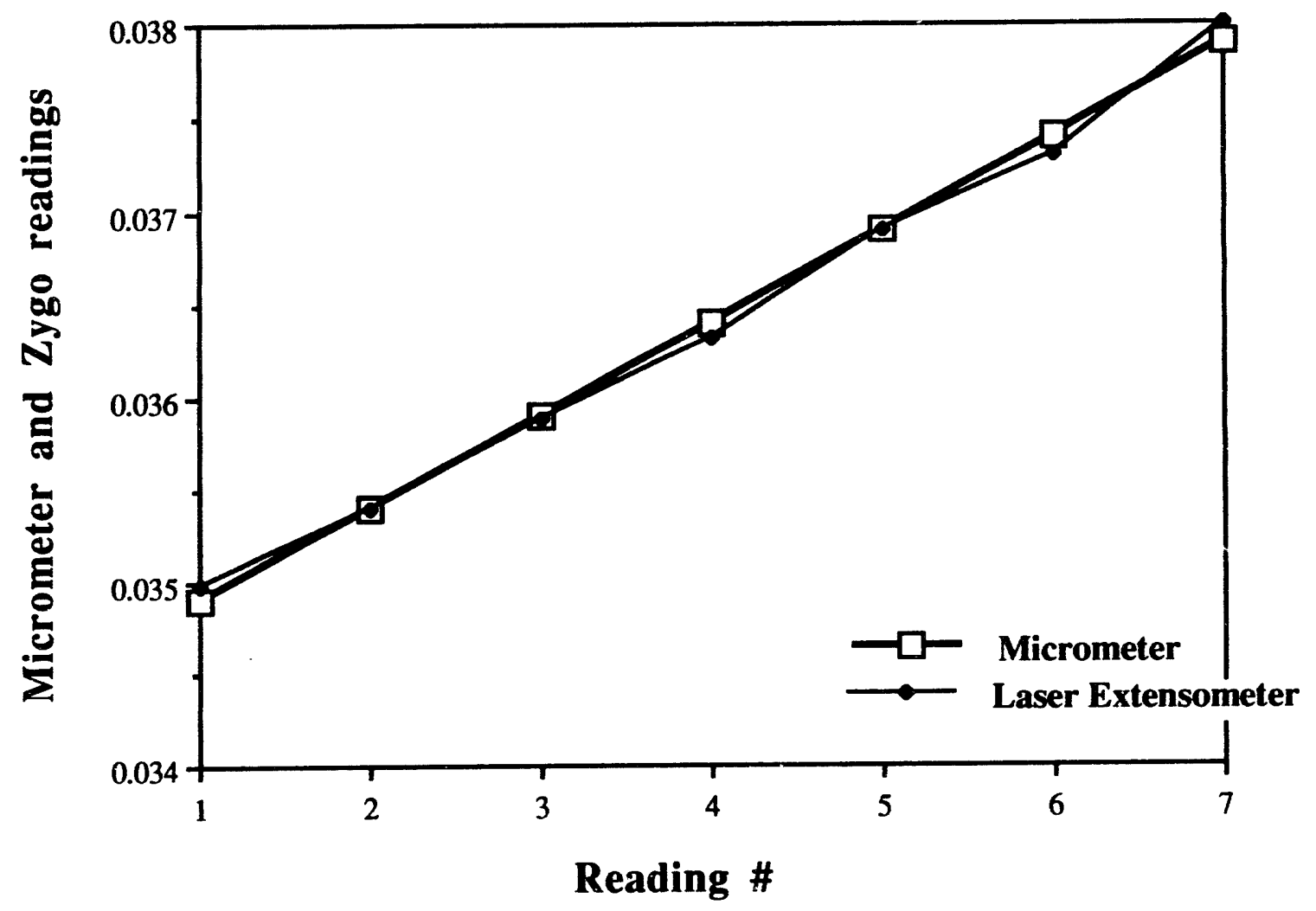

Figure 4.3. Laser Extensometer characterization, 1000 deg. C 


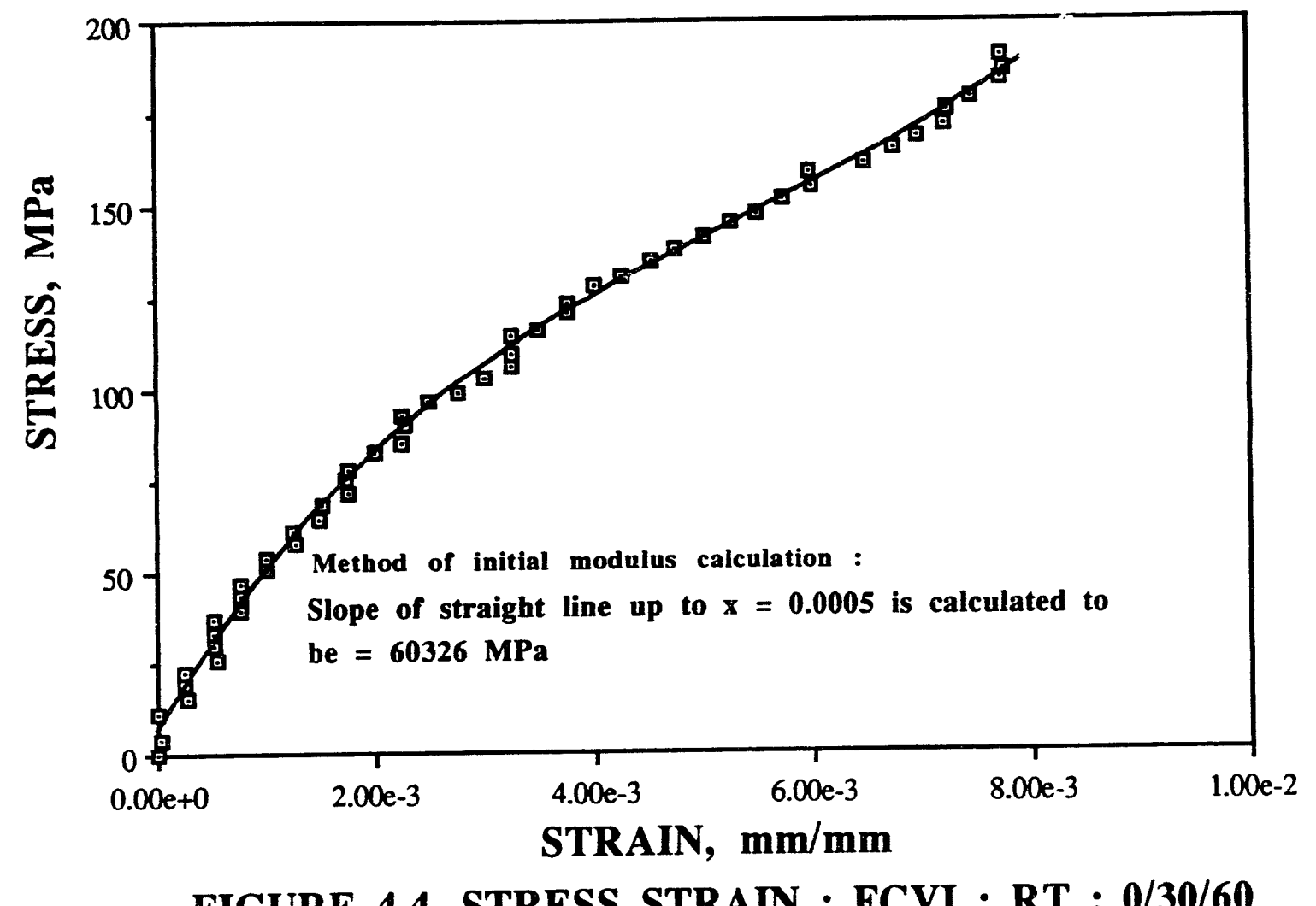

FIGURE 4.4. STRESS STRAIN ; FCVI ; RT ; 0/30/60 
Tabie 4.6. Test Conditions, Tensile Strength and Initial Modulus results for SiC/SiC Ceramic Composite System

\begin{tabular}{|c|c|c|c|c|c|c|}
\hline \multirow[b]{2}{*}{ Layup } & & \multicolumn{4}{|c|}{ Test Condition } & \multirow{2}{*}{ Remarks } \\
\hline & & RT & RT/TS & RT/OX & $1000^{\circ} \mathrm{C}$ & \\
\hline \multirow{3}{*}{$\begin{array}{c}\text { FCVI } \\
(0 / 30 / 60)_{\text {repeat }}\end{array}$} & \# of specimens & 7 & 4 & 2 & 4 & \multirow{3}{*}{$\begin{array}{l}\text { Number of } \\
\text { Specimens } \\
\quad=17\end{array}$} \\
\hline & Avg. Tensile Strength, MPa & $184 \pm 31$ & $211 \pm 8$ & $188 \pm 18$ & $188 \pm 42$ & \\
\hline & Avg. Initial Modulus, GPa & $75 \pm 11$ & $104 \pm 12$ & 131 & $91 \pm 16$ & \\
\hline \multirow{3}{*}{$\begin{array}{c}\text { FCVI } \\
(0 / 45 / 0 / 45)_{\text {repeat }}\end{array}$} & \# of specimens & 6 & 4 & 2 & 4 & \multirow{3}{*}{$\begin{array}{l}\text { Number of } \\
\text { Specimens } \\
\quad=16\end{array}$} \\
\hline & Avg. Tensile Strength, MPa & $175 \pm 30$ & $174 \pm 21$ & 174 & $180 \pm 7$ & \\
\hline & Avg. Initial Modulus, GPa & $49 \pm 13$ & $80 \pm 30$ & 42 & $123 \pm 25$ & \\
\hline \multirow{3}{*}{$\begin{array}{c}\text { ICVI } \\
(0 / 45 / 0 / 45)_{\text {repeat }}\end{array}$} & \# of specimens & 6 & 4 & 2 & 4 & \multirow{3}{*}{$\begin{array}{l}\text { Number of } \\
\text { Specimens } \\
\quad=16\end{array}$} \\
\hline & Avg. Tensile Strength, MPa & $163 \pm 35$ & $166 \pm 62$ & $102 \pm 4$ & $159 \pm 18$ & \\
\hline & Avg. Initial Modulus, GPa & $112 \pm 62$ & $108 \pm 22$ & $99 \pm 8$ & $*$ & \\
\hline \multirow{3}{*}{$\begin{array}{c}\text { ICVI } \\
(0 / 90)_{\text {repeat }}\end{array}$} & \# of specimens & 6 & 4 & 2 & 5 & \multirow{3}{*}{$\begin{array}{l}\text { Number of } \\
\text { Specimens } \\
\quad=17\end{array}$} \\
\hline & Avg. Tensile Strength, MPa & $151 \pm 20$ & $160 \pm 24$ & $161 \pm 22$ & $140 \pm 33$ & \\
\hline & Avg. Initial Modulus, GPa & 185 & $109 \pm 5$ & $125 \pm 39$ & $29 \pm 8$ & \\
\hline $\begin{array}{l}\text { ICVI } \\
(0 / 90)_{\text {repeat }} \\
120 \mathrm{~mm} \text { long }\end{array}$ & \multicolumn{6}{|c|}{$\begin{array}{l}\text { \# of specimens }=3 ; \text { Avg. Tensile Strength, } \mathrm{MPa}=203 \pm 14 ; \\
\text { Avg. Initial Modulus, GPa }=147 \pm 71\end{array}$} \\
\hline
\end{tabular}

* Not Available 


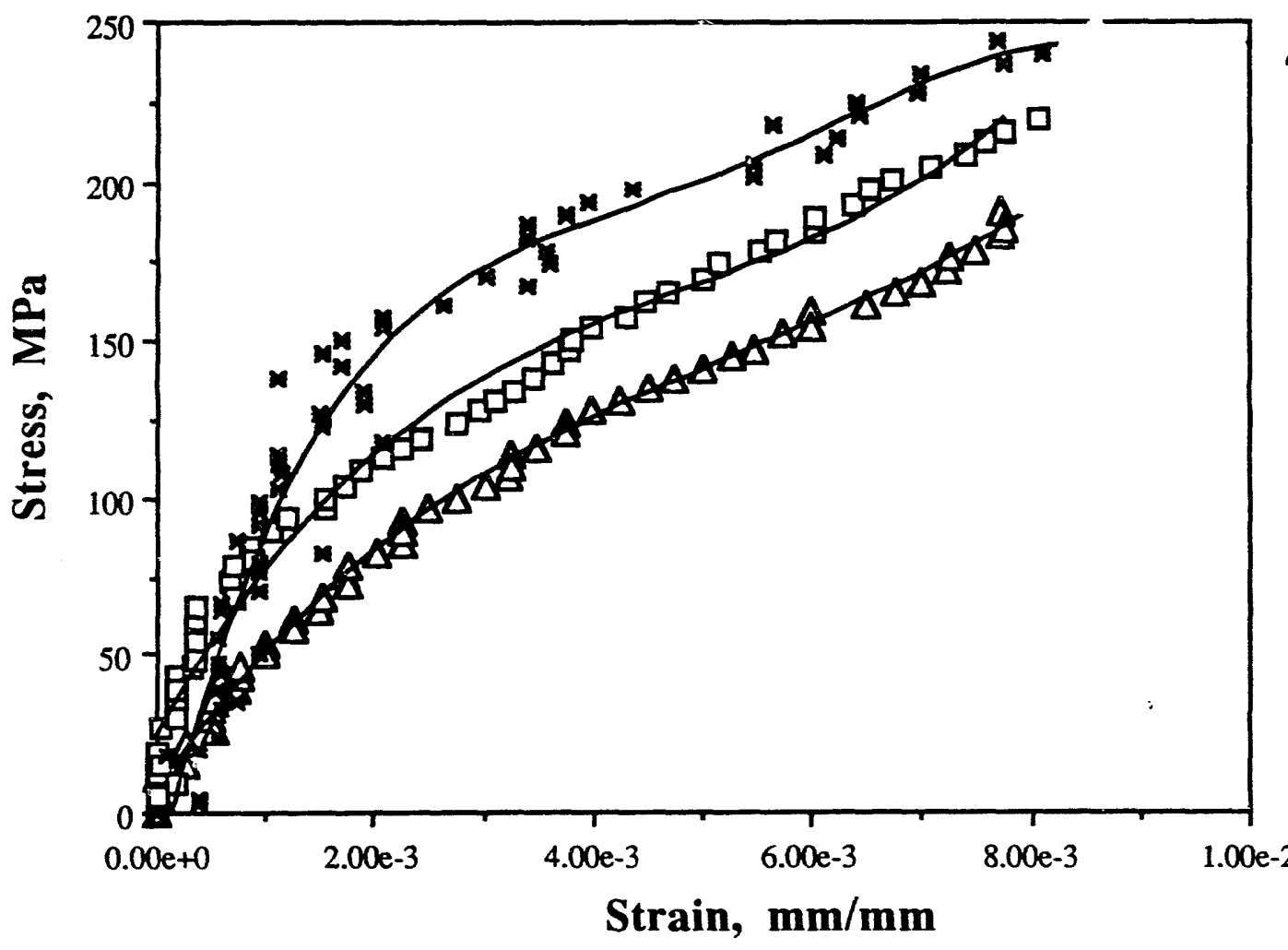

$\begin{array}{ll}\Delta & \text { RT } \\ \square & \text { RT/TS } \\ \times & 1000 \mathrm{C}\end{array}$

Figure 4.5. STRESS STRAIN ; RT ; RT/TS ; $1000 \mathrm{C} ;$ FCVI ; 0/30/60 


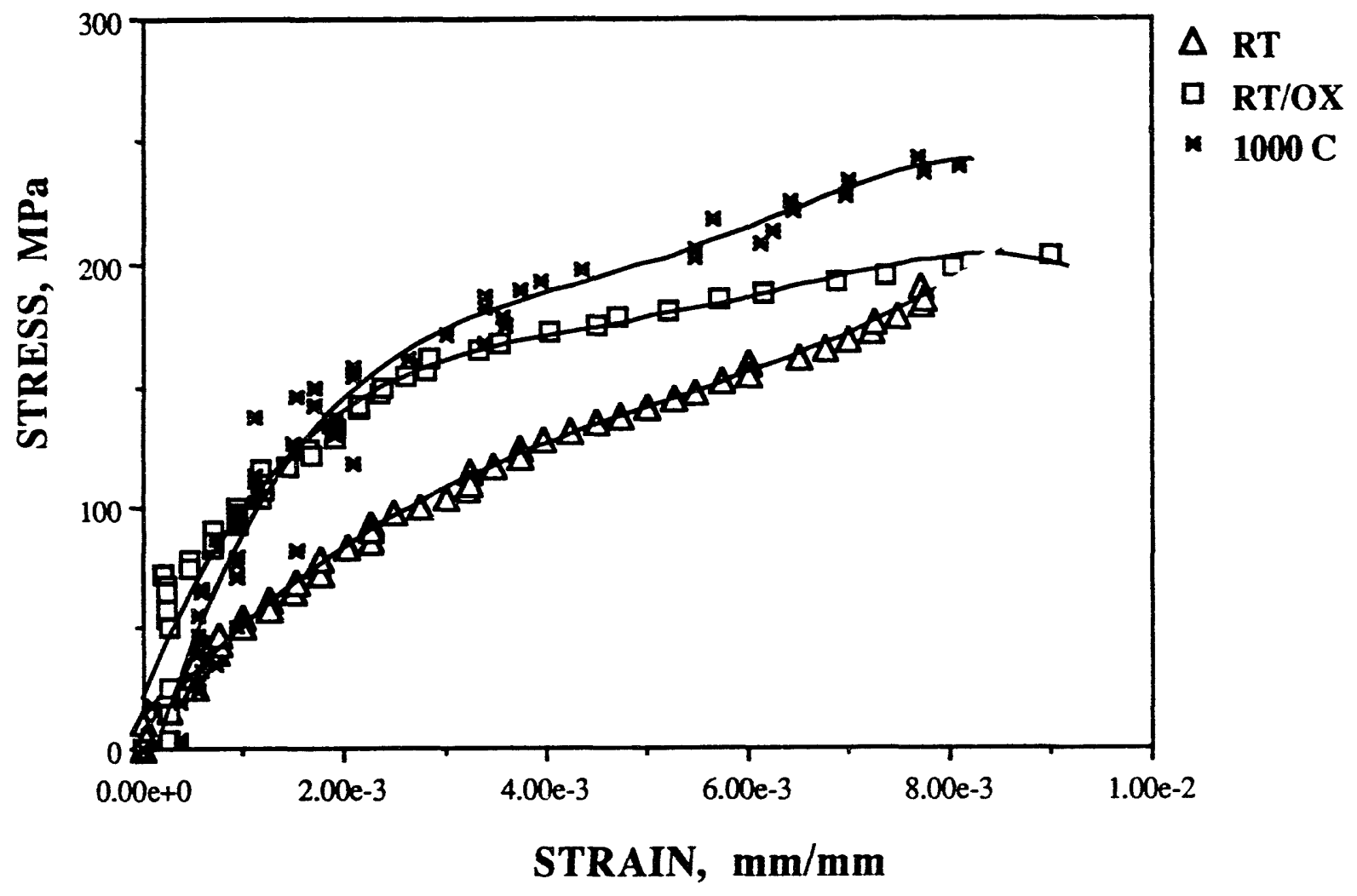

Figure 4.6. STRESS STRAIN ; RT ; RT/OX ; $1000 \mathrm{C} ; \mathrm{FCVI} ; 0 / 30 / 60$ 


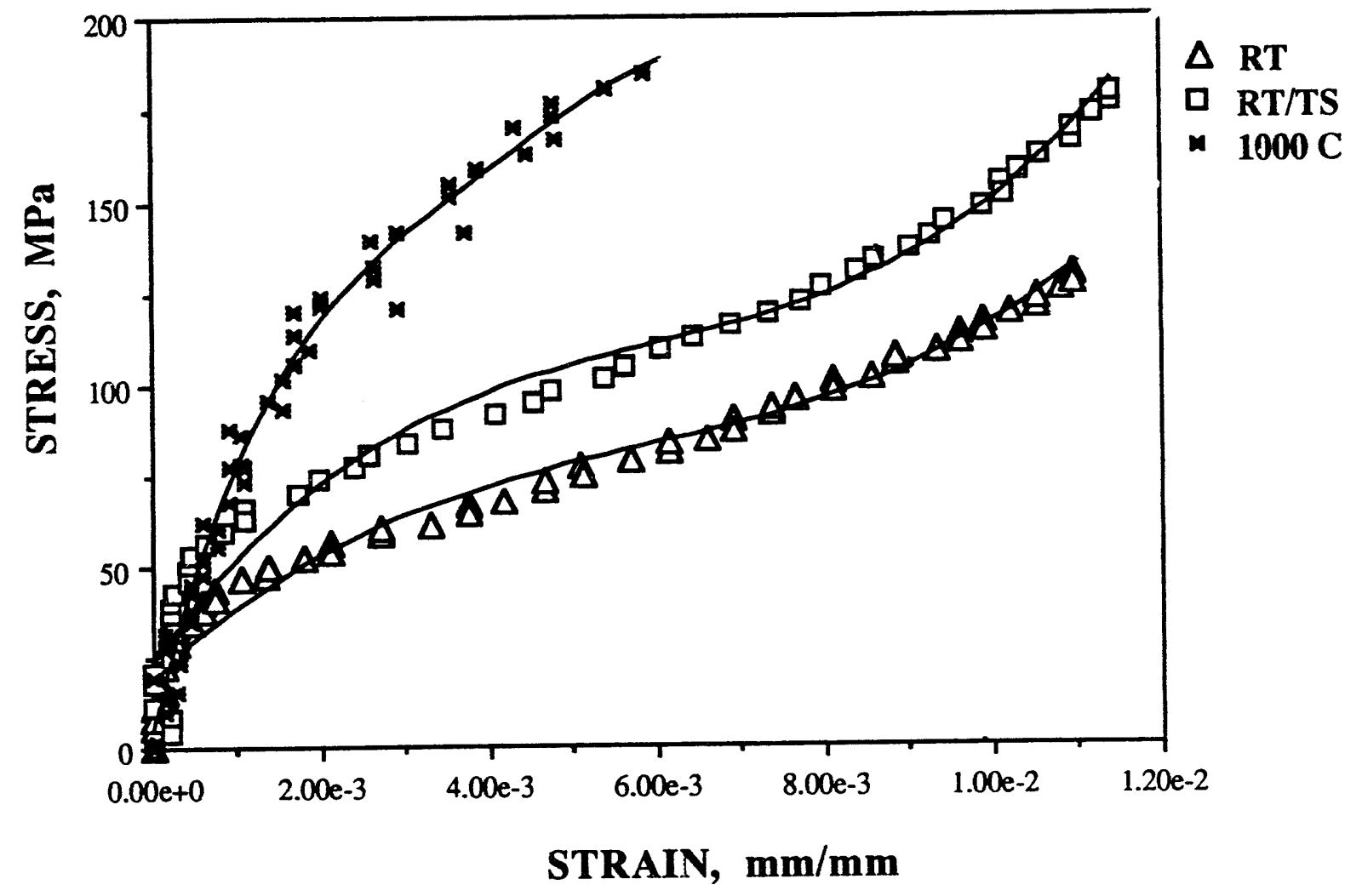

Figure 4.7. STRESS STRAIN ; RT ; RT/TS ; $1000 \mathrm{C} ;$ FCVI ; 0/45 


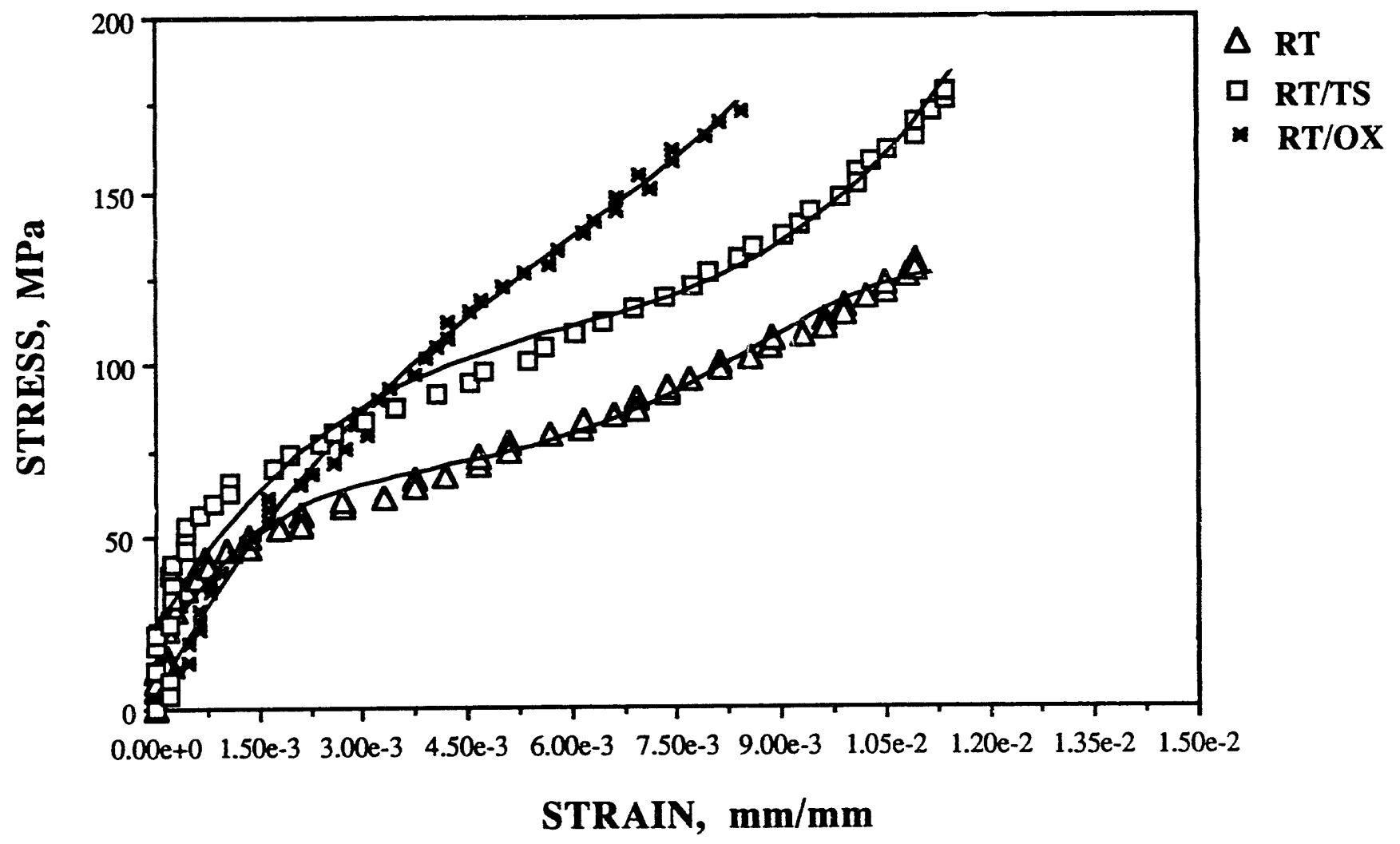

Figure 4.8. STRESS STRAIN ; RT ; RT/TS ; RT/OX ; FCVI ; 0/45 


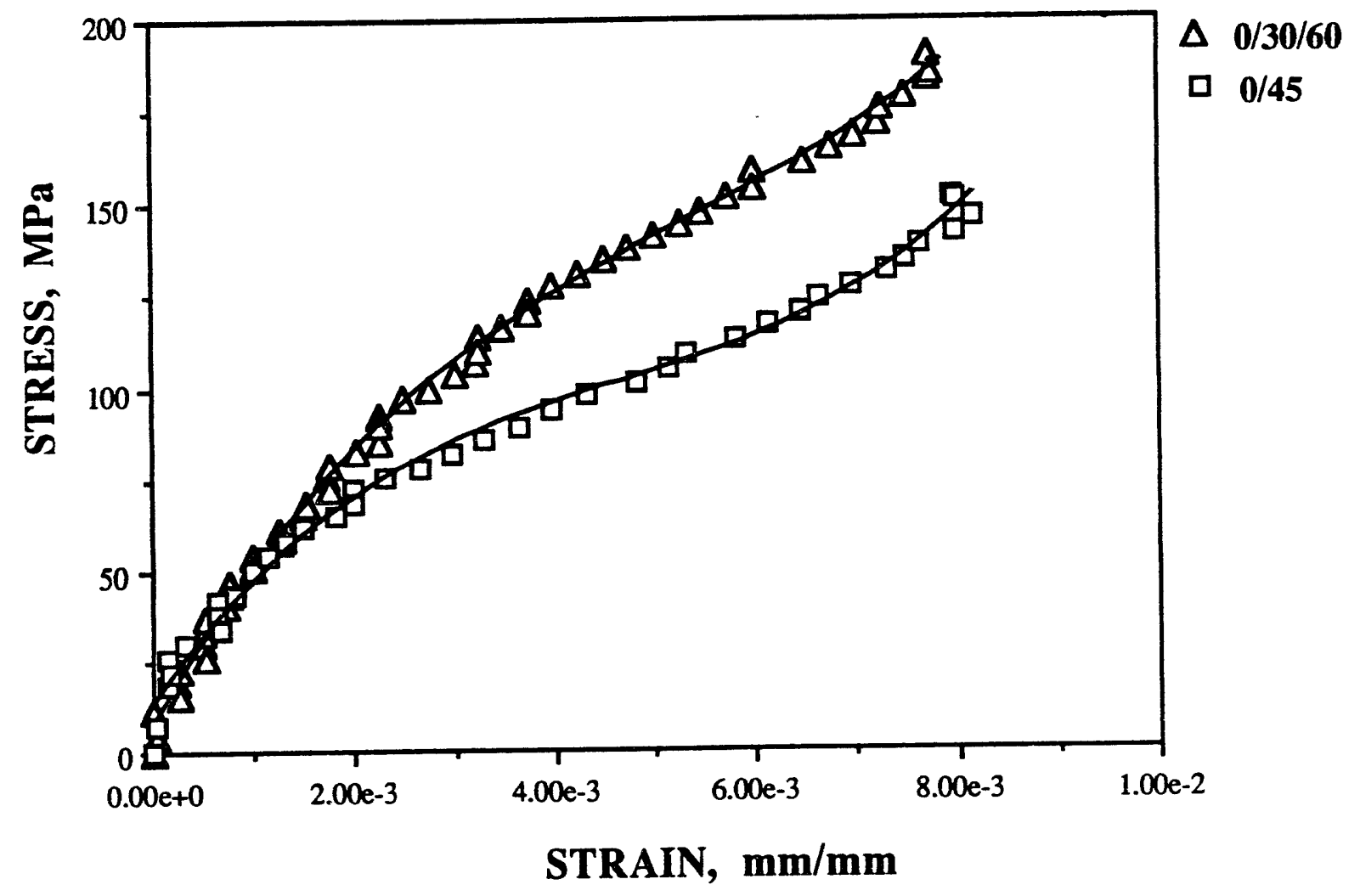

Figure 4.9. COMPARISON OF STRESS STRAIN BEHAVIOR OF FCVI LAYUPS AT RT 


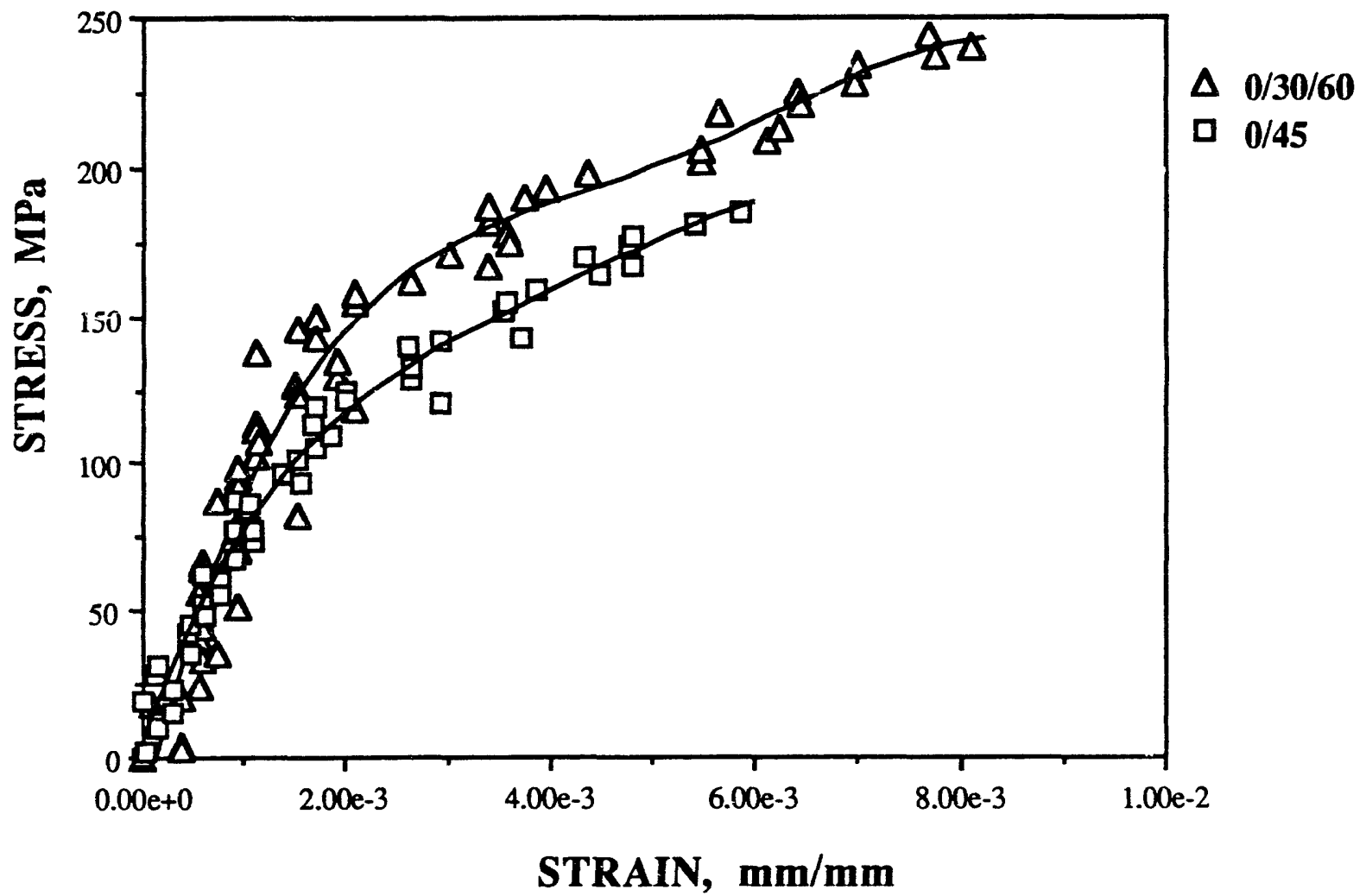

Figure 4.10. COMPARISON OF STRESS STRAIN BEHAVIOR OF FCVI AT $1000 \mathrm{C}$ 


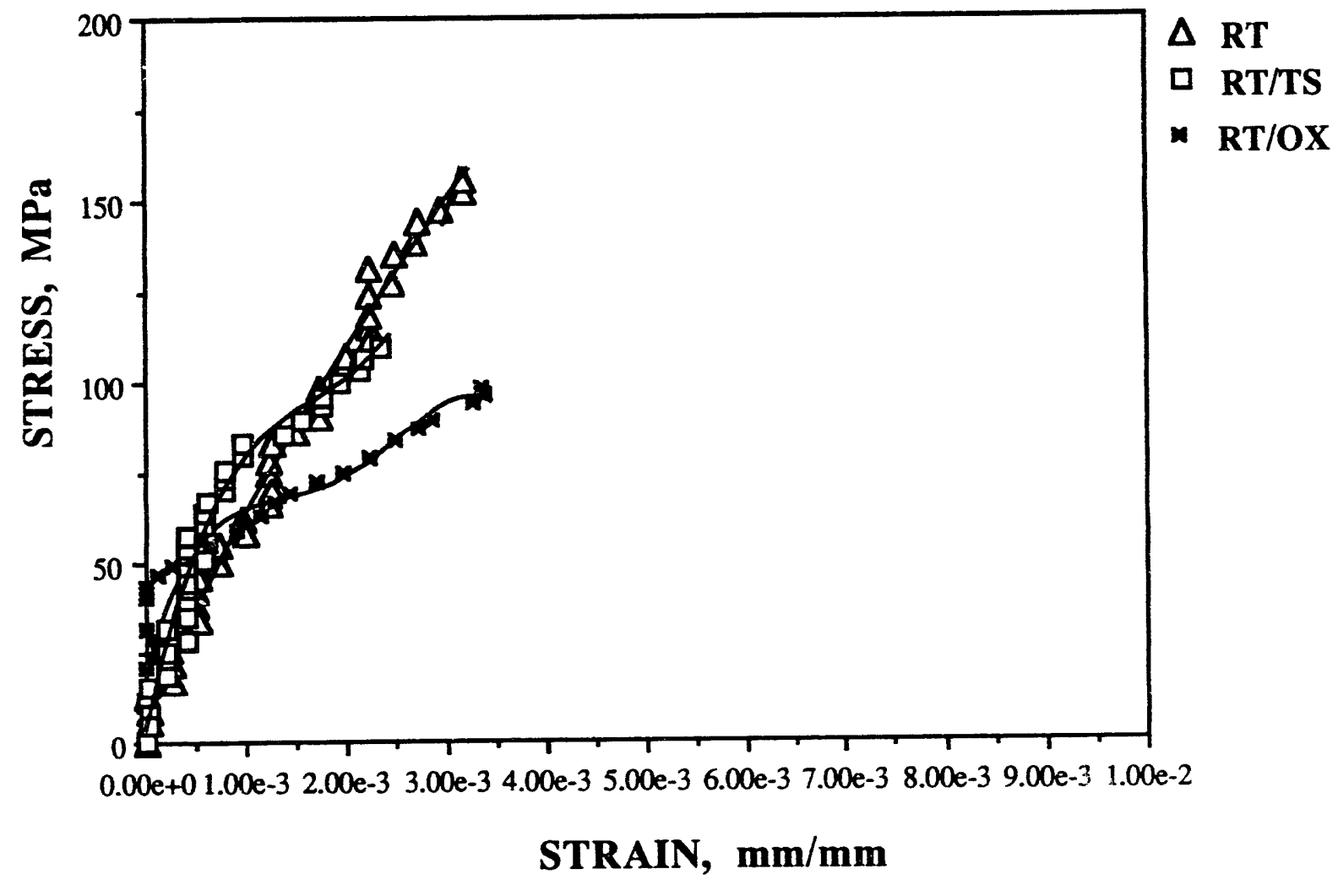

Figure 4.11. STRESS STRAIN ; RT ; RT/TS ; RT/OX ; ICVI ; 0/45 


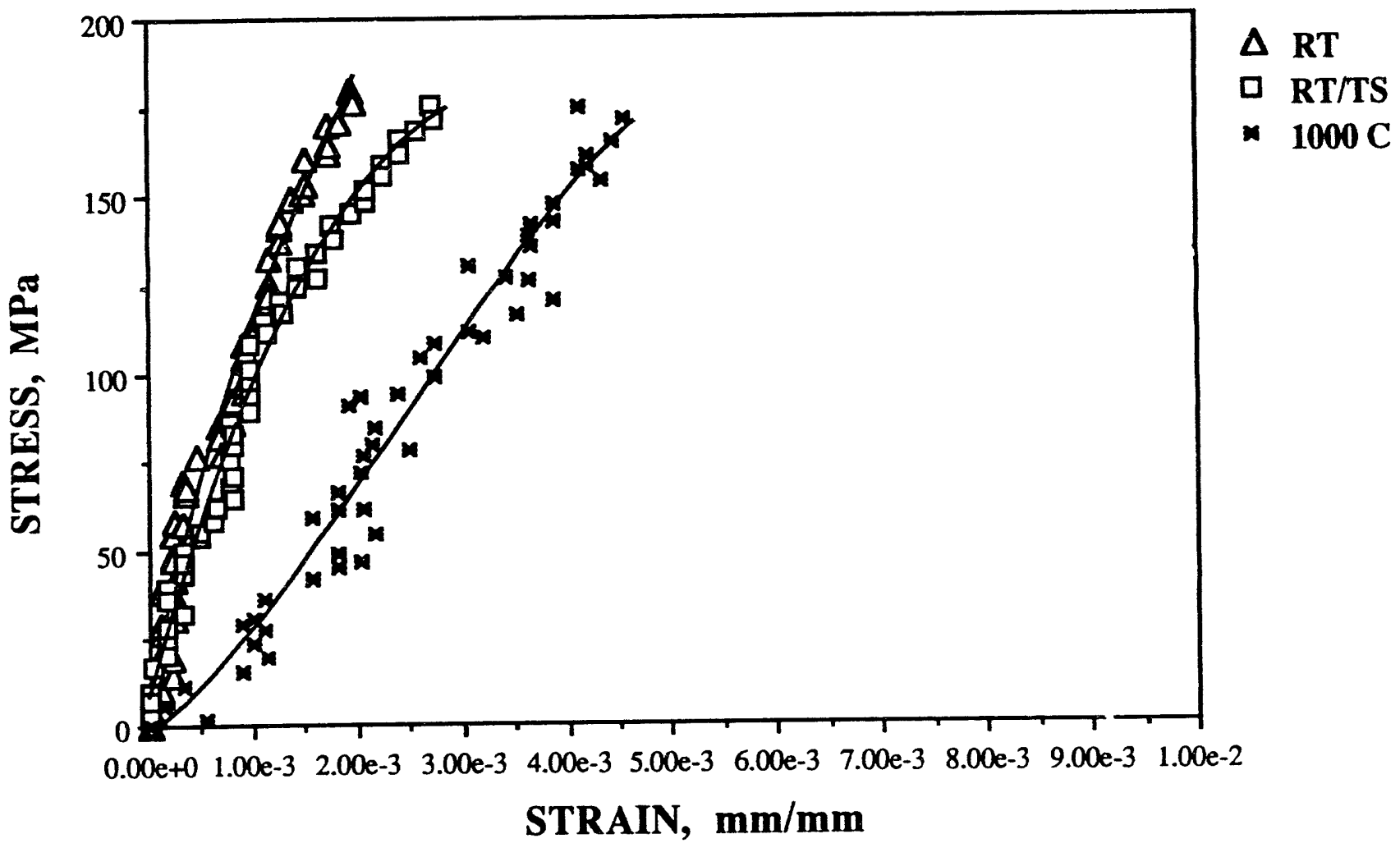

Figure 4.12. STRESS STRAIN ; RT ; RT/TS ; $1000 \mathrm{C}$; ICVI ; 0/90 


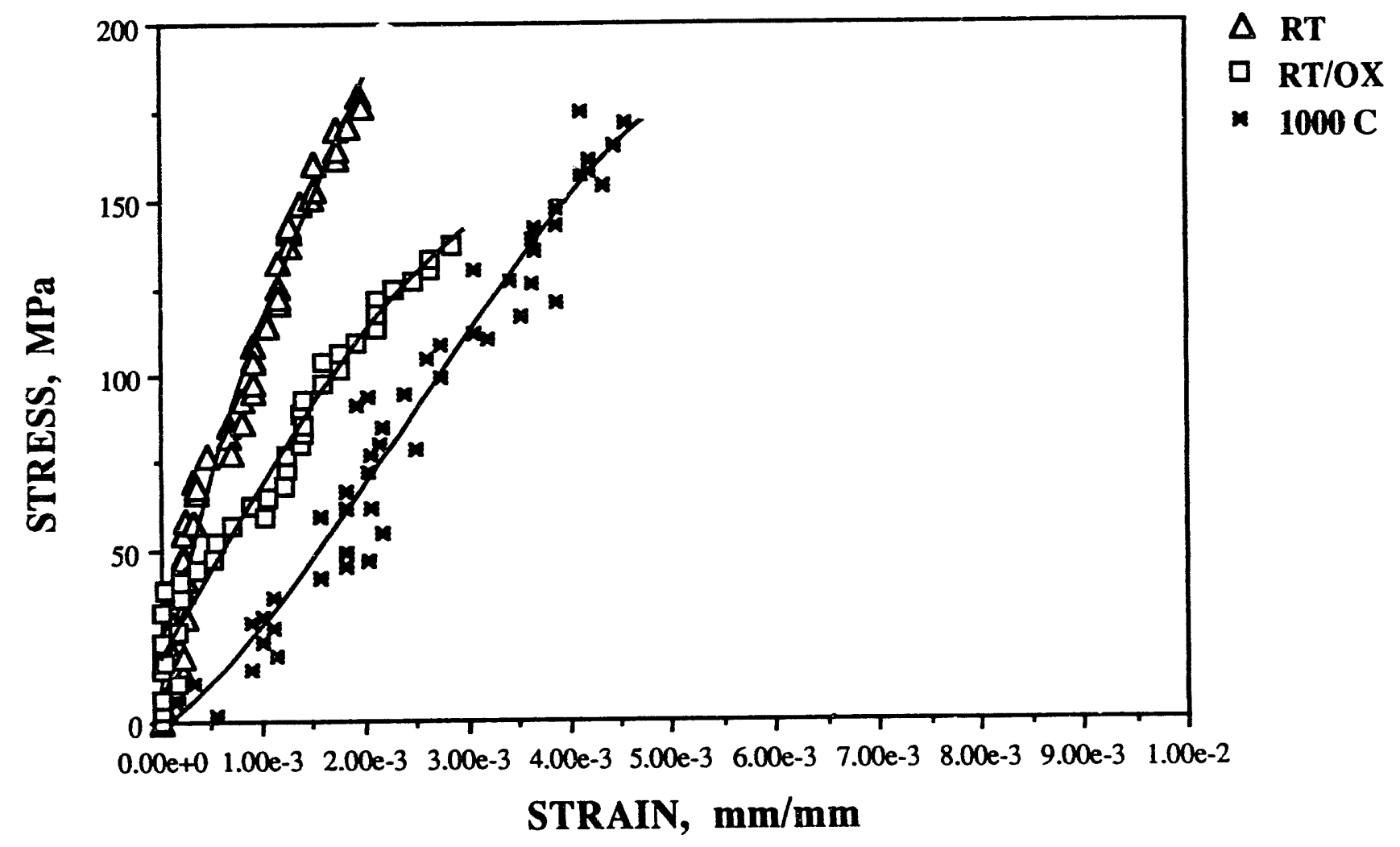

Figure 4.13. STRESS STRAIN ; RT ; RT/OX ; $1000 \mathrm{C}$; ICVI ; 0/90 


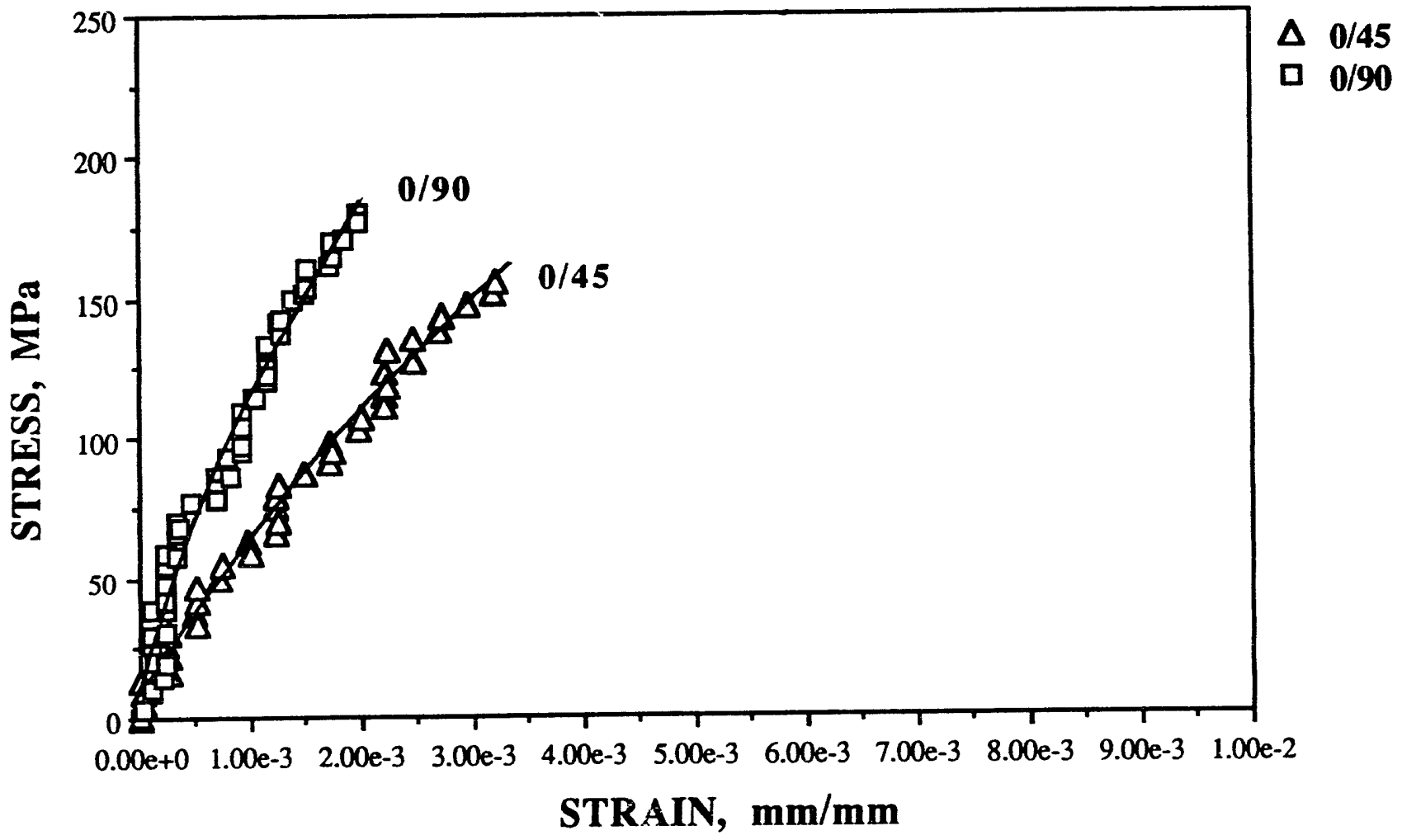

Figure 4.14. RT STRESS STRAIN ; ICVI ; 0/90 AND 0/45 


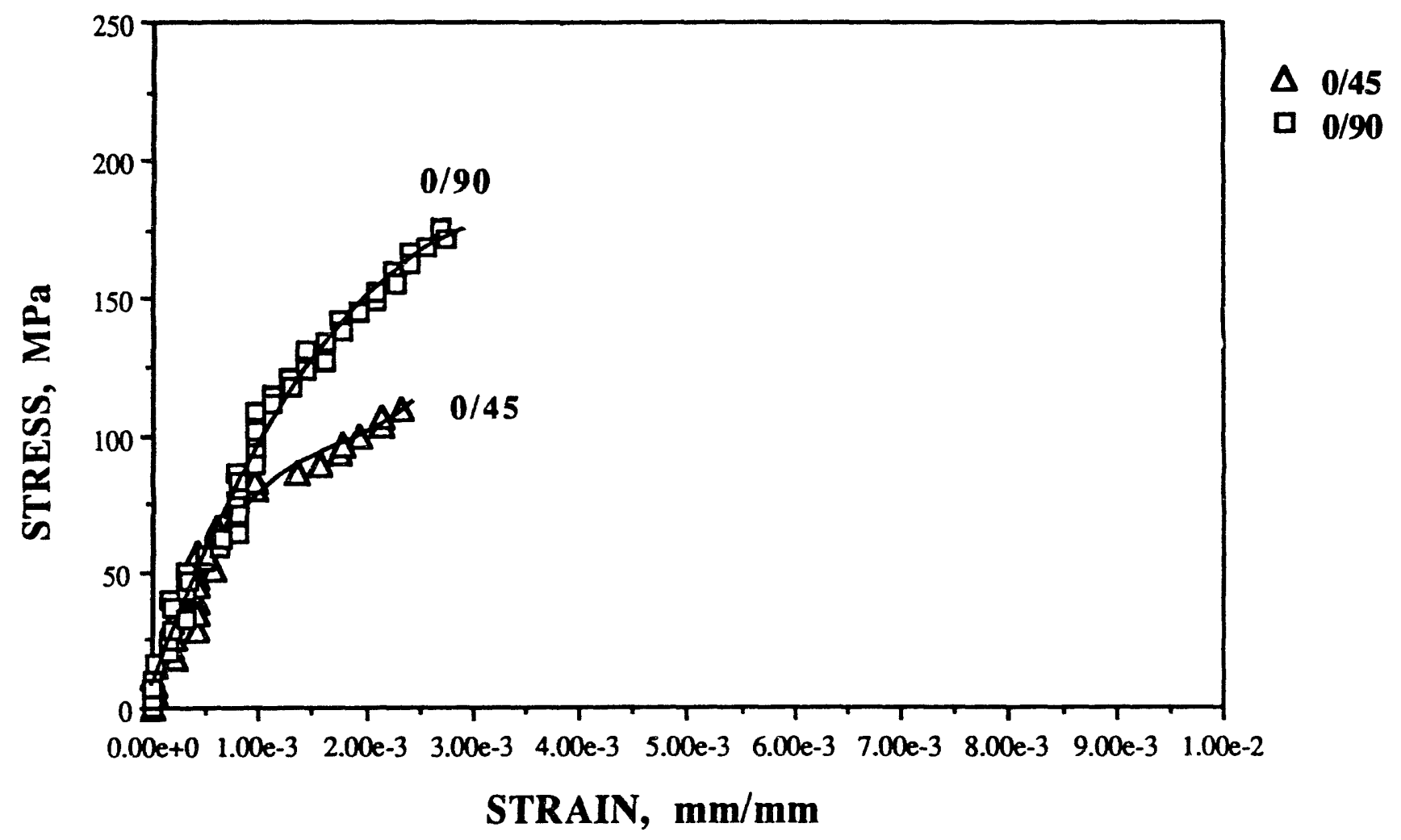

FIGURE 4.15. RT STRESS STRAIN AFTER TS ; ICVI ; 0/45 AND 0/90 


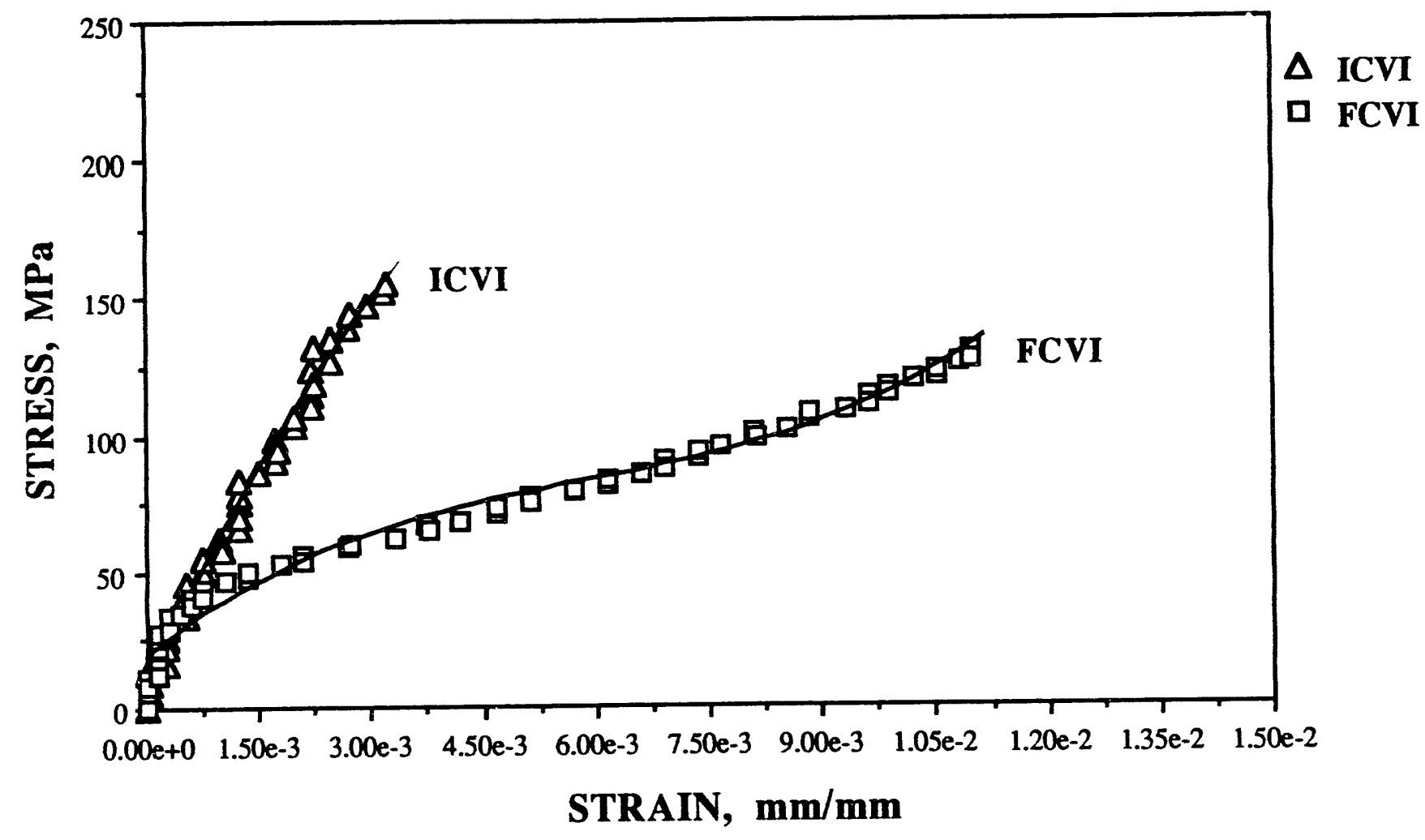

FIGURE 4.16. STRESS STRAIN ; RT ; ICVI AND FCVI ; 0/45 


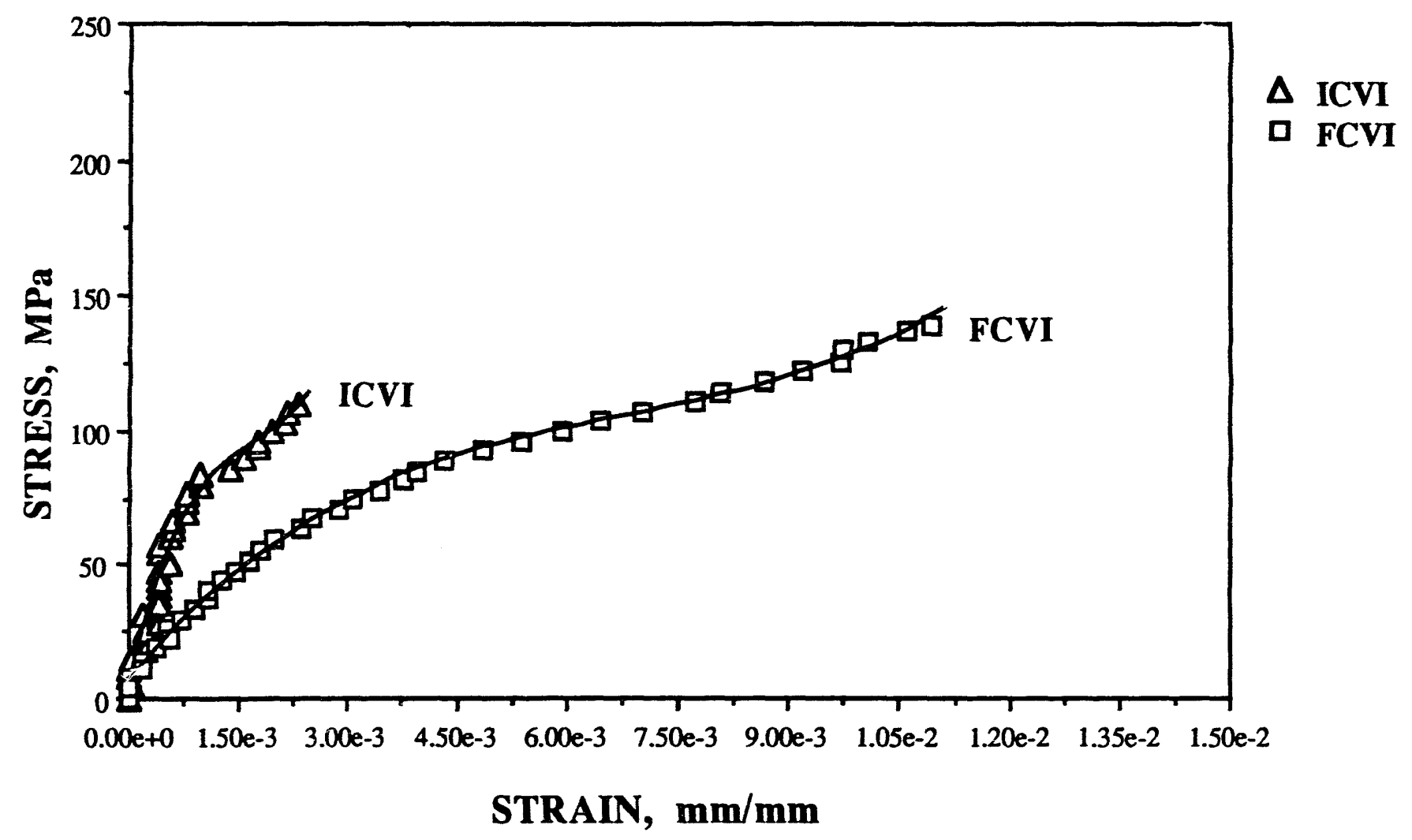

FIGURE 4.17. STRESS STRAIN ; RTTS ; ICVI AND FCVI ; 0/45 
$=$ 


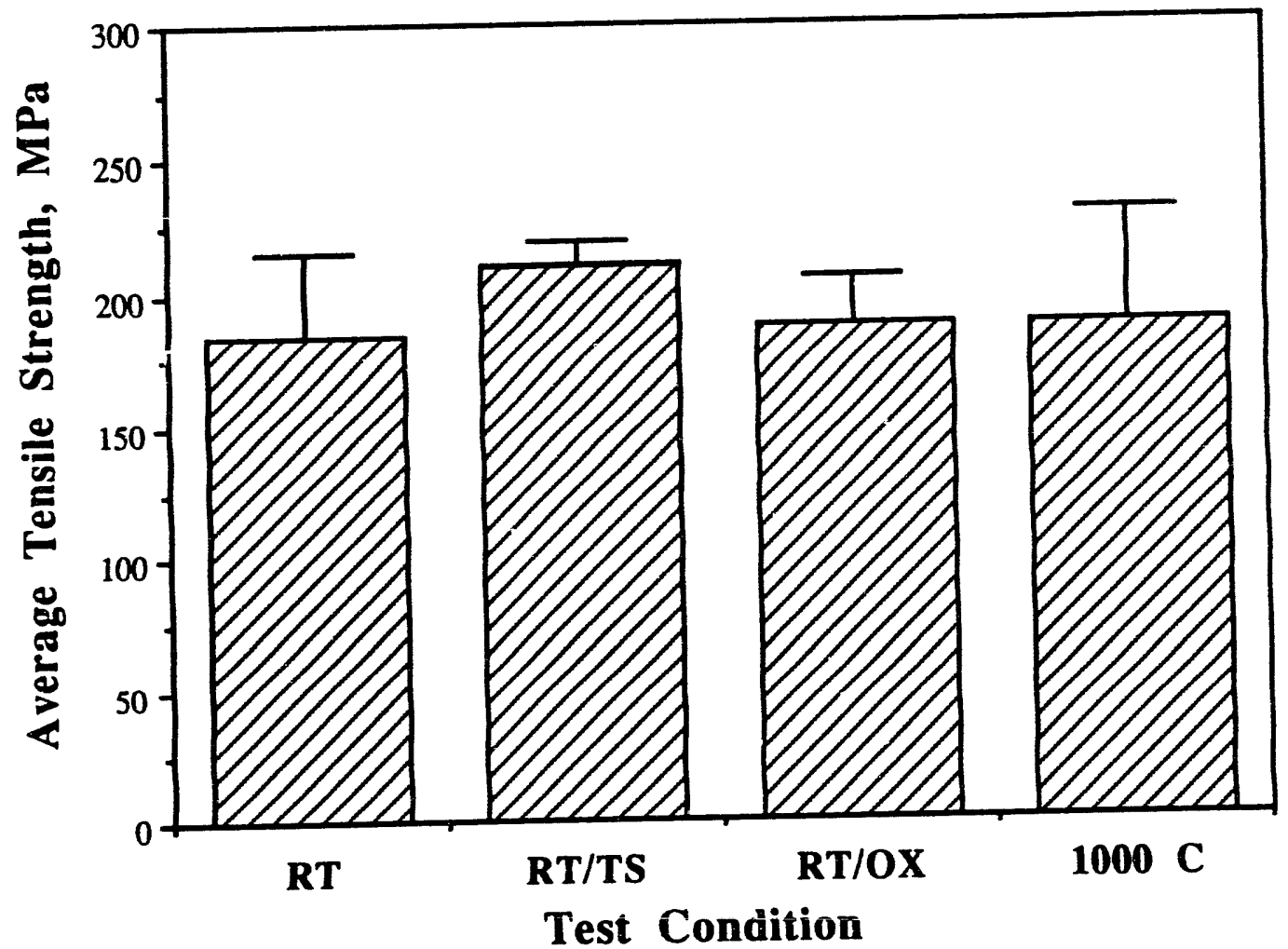

Figure 4.19. Average Tensile Strength for $\mathrm{FCVI} 0 / 30 / 60 \mathrm{SiC} / \mathrm{SiC}$ ceramic composite system for different test conditions 


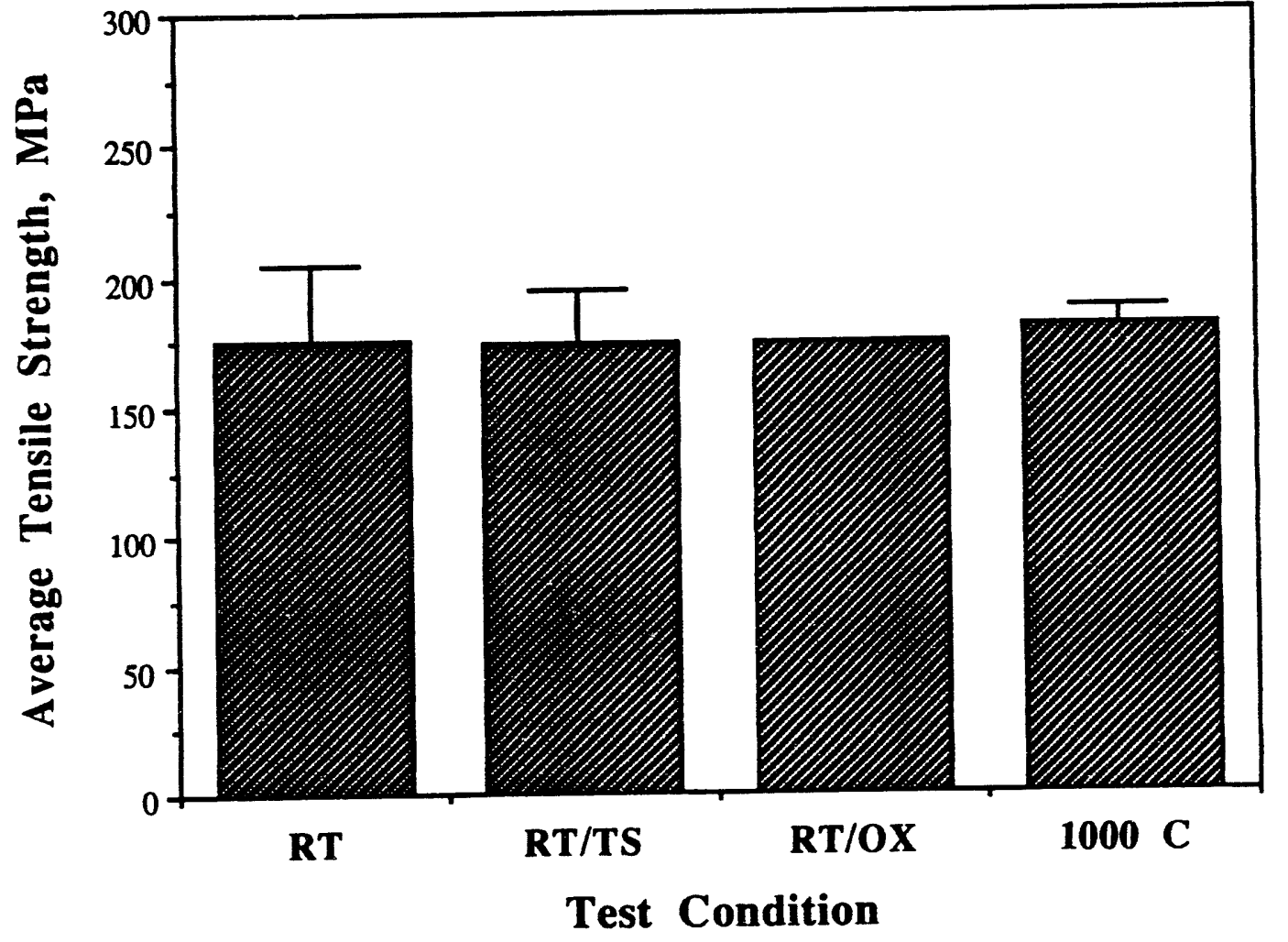

Figure 4.20. Average Tensile Strength for FCVI 0/45 SiC/SiC ceramic composite system for different test conditions 


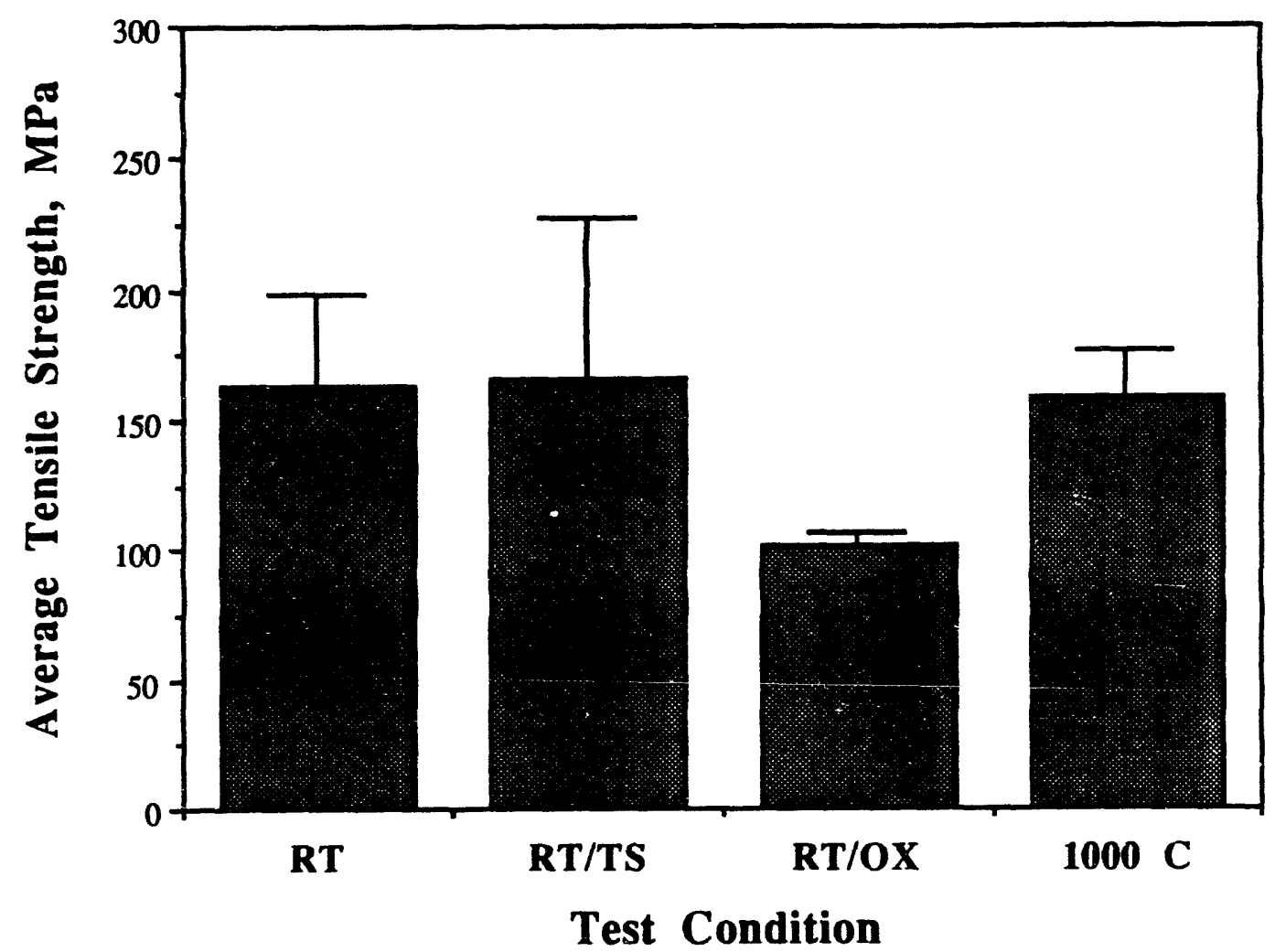

Figure 4.21. Average Tensile Strength for ICVI $0 / 45 \mathrm{SiC} / \mathrm{SiC}$ ceramic composite system for different test conditions 


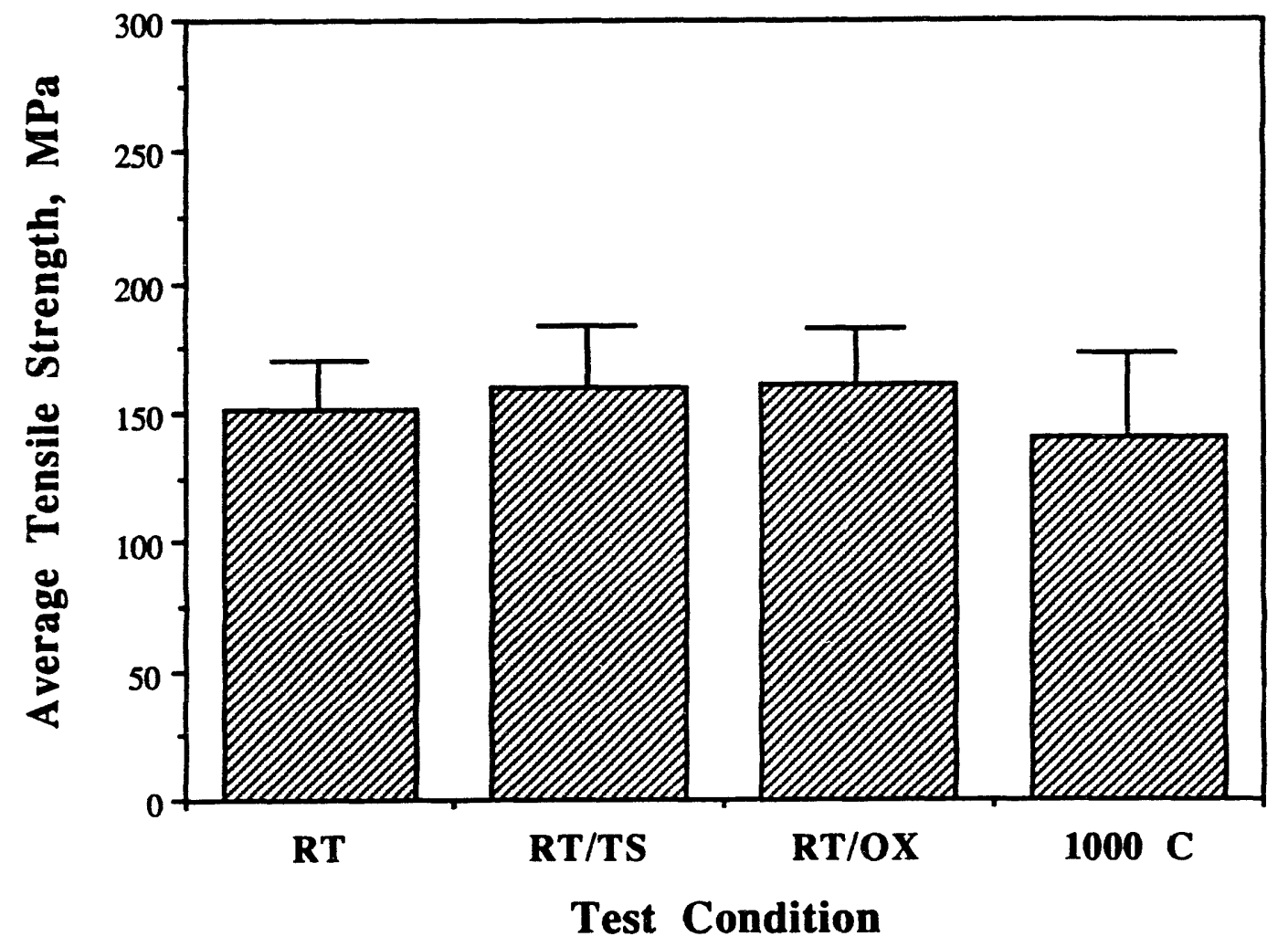

Figure 4.22. Average Tensile Strength for ICVI $0 / 90 \mathrm{SiC} / \mathrm{SiC}$ ceramic composite system for different test conditions 


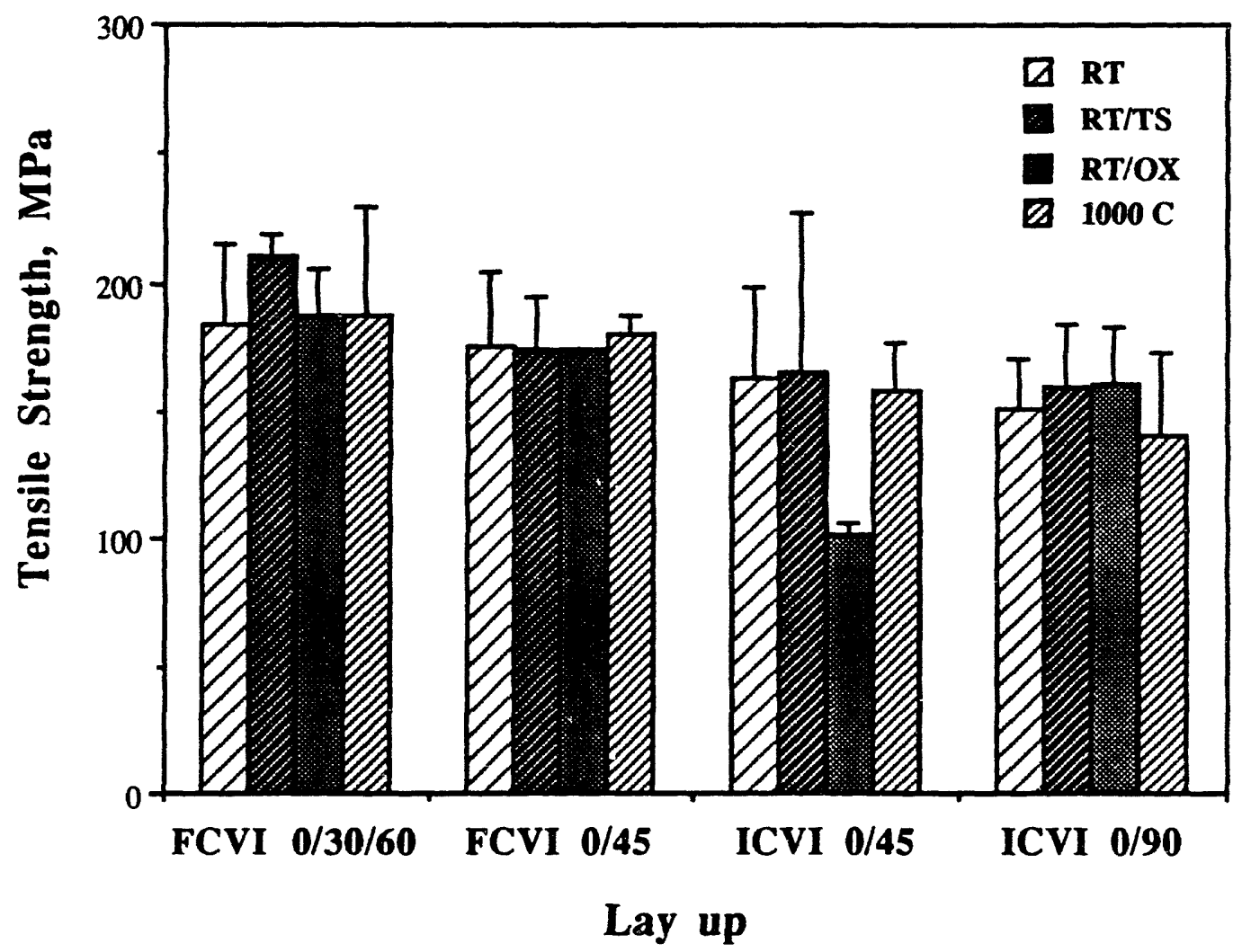

Figure 4.23 Average Tensile Strength for CVI SiC/SiC ceramic composite system for different test conditions 


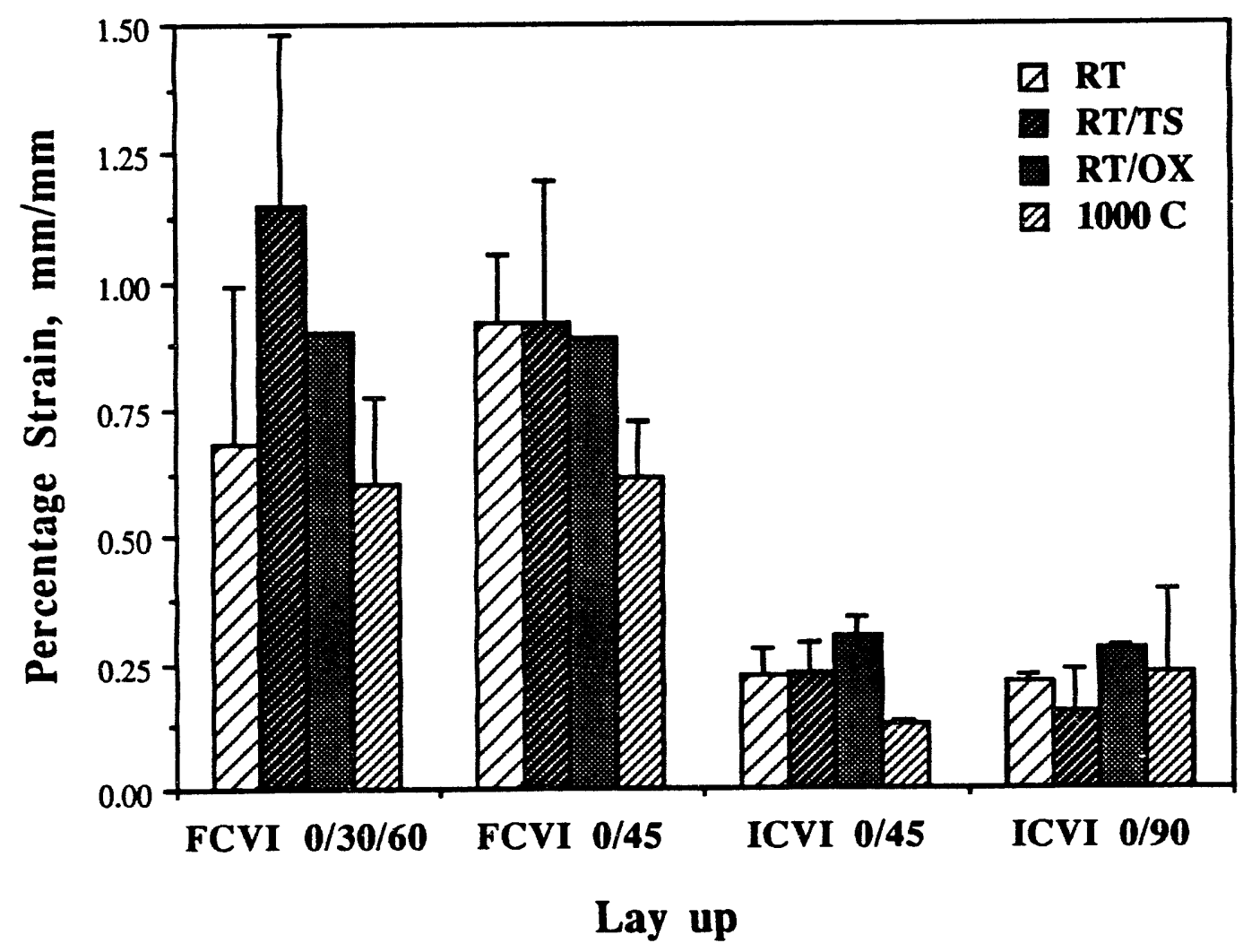

Figure 4.24. Average Strain for $\mathrm{CVI} \mathrm{SiC} / \mathrm{SiC}$ ceramic composite system for different test conditions 


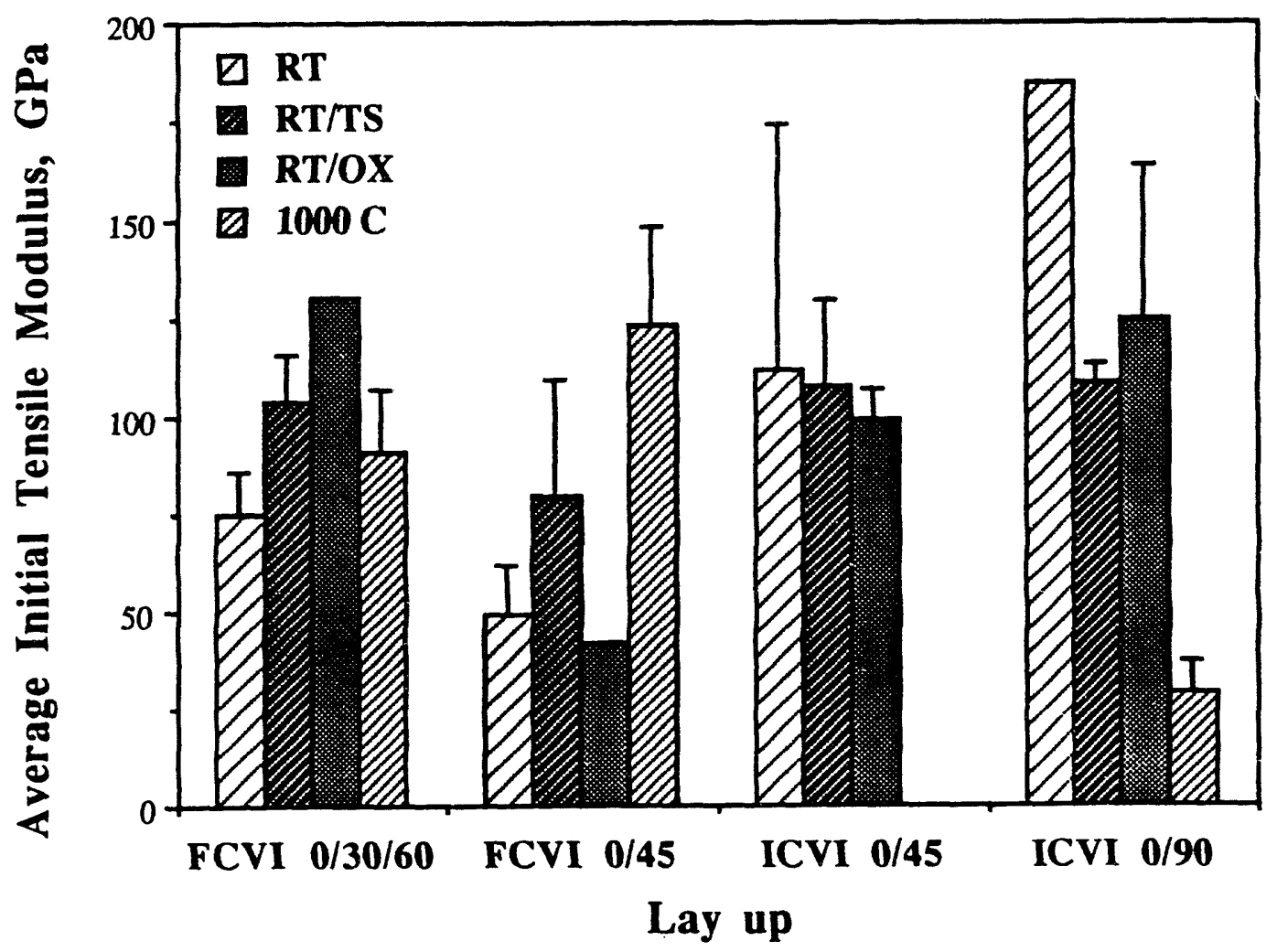

Figure 4.25. Average Initial Tensile Modulus for $\mathrm{CVI} \mathrm{SiC/SiC} \mathrm{ceramic} \mathrm{composite} \mathrm{system}$ for different test conditions 
not dissimilar when comparing the specimens manufactured with the same process.

Figures 4.27 through 4.31 shows SEM fracture surface observed in FCVI material tested at RT for the FCVI $(0 / 45 / 0 / 45)_{\text {repeat }}$ layup. Figure $4.27 \mathrm{~A}$ is the general fracture surface of a FCVI $(0 / 45 / 0 / 45)_{\text {repeat }}$ layup composite. Figure $4.27 \mathrm{~B}$ is a higher magnification image of the fracture surface in Figure 4.27A. Some of the typical cracks observed in these composite systems are illustrated by Figures $4.28 \mathrm{~A}$ and $4.28 \mathrm{~B}$, which are marked by arrows. Figure $4.28 \mathrm{C}$ is the close up view of a fiber from Figure $4.28 \mathrm{~A}$ showing the pyrolytic carbon coating on the fiber surface. Another typical nature of the fracture in this composite can be observed in Figure 4.29. In this figure, the voids between two plain weaves oriented in the 0 and 90 directions can be observed, while Figure 4.30 shows another view of similar voids in these materials. Figures $4.31 \mathrm{~A}$ and 4.31B show some of the cracks observed in the composite along with some of the observed fibers in the fracture surface (Figure 4.31C).

Figure 4.32 illustrates the amount of pullout that could be observed for the FCVI $(0 / 30 / 60)_{\text {repeal }}$ layup tested at $1000^{\circ} \mathrm{C}$. Figure 4.33 is a magnified image of the fiber pull out for the same layup tested at $1000^{\circ} \mathrm{C}$, while Figure 4.34 is a similar image of the composite which shows similar features as in Figure 4.33. Figures 4.35 and 4.36 are the fracture surfaces of the FCVI $(0 / 30 / 60)_{\text {repeat }}$ layup after exposure to thermal shock. Figure 4.36 shows a rather interesting feature, where the fiber coating has clearly debonded.

The fractography results for the FCVI $(0 / 30 / 60)_{\text {repeat }}$ layup tested at RT after exposure to oxidizing atmosphere for 100 hours at $1000^{\circ} \mathrm{C}$ is given in Figures 4.37 and 
4.38. The overall fracture surface is shown by Figure 4.37 , while the close up view of the fibers is given in Figure 4.38.

The fractography results for ICVI $(0 / 45 / 0 / 45)_{\text {repeat }}$ layup composites are shown in Figures 4.39 through 4.46 . The room temperature fracture behavior is shown in Figure 4.39 where the crack deflection can be observed. Figure 4.40 is the fracture surface of a ICVI $(0 / 45 / 0 / 45)_{\text {repeat }}$ layup subjected to thermal shock. Figures 4.41 and 4.42 show the fracture surface of the same layup tested at RT after it is subjected to oxidation for 100 hours. Fracture surfaces of the specimens after testing at $1000^{\circ} \mathrm{C}$ is shown in Figure 4.43 .

The fractography work on ICVI $(0 / 90)_{\text {repeal }}$ layup composites are given in Figures 4.44 and 4.45 . Figure 4.44 is the fracture surface of a specimen tested at RT and Figure 4.45 is the fracture surface of a specimen tested at $1000^{\circ} \mathrm{C}$. Some of the porosities observed in the $\mathrm{SiC} / \mathrm{SiC}$ composites between the fiber layers are shown in Figure 4.46.

The transmission electron micrographs of $\mathrm{SiC} / \mathrm{SiC}$ composites are given in Figures 4.47 through 4.57 . Figures $4.47,4.48$, and 4.49 are the high resolution TEM micrographs of the composite from the matrix, a grain inside the matrix, and the interface between the matrix and the pyrolytic carbon coating respectively, for the FCVI $(0 / 30 / 60)_{\text {repeat }}$ layup. The TEM specimens were prepared from the bulk of a specimen subiected to oxidation for 100 hours. Figures 4.50 and 4.51 are the TEM micrographs from a ICVI $(0 / 45 / 0 / 45)_{\text {repeat }}$ layup specimen. Figure 4.50 shows the interface between the fiber and the carbon coating, and the TEM specimen was prepared from the bulk. Figure 4.51 is the TEM micrograph of the matrix of a ICVI $(0 / 45 / 0 / 45)_{\text {repeal }}$ layup 
composite. The matrix shows both twinned grains as well as fine polycrystalline areas. A typical diffraction pattern observed from the polycrystalline area as well as the twinned grains are given in Figures $4.52 \mathrm{~A}$ and $4.52 \mathrm{~B}$ respectively. The diffraction pattern from the fiber showing partially crystalline nature could be observed from Figure 4.53B.

The TEM micrograph from the matrix/interface/fiber of a FCVI SiC/SiC composite subjected to oxidation treatment is shown in Figure 4.54. This micrograph shows the matrix, the coating, and the fiber areas. Figure 4.55 is a similar area, except that this specimen was prepared from the fracture surface. Here also, the matrix/interface/fiber areas could be observed.

The TEM micrograph of the RT/OX fracture surface of a FCVI $(0 / 30 / 60)_{\text {repeat }}$ layup may be observed in Figure 4.56. From this low magnification TEM micrograph of the interfacial region, the matrix and the fiber area can be observed. Figure $4.57 \mathrm{~A}$ is the general matrix area, while Figure 4.57B gives the diffraction pattern from the matrix of the fracture surface in a FCVI $(0 / 30 / 60)_{\text {repeat }}$ layup composite after testing at RT. A high magnification micrograph of the image in $4.57 \mathrm{~A}$ is given in Figure $4.57 \mathrm{C}$. 

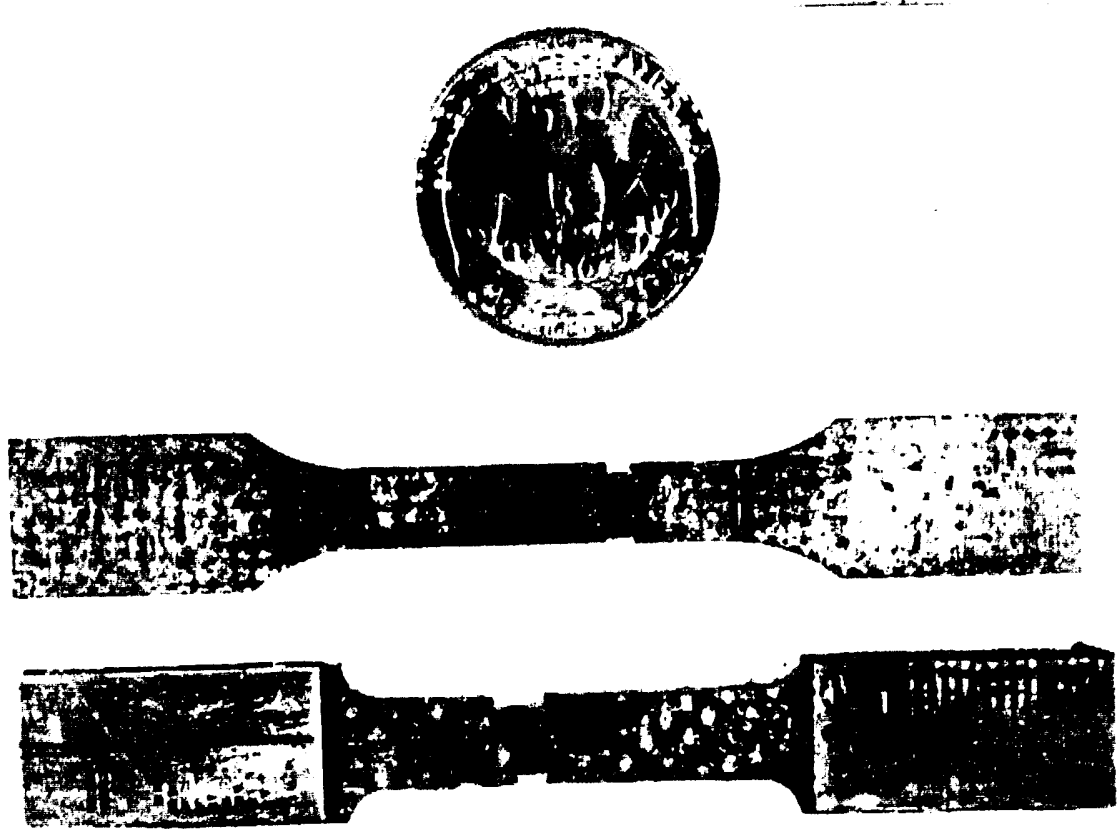

Figure 4.26. Typical failure pattern in $\mathrm{SiC} / \mathrm{SiC}$ tensile specimens 


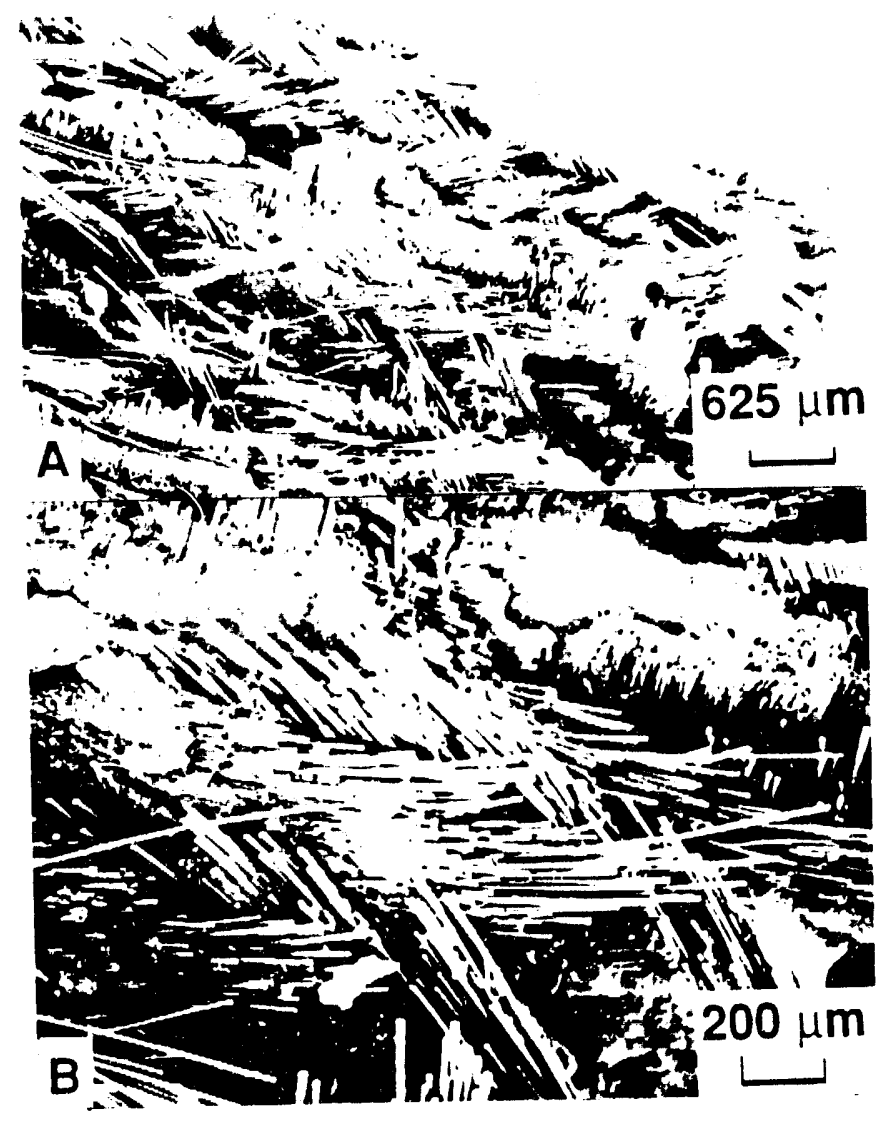

Figure 4.27. Fractography of FCVI SiC/SiC composites ; $(0 / 45 / 0 / 45)_{\text {repeat }}$ layup ; RT test. A. General Fracture surface

B. Indicates pullout of fibers in all directions 


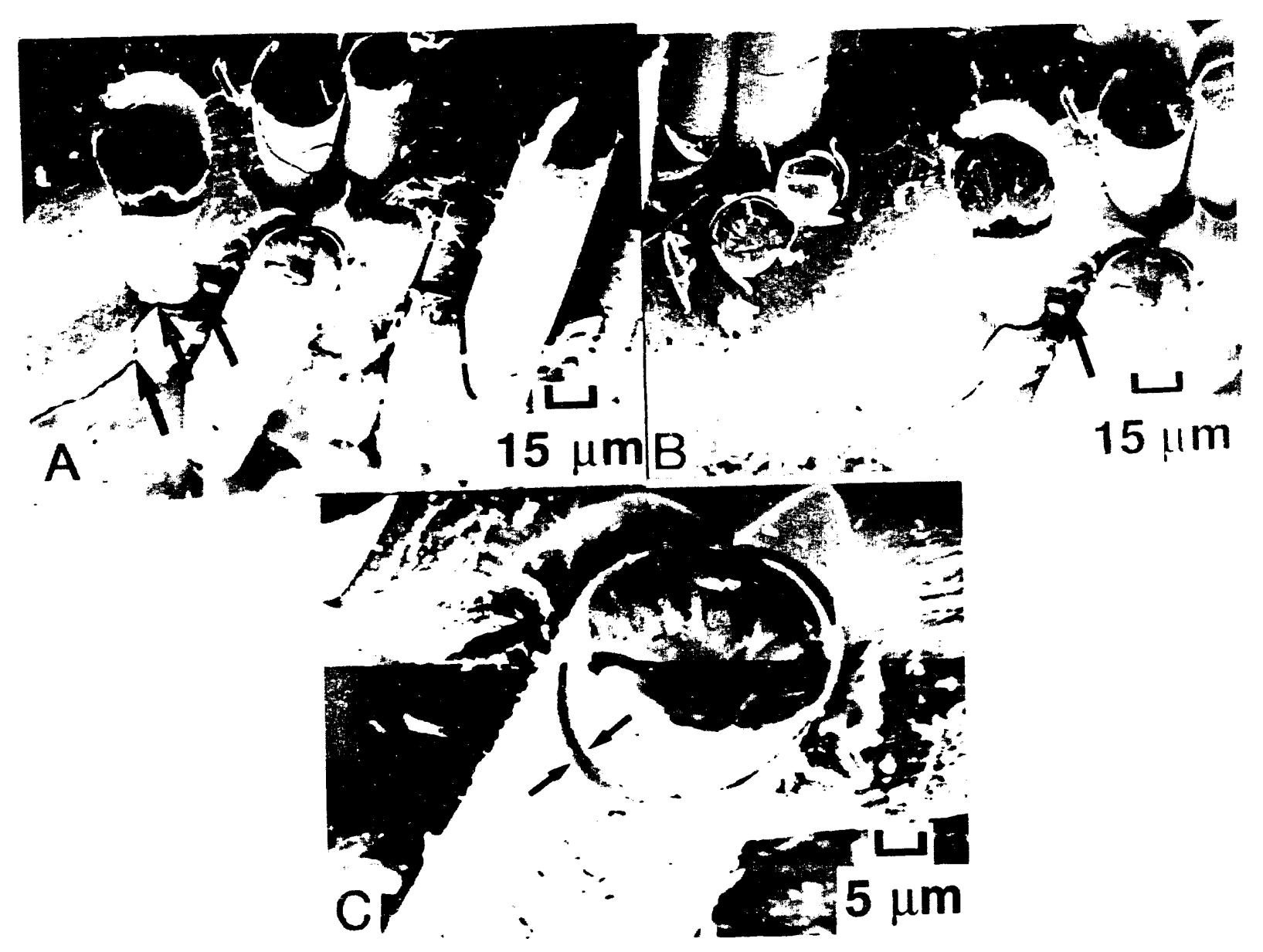

Figure 4.28. Fractography of $\mathrm{FCVI} \mathrm{SiC} / \mathrm{SiC}$ composites; $(0 / 45 / 45 / 0)_{\text {repeat }}$ layup ; RT test A \& B. Cracks running through matrix (blunting along the interface)

C. Close up view of a 0 degree fiber with typical brittle fracture. The coating may be observed (marked with arrows). 


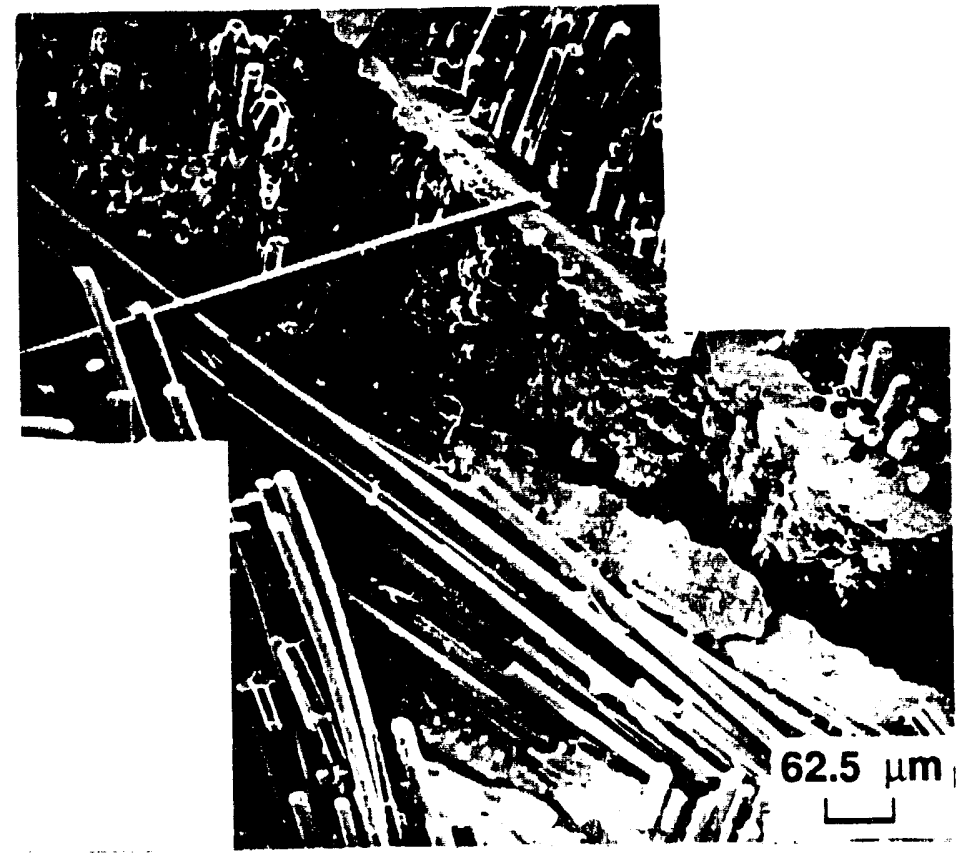

Figure 4.29. Fractography of FCVI SiC/SiC composites ; $(0 / 45 / 0 / 45)_{\text {repeat }}$ layup ; RT test Voids between two plain weaves with fibers oriented in the 0 and 90 degree directions to the stress direction 


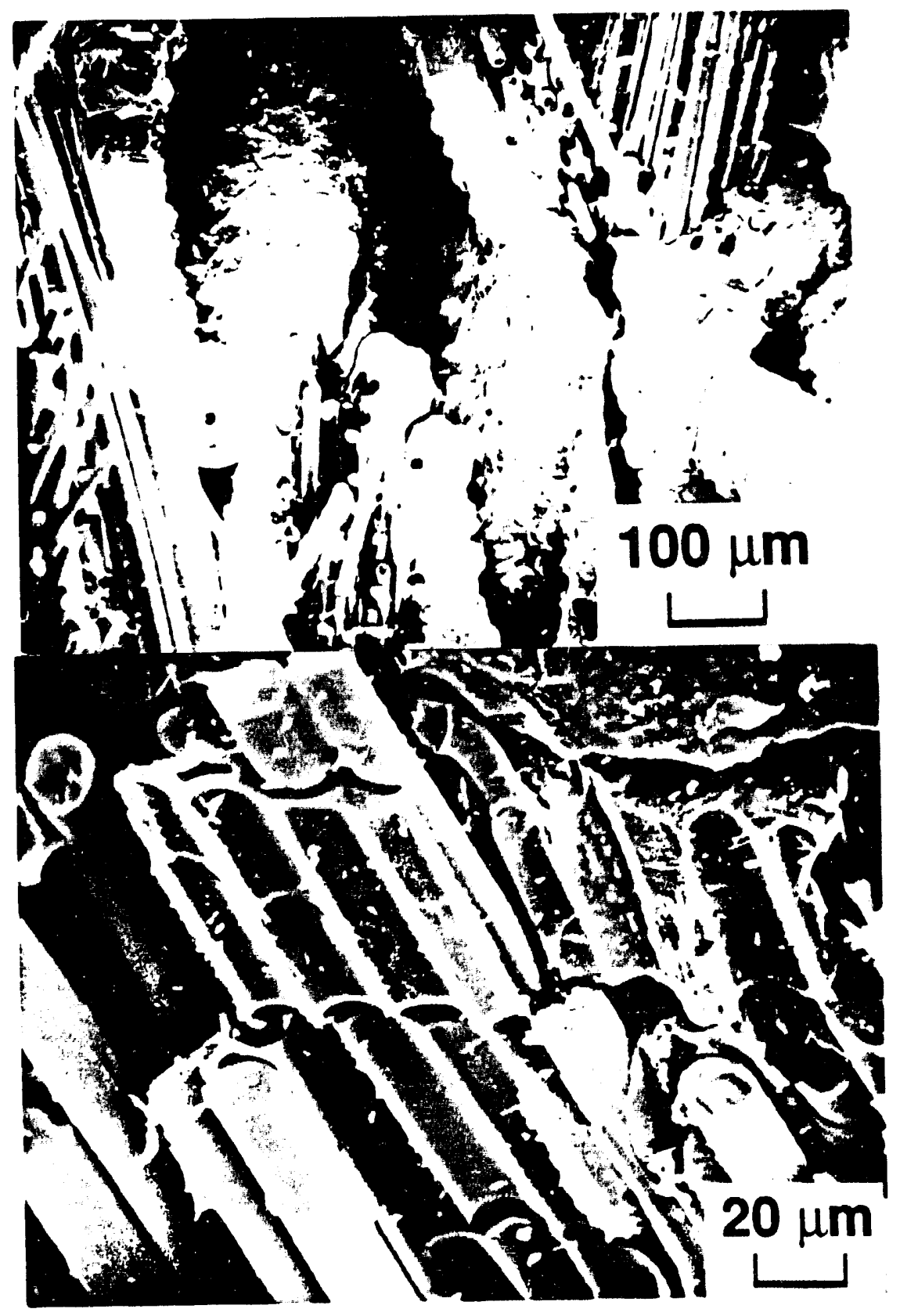

Figure 4.30. Fractography of FCVI SiC/SiC composites : $(0 / 45 / 0 / 45)_{\text {repeal }}$ layup : RT test Another view of similar voids between weaves. The second micrograph indicates fiber bridging of layers of cracked matrix. 


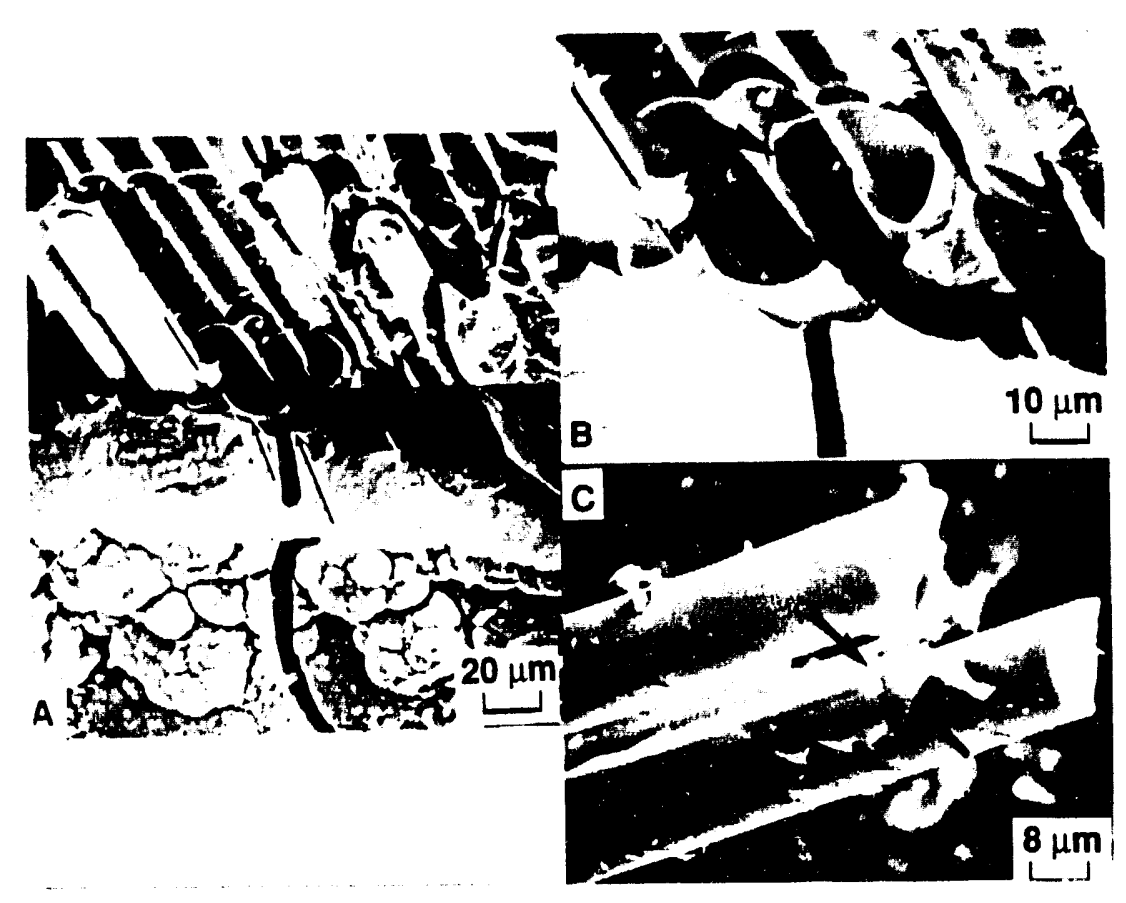

Figure 4.31. Fractography of FCVI SiC/SiC composites ; $(0 / 45 / 0 / 45)_{\text {repeat }}$ layup ; RT test A. Matrix cracks arrested by the fibers.

B. Close up view of the fracture surface in (A) indicating clean pull out of the fibers. C. The pulled out fibers showing coating remaining on the surface of the fibers. 


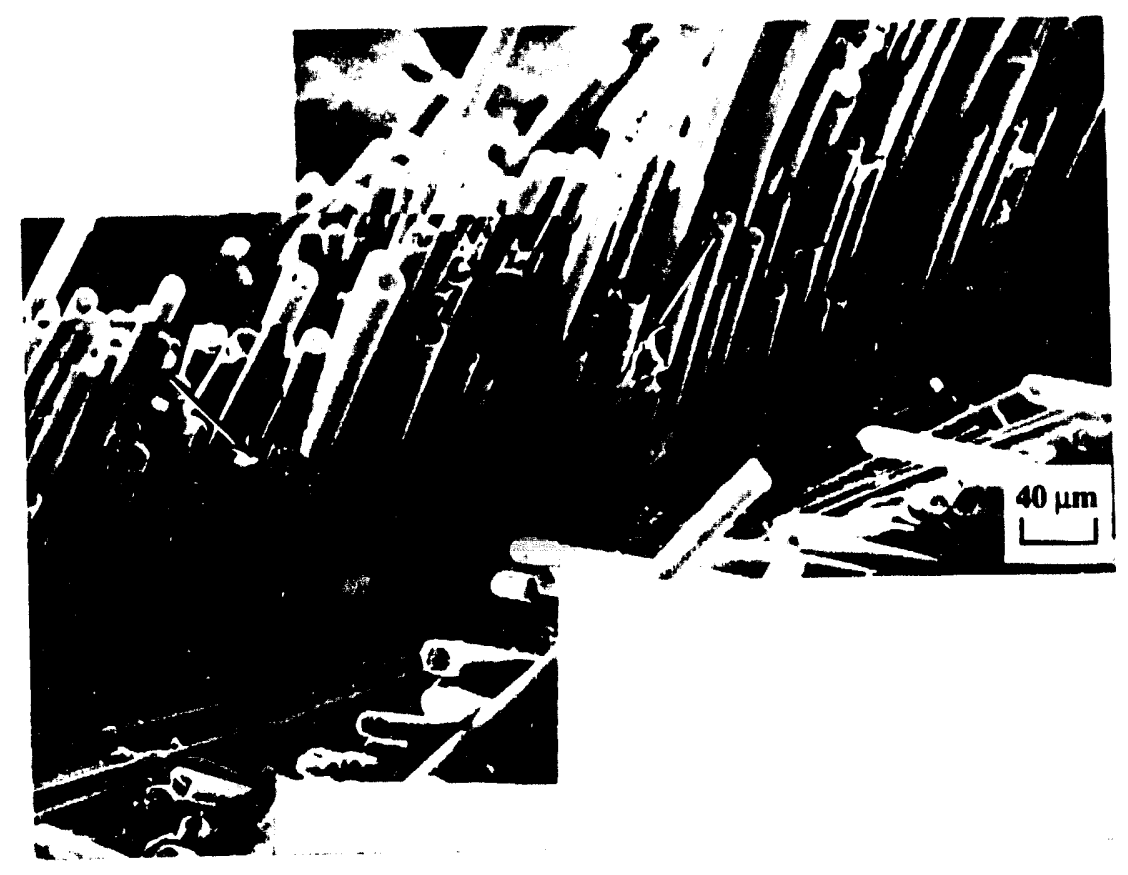

Figure 4.32. Fractography of FCVI SiC/SiC composites ; $(0 / 30 / 60)_{\text {repeat }}$ layup ; $1000^{\circ} \mathrm{C}$ Pullout of fibers on the fracture surface. Note the large amount of pullout of fibers, coupled with fibers bridging matrix cracks. 


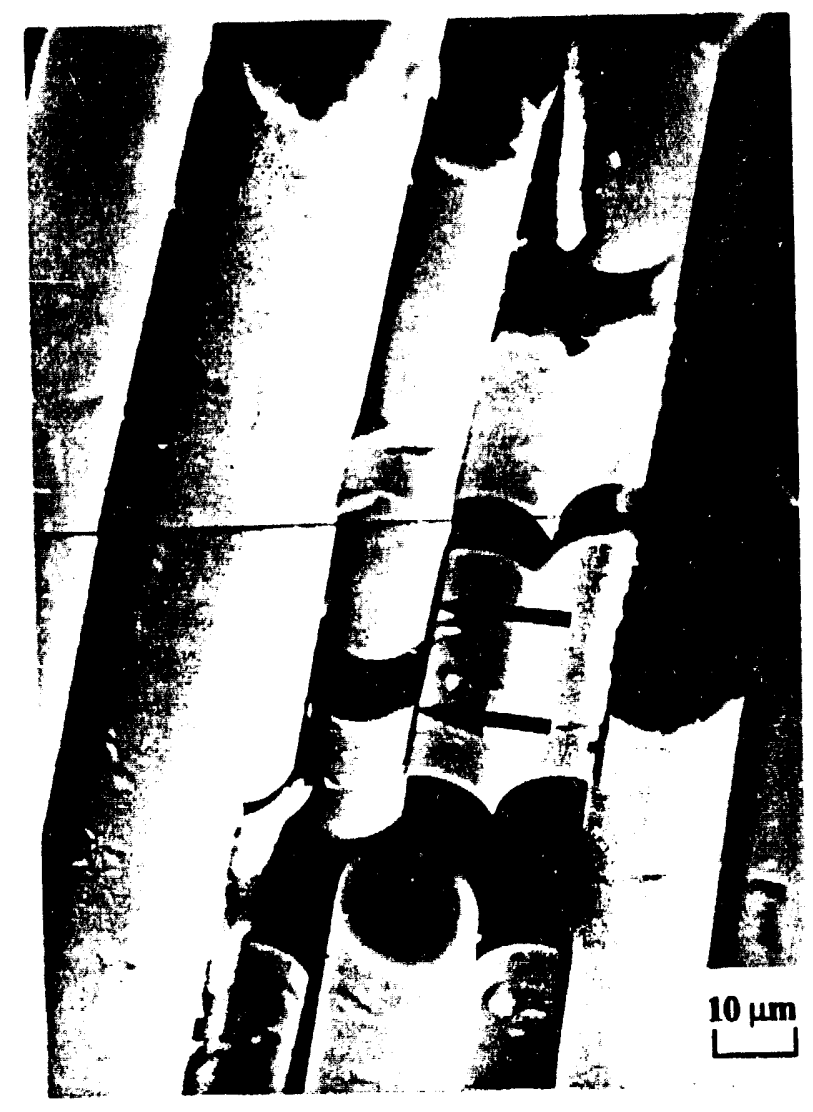

Figure 4.33. Fractography of FCVI SiC/SiC composites ; $(0 / 30 / 60)_{\text {repeat }}$ layup ; $1000^{\circ} \mathrm{C}$ Magnified image of fibers in Figure 4.32. Note the fiber matrix debonding and crack bridging. 


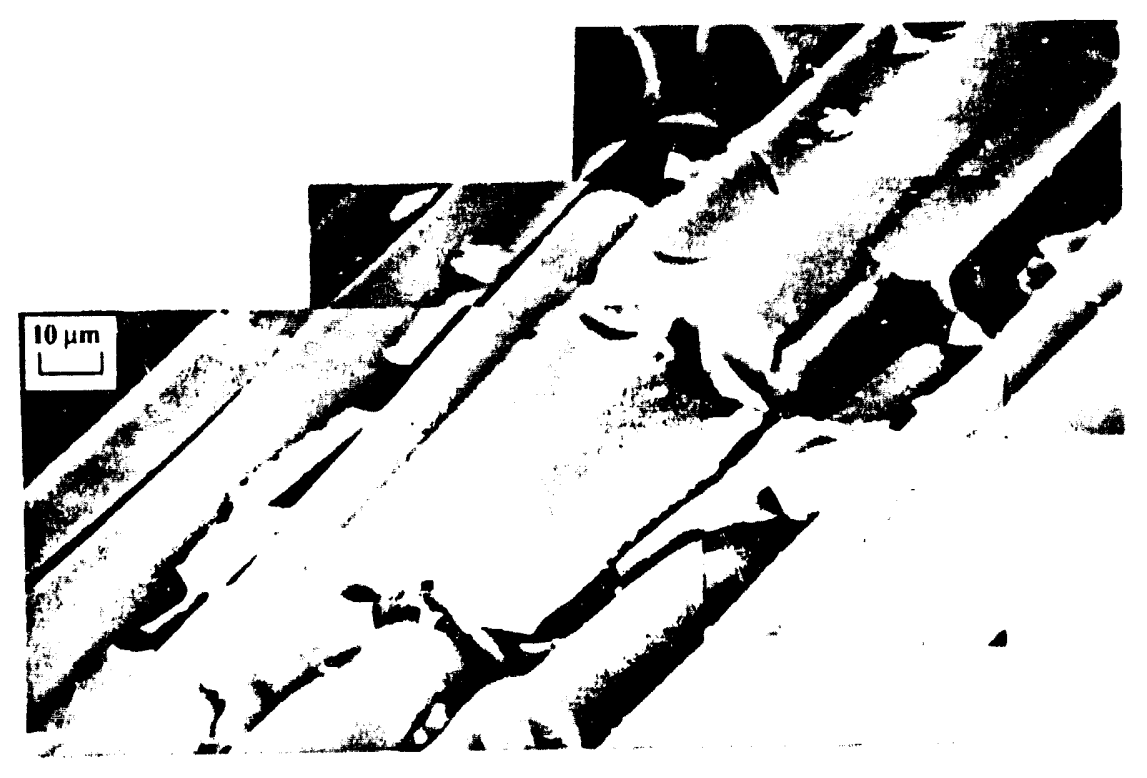

Figure 4.34. Fractography of FCVI SiC/SiC composites ; $(0 / 30 / 60)_{\text {repeat }}$ layup ; $1000^{\circ} \mathrm{C}$ Another image of fiber pullout, similar to Figure 4.33. 


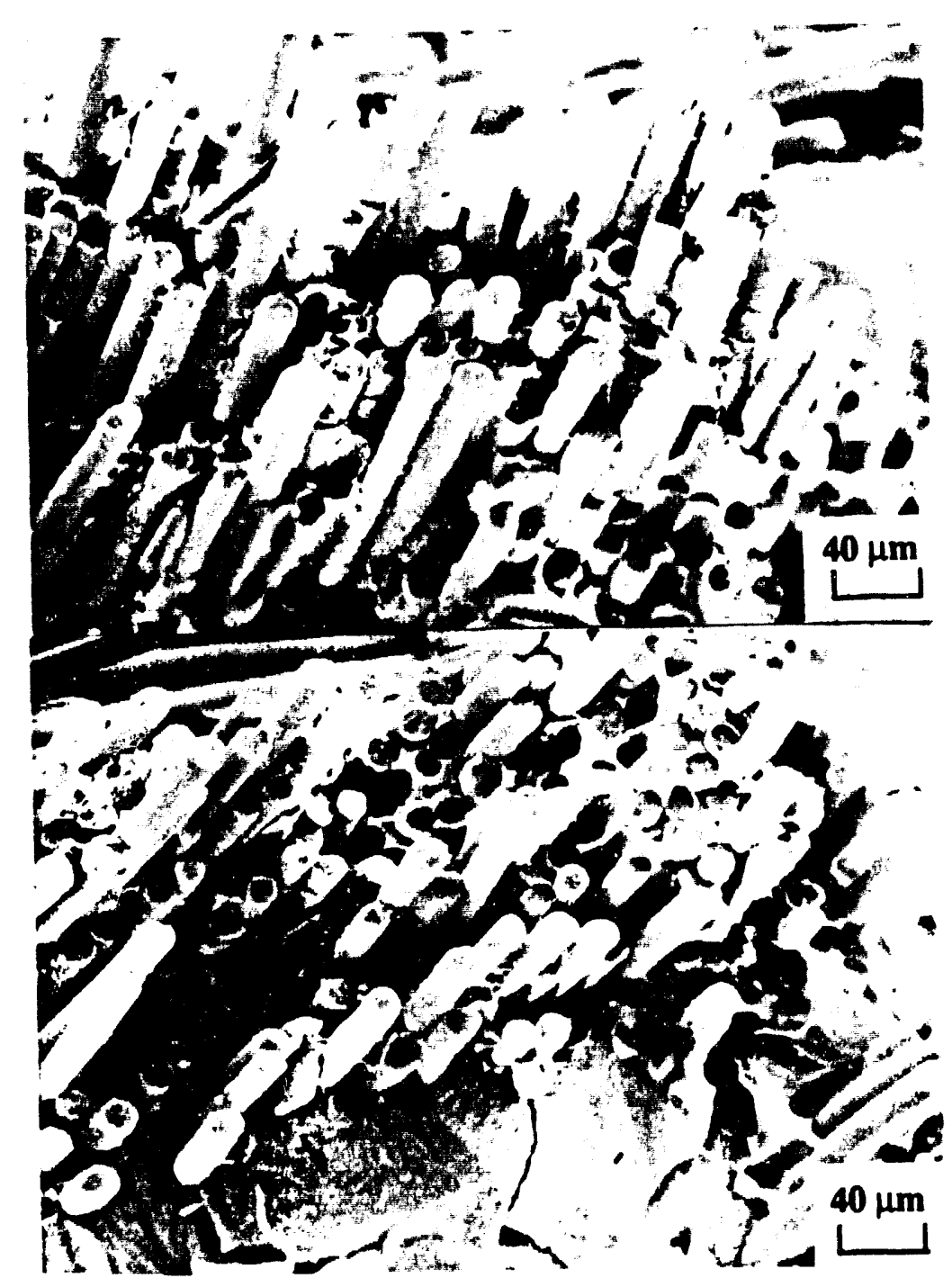

Figure 4.35. Fractography of FCVI SiC/SiC composites ; $(0 / 30 / 60)_{\text {repeat }}$ layup ; RT test after thermal shock ; Fiber pullout on the fracture surface. 


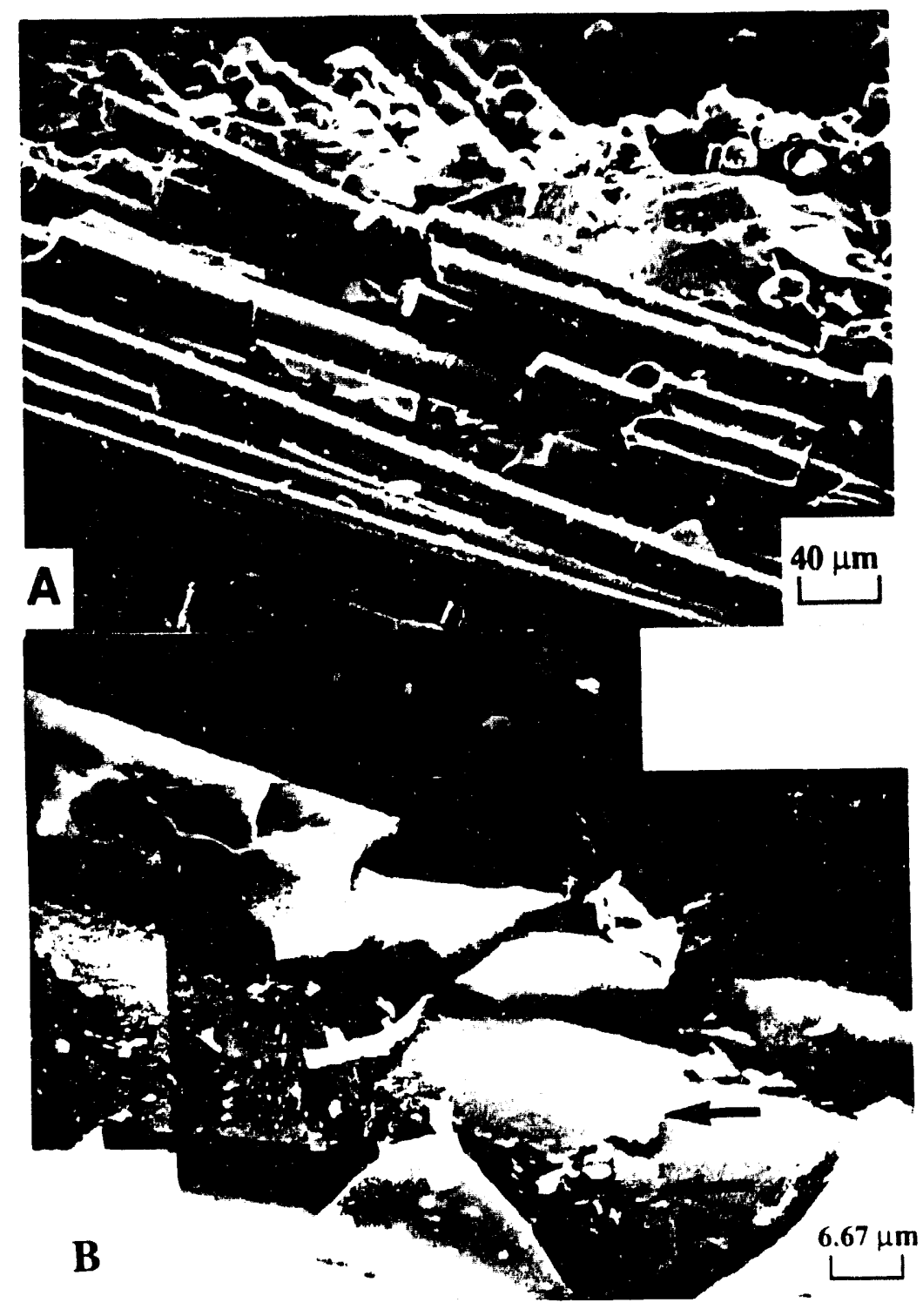

Figure 4.36. Fractography of FCVI SiC/SiC composites : $(0 / 30 / 60)_{\text {repteal }}$ layup : RT test after thermal shock.
A. Fiber pullout on the fracture surface.
B. Magnified image of a fiber in (A) with coating remaining on the surface. 


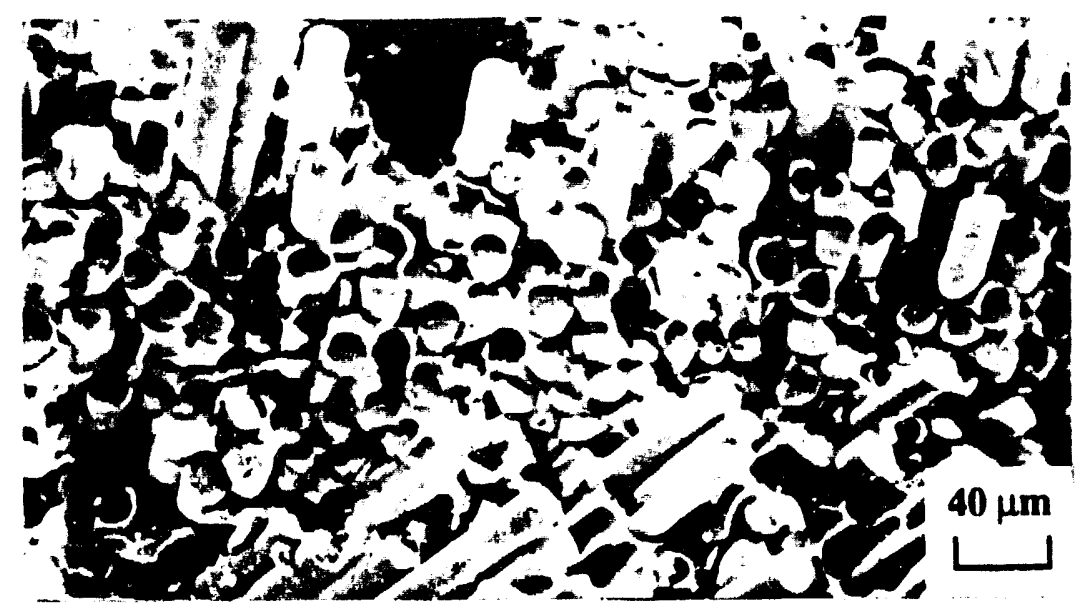

Figure 4.37. Fractography of FCVI SiC/SiC composites ; $(0 / 30 / 60)_{\text {repeat }}$ layup ; RT test after exposure to 100 hours oxidation.

Pullout of fibers on the fracture surface. Note the amount of pullout as compared to specimens tested at $1000^{\circ} \mathrm{C}$. 


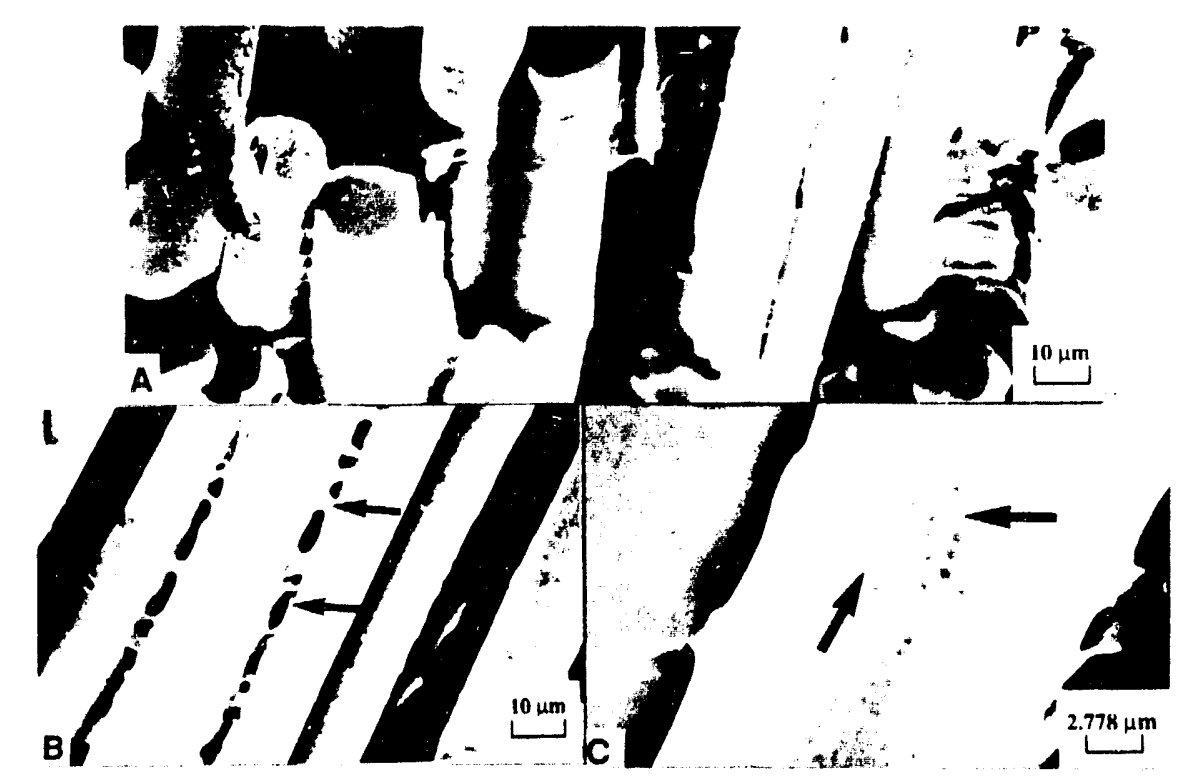

Figure 4.38. Fractography of FCVI SiC/SiC composites ; $(0 / 30 / 60)_{\text {repeat }}$ layup ; RT test after exposure to 100 hours oxidation.
A. Fracture surface showing effect of oxidation on the interfacial layer.
B. Similar effect as in (A).
C. Magnified image of a fiber in (B). 


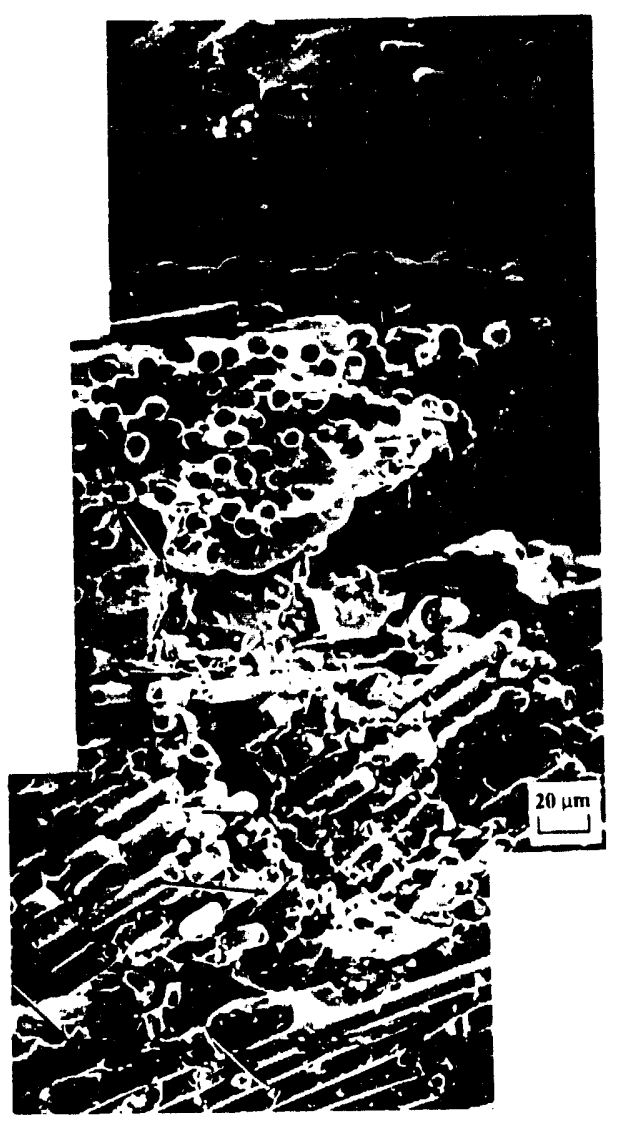

Figure 4.39. Fractography of ICVI SiC/SiC composites ; $(0 / 45 / 0 / 45)_{\text {repeat }}$ layup ; RT test. Fracture surface indicates crack deflection by the fibers. 


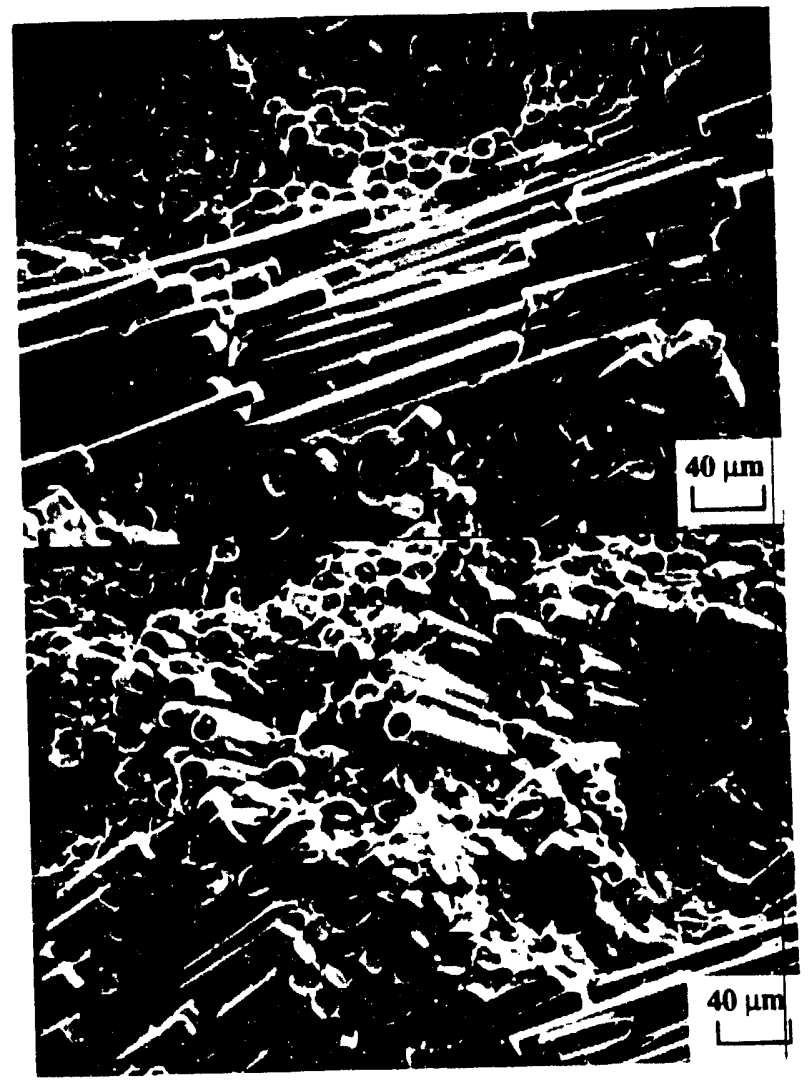

Figure 4.40. Fractography of ICVI SiC/SiC composites ; $(0 / 45 / 0 / 45)_{\text {repeat }}$ layup ; RT test after exposure to thermal shock. 


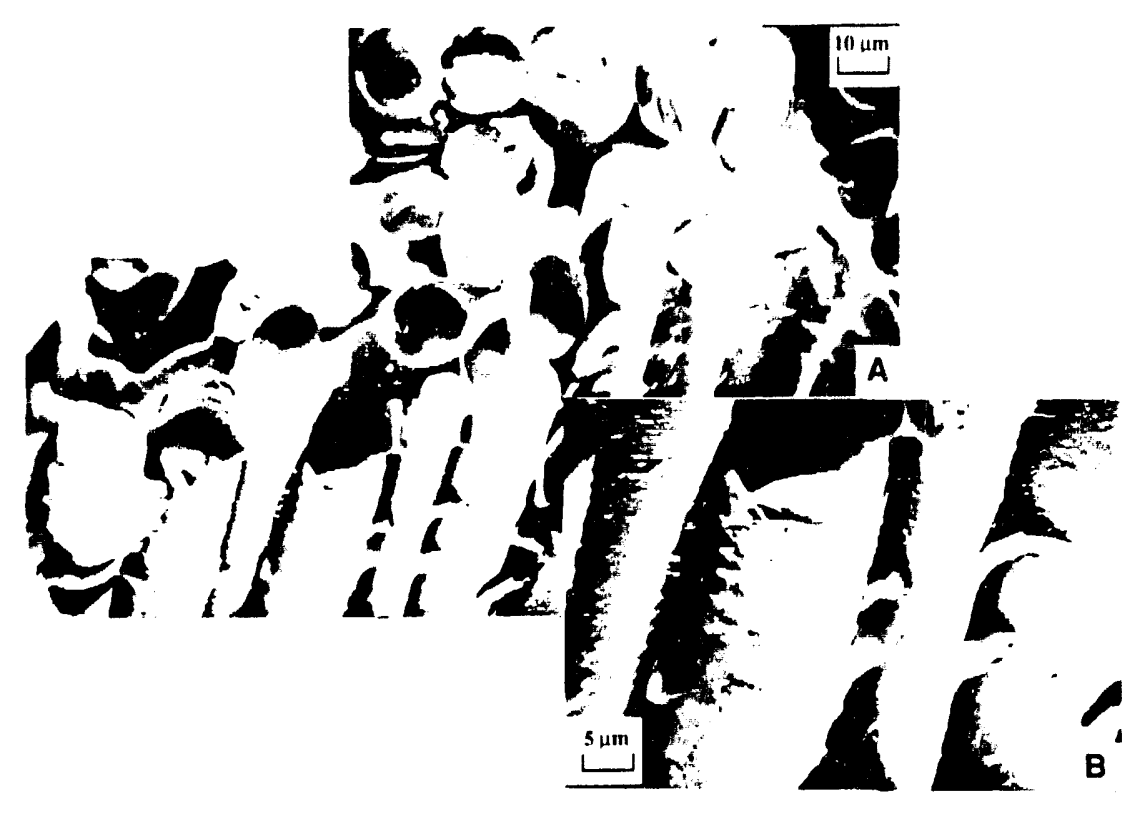

Figure 4.41. Fractography of ICVI SiC/SiC composites ; $(0 / 45 / 0 / 45)_{\text {repeat }}$ layup ; RT test after exposure to 100 hours oxidation.

A. Very little debonding and pullout observed in the fibers.

B. Close up view of an area in (A) indicates little deboricing. 


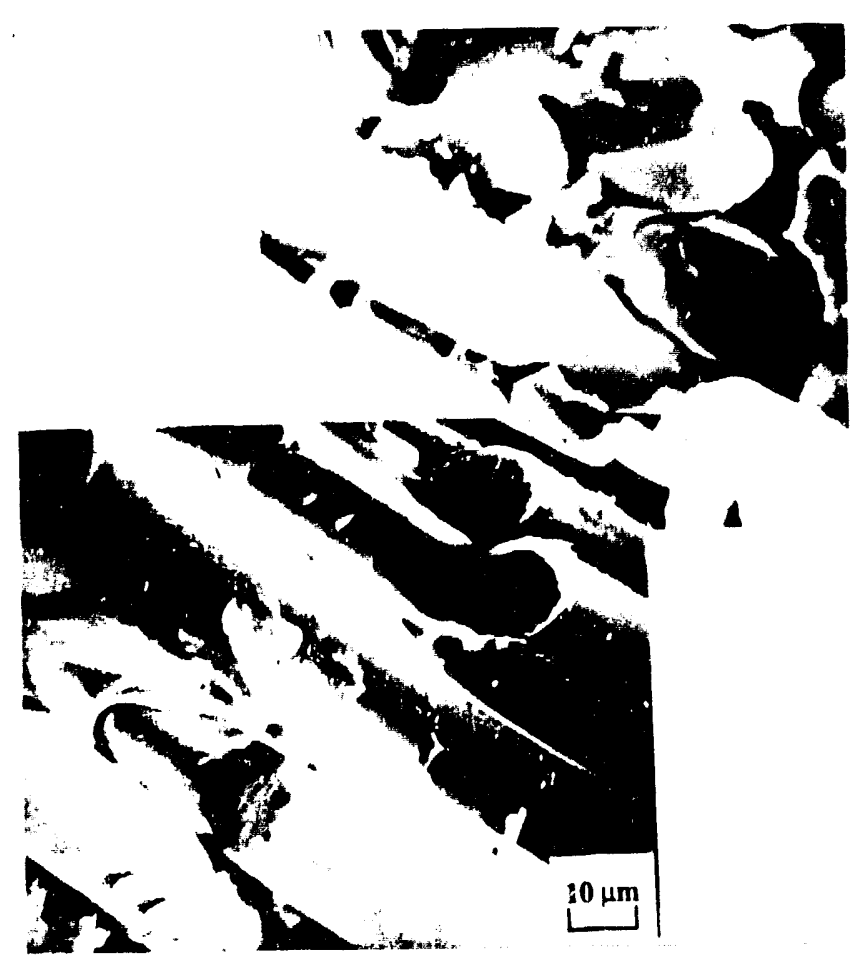

Figure 4.42. Fractography of ICVI SiC/SiC composites ; $(0 / 45 / 0 / 45)_{\text {repeat }}$ layup ; RT test after exposure to 100 hours oxidation.

Indicates pullout but little debonding. 


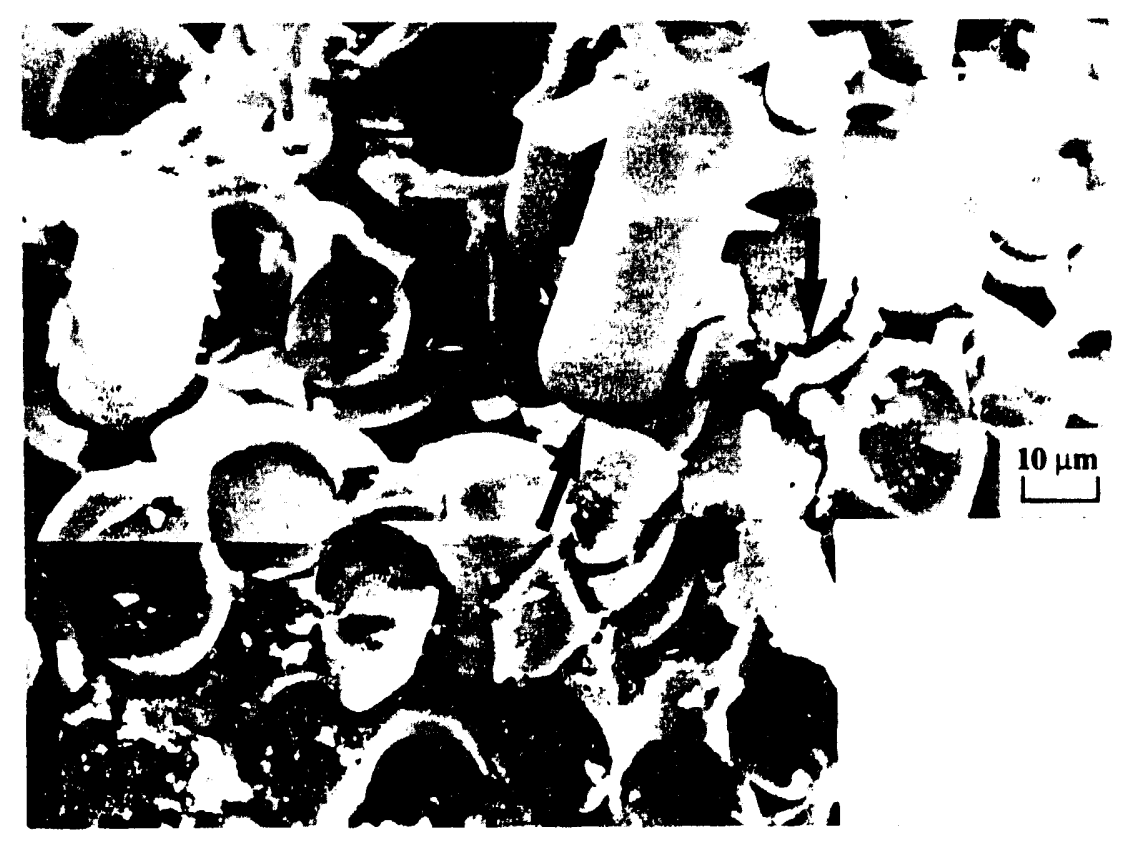

Figure 4.43. Fractography of ICVI SiC/SiC composites ; $(0 / 45 / 0 / 45)_{\text {repeat }}$ layup ; $1000^{\circ}$ C Fiber pullout ; Observe the fiber-matrix debonding and crack deflection by the pulled out fibers. 


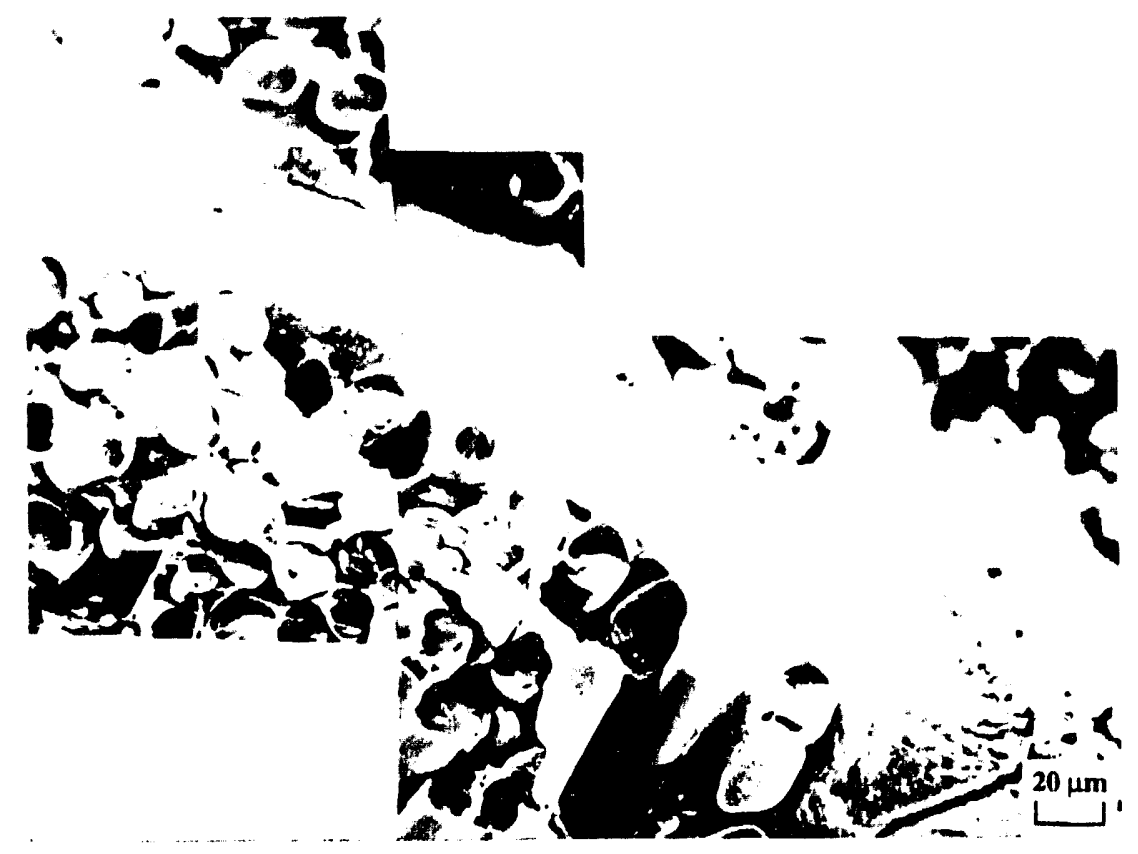

Figure 4.44. Fractography of ICVI SiC/SiC composites ; $(0 / 90)_{\text {repeat }}$ layup ; RT test The features on the fracture surface are similar to that observed in the $(0 / 45 / 0 / 45)_{\text {repeat }}$ layup 


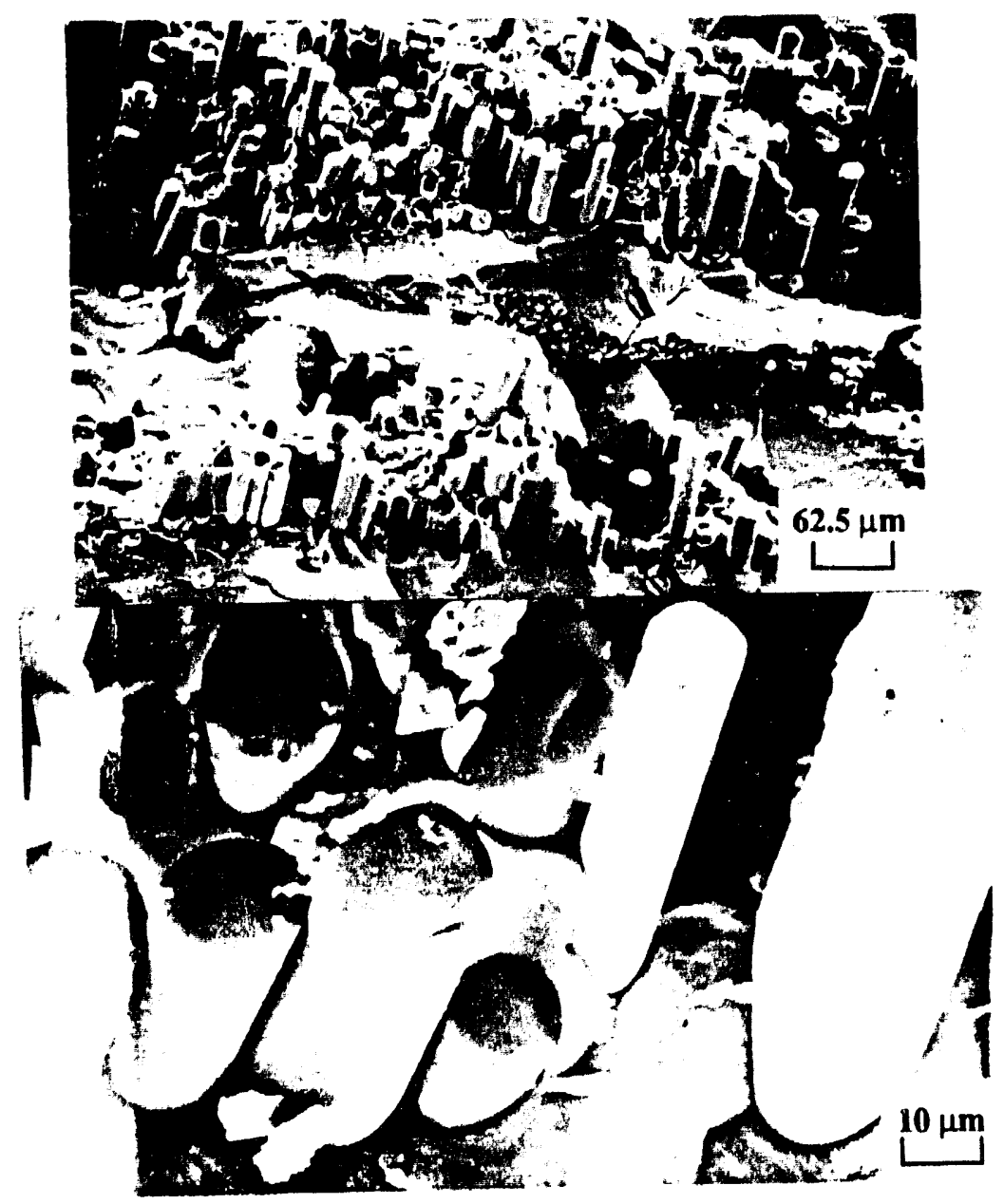

Figure 4.45. Fractography of ICVI SiC/SiC composites ; $(0 / 90)_{\text {repeat }}$ layup ; $1000^{\circ} \mathrm{C}$ Debonding and pullout on the fracture surface. 


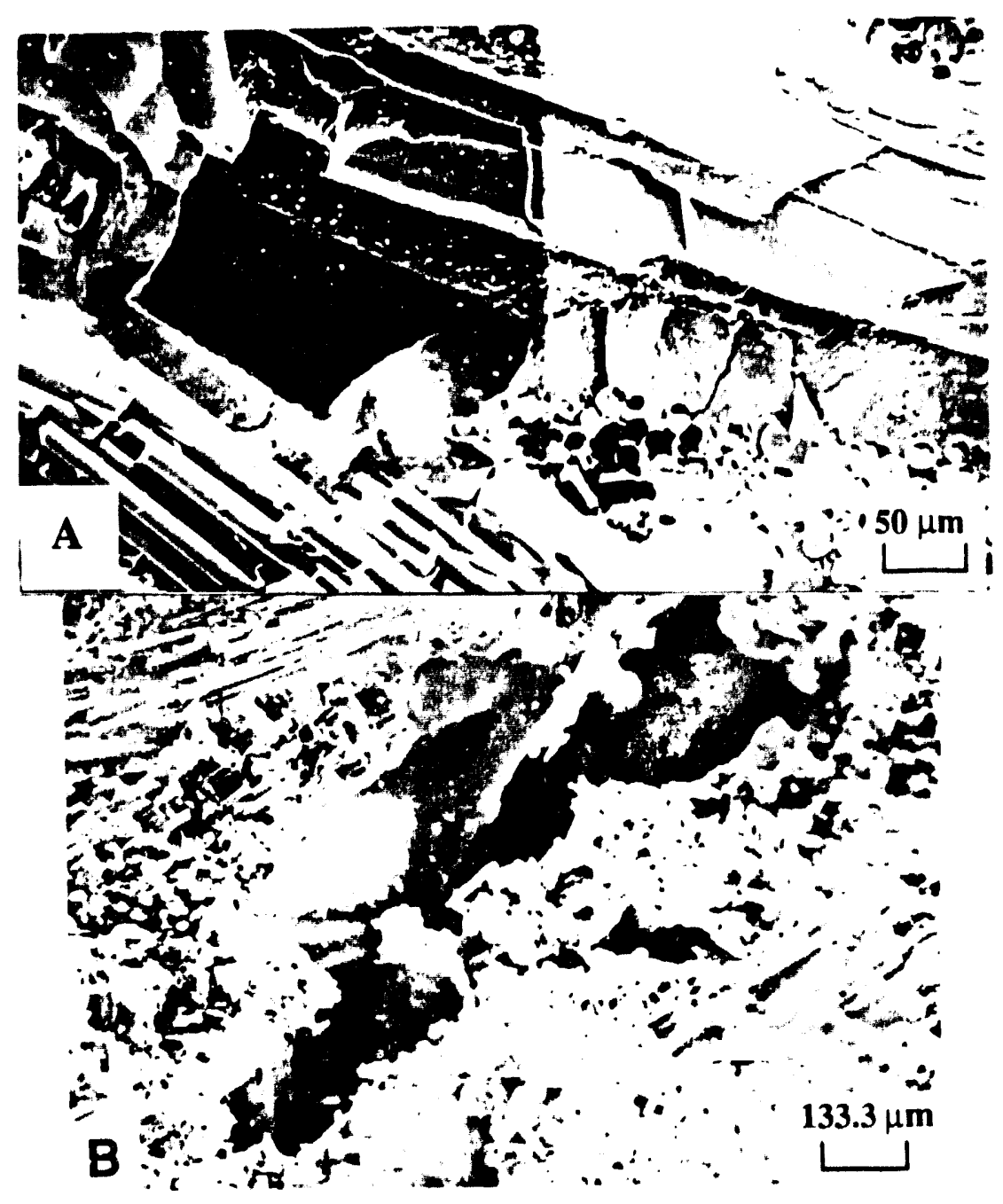

Figure 4.46. Fractography of ICVI $\mathrm{SiC} / \mathrm{SiC}$ composites

A. $(0 / 90)_{\text {repeat }}$ layup, RT test. Fracture appears to initiate from porosities between fiber layers.

B. $(0 / 45 / 0 / 45)_{\text {repeal }}$ layup, $1000^{\circ} \mathrm{C}$. Fracture initiation seems to be similar to (A) Similar porosities were observed in FCVI materials also. 


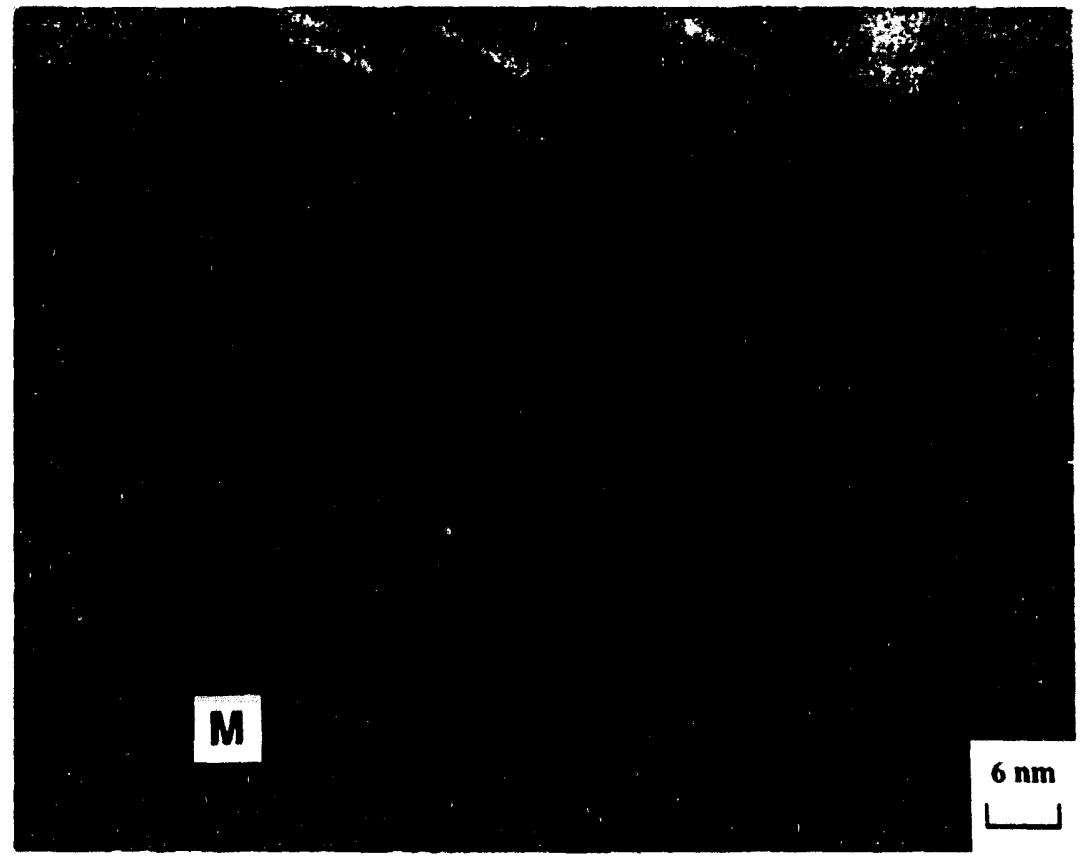

Figure 4.47. FCVI SiC/SiC composite ; $(0 / 30 / 60)_{\text {repeal }}$ layup ; RT/OXY ; TEM of the bulk material.

A single grain of the matrix showing twins. 


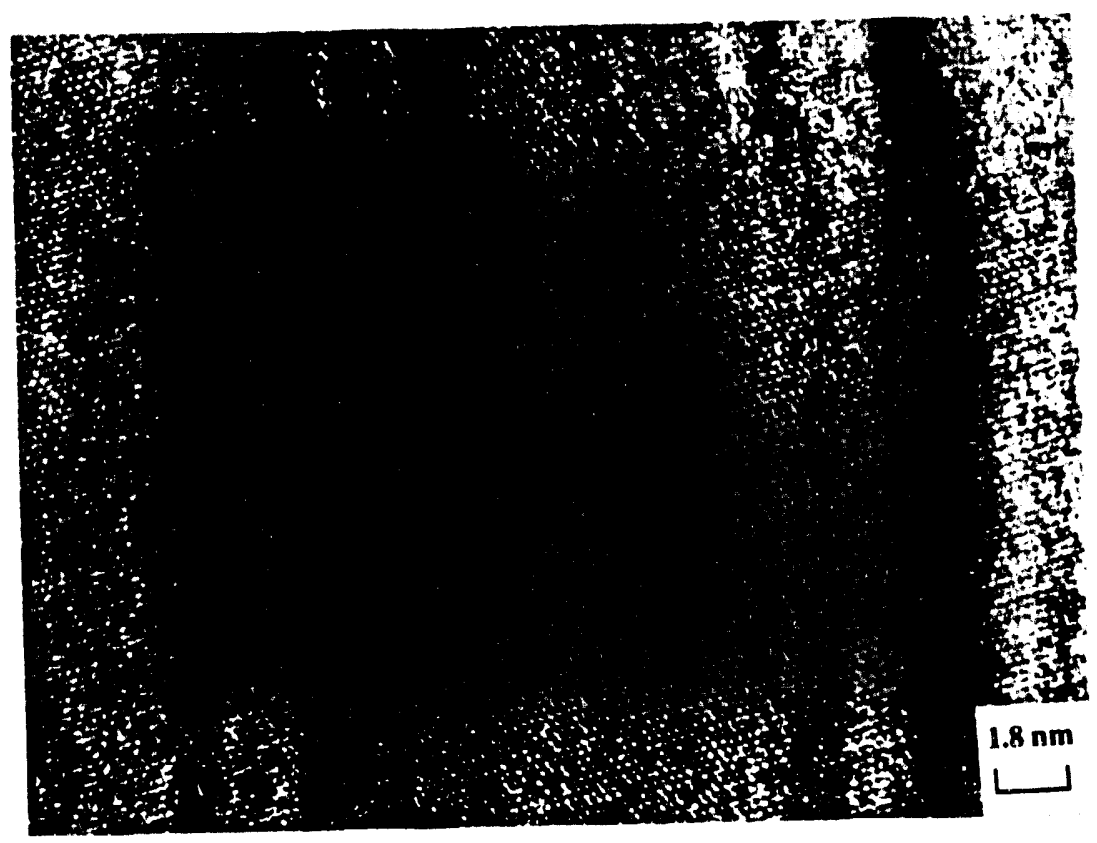

Figure 4.48. FCVI SiC/SiC composite ; $(0 / 30 / 60)_{\text {repeat }}$ layup ; RT/OXY ; TEM of the bulk material.

A higher magnification image of the matrix. 


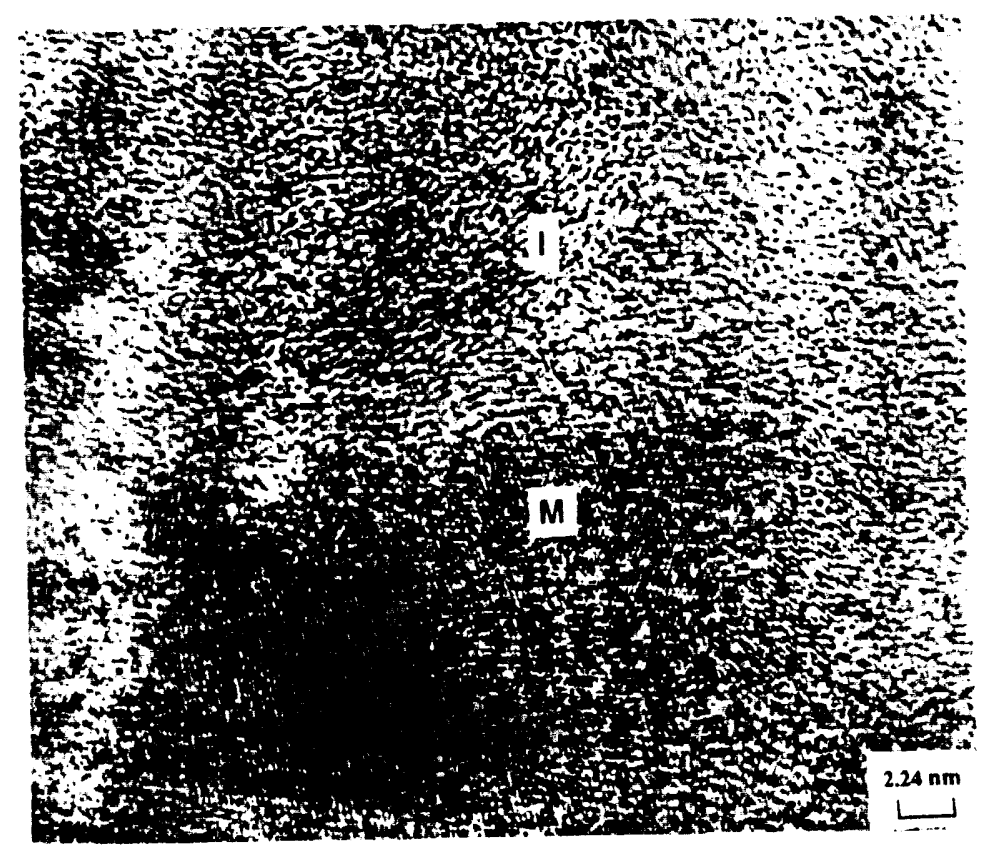

Figure 4.49. FCVI SiC/SiC composite ; $(0 / 30 / 60)_{\text {repeat }}$ layup ; RT/OXY ; TEM of the bulk material.

Interface (I) between the matrix (M) and the pyrolytic carbon coating. 


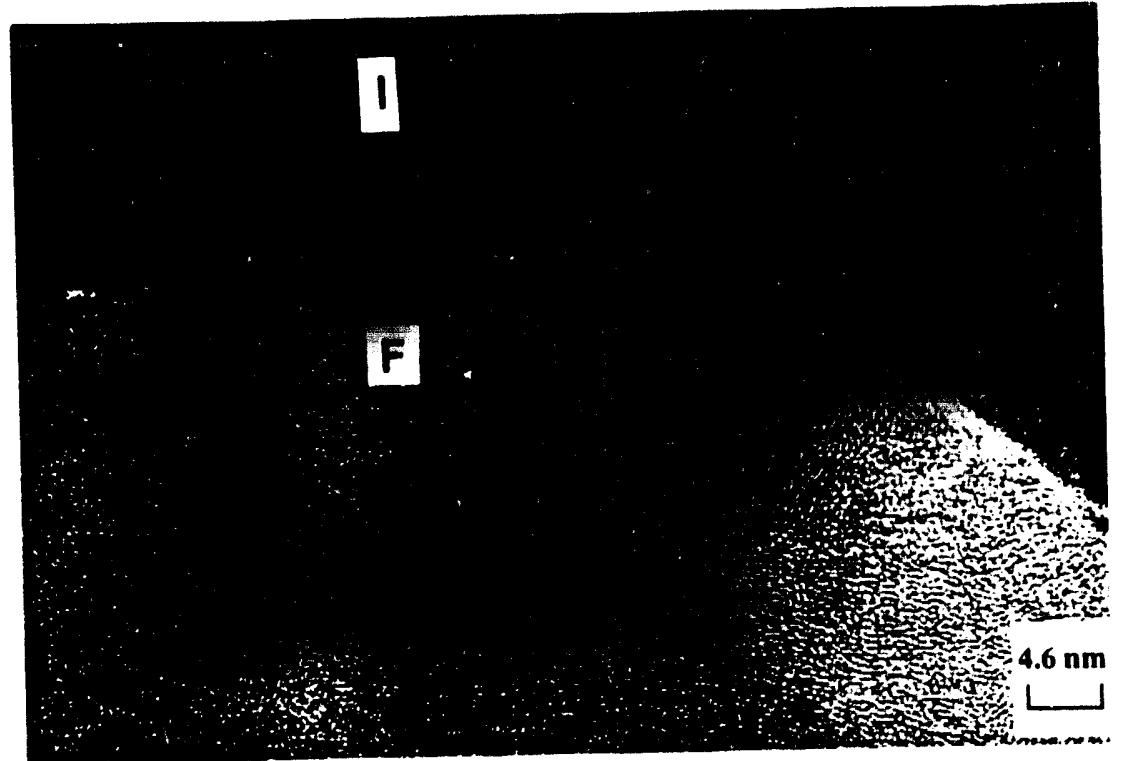

Figure 4.50. ICVI SiC/SiC composite ; $(0 / 45 / 0 / 45)_{\text {sepeal }}$ layup ; RT test ; TEM of the bulk material.

Shows the interface (I) between the fiber (F) and the carbon coating. 


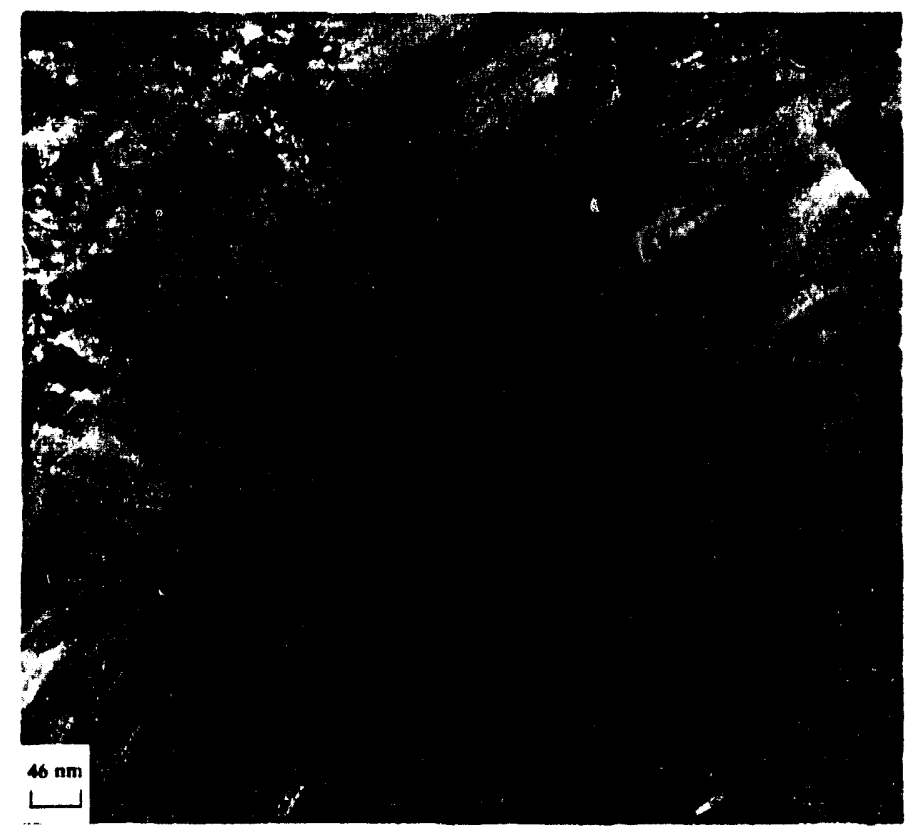

Figure 4.51. ICVI SiC/SiC composite ; $(0 / 45 / 0 / 45)_{\text {repeat }}$ layup ; RT test ; TEM of the bulk material. Matrix showing twinned grains as well as fine polycrystalline a:ea. 


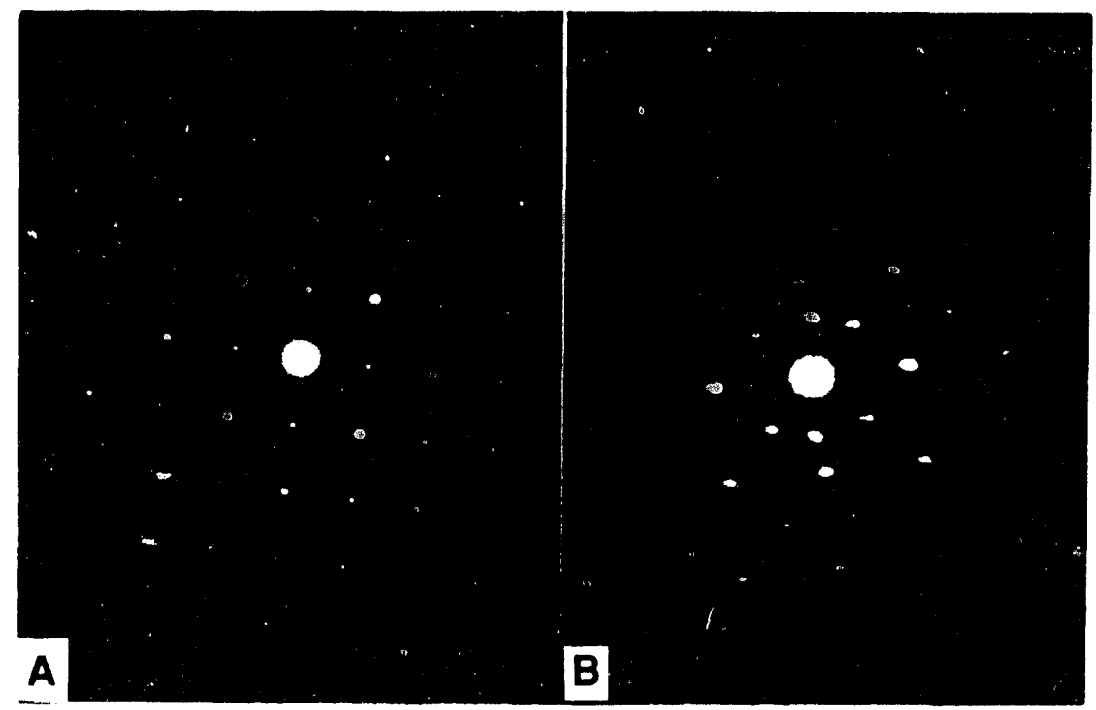

Figure 4.52. ICVI SiC/SiC composite ; $(0 / 45 / 0 / 45)_{\text {repeat }}$ layup ; RT test ; TEM of the bulk material.

A. Diffraction pattern from the polycrystalline area showing cubic structure

B. Diffraction pattern from the twinned area showing a mixed structure Indicates the possibility of pockets of cubic structure separated by twinned areas. 


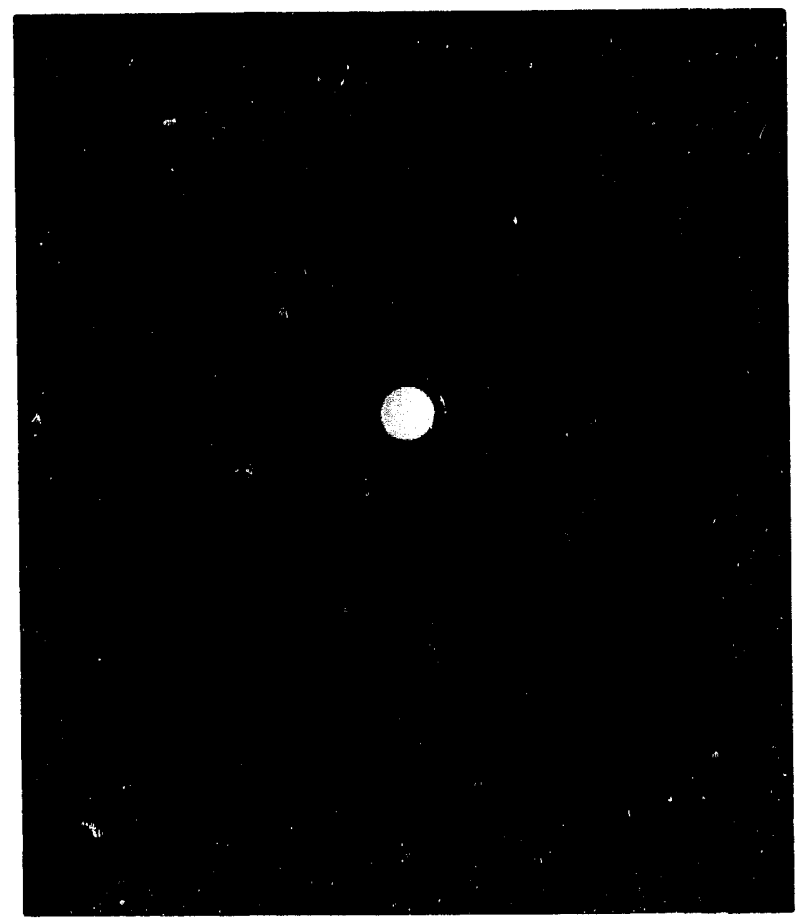

Figure 4.53. ICVI SiC/SiC composite ; $(0 / 45 / 0 / 45)_{\text {repeat }}$ layup ; RT test ; TEM of the bulk material.

Diffraction pattern from the fiber showing partially crystalline structure. 


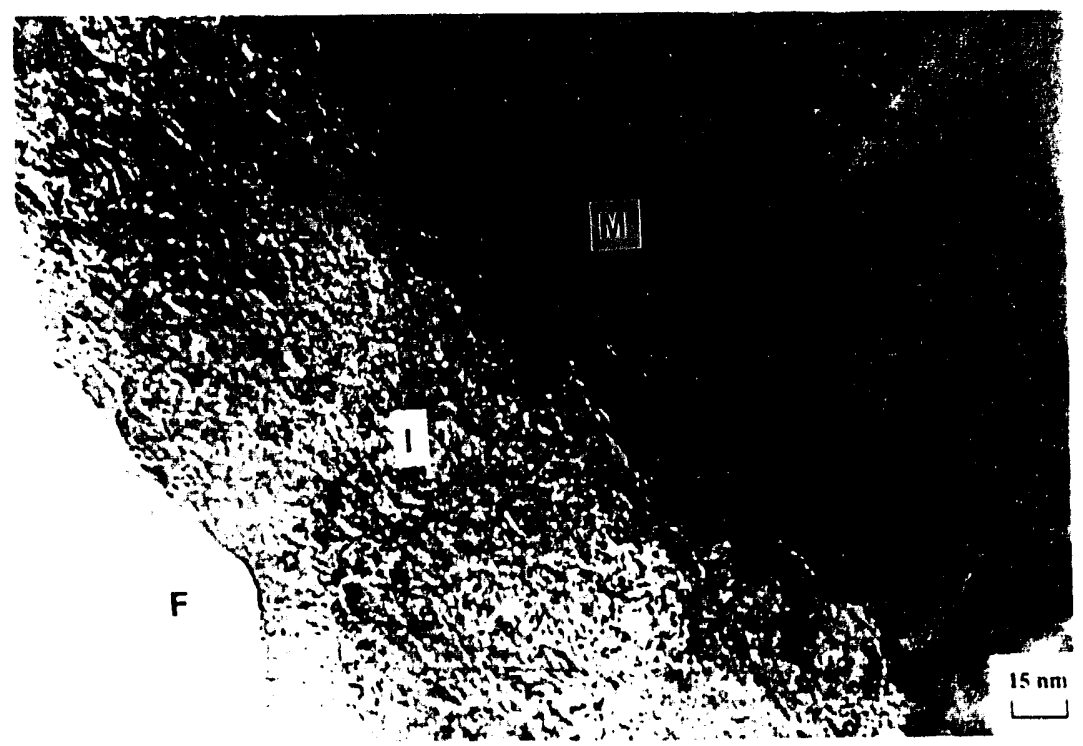

Figure 4.54. FCVI SiC/SiC composite ; $(0 / 30 / 60)_{\text {repeat }}$ layup ; RT/OXY ; TEM of the bulk material.

The TEM micrograph from the bulk material showing the interfacial coating (I), matrix $(\mathrm{M})$, and the fiber $(\mathrm{F})$. Does not show the interface to be affected by the oxidation treatment (the interface is still sharp). 


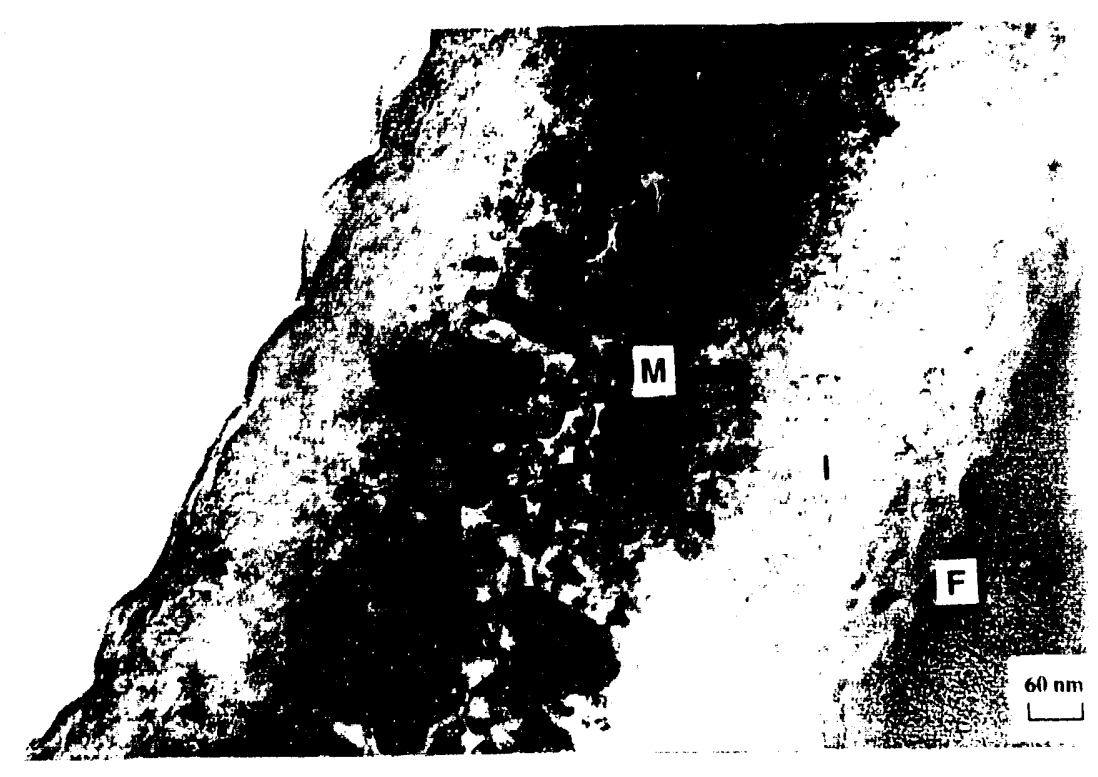

Figure 4.55. FCVI SiC/SiC composite ; $(0,30 / 60)_{\text {repeat }}$ layup ; RT/OXY ; TEM of the fracture surface.

The TEM micrograph from the fracture surface showing the interfacial coating (I), matrix $(M)$, and the fiber $(F)$. Interface appears to have lost its sharp contrast and seems to be diffuse. 


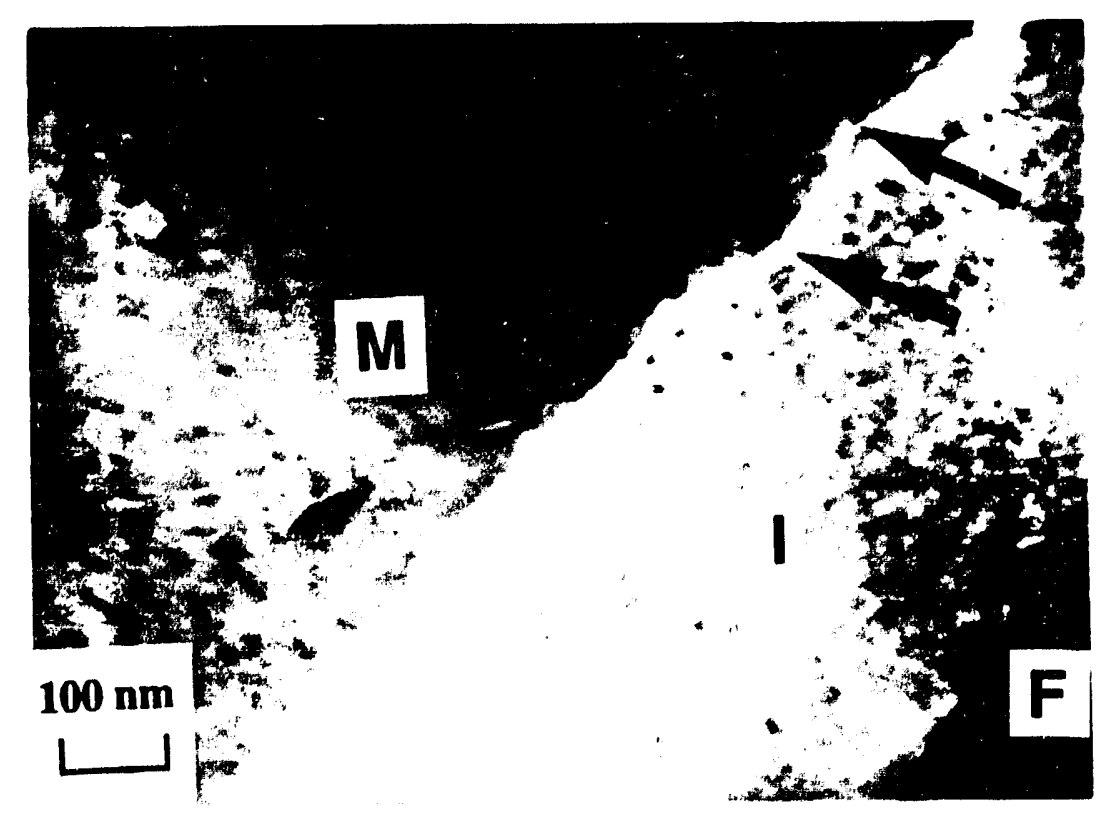

Figure 4.56. FCVI SiC/SiC composite ; $(0 / 30 / 60)_{\text {repeat }}$ layup ; $1000^{\circ} \mathrm{C} ; \mathrm{TEM}$ of the fracture surface.

Low mag TEM micrograph of the interfacial region from the fracture surface. Separation between the matrix and the coating (debonding) can be seen (shown by arrows). 


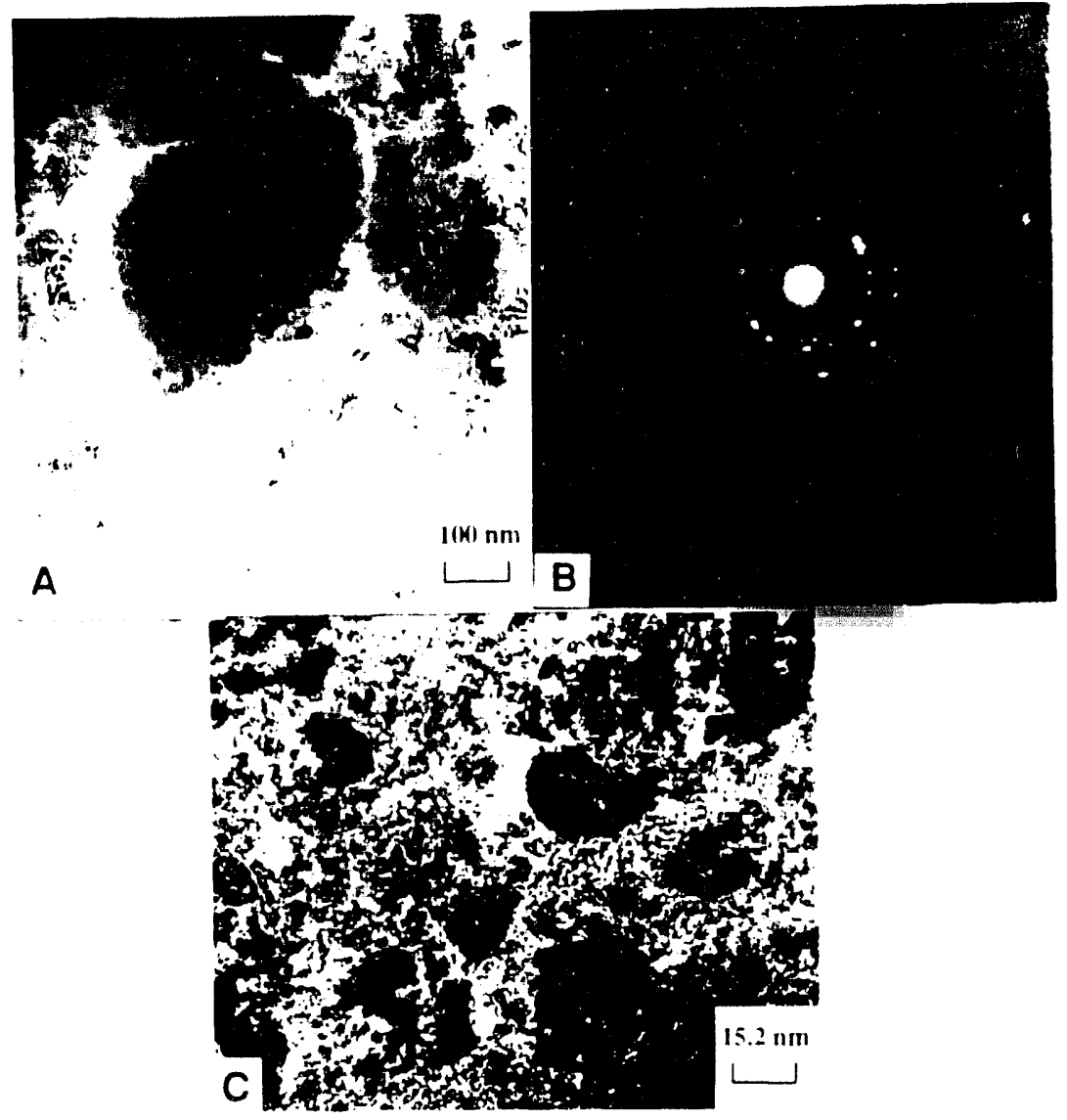

Figure 4.57. ICVI SiC/SiC composite : $\left((0 / 45 / 0 / 45)_{\text {tepeal }}\right.$ layup : RT test : TEM of the fracture surface.
A. Low magnification image of the matrix area.
B. Diffraction pattern from the matrix showing the polycrystalline nature of the matrix.
C. Higher magnification image of the matrix does not appear $t o$ indicate any twinned grains.




\section{CHAPTER 5}

\section{ANALYTICAL MODELING PROCEDURES AND RESULTS}

In the previous chapters, the requirements for uniaxial tensile data for ceramics and ceramic matrix composites (CMC) have been identified and discussed in detail. There is a lack of mechanical property data for these composite systems due to the problems associated with manufacturing suitably sized test specimens. Currently, only short specimens can be made using the FCVI method, which creates major problems for precision alignment in tensile testing of these composites. In addition, suitably sized specimens can be expensive. Therefore, it would be advantageous to develop an analytical model for the prediction of mechanical properties such as Young's modulus, Poisson's ratio, and Shear modulus of these composites, similar to polymer matrix composites. An analytical model on the lines of a model developed originally for the prediction of thermal expansion characteristics of polymer matrix composites(Raju et al., 1990) has been developed for ceramic matrix composites. This technique uses a plain weave classical laminate theory to predict the mechanical properties of ceramic matrix woven fabric composites. The model uses the material properties of fiber, the interface, and the matrix. It is developed by considering a typical representative fabric element of the composite. Within this fabric element, a repeating unit, termed as unit cell is identified. An analytical procedure is developed to determine the mechanical properties of a single plain weave fabric composite using the material properties of constituents. 
These properties can then be used to predict the mechanical properties of ceramic laminates fabricated by stacking these plain weave plies at various orientations.

The major objectives of this study were :

a) To test the analytical model for graphite/epoxy woven composite with known experimental results, and,

b) To extend the model for woven Nicalon fiber/SiC ceramic matrix composites with known experimental results.

\subsection{THE ANALYTICAL MODEL}

\subsubsection{Plain Weave - Classical Laminate Theory Model (PWCLT)}

Several models have been suggested for the theoretical analysis of woven fiberreinforced composites. These include three models suggested by Ishikawa and Chou(1982, 1982a, 1983), and a more recent model by Kuo and Chou(1991), which attempted to analyze woven ceramic matrix composites. The model suggested in this thesis differs from the Kuo and Chou(1991) model, which are :

i. The unit cell analyzed in the PWCLT model is one-quarter the size of the unit cell suggested by Kuo and Chou(1991).

ii. The PWCLT model attempts to take the influence of the interface into consideration, since the interface controls the mechanical properties of the composite to a large extent. The Kuo and Chou(1991) model does not take the interface into account. 
iii. The PWCLT model also attempts to take the volume fraction and packing density of the composite into account. Therefore, the effect of volume fraction and packing density can also be studied easily with this model.

Three common interlacing patterns are used in various fabric composites, as shown in Figure 5.1. The repeating units with side length $=\mathrm{L}$ are highlighted with darker lines. Since the model is developed for the plain weave ceramic matrix composites, the discussion here is be limited to the plain weave repeating cells. However, the model may easily be extended to the other types of interlacing patterns.

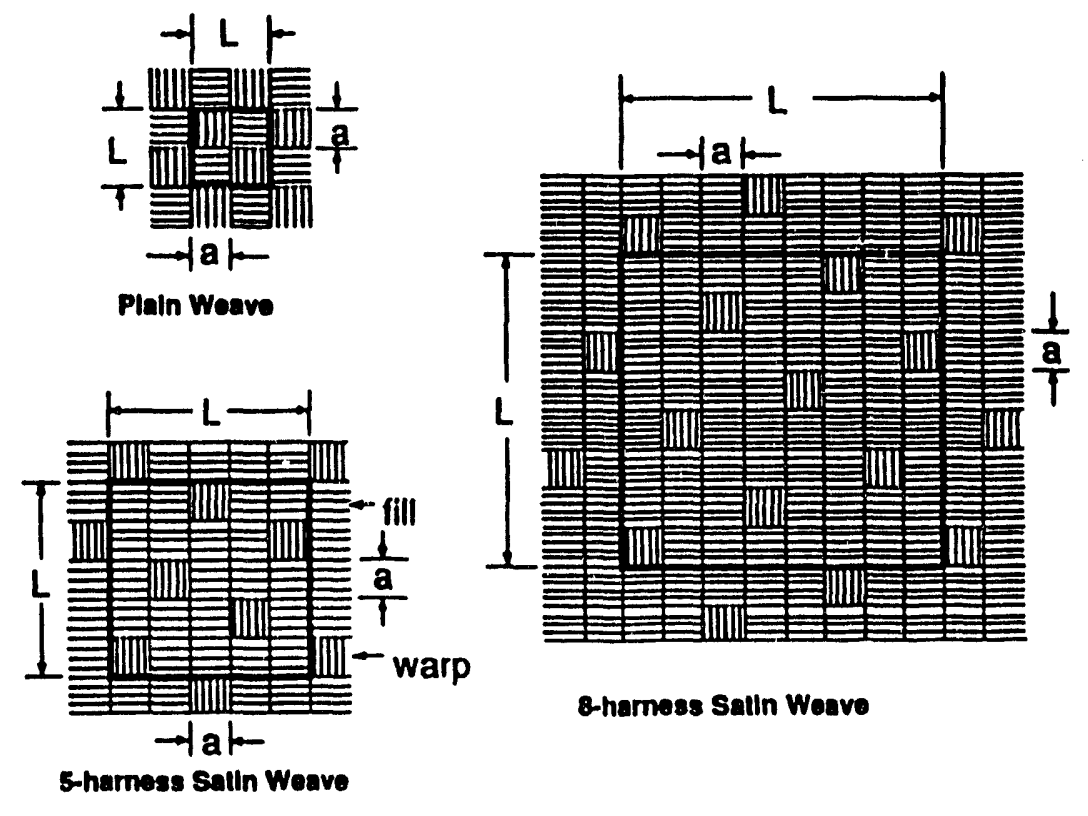

Figure 1. Common interlacing patterns used in various fabric composites 
Figure 5.2 shows the unit cell representation of the plain weave pattern. Each unit cell has two Fill tows (horizontal sets of fibers) and two Warp tows (vertical sets of fibers). The $\mathrm{x}$ and $\mathrm{y}$ directions are along the midplane of the unit cell. The tow thickness is assumed to be $h_{t}$, while the ply thickness is assumed to be $2 h$. The height of the matrix on the top and bottom of the unit cell therefore is $=\left(h-h_{\downarrow}\right)$. The unit cell may be divided into three regions each, along the $\mathrm{x}$ and $\mathrm{y}$ directions. There are two regions with a length of $a_{0}$ each where the properties of the unit cell are constant, while in the region with a length of $a_{u}$, the properties of the unit cell are assumed to be changing sinusoidally. The length $a_{u}$ is called the undulation length. Schematically, these three regions are shown as $0 \leq x \leq a_{0}, a_{0} \leq x \leq a_{2}$, and $a_{2} \leq x \leq a$ along the $x$ direction, and $0 \leq y \leq a_{0}, a_{0} \leq y \leq a_{2}$, and $a_{2} \leq y \leq a$ along the $y$ direction.

From the knowledge of the individual constituent properties of the fibers and the matrix, an off-axis stiffness matrix $\left(Q_{i j}\right)$ is obtained. By integrating $Q_{i j}$ along the height, a reduced inplane, coupling and bending stiffness matrix $\left(\mathrm{Qbar}_{\mathrm{ij}}\right)$ for the unit cell is obtained. This reduced stiffness matrix is further integrated along a volume element to provide the inplane $\left(A_{i j}\right)$, bending $\left(D_{i j}\right)$, and coupling $\left(B_{i j}\right)$ stiffness matrices for the unit cell. 


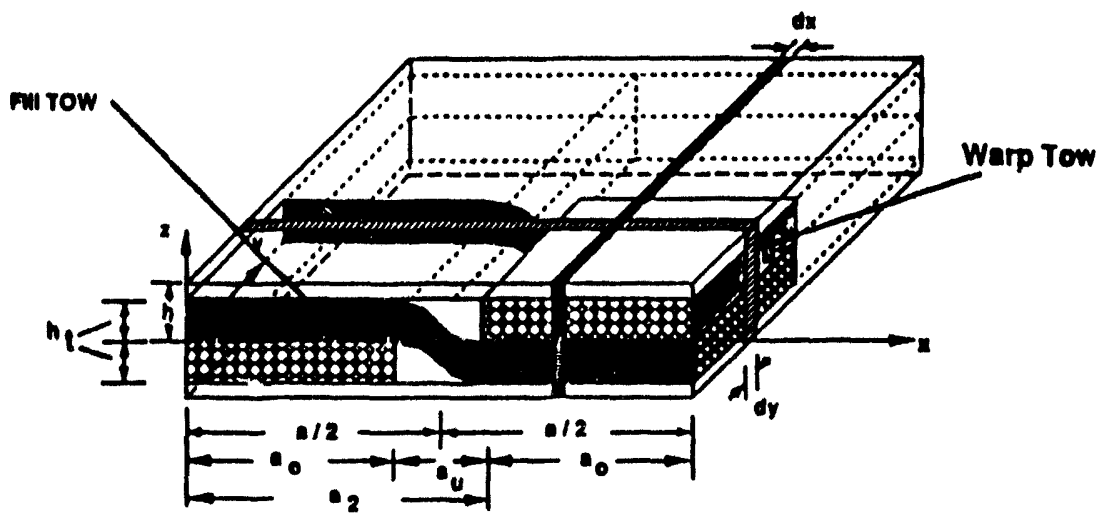

Figure 5. 2. Unit cell representation of the plain weave pattern

\subsubsection{Volume Fraction and Undulation length Computation}

From Figure 5.2, Volume of fill tows $=a\left(a-a_{4}\right) h_{1}=$ Volume of warp tows.

Therefore, Total fill + warp volume $=2 a\left(a-a_{u}\right) h_{4}$

If $V_{f}$ is the volume fraction, and $p_{d}$ is the packing density of the fibers,

then the volume of the fill + warp should be $=\left(2 h a^{2} V_{f} / p_{d}\right)=2 a\left(a-a_{u}\right) h_{t}$

or the undulation length $a_{u}=a\left\{1-\left(h / h_{d}\right)\left(V_{f} / p_{d}\right)\right\}$ 


\subsubsection{Boundary conditions for Fill and Warp fibers}

Along the $\mathrm{x}$-direction :

Region I : $0 \leq x \leq a_{0}$; Region II : $a_{0} \leq x \leq a_{2}$; Region III : $a_{2} \leq x \leq a$ Along the $y$-direction :

Region $1: 0 \leq y \leq a_{0}$; Region II : $a_{0} \leq y \leq a_{2}$; Region III : $a_{2} \leq y \leq a$

Fill Fibers :

For $0 \leq y \leq a_{0}$

$h_{1}(x)=h_{t}$

Region I

$h_{1}(x)=\left[1-\sin \{x-(a / 2)\}\left(\pi / a_{u}\right)\right]\left(h_{l} / 2\right)$

Region II

$h_{1}(x)=0$

Region III

For $\mathrm{a}_{2} \leq \mathrm{y} \leq \mathrm{a}$

$h_{1}(x)=0$

Region I

$h_{1}(x)=\left[1+\sin \{x-(a / 2)\}\left(\pi / a_{u}\right)\right]\left(h_{l} / 2\right)$

Region II

$h_{1}(x)=h_{t}$

Region III

Warp Fibers :

For $0 \leq \mathrm{x} \leq \mathrm{a}_{0}$

$h_{2}(y)=0$

Reyion I

$\mathrm{h}_{2}(\mathrm{y})=\left[1+\sin \{\mathrm{y}-(\mathrm{a} / 2)\}\left(\pi / \mathrm{a}_{\mathrm{u}}\right)\right]_{\left(\mathrm{h}_{\mathrm{l}} / 2\right)}$

Region II

$h_{2}(y)=h_{1}$

Region III 
For $\mathrm{a}_{2} \leq \mathrm{x} \leq \mathrm{a}$

$h_{2}(y)=h_{1}$

Region I

$\mathrm{h}_{2}(\mathrm{y})=\left[1-\sin \{\mathrm{y}-(\mathrm{a} / 2)\}\left(\pi / \mathrm{a}_{\mathrm{u}}\right)\right]\left(\mathrm{h}_{\mathrm{t}} / 2\right)$

Region II

$h_{2}(y)=0$

Region III

The $A_{i j}, B_{i j}$, and $D_{i j}$ matrices for the unit cell are derived as follows :

$\left.\left(A_{i j}, B_{i j}, D_{i j}\right)(x, y)=\int_{0}^{a_{0}}\left[\int Q_{i j}\left(1, Z, Z^{2}\right) d Z\right] d y+\int_{a_{0}}^{a_{2}}\left[\int Q_{i j} 1, Z, Z^{2}\right) d Z\right] d y$

$+\int_{a_{2}}^{a}\left[\int Q_{i j}\left(1, Z, Z^{2}\right) d Z\right] d y$

The average value of $A_{i j}=\frac{1}{a} \int_{0}^{a} A_{i j}(x) d x$ is derived as

$=2 Q_{i j}{ }^{M} h-2 Q_{i j}{ }^{M} h_{t}\left(1-\frac{a_{u}}{a}\right)+Q_{i j}{ }^{F} h_{t}\left(1-\frac{a_{u}}{a}\right)^{2}$ 


$$
\begin{aligned}
& +Q_{i j}{ }^{w} h_{t}\left(1-\frac{a_{u}}{a}\right)^{2}+\frac{h_{t}}{a} \frac{a_{0}}{a} \int_{a_{0}}^{a_{2}} Q_{i j}{ }^{F}(\phi) d x+\frac{h_{t}}{a}\left(1-\frac{a_{2}}{a}\right) \int_{a_{0}}^{a_{2}} Q_{i j}{ }^{F}\left(\phi^{\prime}\right) d x \\
& +\frac{h_{1}}{a} \frac{a_{0}}{a} \int_{a_{0}}^{a_{2}} Q_{i j}{ }^{w}(\theta) d y+\frac{h_{t}}{a}\left(1-\frac{a_{2}}{a}\right) \int_{a_{0}}^{a_{2}} Q_{i j}{ }^{w}\left(\theta^{\prime}\right) d y
\end{aligned}
$$

For the $\mathrm{B}_{\mathrm{ij}}$ coupling matrix, it can be derived to be $=0$, and there is no coupling between extension and bending.

The average value of $\mathrm{D}_{\mathrm{ij}}$ can be derived as $=\frac{1}{a} \int_{0}^{a} D_{i j}(x) d x$

$$
=Q_{i j}{ }^{M}\left[\frac{8}{3}\left(\frac{a_{0}}{a}\right)^{2}\left(h^{3}-h_{t}{ }^{3}\right)+\left(\frac{a_{u}}{a}\right)^{2} \frac{2 h^{3}}{3}\right]+\left(Q_{i j}{ }^{F}+Q_{i j}{ }^{W}\right) \frac{4}{3} h_{l}{ }^{3}\left(\frac{a_{0}}{a}\right)^{2}
$$

$$
+Q_{i j}{ }^{M}\left[\frac{a_{0}}{a} \frac{1}{a} \int_{a_{0}}^{a_{2}}\left\{\frac{\left(h_{3}-h_{t}\right)^{3}+2 h^{3}-h_{3}{ }^{3}}{3}+\frac{\left(h_{4}-h_{t}\right)^{3}+2 h^{3}-h_{4}{ }^{3}}{3}\right\} d x\right]
$$




$$
\begin{aligned}
& +\frac{a_{0}}{a} \frac{1}{a} \int_{a_{0}}^{a_{2}}\left[Q_{i j}{ }^{W}(\theta) \frac{h_{1}{ }^{3}-\left(h_{1}-h_{t}\right)^{3}}{3}+Q_{i j}{ }^{W}\left(\theta^{\prime}\right) \frac{h_{2}{ }^{3}-\left(h_{2}-h_{t}\right)^{3}}{3}\right] d y \\
& +\frac{a_{0}}{a} \frac{1}{a} \int_{a_{0}}^{a_{2}}\left[Q_{i j}{ }^{F}(\phi) \frac{h_{3}{ }^{3}-\left(h_{3}-h_{t}\right)^{3}}{3}+Q_{i j}{ }^{F}\left(\phi^{\prime}\right) \frac{h_{4}{ }^{3}-\left(h_{4}-h_{t}\right)^{3}}{3}\right] d x
\end{aligned}
$$

The details of the proilem formulation has been presented by Raju et al.(1990).

\subsection{RESULTS OF THE ANALYTICAL MODEL}

The constituent material properties for Graphite/Epoxy and $\mathrm{SiC} / \mathrm{SiC}$ system are given in Table 5.1. The properties of the Graphite/Epoxy system were used to test the analytical model and the $\mathrm{SiC} / \mathrm{SiC}$ system properties were used to extend the model to ceramic matrix composites(CMC). Since all the constituent material properties for the $\mathrm{SiC} / \mathrm{SiC}$ system were not available, it was assumed that both the fibers as well as the matrix were isotropic. From transmission electron micrographs of the fiber, it could be reasonably assumed that the fiber properties were isotropic. This isotropic nature of the Nicalon fibers has also been assumed by the Kuo and Chou (1991) model. However, in ceramic matrix composites, the fiber contains a thin coating of pyrolytic carbon to facilitate the fibers to pull out from the matrix. The current model has been modified to 
take this factor into consideration. This was done by considering the fiber and coating as separate entities and calculating the equivalent properties of the fiber based on the coating thickness, as well as the individual fiber and coating properties. However, for more accurate calculations, it may be necessary to calculate the equivalent fiber properties using micromechanics equations. The basic calculations are shown below briefly.

The elastic modulus of the coated fiber may be calculated using rule of mixtures, considering that the uncoated fiber as well as the coating contribute to the elastic modulus.

$$
\begin{aligned}
& E_{\text {Coated Fiber }}=E_{F i b e r} V_{\text {Fiber }}+E_{\text {Coating }} V_{\text {Coating }} \\
& \text { Let } d_{0}=\text { diameter of fiber }+ \text { coating, and } \\
& d_{F}=\text { diameter of the coated fiber }
\end{aligned}
$$

For a coated fiber,

$$
\mathrm{V}_{\text {Fiber }}=\left(\mathrm{d}_{\mathrm{F}} / \mathrm{d}_{0}\right)^{2} ; \mathrm{V}_{\text {Coating }}=1-\left(\mathrm{d}_{\mathrm{F}} / \mathrm{d}_{0}\right)^{2}
$$

Individual properties are taken as follows (Lowden and Stinton, 1992) :

$$
\begin{aligned}
& E_{\text {Fiber }}=130 \mathrm{GPa} ; \mathrm{E}_{\text {Coating }}=7.5 \mathrm{GPa} \\
& \nu_{\text {Fiber }}=0.20 ; \nu_{\text {Coating }}=0.10
\end{aligned}
$$

For calculating the equivalent Poisson's ratio,

$$
\begin{aligned}
& \nu_{\text {Fiber }}=\delta_{1} / d_{F}, \text { where } \delta_{1}=\text { contraction of the fiber in the } y \text { direction, or } \\
& \delta_{1}=\nu_{\text {Fiber }} d_{F}
\end{aligned}
$$

Similarly, if $\delta_{2}=$ contraction of the coating in the y direction,

$$
\delta_{2}=\nu_{\text {Coating }}\left(\mathrm{d}_{0}-\mathrm{d}_{\mathrm{F}}\right)
$$


Therefore,

$$
v_{\text {Effective }}=\frac{\left(\delta_{1}+\delta_{2}\right)}{d_{0}}
$$

Now, assuming the fiber to be isotropic,

$$
G_{\text {CoatedFiber }}=\frac{E_{\text {CoatedFiber }}}{2\left(1+v_{\text {Effective }}\right)}
$$

Correction for volume fraction of fiber in the composite due to the coating :

$\mathrm{V}_{\text {Coated Fiber }}=\mathrm{V}_{\text {Uncoated Fiber }}\left(\mathrm{d}_{0} / \mathrm{d}_{\mathrm{F}}\right)^{2}$

The equivalent fiber properties were calculated as a function of the coating thickness. This is given in Table 5.2.

\begin{tabular}{|c|c|}
\hline Graphite/Epoxy & $\mathrm{SiC} / \mathrm{SiC}$ \\
\hline Fiber Properties & Fiber Properties \\
\hline $\begin{array}{l}\mathrm{E}_{11}=151 \mathrm{GPa} \\
\mathrm{E}_{22}=\mathrm{E}_{33}=13.8 \mathrm{GPa} \\
\nu_{12}=\nu_{13}=0.25 \\
\nu_{23}=0.40 \\
\mathrm{G}_{12}=\mathrm{G}_{13}=\mathrm{G}_{23}=7.0 \mathrm{GPa}\end{array}$ & $\begin{array}{c}\mathrm{E}=\text { Properties taken } \\
\nu=\text { from equivalent } \\
\mathrm{G}=\text { fiber properties } \\
\\
(\text { Table } 5.2)\end{array}$ \\
\hline Matrix Properties & Matrix Properties \\
\hline $\begin{array}{l}\mathrm{E}=3.5 \mathrm{GPa} \\
\nu=0.35 \\
\mathrm{G}=1.276 \mathrm{GPa}\end{array}$ & $\begin{array}{l}\mathrm{E}=300 \mathrm{GPa} \\
\nu=0.18 \\
\mathrm{G}=127 \mathrm{GPa}\end{array}$ \\
\hline
\end{tabular}

Table 5.1. Constituent Material Properties 
Table 5.2. Equivalent Fiber Properties as a function of coating thickness

\begin{tabular}{||c|c|c|c|c|c||}
\hline \hline \multirow{2}{*}{$\begin{array}{c}\text { Equivalent } \\
\text { Properties }\end{array}$} & \multicolumn{5}{|c||}{ Coating Thickness, $\mu \mathrm{m}$} \\
\cline { 2 - 6 } & 0.1 & 0.2 & 0.3 & 0.4 & 0.5 \\
\hline $\mathrm{E}_{\text {Fiber }}, \mathrm{GPa}$ & 126.8 & 123.7 & 120.7 & 117.9 & 115.1 \\
\hline $\mathrm{G}_{\text {Fiber }}, \mathrm{GPa}$ & 52.9 & 51.6 & 50.5 & 42.3 & 48.2 \\
\hline$\nu_{\text {Effective }}$ & 0.1987 & 0.1974 & 0.1962 & 0.1949 & 0.1938 \\
\hline $\mathrm{V}_{\text {Fiber Fraction }}$ & 0.4107 & 0.4216 & 0.4326 & 0.4438 & 0.4551 \\
\hline
\end{tabular}

A computer program PWCLT written in FORTRAN was used for calculating the properties of a single lamina of the fabric composite. The input/output format for using this program is essentially simple, and is given in Table 5.3.

The results obtained for the Graphite/Epoxy system are given in Table 5.4. Two different packing densities were tested for the Graphite/Epoxy case : $p_{d}=0.8$, and $p_{d}$ $=0.74$. 
Table 5.3. Input/Output format for program PWCLT

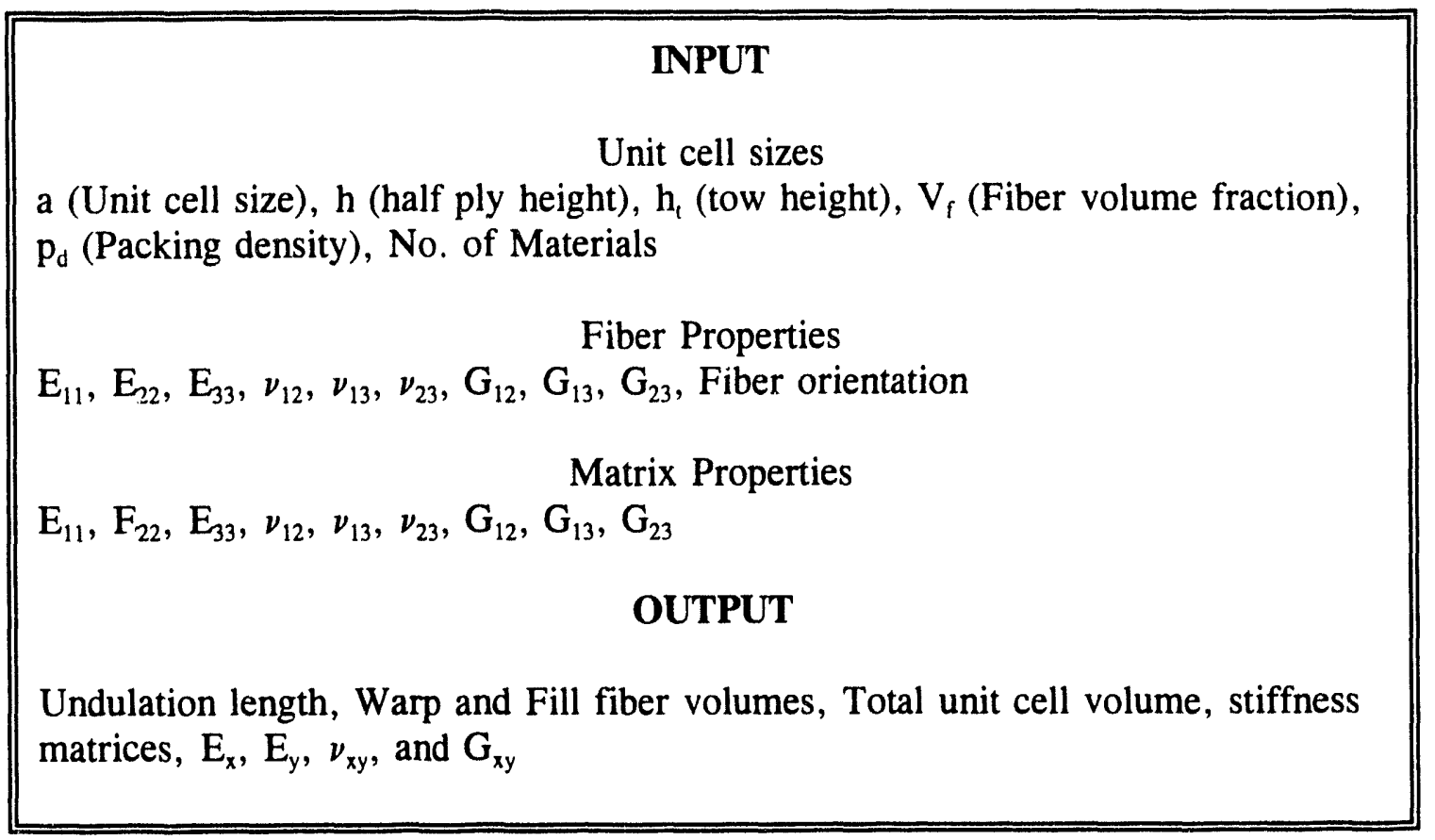

The program PWCLT was then tested for the case of the $\mathrm{SiC} / \mathrm{SiC}$ composite. The results are shown in Table 5.5.

Table 5.4. Comparison of PWCLT model results with experimental results for Graphite/Epoxy fabric composite.

\begin{tabular}{|c|c|c|c|}
\hline \multirow{2}{*}{$\begin{array}{l}\text { Overall } \\
\text { Composite } \\
\text { Properties }\end{array}$} & \multicolumn{2}{|c|}{ PLAIN WEAVE CLT $\left(V_{f}=0.64\right)$} & \multirow{2}{*}{$\begin{array}{c}\text { NASA Langley } \\
\text { Experimental } \\
\text { Values } \\
\left(\mathrm{V}_{\mathrm{f}}=0.64\right) \\
\text { (Raju et al., 1990) }\end{array}$} \\
\hline & $\begin{array}{c}\mathrm{p}_{\mathrm{d}}=0.8 \\
\mathrm{a}_{\mathrm{u}}=0.0111 \\
\text { (Raju }\end{array}$ & $\begin{array}{l}\mathrm{p}_{\mathrm{d}}=0.74 \\
\mathrm{a}_{\mathrm{u}}=0.0075 \\
1990)\end{array}$ & \\
\hline $\mathrm{E}_{\mathrm{x}}, \mathrm{GPa}(\mathrm{Msi})$ & $59.0(8.56)$ & $65.7(9.528)$ & $62.95(9.13)$ \\
\hline $\mathrm{E}_{\mathrm{y}}, \mathrm{GPa}(\mathrm{Msi})$ & $59.0(8.56)$ & $65.7(9.528)$ & $60.88(8.83)$ \\
\hline$\nu_{x y}$ & 0.0516 & 0.0489 & 0.11 \\
\hline $\mathrm{G}_{\mathrm{xy}}, \mathrm{GPa}(\mathrm{Msi})$ & $5.8(0.837)$ & $6.14(0.890)$ & - \\
\hline
\end{tabular}


Table 5.5. Comparison of PWCLT model results with experimental results for $\mathrm{SiC} / \mathrm{SiC}$ fabric composite.

\begin{tabular}{|c|c|c|c|c|}
\hline \multirow[t]{2}{*}{$\begin{array}{l}\text { Overall } \\
\text { Composite } \\
\text { Properties }\end{array}$} & \multirow[t]{2}{*}{$\begin{array}{c}\operatorname{PWCLT}\left(\mathrm{V}_{\text {Fiber }}=0.40\right)^{*} \\
\mathrm{p}_{\mathrm{d}}=0.88\end{array}$} & \multicolumn{3}{|c|}{$\begin{array}{l}\text { Experimental Values } \\
\left(\mathrm{V}_{\text {Fiber }}=0.4-0.5\right) \\
\mathrm{p}_{\mathrm{d}}=0.85-0.90\end{array}$} \\
\hline & & $\mathrm{Ko}^{* *}$ & DuPont $^{* * *}$ & $\begin{array}{c}\text { Present } \\
\text { work }\end{array}$ \\
\hline $\mathrm{E}_{\mathrm{x}}, \mathrm{GPa}(\mathrm{Msi})$ & 219.2(31.79) & $240(34.8)$ & $213.7(31)$ & $185(26.8)$ \\
\hline $\mathrm{E}_{\mathrm{y}}, \mathrm{GPa}(\mathrm{Msi})$ & 219.2(31.79) & $240(34.8)$ & $213.7(31)$ & $185(26.8)$ \\
\hline & 0.185 & 0.19 & 0.18 & - \\
\hline$\sigma_{x y}, \sigma_{0}$ & $92.46(13.41)$ & $22(3.2)$ & - & - \\
\hline
\end{tabular}

* Assumptions are : (0/90) repeat $_{\text {layup ; Fiber coating }=0.1 \mu \mathrm{m}}$

** Ko (1989)

*** Headinger et al., $(1991,1991 a)$

Single lamina properties were also calculated for changing coating thickness on the fibers. A plot of the coating thickness versus the Elastic modulii $E_{x}$ and $E_{y}$ as well as the Shear modulus is plotted in Figure 5.3. The change in Poisson's ratio with coating thickness is also plotted, which is given in Figure 5.4. 


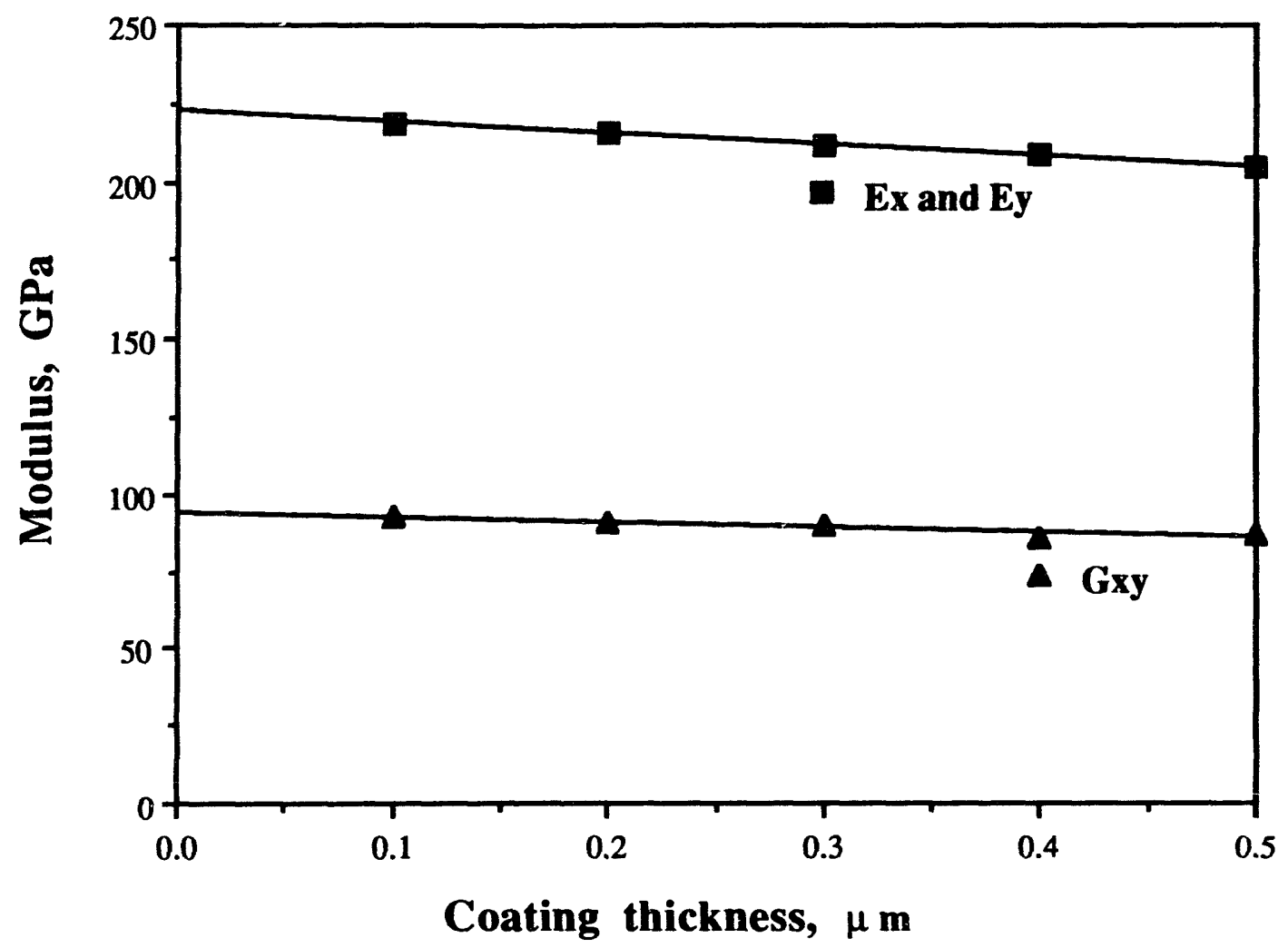

Figure 5.3. Predicted single lamina properties of CVI SiC/SiC composites vs. fiber coating thickness using program PWCLT 


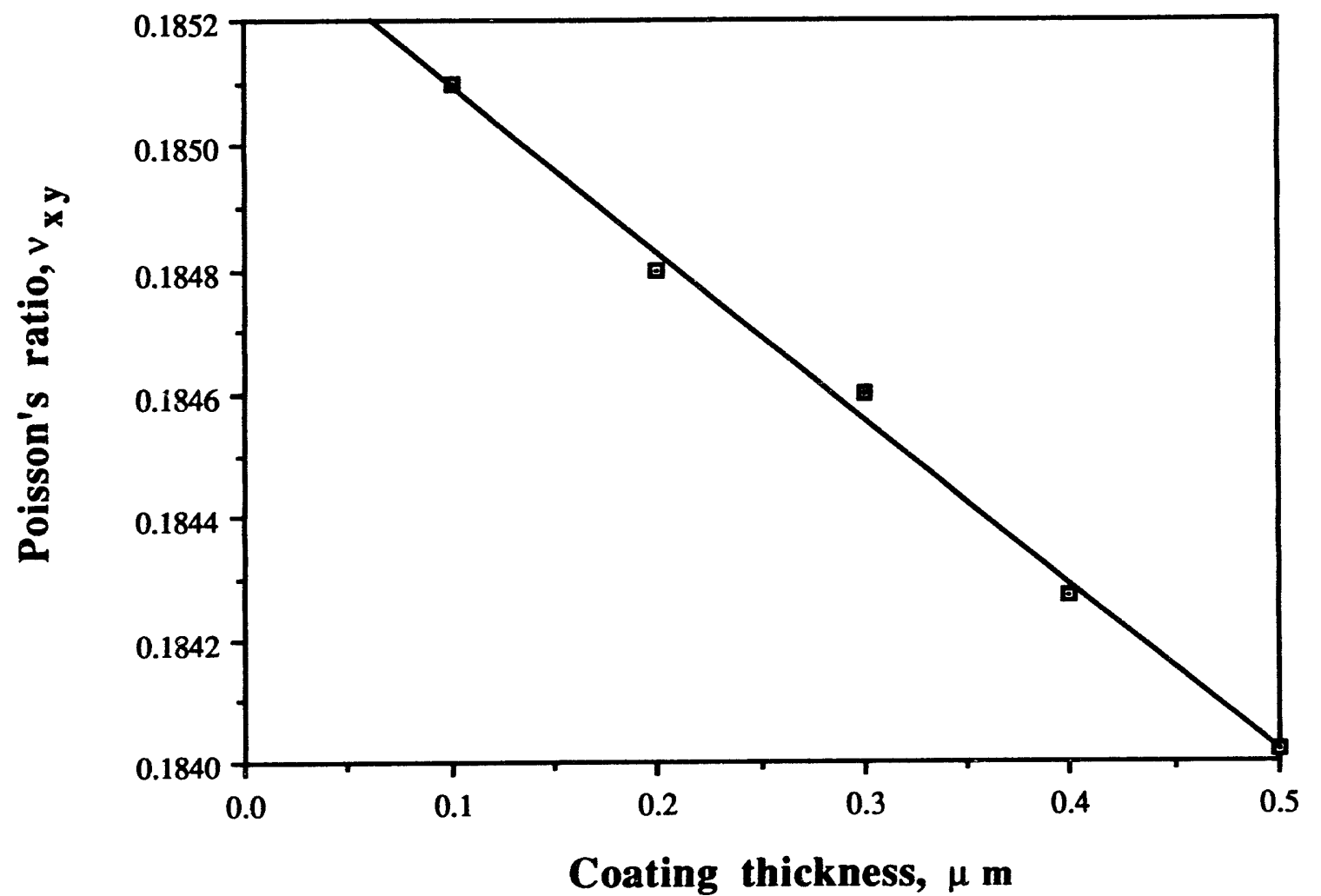

Figure 5.4. Predicted Poisson's ratios of CVI SiC/SiC composites vs fiber coating thickness using program PWCLT 


\title{
CHAPTER 6
}

\author{
DISCUSSION
}

\subsection{EXPERIMENTAL}

\subsubsection{CHARACTERIZATION OF THE LASER EXTENSOMETER}

From Figures 4.1 through 4.3 for short term period evaluation, it may be observed that the gaps measured simultaneously by the Laser extensometer and the standard micrometer matched up to the temperature of investigation, in this case being $1000^{\circ} \mathrm{C}$. The maximum deviation at $1000^{\circ} \mathrm{C}$ was only $2.565 \mu \mathrm{m}$ (Table 4.5 ). This showed that the laser extensometer can be effectively used to measure the strains for brittle materials at elevated temperatures. However, Gao(1990) has observed that for long term observations, the gap measured by the laser extensometer varied with time. This was found to be random and could be attributed to the air density fluctuations that develop in the path of the laser beam. Since the index of refraction of air depends on its density, such fluctuation leads to small random variations in the gap length measurements. 


\subsubsection{MECHANICAL BEHAVIOR OF FCVI AND ICVI SiC/SiC COMPOSITES}

From the test results given in Table 4.6 and from test curves and test comparison plots given in Figures 4.4 through 4.25 , the general mechanical behavior of FCVI and ICVI SiC/SiC composites under various test conditions (Room temperature, Room temperature after exposure to thermal shock, Room temperature after exposure to oxidation atmosphere, and $1000^{\circ} \mathrm{C}$ ) can be summarized in a Table form. This is given in Table 6.1.

From Figures 4.4 through 4.18 , it could be observed that the stress-strain plots generally exhibited an initial elastic region, followed by a non-linear region with a smooth slope change. It was also observed that FCVI composites exhibited average failure strains of 0.6 to $1.15 \%$, while ICVI composites exhibited failure strains in the range of 0.13 to $0.3 \%$. One of the major differences in the materials under investigation is the interfacial coating thickness, $(0.3 \mu \mathrm{m}$ coating thickness in the case of FCVI composites and $0.1 \mu \mathrm{m}$ coating thickness in the case of ICVI composites). Therefore one of the reasons for the differences in strain to failure could be the differences in the interfacial coating thickness between the FCVI and ICVI composites. From Table 3.1, it could also be seen that the processing conditions are different for the FCVI and ICVI composites. This could also have influenced the properties of these composites.

From Figures 4.9 and 4.10 , it could be seen that the FCVI $(0 / 30 / 60)_{\text {repeat }}$ layup is stronger than the FCVI $(0 / 45 / 45 / 0)_{\text {repeat }}$ at both RT as well as at $1273^{\circ} \mathrm{K}\left(1000^{\circ} \mathrm{C}\right)$. 
Table 6.1. General Mechanical Behavior under various test conditions (RT, RT/TS, $\mathrm{RT} / \mathrm{OX}, 1000^{\circ} \mathrm{C}$ ) for $\mathrm{SiC} / \mathrm{SiC}$ composites

\begin{tabular}{|c|c|}
\hline $\begin{array}{c}\text { FCVI (ORNL : } 0.3 \mu \mathrm{m} \text { nominal interfacial } \\
\text { coating) }\end{array}$ & $\begin{array}{c}\text { ICVI (DuPont : } 0.1 \mu \mathrm{m} \text { nominal interfacial } \\
\text { coating) }\end{array}$ \\
\hline $\begin{array}{l}\text { Stress-strain curves at all conditions shows } \\
\text { linear elastic region followed by a non- } \\
\text { linear region with a smooth slope change. }\end{array}$ & Same as FCVI composites \\
\hline $\begin{array}{l}\text { Strain to failure in the range of } 0.6 \text { to } \\
1.15 \% \text {. }\end{array}$ & Strain to failure in the range of 0.13 to $0.3 \%$. \\
\hline $\begin{array}{l}\text { Strength values remained somewhat similar } \\
\text { for all the test conditions. }\end{array}$ & $\begin{array}{l}\text { Strength decreased slightly from RT up to } \\
1000^{\circ} \mathrm{C} \text {. }\end{array}$ \\
\hline $\begin{array}{l}\text { Average initial modulus of the material } \\
\text { increased slightly as the test conditions are } \\
\text { varied from RT to } 1000^{\circ} \mathrm{C} \text {. This is } \\
\text { probably controlled by the interfacial bond } \\
\text { and the nature of processing. }\end{array}$ & $\begin{array}{l}\text { Average initial modulus of the material } \\
\text { decreased as the test conditions are varied from } \\
\text { RT to } 1000^{\circ} \mathrm{C} \text {. }\end{array}$ \\
\hline $\begin{array}{l}\text { The area under the stress-strain curves } \\
\text { showed a slightly increasing trend as the test } \\
\text { conditions are varied from RT and } 1000^{\circ} \mathrm{C} \text {. } \\
\text { This showed that the material was more } \\
\text { strain tolerant at elevated temperatures than } \\
\text { at RT. }\end{array}$ & $\begin{array}{l}\text { Not much change in the area under the stress- } \\
\text { strain curve as the test conditions are varied } \\
\text { from RT to } 1000^{\circ} \mathrm{C} \text {. }\end{array}$ \\
\hline \multirow[t]{2}{*}{$\begin{array}{l}\text { Strength of }(0 / 30 / 60)_{\text {repeat }}>\text { Strength of } \\
(0 / 45 / 45 / 0)_{\text {repeat }} \text { under all test conditions. }\end{array}$} & $\begin{array}{l}\text { Stiffness of }(0 / 90)_{\text {repeat }}>\text { Stiffness of } \\
(0 / 45 / 45 / 0)_{\text {repeat }} \text { at RT. }\end{array}$ \\
\hline & Specimen volume effect (?) \\
\hline
\end{tabular}

From Figures 4.16 and 4.17 , it could be observed that the 0/45 layup ICVI composite is stiffer than the $0 / 45$ layup FCVI composite. Since the interfacial coating thickness could be one of the major factors affecting the strain to failure (from the previous argument), it could be concluded that the change in stiffness could be due to the differences in coating thickness rather than the differences in the process parameters. In addition, since the interfacial sliding stress is indirectly proportional to the interfacial coating thickness (Thouless and Evans, 1988; Evans, 1990), it could be concluded that the interfacial sliding stresses in ICVI composites are higher than that observed in FCVI 
composites. Therefore, to extend this argument, the initial modulus of the stress-strain curves may be controlled by the interfacial coating thickness.

However, it has to be noted that FCVI composites are processed at higher temperatures than ICVI composites. The residual stress-strain states at the fiber-matrix interfaces are also such that the fibers are in residual tension while the matrix is in residual compression (Rice 1981, 1985), due to the mismatches between the coefficient of thermal expansion of the fiber and matrix. At elevated temperatures (close to the processing temperature), these residual stresses might tend to get relaxed, leading to easier fiber-matrix debonding. In the case of FCVI materials due to the fiber-matrix debonding, more fibers might be carrying the load in the case of tests carried out at elevated temperatures than at room temperature, thereby improving the initial modulus slightly (Table 4.6 and Figures 4.5 through 4.8$)$ of specimens tested at $1273^{\circ} \mathrm{K}\left(1000^{\circ}\right.$ C) as compared to room temperature. However, in the case of ICVI composites, even though the fiber-matrix debonding might be promoted by exposure to elevated temperatures, it could also possibly damage the fibers (especially if the processing temperature is lower than $1273^{\circ} \mathrm{K}$ or $1000^{\circ} \mathrm{C}$ ), thus leading to a drop in the initial modulus of these materials (Table 4.6 and Figures 4.11 through 4.13).

From Figure 4.18, it can be observed that there might be a volume effect on the stress-strain behavior of $\mathrm{SiC} / \mathrm{SiC}$ composites fabricated through the ICVI process (120 $\mathrm{mm}$ and $76 \mathrm{~mm}$ gage length). Another study similar to the present work carried out at Du Pont(Headinger et al., $1991 ; 1991$ a) indicated slightly higher strength levels for ICVI $\mathrm{SiC} / \mathrm{SiC}$ composites compared to the results in the current study under all test 
conditions. Here, it should be noted that the tensile specimens used in the current study are much smaller compared to the tensile coupons used in the study cited (Headinger et al., 1991 ; 1991a). We feel that the test volume of the sample may play a role in controlling the effective densification of the composite, thus indirectly controlling the tensile strength obtained. However, due to the limited number of specimens tested with the different volume (120 mm gage length), it may be necessary to test more specimens to validate this assumption.

For the FCVI composites, the strength values for the same layup on an average remained somewhat similar under different test conditions. This could be seen quite clearly in Figures $4.19,4.20$ and 4.23. However, for the ICVI composites, the strength values showed a slight decrease from room temperature up to $1273^{\circ} \mathrm{K}$ (Figures 4.21 , 4.22 and 4.23).

From Figures 4.5 through 4.8 and 4.25 , it could be concluded that for the same layup in FCVI material, the initial modulus increased slightly when the test conditions were varied from room temperature, room temperature after thermal shock, room temperature after oxidation, and $1273^{\circ} \mathrm{K}$.

In the case of ICVI composites, it is observed in the current work that there is a tendency for the initial modulus of the stress-strain curves to reduce as a function of testing conditions (Figures 4.11 through 4.13 and 4.25). Similar stress-strain behavior has also been observed by Headinger et al., (1991, 1991a) who investigated the properties of $(0 / 90)_{\text {repeat }}$ layup ICVI composites as function of different test conditions. They observed that the initial modulus of the stress-strain curves decreased as a function 
of temperature as well as a function of oxidation treatment, which possibly means that the interfacial sliding stress is decreasing as a function of test conditions.

A comparison of the results for the $(0 / 30 / 60)_{\text {repeat }}$ layup FCVI composites shows that the average tensile strength in the present study for the FCVI $(0 / 30 / 60)$ lay-up falls within the range of tensile strength reported by Caputo et al., (1987). In the case of ICVI (0/90) composites, the tensile strength obtained in the current study are slightly lower than those reported by Headinger et al. $(1991,1991$ a) but match the results reported by Akimune et al. (1991). However, it must be noted that Caputo et al., only reported results from one test and pure uniaxial tests tend to produce strength levels lower than that reported from flexural tests.

\subsubsection{MECHANICAL BEHAVIOR vS. MICROSCOPY OF FCVI AND ICVI SiC/SiC COMPOSITES}

Table 6.2 is a summary of the results of the fracture surface investigation of FCVI and ICVI composites under various test conditions as observed from Figures 4.27 through 4.46, while Table 6.3 attempts to summarize the possible effects of interfacial coating on the mechanical behavior of the $\mathrm{SiC} / \mathrm{SiC} \mathrm{CMC}$ system based on both the mechanical behavior and fracture surface results.

Findings of the Transmission electron microscopy work on the SiC/SiC system based on Figures 4.47 through 4.57 are given in Table 6.4. Based on Tables 6.1 through 6.4, the possible factors controlling the failure processes in $\mathrm{SiC} / \mathrm{SiC} \mathrm{CVI}$ composites can 
be derived, which are listed in Table 6.5.

Based on the above experimental results, we feel that the initial elastic region in the stress-strain curves in these composites are probably controlled by matrix cracking/partial fiber-matrix debonding processes. The secondary non-linear region is probably controlled by fiber pullout, crack deflection, and fiber-bridging mechanisms. These conclusions also match the findings of several other researchers (Lowden and More, 1990; Caputo et al. 1987; Dauchier et al. 1985; Evans 1990; Evans and Marshall, 1990, 1989, and 1988). Fractographic analyses as seen in Figures 4.28 through 4.37 for FCVI composites show clearly that toughening in FCVI composites is through matrix cracking, fiber-matrix debonding, crack deflection, and blunting followed by extensive fiber pullout and crack bridging. From Figures $4.39,4.40$ and 4.44 in the case of ICVI composites, it can be seen that the amount pullout in ICVI composites is rather limited. Therefore, the toughening in $\mathrm{ICV}_{\boldsymbol{1}}$, usites is more due to matrix cracking, crack deflection, and to a lesser extent due to fiber pullout.

In the cases where the slope of the stress-strain curves are observed to be changing gradually with no clear separation between the linear and non-linear regions, the only explanation could be that fiber pullout could be occurring from the beginning of the fracture process itself, leading to a gradual change in the slope of the stress-strain curve.

The stress-strain behavior is also directly related to the degree of infiltration (and therefore porosity) caused by the different layups. From Figure 4.23, it can be observed that one layup of the FCVI or ICVI composite is slightly stronger than another layup. 
Table 6.2. General Fracture Surface Features of $\mathrm{SiC} / \mathrm{SiC} \mathrm{CVI}$ composites under various test conditions (RT, RT/TS, RT/OX, $1000^{\circ} \mathrm{C}$ )

\begin{tabular}{|c|c|}
\hline $\begin{array}{l}\text { FCVI Composites }(0.3 \mathrm{~mm} \text { nominal interfacial } \\
\text { coating thickness) }\end{array}$ & $\begin{array}{l}\text { ICVI Composites ( } 0.1 \mathrm{~mm} \text { nominal interfacial } \\
\text { coating thickness) }\end{array}$ \\
\hline \multicolumn{2}{|c|}{$\begin{array}{l}\text { In general, fibers oriented in } 30,45 \text {, and } 60 \text { direction (depending upon the layup) showed a lot of } \\
\text { fiber pull-out. }\end{array}$} \\
\hline $\begin{array}{l}\text { Degree of pull-out in FCVI composites is found } \\
\text { to be quite significant for fibers in all directions. }\end{array}$ & $\begin{array}{l}\text { Degree of pull-out in ICVI composites are found } \\
\text { to be less significant than FCVI composites. }\end{array}$ \\
\hline \multicolumn{2}{|c|}{$\begin{array}{l}\text { The initial elastic region in stress-strain curves is probably controlled by matrix cracking/partial } \\
\text { fiber-matrix debonding processes. The secondary non-linear region is controlled by fiber pull-out, } \\
\text { crack deflection, and fiber bridging mechanisms. }\end{array}$} \\
\hline $\begin{array}{l}\text { Toughening in FCVI composites is through } \\
\text { matrix cracking/limited fiber matrix debonding, } \\
\text { followed by extensive fiber pull-out, and crack } \\
\text { bridging. }\end{array}$ & $\begin{array}{l}\text { Toughening in ICVI composites is through a } \\
\text { combination of crack deflection, matrix cracking } \\
\text { and to a lesser extent due to fiber pull-out. }\end{array}$ \\
\hline \multicolumn{2}{|c|}{$\begin{array}{l}\text { In both the materials, there were areas of high porosity, especially between fiber layers. The cracks } \\
\text { could be traced to these areas of porosity, establishing the fact that these could be fracture initiation } \\
\text { sites. }\end{array}$} \\
\hline \multicolumn{2}{|c|}{$\begin{array}{l}\text { According to the classical laminate theory, a } 0 / 45 \text { layup should be stronger than a } 0 / 30 / 60 \text { layup. } \\
\text { However, experimentally, } 0 / 30 / 60 \text { is stronger than any other layup, possibly due to the influence of } \\
\text { higher porosity in the case of the } 0 / 45 \text { layups. }\end{array}$} \\
\hline $\begin{array}{l}\text { FCVI composites tested at elevated temperatures } \\
\text { display a different fracture mode as compared to } \\
\text { RT. These are, a large amount of pull-out of } \\
\text { fibers oriented in the } 0 \text { direction, coupled with } \\
\text { fiber-bridging and fiber-matrix debonding. }\end{array}$ & $\begin{array}{l}\text { ICVI composites tested at elevated temperatures } \\
\text { indicate very little pull-out in the fibers oriented } \\
\text { in the } 0 \text { direction. There is a lot of fiber-matrix } \\
\text { debonding and crack deflection by the pulled out } \\
\text { fibers. }\end{array}$ \\
\hline
\end{tabular}

Stinton (1991) has found that the ratio of theoretical to actual density of $(0 / 30 / 60)_{\text {repeat }}$ layup FCVI composites are higher $(0.85-0.88)$ than that of $(0 / 45 / 45 / 0)_{\text {repeat }}$ layup FCVI composites (0.75-0.80). From Figures 4.9 and 4.10, it can be observed that in FCVI materials, the $(0 / 30 / 60)_{\text {repeat }}$ layup is actually stronger than the $(0 / 45 / 45 / 0)_{\text {repeat }}$ layup at both $\mathrm{RT}$ and $1273^{\circ} \mathrm{K}\left(1000^{\circ} \mathrm{C}\right)$. Since the fractography indicated that fracture originated from the porosities between the weaves of fibers (Figures 4.29, 4.30 and 4.46), it could 
Table 6.3. Effect of Interfacial coating on Mechanical properties of CVI SiC/SiC composites under various test conditions.

\begin{tabular}{|c|c|}
\hline $\begin{array}{c}\text { FCVI Composites }(0.3 \mathrm{~mm} \text { nominal interfacial } \\
\text { coating thickness })\end{array}$ & $\begin{array}{c}\text { ICVI Composites }(0.1 \mathrm{~mm} \text { nominal interfacial } \\
\text { coating thickness })\end{array}$ \\
\hline
\end{tabular}

The strain to failure is controlled by the interfacial coating thickness, test conditions and the processing conditions.

FCVI composites exhibited an average strain of 0.6 to $1.15 \%$ under different test conditions. Average strain did not change significantly under the test conditions.

ICVI specimens exhibited an average strain of 0.13 to $0.3 \%$ under different test conditions. Average strain did not change significantly under the test conditions.

Under the same test conditions, there seems to be a direct correiationship between the interfacial coating thickness and the strain to failure, though this relationship may be non-linear.

Average initial modulus of FCVI composites < Average initial modulus of ICVI composites at RT, which is related to interfacial coating thickness, and processing conditions.

Strain tolerance and toughness of FCVI composites $>$ Strain tolerance and toughness of ICVI composites, due to thicker interfacial coating layer.

be concluded that the increased porosity due to infiltration difficulties in processing could weaken these composites. In the case of polymeric composites, according to classical laminate theory calculations, a $(0 / 45 / 45 / 0)_{\text {repeat }}$ layup composite would be stronger than a (0/30/60) repeat layup composite (Vaidyanathan, 1992). This is quite different in ceramic composites due to the difficulties in infiltration during processing.

The SEM micrographs of FCVI composites (Figures 4.35 through 4.37) show that the degree of pullout is comparatively lesser under RT/TS, and RT/OX test conditions as compared to FCVI composites tested at room temperature (Figure 4.27). However, FCVI composites tested at $1273^{\circ} \mathrm{K}$ (Figures 4.32 through 4.34) showed a greater degree of pullout and fiber-matrix debonding, especially in the fibers parallel to the tensile direction ( $0^{0}$ fibers). This supported our conclusion (from the discussion in the previous 
section) that the interfacial sliding stresses had actually reduced at $1273^{\circ} \mathrm{K}$ compared to RT.

Abbe and Chermant (1990) have also investigated the fiber-matrix interfacial bond strength as a function of temperature in ICVI composites. They observed that the frictional stress decreased as a function of temperature in these materials. Abbe and Chermant believed this reduction in frictional stress to be due to either the modification of the interface or the degradation of the fibers. In addition, they also found a linear relationship between the fiber strength and the ultimate strength of the composite. It could be concluded from our investigation that the fibers in ICVI materials might be getting degraded to a greater extent than the fibers in FCVI materials as a function of both the temperature and test conditions. This is probably a direct result of the thin interfacial coating thickness $(0.1 \mu \mathrm{m})$ in ICVI composites. In the current study, it was found that ICVI composites subjected to oxidation shows less pullout as compared to composites tested at RT (Figures 4.41-42). In addition, in ICVI composites tested at $1273^{\circ} \mathrm{K}\left(1000^{\circ} \mathrm{C}\right)$, possibly due to fiber degradation, the fiber pullouts as compared to RT were not significant, in spite of debonding being more(Figures $4.43,4.45)$. In contrast, in FCVI composites, possibly due to fiber degradation being less compared to ICVI composites, the fiber pull-out distances are higher in the case of composites tested at $1273^{\circ} \mathrm{K}$ (Figure 4.32 ) than those tested at RT. This is also probably reflected in the fact that the initial modulus of the FCVI composites tested at $1273^{\circ} \mathrm{K}$ is higher than the FCVI composites tested at RT.

In FCVI and ICVI composites subjected to oxidation, the fiber pullout processes 
are found to be affected considerably. It has been known that the carbon interfacial layer tends to be removed by the harsh environments and replaced by a layer of $\mathrm{SiO}_{2}$ after long term exposures at elevated temperatures in air(James et al., 1991; Pluvinage et al., 1991). However, it is also possible that this phenomenon could be occurring only in selective areas of the composite where the interface might have been exposed.

A comparison of the results for the $(0 / 30 / 60)_{\text {repeat }}$ lay-up FCVI composites in the present study shows that the average tensile strength for this lay-up falls within the range of tensile strength reported by Caputo et al. (1987). In the case of ICVI (0/90) composites, the tensile strongth obtained in the current study are slightly lower than those reported by Headinger et al. $(1991,1991 \mathrm{a}, 1992)$ but match the results reported by Akimune et al. (1991).

In the present study, the range of strain values in room temperature tests of FCVI $(0 / 30 / 60)$ and ICVI $(0 / 90)$ composites were also found to be in the same range as that reported by Caputo et al.(1987) and Headinger et al (1991, 1991a, 1992). This indicated that the test methodology used here produced comparable results both in the tensile strength and tensile strain values.

In general, in both the FCVI and ICVI composites, the CVI SiC matrix (Figures 4.47 and 4.51) was found to contain a columnar microstructure with the $\mathrm{c}$ axis normal to the fiber surface. The columnar grains contained a high density of rotational twins. This has also been reported by Stinton et al., (1990) who did some of the pioneering work on the structure of CVI SiC/SiC composites. The pyrolytic carbon coating was found to be amorphous in nature (as seen in Figure 4.50 ). Between two fibers, the matrix 
Table 6.4. Transmission electron microscopy (TEM) results of CVI SiC/SiC Composites

\begin{tabular}{l} 
In general, in both FCVI and ICVI composites, the CVI SiC matrix is seen to have \\
a columnar microstructure with the c axis normal to the fiber surface. The \\
columnar grains contained a high density of rotational twins. \\
Between 2 fibers, the matrix grain size varied from a fine structure to a columnar \\
structure. The columnar grain structure was observed in the center region between \\
the fibers and the fine structure was observed near the fibers. The columnar grain \\
structure also contained porous areas. \\
The effects of mechanical working were seen in the micrograph of a specimen \\
prepared from the fracture surface. \\
\hline Fiber-matrix debonding could be observed in the TEM micrograph of a specimen \\
prepared from the fracture surface of a composite specimen tested at elevated \\
temperatures. \\
\hline $\begin{array}{l}\text { Composites tested at RT after exposure to oxidizing atmosphere showed effects of } \\
\text { oxidation on the interface in specimens prepared from the fracture surface. }\end{array}$
\end{tabular}

grain structure varied from a very fine structure (Figure 4.51) to a columnar grain structure. The columnar grain structure was observed in the region between the fibers (Figure 4.55). The center of the matrix area was also observed to contain porous areas (Figure 4.55).

The matrix grain structure has been reported to be a mixture of polytypes (Stinton et al., 1990) with the twinned areas showing cubic structure. From Figure 4.52, it can be seen that the diffraction pattern from the fine structure area showed (Figure 4.51) a cubic structure, while the twinned areas showed a mixture of different polytypes. This indicated the possibility of pockets of cubic structure separated by twinned areas.

The diffraction pattern from the fiber showed a partially crystalline structure (Figure 4.53). It has been reported by Maniette and co-workers (1989) that the fiber structure basically consists of small b-SiC crystallites held together in an amorphous 
Table 6.6. Possible factors controlling failure processes in $\mathrm{CVI} \mathrm{SiC/SiC} \mathrm{composites}$

\begin{tabular}{||ll|}
\hline$*$ & Interfacial (pyrolytic carbon) coating thickness \\
$*$ & Test temperature \\
$*$ & Test conditions \\
$*$ & Density of infiltration \\
$*$ & Processing conditions \\
$*$ & The layup sequence \\
\hline
\end{tabular}

structure of aromatic carbon. The nature of the fiber and the amorphous nature of the structure holding the crystallites together can be seen clearly in Figure 4.50. Due to this type of structure, it could be safely assumed that the fibers are isotropic in nature.

One of the important findings in the current research was the fact that it was more informative to observe the interfacial characteristics of the material taken near the fracture surface compared to the bulk of the material. A comparison of the interfacial structure from Figures 4.54 and 4.55 which were taken from the bulk material and the fracture surface respectively, show different interfacial structures, proving this point. As mentioned earlier, Pluvinage et al., (1991) found that long term oxidation exposure changed the interface completely into $\mathrm{SiO}_{2}$. The TEM specimen (Figure 4.54) prepared from the bulk specimen showed that the interface had not been affected at all by the oxidation exposure. However, Figure 4.55 (sample prepared from the fracture surface) showed a diffuse interface which might be due to the effects of oxidation. Though effects such as sample thickness and specimen tilt could have played a role in the effect shown here, we believe that it is more interesting to study TEM specimens prepared from the fracture surface rather than from the bulk material.

TEM specimens prepared from the fracture surface of a FCVI composite tested 
at elevated temperatures clearly showed the debonding between the interfacial layer and the matrix (Figure 4.56). In an ICVI composite tested at room temperature, the TEM sample prepared from the fracture surface (Figure 4.57) showed a matrix with a polycrystalline nature after deformation. The matrix structure here, unlike the matrix structure from bulk material, did not appear to contain any twinned grains. These observations, once again, support the idea that we need to prepare TEM specimens from the fracture surface.

\subsection{ANALYTICAL}

\subsubsection{Graphite-Epoxy System}

Two different packing densities were tested for the Graphite/Epoxy case : $\mathrm{p}_{\mathrm{d}}=$ 0.8 , and $\mathrm{p}_{\mathrm{d}}=0.74$. It might be observed that the longitudinal and transverse modulii obtained using PWCLT are very close to the experimental values reported by NASA Langley for the Graphite/Epoxy system (Table 5.4). However, the Poisson's ratio reported and calculated by the PWCLT program varied by about $50 \%$. This discrepancy may be due to the fact that experimental evaluation of Poisson's ratio is extremely difficult especially when these values are very small and may lead to erroneous results. Experimental values for shear modulus for Graphite/Epoxy were not available during the course of this study. 


\subsubsection{SiC/SiC System}

From Table 5.5, it may be observed that the modulii as well as the Poisson's ratio obtained with the Program PWCLT are close to the experimental values reported in the literature. It could also be observed that the shear modulus calculated by the present model (92.46 GPa) matches very well with the values of shear modulus calculated by the Kuo and Chou (1991) model (95 GPa). The shear modulus of $\mathrm{SiC} / \mathrm{SiC}$ composites has recently been determined experimentally by Steffier (1993) to be $75.8 \mathrm{GPa}$. Though this property has been determined for a composite with a eight harness satin-weave interlacing pattern, it is quite comparable with the shear modulus values calculated by the present model.

However, there are some unresolved issues. Firstly, the fiber, though isotropic, may not turn out to be isotropic after it has been coated with pyrolytic carbon, which is anisotropic. Secondly, several researchers have reported that the fibers lose their strength after exposure to the processing conditions (Stinton et al., 1990). Further, the exact values of the fiber properties after processing are not available, and can only be guessed. Thirdly, it has been reported that the modulus in $\mathrm{SiC} / \mathrm{SiC}$ composites is influenced by the density of the composite itself (Headinger et al., 1991, 1991a; Riccitiello et al., 1991). The differences in the predicted elastic properties and the experimental values may be due to all the above reasons. As seen from Table 5.2, the tnickness of the pyrolytic carbon coating affects the equivalent fiber properties quite drastically. Additionally, the experimental modulus values in the current studies are derived from only a few tests. 
More experiments could help in resolving this issue.

From Figure 5.3, it may be observed that the predicted modulii values decrease with increasing coating thickness, which is directly related to the fiber reinforcement. Therefore, it can be seen that a fiber with a higher coating thickness can give rise to a composite which is tougher (more strain tolerant) as compared to a fiber with a smaller coating thickness. The Poisson's ratio also follows a similar trend with increasing coating thickness, though it is not affected in the same fashion as the modulii values.

The predicted model did match the mechanical property values reported in the literature by Headinger et al., (1991, 1991a) and Dauchier et al., (1985) very well, and was close to the values reported by Ko (1989) and Akimune et al., (1991) . Further, we believe that the program PWCLT can accurately predict the elastic properties provided accurate constituent property values are available. The PWCLT model can als $\approx$ predict the stress-strain behavior. However, in contrast to the Kuo and Chou model, the PWCLT model does not have the provision to accommodate progressive failure mechanisms of ceramic matrix composites. Efforts to extend the PWCLT model to include these effects are currently under way.

In this model, the calculation of the mechanical properties of fabric ceramic matrix composites only requires the accurate knowledge of the constituent material properties for the fiber and the matrix. It does not require the development of a finite element code and complex algorithms. Once the properties of a single plain weave are known, then the classical laminate theory can be used to predict the mechanical properties of a laminate fabricated by stacking single plain weave plies at various 
orientations. The effect of packing density and different fiber volume fractions may also be calculated using this model. 


\section{CHAPTER 7}

\section{CONCLUSIONS AND RECOMMENDATIONS}

\subsection{CONCLUSIONS}

\subsubsection{EXPERIMENTAL}

Based on the experimental results obtained for FCVI (ORNL) and ICVI (DuPont) $\mathrm{SiC} / \mathrm{SiC}$ ceramic matrix composites in the current research work, the following could be concluded.

1. The experimental set-up designed using the MTS 880 servohydraulic testing machine, ORNL self-aligning hydraulic grips, MAR M246 wedge grips, $\mathrm{PH}-17$ extension adaptors, single zone high temperature furnace and laser extensometry is effective in conducting uniaxial tensile tests for flat ceramic composite specimens at temperatures up to $1000^{\circ} \mathrm{C}$.

2. $\mathrm{SiC} / \mathrm{SiC} \mathrm{CVI}$ ceramic composites exhibit a tensile behavior showing both a linear elastic range and a non-linear region with a smooth slope change at the test conditions (Room temperature, $1000^{\circ} \mathrm{C}, \mathrm{RT} / \mathrm{Thermal}$ shock, and RT/oxidation exposure).

3. The stress-strain and toughening behavior of CVI composites depend upon the interfacial coating thickness, test temperature, test conditions, density of infiltration, 
processing conditions, and the lay-up sequence.

4. The average $\mathrm{RT}$ tensile strength of the $\mathrm{CVI} \mathrm{SiC/SiC}$ composite system for both FCVI (0/30/60 lay-up : $184 \pm 31 \mathrm{MPa} ; 0 / 45$ lar-up : $175 \pm 30 \mathrm{MF}$ ) and ICVI (0/45 lay-up : $163 \pm 35 \mathrm{MPa}$; and 0/90 lay-up : $151 \pm 20 \mathrm{MPa}$ ) composites is retained under the test conditions of $1000^{\circ} \mathrm{C}, \mathrm{RT} / \mathrm{Thermal}$ shock, and RT/Oxidation exposure.

5. The pyrolytic carbon coating is very effective in controlling the extent of fiber pull-out in this composite system.

6. The toughness in $\mathrm{SiC} / \mathrm{SiC} \mathrm{CVI} \mathrm{ceramic} \mathrm{composite} \mathrm{system} \mathrm{is} \mathrm{controlled} \mathrm{through}$ combinations of matrix cracking/partial fiber-matrix debonding, fiber pull-out, crack bridging, crack deflection, and crack blunting mechanisms. At elevated temperatures, fiber/matrix debonding and fiber pull-out dominates more than the other factors.

7. TEM of the fracture surface yielded valuable information and helped differentiate the effects of elevated temperature, oxidation, and mechanical testing on the interfacial properties.

8. Initial experiments indicate that there might be an effect of specimen volume en the stress-strain behavior of these materials.

\subsubsection{ANALYTICAL}

1. An analytical model (PWCLT) to predict the mechanical properties of a single plain weave fabric composite has been developed.

2. The properties of a single plain weave composite can be used to predict the 
mechanical properties of composite laminate fabricated by stacking single plain weave plies at various orientations.

3. The PWCLT model can accurately predict the mechanical properties of woven composites provided accurate constituent material properties are known. This model is also capable of predicting the mechanical properties of woven composites for different fiber volume fractions and packing densities. Furthermore, it also can be extended easily to other types of weaves such as Satin, Eight Harness etc.

4. The PWCLT model is able to predict the mechanical properties of Graphite/Epoxy and SiC/SiC (CMC) woven composites which correlates well with experimental results from literature.

5. Experimental studies to correlate failure behavior and theories can help in the prediction of strength.

\subsection{RECOMMENDATIONS}

Based on the results and conclusions from this study, the following are the recommendations for future work.

1. The effect of interfacial sliding stress on the mechanical properties at elevated temperatures need to be investigated in detail. It is necessary to obtain these values as a function of temperature to explain its effect on mechanical properties.

2. Fiber pull-out distributions, fiber strength distributions, and related analyses may be done on the lines of Thouless et al., (1989) to find out the fiber pull-out 


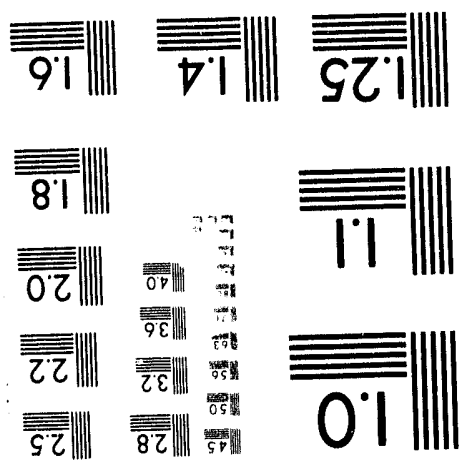



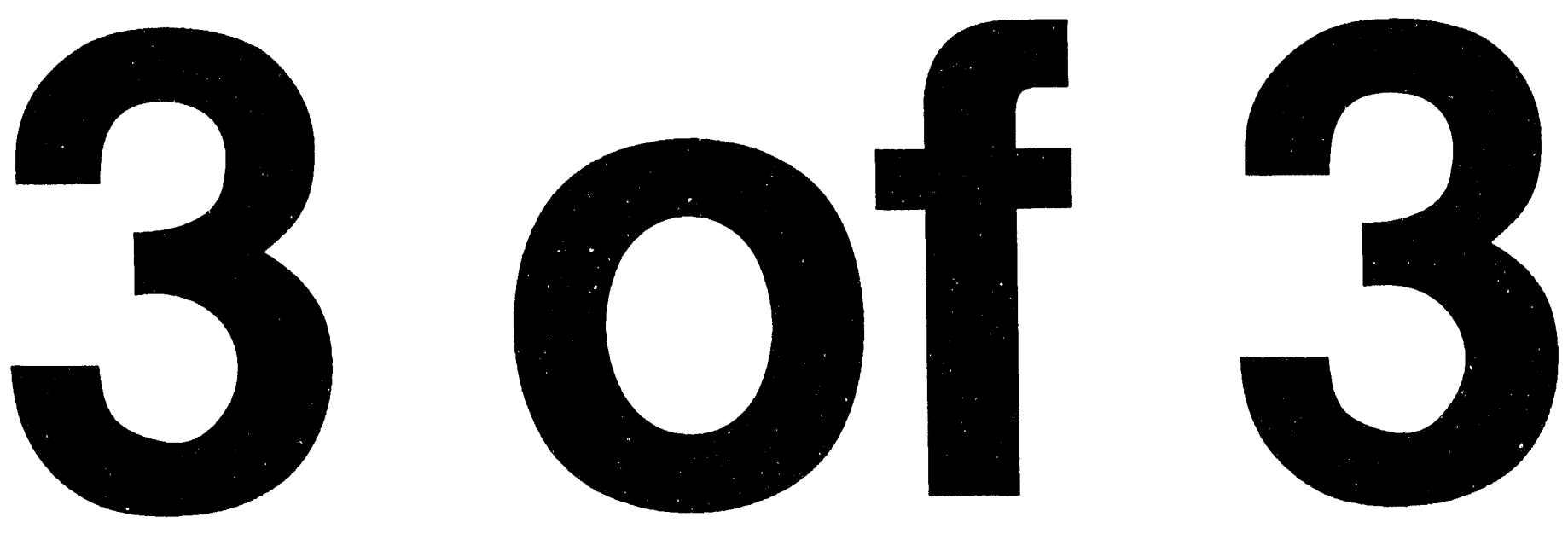
contributions to toughening behavior in these composites.

3. Analytical modeling needs to accommodate the effect of interfacial coating by micromechanics models to predict equivalent fiber properties.

4. Specimen volume effects need to be investigated. 


\section{REFERENCES}

1. Abbé, F., and Chermant, J., "Fiber-Matrix Bond-Strength Characterization of Silicon Carbide-Silicon Carbide Materials", Journal of the American Ceramic Society, 73[8], pp. 2573-2575, (1990).

2. Abbé, F., Carin, R., and Chermant, J., "Tensile and Creep Characteristics from Bending Tests: Application to SiC-SiC Composites", Journal of the European Ceramic Society, $\underline{\mathbf{5}}$, pp. 201-205, (1989).

3. Akimune, Y., Ogasawara, T., Hirosaki, N., and Yoneda, K., "Mechanical Properties of a SiC-Fiber reinforced CVI-SiC Composite", Nippon Seramikkusu Gakujutsu Ronbunshi, 99[2], pp. 180-182, (1991).

4. Aveston, J., Cooper, G. A., and Kelly, A., "Single and Multiple fracture", in The Properties of Fibre composites, Conference Proceedings, IPC Science and Technology Press Ltd., Surrey, England, pp. 15-26, (1971).

5. Becher, P. F., Hsueh, C., Angelini, P., and Tiegs, T., "Toughening Behavior in Whisker-Reinforced Ceramic Matrix Composites", Journal of the American Ceramic Society, 1ㅣ12], pp. $1050-1061$, (1988).

6. Becher, P. F., "Microstructural Design of Toughened Ceramics", Journal of the American Ceramic Society, 74[2], pp. 255-269, (1991).

7. Bischoff, E., Rühle, M., Sbaizero, O., and Evans, A. G., "Microstructural Studies of the Interfacial Zone of a SiC-Fiber-Reinforced Lithium Aluminum Silicate Glass-Ceramic", Journal of the American Ceramic Society, 72[5], pp. 741-745, (1989). 
8. Brennan, J. J., "Glass and Ceramic Matrix Composites", in Fiber Reinforced Ceramic Composites, edited by Mazdiyasni, K. S., pp. 222-258, Noyes Publications, New Jersey, USA, (1990).

9. Buckley, J. D., "Carbon-Carbon, An overview", American Ceramic Society Bulletin, 67 (2), pp. 364-368, (1988).

10. Bunsell, A. R., "Fibres for metallic and ceramic composites, the scientific aspects and their relation to composite performances", in Mechanical and Physical Behavior of Metallic and Ceramic Composites, edited by Anderson, S. I., Liholt, H., and Pederson, O. B., pp. 1-12, (1988).

11. Cao, H. C., Bischoff, E., Sbaizero, O., Rühle, M., Evans, A. G., Marshall, D. B., and Brennan, J. J., "Effect of Interfaces on the Properties of Fiber-Reinforced Ceramics", Journal of the American Ceramic Society, 73[6], pp. 1691-1699, (1990).

12. Cao, H., and Thouless, M. D., "Tensile Tests of Ceramic-Matrix Composites: Theory and Experiment", Journal of the American Ceramic Society, 73[7], pp. 2091-2094, (1990).

13. Caputo, A. J., Stinton, D. P., Lowden, R. A., and Besmann, T. M., "FiberReinforced SiC Composites with Improved Mechanical Properties", American Ceramic Society Bulletin, 66[2], pp. 368-372, (1987).

14. Caputo, A. J., Lackey, W. J., and Stinton, D. P., "Development of a new faster process for the fabrication of ceramic fiber reinforced ceramic composites by chemical vapor infiltration", Ceramic Engineering and Science Proceedings, $\mathbf{6}$ [7-8], pp. 
694-706, (1985).

15. Caputo, A. J., and Lackey, W. J., "Fabrication of Fiber-Reinforced Ceramic Composites by Chemical Vapor Infiltration", Ceramic Engineering and Science Proceedings, 5 [7-8], pp. 654-667, (1984).

16. Charalambides, P. G., and Evans, A. G., "Debonding Properties of Residually Stressed Brittle Matrix Composites", Journal of the American Ceramic Society, 72[5], pp. 746-753, (1989).

17. Charalambides, P. G., "Some Anisotropic Aspects and the Analysis of Mixed Mode Delamination Cracking in Fiber Reinforced and Laminated Ceramic Matrix Composites", in Industry-University Advanced Materials Conference II, edited by Smith, F. W., Advanced Materials Institute, Golden, CO, USA, pp. 108-122, (1989).

18. Cheng, D. J., Shyy, W. J., Kuo, D. H., and Hon, M. H., "Growth Characteristics of CVD Beta Silicon Carbide", Journal of the Elect chemical Society : Solid State Science and Technology, 134[12], pp. 3145-3149, (1987).

19. Christin, F., Naslain, R., and Bernard, C., "A thermodynamic and experimental approach of silicon carbide - CVD application to the CVD infiltration of porous carbon-carbon composites", in Proceedings of the 7th International Conference on Chemical Vapor Deposition, Sedgewick, T. O., and Lydin, H., editors, Electrochemical Society, Princeton, pp. 499-514, (1979).

20. Clark, T. J., Jaffe, M., Rabe, J., and Langley, N. R., "Thermal Stability Characterization of SiC Ceramic Fibers : I, Mechanical Property and Chemical Structure 
Effects", Ceramic Engineering and Science Proceedings, 7[7-8], pp. 901-913, (1986).

21. Cox, B. N., and Marshall, D. B., "Stable and Unstable Solutions for Bridged Cracks in Various Specimens", Acta Metallurgica, 39[4], pp. 579-589, (1991).

22. Danforth, S. C., "Processing of ceramic-ceramic composites", in Processing of Ceramic and Metal Matrix Composites, Proceedings of International Symposium Vol. 17, edited by Mostaghaci, H., Pergamon Press, London, pp. 107-119, (1989).

23. Dauchier, M., Bernhart, G., Bonnet, C., "Properties of Silicon Carbide based Ceramic-Ceramic Composites", in Proceedings of the 30th National SAMPE Symposium, 30, pp. 1519-1525, SAMPE, CA, 1985.

24. Davis, R. F., "Correlation among Process Routes, Microstructures and Properties of Chemically Vapor Deposited Silicon Carbide", in Chemical Vapor Deposition of Refractory Metals and Ceramics, Materials Research Society Symposium Proceedings Vol 168, edited by Besmann, T. D., and Gallois, B. M., pp. 149-158, (1990).

25. Davis, R. F., Carter, C. H., and Lane, J. E., "Deformation behavior of reaction bonded, chemically vapor deposited and sintered silicon carbides at elevated temperatures", in Ceramic Transactions Vol. 2 : Silicon Carbide '87, edited by Cawley, J. D., and Semler, C. E., pp. 253-274, (1987).

26. Eckel, A. J., and Bradt, R. C., "Strength Distribution of Reinforcing Fibers in a Nicalon Fiber/Chemically Vapor Infiltrated Silicon Carbide Matrix Composite", Journal of the American Ceramic Society, 72[3], 455-458, (1989). 
27. Ellingson, W. A., and Holloway, D. A., "Characterization of Continuous Fiber SiC/SiC CVI composites by X-Ray Microtomography", paper \# 44 presented at the open sessions of the 16th Annual Conference on Composites, Materials, and Structures, Cocoa Beach, FL, 1992 (to be published in Volume 13, Ceramic Engineering and Science Proceedings).

28. Evans, A. G., "The strength of brittle materials containing second phase dispersions", Phil. Mag., 트, pp. 1327-1344, (1972).

29. Evans, A. G., "The Fracture of Brittle Materials", in Nitrogen Ceramics, edited by Riley, F. L., Noordhoff International Publishing, Netherlands, pp. 451-475, (1977).

30. Evans, A. G., and McMeeking, R. M., "On the Toughening of Ceramics by Strong Reinforcements", Acta Metallurgica, 34[12], pp. 2435-2441, (1986).

31. Evans, A. G., and Dalgleish, B. J., "Some Aspects of the High Temperature Performance of Ceramics and Ceramic Composites", Ceramic Engineering and Science Proceedings, 7[9-10], pp. 1073-1094, (1986).

32. Evans, A. G., and Marshall, D. B., "The Mechanical Performance of Fiber Reinforced Ceramic Matrix Composites", Materials Research Society Symposium Proceedings Vol. 120, pp. 213-246, (1988).

33. Evans, A. G., "The Mechanical Performance of Fiber-reinforced Ceramic Matrix Composites", in Mechanical and Physical Behavior of Metallic and Ceramic Composites, edited by Anderson, S. I., Liholt, H., and Pederson, O. B., pp. 13-34, 
(1988).

34. Evans, A. G., "The Mechanical Performance of Fiber-reinforced Ceramic Matrix Composites", Materials Science and Engineering, $\underline{\mathbf{A 1 0 7}}$, pp. 227-239, (1989).

35. Evans, A. G., and Marshall, D. B., "The Mechanical Behavior of Ceramic Matrix Composites", Acta Metallurgica, 37[10], pp. 2567-2583, (1989).

36. Evans, A. G., "Perspective on the Development of High-Toughness Ceramics", Journal of the American Ceramic Society, 73[2], pp. 187-206, (1990).

37. Evans, A. G., and Marshall, D. B., "Mechanical Behavior of Ceramic Matrix Composites", in Fiber Reinforced Ceramic Composites, edited by Mazdiyasni, K. S., pp. 1-38, Noyes Publications, New Jersey, USA, (1990).

38. Fischman, G. S., and Petuskey, W. T., "Thermodynamic Analysis and Kinetic Implications of Chemical Vapor Deposition of $\mathrm{SiC}$ from $\mathrm{Si}-\mathrm{C}-\mathrm{Cl}-\mathrm{H}$ Gas Systems", Journal of American Ceramic Society, 68 (4), pp. 185-190, (1985).

39. Fisher, R. E., Burkland, C. B., and Bustamante, W. E., Ceramic Engineering and Science Proceedings, 6, pp. 806-819, (1985).

40. Fitzer, E., Hegen, D., and Strohmeier, H., "Chemical Vapor Deposition of silicon carbide and silicon nitride and its application for preparation of improved silicon ceramics", in Proceedings of the 7th International Conference on Chemical Vapor Deposition, Sedgewick, T. O., and Lydin, H., editors, Electrochemical Society, Princeton, pp. 525-535, (1979).

41. Fitzer, E., and Gadow, R., "Fiber Reinforced Silicon Carbide", American 
Ceramic Society Bulletin, 65[2], pp. 326-35, (1986).

42. Foltz, T. F., "SiC fibers for Advanced Ceramic Composites", Ceramic Engineering and Science Proceedings, 6[9-10], pp. 1206-1220, (1985).

43. Gao, J., M. S. Thesis, North Carolina A \& T State University, (1990).

44. Grande, D. H., Mandell, J. F., and Hong, K. C. C., "Fibre-matrix bond strength studies of glass, ceramic, and metal matrix composites", Journal of Materials Science, 23, pp. 311-328, (1988).

45. Gomina, M., Fourvel, P., and Rouillon, M. H., "High Temperature Mechanical Behavior of an Uncoated SiC-SiC Composite Material", Journal of Materials Science, 26, pp. 1891-1898, (1991).

46. Govila, R. K., Journal of the American Ceramic Society, 65, pp. 15-21, (1982).

47. Govila, R. K., Journal of Materials Science, 18, pp. 1967-76, (1983).

48. Gulden, T. D., "Mechanical Properties of Polycrystalline Beta Silicon

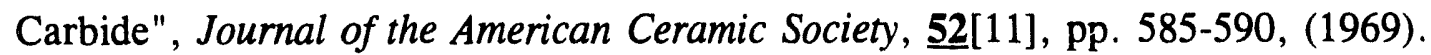

49. Gulden, T. D., "Stacking Faults in Chemically Vapor deposited Beta Silicon Carbide", Journal of the American Ceramic Society, 54[10], pp. 498-501, (1971).

50. Günther, W., "Basis of Mechanical Compatibility of Composite Materials", in Composite Materials : edited by Schlicting, J., TAE, Grafenau, West Germany, (1978).

51. Gyekenyesi, J. Z., and Hemann, J. H., "High Temperature Tensile Testing of Ceramic Composites", NASA Contractor Report 180888, February 1988. 
52. Headinger, M. H., Roach, D. H., Driver, H. D., and Gentile, M., "Comparison of Flex and Tensile Properties for SiC Matrix Composites Reinforced with Nicalon and T-300 Fibers", paper \# 52 presented at the open sessions of the 16th Annual Conference on Composites, Materials, and Structures, Cocoa Beach, FL, 1992 (to be published in Volume 13, Ceramic Engineering and Science Proceedings).

53. Headinger, M. H., Personal communications (1992a).

54. Headinger, M. H., Roach, D. H., and Carter, R. J., "Mechanical Property Design Database for Ceramic Matrix Composites", Du Pont CVI Ceramic Matrix Composites Preliminary Engineering Data, (1991).

55. Headinger, Roach, D. H., Carter, R. J., and Gray, P. E., "Mechanical Properties of Application Tailored Ceramic Matrix Composites", Du Pont CVI Ceramic Matrix Composites Preliminary Engineering Data, (1991a).

56. Hembree, D. M., Stinton, D. P., and Headinger, M. H., "Raman Investigation of the Fiber-Matrix Interface region in Silicon Carbide Composites Produced by Chemical Vapor Infiltration", paper \# 52 presented at the open sessions of the 16th Annual Conference on Composites, Materials, and Structures, Cocoa Beach, FL, 1992 (to be published in Volume 13, Ceramic Engineering and Science Proceedings).

57. Heraud, L. H., Christin, F., Naslain, R., and Hagenmuller, P., "Properties and Applications of Oxidation-Resistant Composite Materials Obtained by SiC Infiltration", in Proceedings of the Ninth International Conference on Chemical Vapor Deposition 1984, edited by Robinson, M., Cullen, G., Van den Brekel, C., and Blocher, 
J. M., Electrochemical Society, Princeton, NJ, pp. 782-789, (1984).

58. Hurwitz, F. I., "Ceramic Matrix and Resin Matrix Composites : A comparison", Proceedings of the 32nd International SAMPE Symposium, edited by Carson, R., Burg, M., Kjoller, K. J., and Riel, F. J., pp. 433-442, (1987).

59. T. Ishikawa and T. W. Chou, "Elastic behavior of woven hybrid composites", Journal of Composite Materials, 16, pp. 2-19, (1982).

60. T. Ishikawa and T. W. Chou, "Stiffness and strength behavior of woven fabric composites", Journal of Materials Science, 17, pp. 3211-3220, (1982).

61. T. Ishikawa and T. W. Chou, "In-plane thermal expansion and thermal bending coefficients of fabric composites", Journal of Composite Materials, 17, pp. 92104, (1983).

62. Kerans, R. J., Hay, R. S., Pagano, N. J., and Parthasarathy, T. A., "The Role of the Fiber-Matrix Interface in Ceramic Composites", American Ceramic Society Bulletin, 68[2], pp. 429-442, (1989).

63. Kingery, W. D., Bowen, H. K., and Uhlmann, D. R., "Introduction to Ceramics", John Wiley and Sons, New York, (1976).

64. Kmetz, M., and Suib, S., "Silicon Carbide/Silicon and Silicon Carbide/Silicon Carbide Composites Produced by Chemical Vapor Infiltration", Journal of the American Ceramic Society, 73[10], pp. 3091-3093, (1990).

65. Ko, F. K., "Preform Fiber Architecture for Ceramic Matrix Composites", American Ceramic Society Bulletin, 68[2], pp. 401-414, (1989). 
66. Kossowsky, R., Miller, D. G., and Diaz, E. S., Journal of Materials Science, 10, pp. 983-997, (1975).

67. Kotlensky, W. V., "Deposition of Pyrolytic carbon in porous solids", in Chemistry and Physics of Carbon, Vol. 9, edited by Walker, P. L. Jr., and Thrower, P. A., pp. 173-262, Marcel Dekker, New York, (1973).

68. W. S. Kuo and T. W. Chou, "Modeling of nonlinear constitutive relations of woven ceramic composites", Ceramic Engineering and Science Proceedings, 12 [7-8], pp. 1556-1573, (1991).

69. Lackey, W. J., and Starr, T. L., "Fabrication of Fiber-Reinforced Ceramic Composites by Chemical Vapor Infiltration: Processing, Structure and Properties", in Fiber Reinforced Ceramic Composites, edited by Mazdiyasni, K. S., pp. 397-445, Noyes Publications, New Jersey, USA, (1990).

70. Lackey, W. J., "Review, Status, and Future of the Chemical Vapor Infiltration Process for Fabrication of Fiber-Reinforced Ceramic Composites", Ceramic Engineering and Science Proceedings, 10[7-8], pp. 577-584, (1989).

71. Lamicq, P. J., Bernhart, G. A., Dauchier, M. M., and Mace, J. G., "SiC/SiC Composite Ceramics", American Ceramic Society Bulletin, 65 [2], pp. 336-338, (1986).

72. Lange, F. F., "Fracture Toughness of $\mathrm{Si}_{3} \mathrm{~N}_{4}$ as a function of the initial $\alpha$ phase content", Journal of the American Ceramic Society, 62 [7-8], pp. 428-430, (1979).

73. Lange, F. F., Diaz, E. S., and Anderson, C. A., American Ceramic Society 
Bulletin, 58, pp. 845-48, (1979a).

74. Lange, F. F., "The Interaction of a Crack front with a second phase dispersion", Philosophical Magazine, 22, pp. 983-992, (1970).

75. Larsen, D. C., and Struchly, S. L., "The Mechanical Evaluation of Ceramic Fiber Composites", in Fiber Reinforced Ceramic Composites, edited by Mazdiyasni, $\mathbf{K}$. S., pp. 182-220, Noyes Publications, New Jersey, USA, (1990).

76. Liu, K. C., and Brinkman, C. R., "Tensile cyclic fatigue of structural ceramics", Proceedings of the 23rd Automotive Technology Development Contractor's Coordination meeting, Society of the Automotive Engineers, Inc., P-165, pp. 279-284, (1986).

77. Lowden, R. A., and Stinton, D. P., Personal Communications, (1992).

78. Lowden, R. A., and James, R. D., "Effects of oxidizing and combustion environments on the interface and the mechanical properties of Nicalon/SiC composites", Proceedings of the fifth Annual Conference on Fossil Energy Materials, published by the Department of Energy and ASM International, pp. 33-46, (1991).

79. Lowden, R. A., and More, K. L., "The Effect of Fiber Coatings on Interfacial Shear Strength and the Mechanical Behavior of Ceramic Composites", Materials Research Society Symposium Proceedings Vol. 170, pp. 205-214, (1990).

80. Lowden, R. A., Stinton, D. P., and Starr, T. S., "Improved Processing of CVI Composites", Ceramic Engineering and Science Proceedings, 10[7-8], pp. 585, (1989). 
81. Lowden, R. A., and Stinton, D. P., "Interface Modification in Nicalon/SiC Composites", Ceramic Engineering and Science Proceedings, 9[7-8], pp. 705-722, (1988).

82. Lu, Mei-Chien, "Evaluation of Interfacial Properties in Ceramic Coating/Fiber Composites", Ceramic Engineering and Science Proceedings, 11[9-10], pp. 1761-1777, (1990).

83. Luh, E. L., and Evans, A. G., "High Temperature Mechanical Properties of a Ceramic Matrix Composite", Journal of the American Ceramic Society, 70[7], pp. 466469, (1987).

84. Mah, T., Mendiratta, M. G., Katz, A. P., and Mazdiyasni, K. S., "Recent Developments in Fiber-Reinforced High Temperature Ceramic Composites", American Ceramic Society Bulletin, 66[2], pp. 304-308, (1987).

85. Maniette, Y., and Oberlin, A., "TEM characterization of some crude or air heat-treated SiC Nicalon fibers", Journal of Materials Science, 24, pp. 3361-3370, (1989).

86. Mah, T., et al., "Thermal Stability of SiC fibers", Journal of Materials Science, 19, pp. 1191-1201, (1984).

87. Marshall, D. B., and Ritter, J. E., "Reliability of Advanced Structural Ceramics and Ceramic Matrix Composites", American Ceramic Society Bulletin, 66[2], pp. 309-317, (1987).

88. Marshall, D. B., "Strength and Interfacial Properties of Ceramic 
Composites", Material Research Society Symposium Proceedings Vol. ㄹ, pp. 175-179, (1987).

89. Marshall, D. B., and Cox, B. N., "Tensile Fracture of Brittle Matrix Composites: Influence of Fiber Strength", Acta Metallurgica, 35[11], pp. 2607-2619, (1987).

90. Marshall, D. B., and Oliver, W. C., "Measurement of Interfacial Mechanical Properties in Fiber-Reinforced Ceramic Composites", Journal of the American Ceramic Society, 70[8], pp. 542-548, (1987).

91. Marshall, D. B., and Evans, A. G., "Failure Mechanisms in CeramicFiber/Ceramic-Matrix Composites", Journal of the American Ceramic Society, 68 [5], pp. 225-231, (1985).

92. Marshall, D. B., Cox, B. N., and Evans, A. G., "The Mechanics of Cracking in Brittle Matrix Fiber Composites", Acta Metallurgica, 33[11], pp. 2013-2021, (1985).

93. Moeller, H. H., Long, W. G., Caputo, A. J., and Lowden, R. A., Ceramic Engineering and Science Proceedings, ㅈ, pp. 977-984, (1987).

94. Morrel, R., "Engineering Applications of Ceramic Materials", pp. 3-12 in Ceramic Materials Source Book, American Society for Metals, Ohio, (1985).

95. Nair, S. V., and Wang, Y., "Fracture Behavior of a 2-D woven SiC fiber/SiC matrix composite at ambient and elevated temperatures", paper \#68 presented at the open sessions of the 16th Annual Conference on Composites, Materials, and Structures, Cocoa Beach, FL, 1992 (to be published in Volume 13, Ceramic Engineering and Science 
Proceedings).

96. Nair, S. V., "Crack wake debonding and toughness in fiber or whisker reinforced brittle matrix composites", Journal of the American Ceramic Society, 73[10], pp. 2839-2847, (1990).

97. Naslain, R., et al., "The Carbon fibre-Carbon and Silicon Carbide Binary Matrix Composites, a new class of materials for high temperature applications", Advances in Composite Materials, 2, pp. 1084-1094, (1980).

98. Naslain, R., and Langlais, F., in Multiphase and Composite Ceramics, edited by Tressle:, R. E., et al., Materials Science Research, Volume 20, Plenum Press, New York, pp. 145-164, (1986).

99. Navarre, G., Rouais, J. C., and Rouby, D., "Observation of crack path in an SiC-SiC fibre composite by X-Ray radiography and SEM", Journal of Materials Science Letters, 9, pp. 636-638, (1990).

100. Neil, J. T., Materials Engineering, 99(3), pp. 27-41, (1984).

101. Phillips, D. C., "Ceramic Composites at extremes of performance", in Mechanical and Physical Behavior of Metallic and Ceramic Composites, edited by Anderson, S. I., Liholt, H., and Pederson, O. B., pp. 183-199, (1988).

102. Pluvinage, P., Filipuzzi, L., and Camus, G., "Mechanical Behavior and Oxidation Resistance of a unidirectional $\mathrm{SiC} / \mathrm{SiC}$ fibrous composite", pp. 937-944, in Ceramic Transactions, Vol. $\underline{\text { 19, }}$, edited by Sacks, M. D., The American Ceramic Society, Westerville, OH, USA, (1991). 
103. Prewo, K. M., and Brennan, J. J., "High strength silicon carbide fiber reinforced glass matrix composites", Journal of Materials Science, 15[2], pp. 463-468, (1980).

104. Prewo, K. M., and Brennan, J. J., "Silicon carbide yarn reinforced glass matrix composites", Journal of Materials Science, 17[4], pp. 1201-1206, (1982).

105. Prewo, K. M., Johnson, B., and Starret, S., "Silicon Carbide Fibrereinforced glass-ceramic composite tensile behavior at elevated temperature", Journal of Materials Science, 24, pp. 1373-1379, (1989).

106. Prewo, K. M., "Fiber-Reinforced Ceramics : New Opportunities for Composite Materials", American Ceramic Society Bulletin, 68[2], pp. 395-400, (1989).

107. Raju, I. S., Craft, W. J., and Avva, V. S., "Thermal expansion coefficients of woven fabric composites", Proceedings of the Advances in Structural Testing, Analysis, and Design (ICSTAD) conference, Vol. 1, pp. 3-10, Bangalore, India, (1990). 108. Rawlins, M. H., Nolan, T. A., Stinton, D. P., and Lowden, R. A., "Interfacial characterizations of Fiber-Reinforced SiC Composites Exhibiting Brittle and Toughened Fracture Behavior", Materials Research Society Symposium Proceedings Vol. 78, pp. 223-230, (1987).

109. Rice, R. W., "Mechanisms of Toughening in Ceramic Matrix Composites", Ceramic Engineering and Science Proceedings, 2 [7-12], pp. 661-701, (1981).

110. Rice, R. W., Spann, J. R., Lewis, D., and Coblenz, W., "The effect of ceramic fiber coatings on the room temperature mechanical behavior of ceramic fiber 
comp «sites", Ceramic Engineering and Science Proceedings, 5 [7-8], pp. 614-624, (1984).

111. Rice, R. W., "Ceramic Matrix Composite Toughening Mechanisms : An Update", Ceramic Engineering and Science Proceedings, 6 [7-8], pp. 589-607, (1985).

112. Sawyer, L. C., Chen, R. T., Haimbach IV, F., Harget, P. J., Prack, E. R., and Jaffe, M., "Thermal Stability Characterization of SiC Ceramic Fibers : II, Fractography and Structure", Ceramic Engineering and Science Proceedings, 7[7-8], pp. 914-930, (1986).

113. Sbaizero, O., and Evans, A. G., "Tensile and Shear Properties of Laminated Ceramic Matrix Composites", Journal of the American Ceramic Society, 69[6], pp. 481486, (1986).

114. Schlichting, J., "Silicon Carbide as an Oxidation Resistant High Temperature Material : Oxidation and Hot-Gas-Corrosion Behavior", Ber. Dt. Keram. Ges., CFI, $\underline{\mathbf{5}}$ [8], pp. 196-200 and 256-261, (1979).

115. Schneider, G. A., and Petzow, G., "Thermal Shock Testing of Ceramics-A new testing method", Journal of the American Ceramic Society, 74[1], pp. 98-102, (1991).

116. Simon, G., and Bunsell, A. R., "Creep behavior and structural characterization at high temperatures of Nicalon SiC fibers", Journal of Materials Science, 19, pp. 3658-70, (1984).

117. Singh, D., and Singh, J. P., "Effect of Processing on Strength of Nicalon 
Fibers in Nicalon Fiber-SiC Matrix Composites", paper \# 41 presented at the open sessions of the 16th Annual Conference on Composites, Materials, and Structures, Cocoa Beach, FL, 1992 (to be published in Volume 13, Ceramic Engineering and Science Proceedings).

118. Sotirochos, S. V., and Tomadakis, M. M., "Modeling Transport, Reaction, and Pore Structure Evolution during Densification of Cellular or Fibrous Structures", in Chemical Vapor Deposition of Refractory Metals and Ceramics, Materials Research Society Symposium Proceedings Vol $\underline{\mathbf{1 6 8}}$, edited by Besmann, T. D., and Gallois, B. M., pp. 73-78, (1990).

119. Starr, T. L., and Smith, A. W., "3-D Modeling of Forced-Flow Thermal Gradient CVI for Ceramic Composite Fabrication", in Chemical Vapor Deposition of Refractory Metals and Ceramics, Materials Research Society Symposium Proceedings Vol 168, edited by Besmann, T. D., and Gallois, B. M., pp. 55-72, (1990).

120. Starr, T. L., "Model for Rapid CVI of Ceramic Composites", in Proceedings of the 10th International Conference on Chemical Vapor Deposition 1987. edited by Cullen, G. W., The Electrochemical Society, NJ, USA, pp. 1147-1155, (1987).

121. Steffier, W. S., "Mechanics of Continuous Fiber Reinforced Brittle Matrix Composites with Elastic Interfaces", paper \# 109 presented at the open sessions of the 16th Annual Conference on Composites, Materials, and Structures, Cocoa Beach, FL, 1992 (to be published in Volume 13, Ceramic Engineering and Science Proceedings). 
122. W. S. Steffier, "The orthotropic behavior of Nicalon fiber reinforced ceramic composites", paper \# C-118-93F presented at the open sessions of the 17th Annual Conference on Composites, Materials, and Structures, Cocoa Beach, FL, 1993 (to be published in Volume 14, Ceramic Engineering and Science Proceedings).

123. Stinton, D. P., Personal Communications, (1992).

124. Stinton, D. P., Personal Communications, (1991).

125. Stinton, D. P., Lowden, R. A., and Krabil, R. H., "Mechanical Property Characterization of Fiber-Reinforced SiC Matrix Composites", Preliminary report No. ORNL/TM-11524, (April 1990a).

126. Stinton, D. P., Hembree, D. M., More, K. L., Sheldon, B. W., and Besmann, T. M., "Characterization of Ceramic Matrix Composites Fabricated by Chemical Vapor Infiltration", in Chemical Vapor Deposition of Refractory Metals and Ceramics, Materials Research Society Symposium Proceedings Vol 168, edited by Besmann, T. D., and Gallois, B. M., pp. 273-280, (1990).

127. Stinton, D. P., Besmann, T. M., and Lowden, R. A., "Advanced Ceramics by Chemical Vapor Deposition Techniques", American Ceramic Society Bulletin, $\underline{67}$ (2), pp. 350-355, (1988).

128. Stinton, D. P., "Ceramic Composites by Chemical Vapor Infiltration", in Proceedings of the 10th International Conference on Chemical Vapor Deposition 1987, edited by Cullen, G. W., The Electrochemical Society, NJ, USA, pp. 1028-1040, (1987). 
129. Stinton, D. P., Caputo, A. J., and Lowden, R. A., "Synthesis of FiberReinforced SiC Composites by Chemical Vapor Infiltration", American Ceramic Society Bulletin, 65[2], pp. 347-350, (1986).

130. Stinton, D. P., Caputo, A. J., Lowden, R. A., and Besmann, T. M., "Improved Fiber-Reinforced SiC Composites Fabricated by Chemical Vapor Infiltration", Ceramic Engineering and Science Proceedings, 7[7-8], pp. 983-989, (1986a).

131. Stinton, D. P., and Lackey, W. J., Ceramic Engineering and Science Proceedings, 6, pp. 707-713, (1985).

132. Stinton, D. P., and Lackey, W. J., "Effect of Deposition conditions on the properties of Pyrolytic Silicon carbide coatings for high temperature gas cooled reactor fuel particles", American Ceramic Society Bulletin, 57 (6), pp. 568-573, (1978).

133. Strife, J. R., Brennan, J. J., and Prewo, K. M., "Status of Continuous Fiber-Reinforced Ceramic Matrix Composite Processing Technology", Ceramic Engineering and Science Proceedings, 11[7-8], pp. 871-919, (1990).

134. Sutcu, M., "Weibull Statistics applied to fiber failure in ceramic composites and work of fracture", Acta Metallurgica, 37[2], pp. 651-661, (1989).

135. Tai, N., and Chou, T., "Analytical Modeling of Chemical Vapor Infiltration in Fabrication of Ceramic Composites", Journal of the American Ceramic Society, 72[3], pp. 414-420, (1989).

136. Tandon, G. P., and Pagano, N. J., "A Study of Fiber-Matrix Interfacial Modeling", in Proceedings of the Fourth Japan-US Conference on Composite Materials, 
American Society for Composites \& ASME, Technomic Publishing Co., PA, pp. 191200, (1988).

137. Thouless, M. D., Sbaizero, O., Sigl, L. S., and Evans, A. G., "Effect of Interface Mechanical Properties on Pullout in a SiC-Fiber-Reinforced Lithium Aluminum Silicate Glass-Ceramic", Journal of the American Ceramic Society, 72[4], pp. 525-532, (1989).

138. Thouless, M. D., and Evans, A. G., "Effects of Pull-out on the Mechanical Properties of Ceramis-Matrix Composites", Acta Metallurgica, 36[3], pp. 517-522, (1988).

139. Vaidyanathan, R., Sankar, J., and Avva, V. S., "Testing and Evaluation of $\mathrm{Si}_{3} \mathrm{~N}_{4}$ in Uniaxial Tension at Room Temperature", Proceedings of the 25th Automotive Technology Development Contractor's Co-ordination Meeting, P-209, pp. 175-186, Society of Automotive Engineers, Warrendale, PA, (1988).

140. Veltri, R. D., Condit, D. A., and Galasso, F. S., "Chemical Vapor Deposited SiC Matrix Composites", Journal of the American Ceramic Society, 72[3], pp. 478-480, (1989).

141. Weihs, T. P., and Nix, W. D., "Experimental examination of the push down technique for measuring the sliding resistance of silicon carbide fibers in a ceramic matrix", Journal of the American Ceramic Society, 74[3], pp. 524-534, (1991).

142. Weihs, T. P., Sbaizero, O., Luh, E. Y., and Nix, W. D., "Correlating the mechanical properties of a continuous fiber-reinforced ceramic-matrix composite to the 
sliding resistance of the fibers", Journal of the American Ceramic Society, 74[3], pp. 535-540, (1991).

143. Weiss, J. R., and Diefendorf, R. J., "Relationship of structure to properties in chemically vapor deposited silicon carbide", in Proceedings of the 4th International Conference on Chemical Vapor Deposition, Wakefield, G. E., and Blocher, J. M., editors, pp. 488-497, Electrochemical Society, New Jersey, (1973).

144. Wells, J. K., and Beaumont, P. W. R., "Debonding and pullout processes in Fibrous Composites", Journal of Materials Science, 20, pp. 1275-1284, (1985).

145. Yang, J. M., Lin, W., Shih, C. J., Kai, W., Jeng, S. M., and Burkland, C. V., "Mechanical Behavior of Chemical Vapor Infiltration-Processed Two- and Threedimensional Nicalon/SiC Composites", Journal of Materials Science, 26, pp. 2954-2960, (1991).

146. Yang, J. M., Chou, J. C., and Burkland, C. V., "Fracture Behavior of 3-D Braided Nicalon/Silicon Carbide Composite", Materials Research Society Symposium Proceedings Vol. 120, pp. 163-168, (1988).

147. Zok, F., Sbaizero, O., Hom, C. L., and Evans, A. G., "Mode I Fracture Resistance of a Laminated Fiber-Reinforced Ceramic", Journal of the American Ceramic Society, 74 [1], pp. 187-193, (1991). 


\section{DISTRIBUTION}

1. A. P. GREEN REFRACTORIES COMPANY Green Blvd.

Mexico, MO 65265

J. L. Hill

2-3. ADVANCED MATERIALS AND PROCESSES

Route 87

Metals Park, OH 44073

L. M. Sheppard

D. F. Baxter, Jr.

4. ADVANCED COMPOSITE MATERIALS CORPORATION 1525 South Buncombe Road

Greer, SC 29651-9208

E. A. Lauder

5-6. AIR PRODUCTS AND CHEMICALS

P. O. Box 538

Allentown, PA 18105

S. W. Dean

S. C. Weiner

7. AIR FORCE OFFICE OF SCIENTIFIC RESEARCH Bolling AFB

Washington DC 20332-6448

L. J. Schioler

8-9. ALLISON GAS TURBINE DIVISION

P. O. Box 420

Indianapolis, IN 46206-0420

P. Khandelwal (Speed Code W-5)

R. A. Wenglarz (Speed Code W-16)

10. AMA RESEARCH \& DEVELOPMENT CENTER

5950 McIntyre Street

Golden, CO 80403

T. B. Cox

11. AMERCOM, Inc.

8928 Fullbright Avenue

Chatsworth, CA 91311

C. V. Burkland 
12. AMERICAN CERAMIC SOCIETY, INC.

757 Brooksedge Plaza Drive

Westerville, OH 43081-6136

J. Hines

13-14. ARGONNE NATIONAL LABORATORY

9700 Cass Avenue

Argonne, IL 60439

W. A. Ellingson

J. P. Singh

15. ARGONNE NATIONAL LABORATORY - WEST

P. O. Box 2528

Idaho Falls, ID 83403-2528

S. P. Henslee

16-20. ARMY MATERIALS TECHNOLOGY LABORATORY

Ceramics Research Division

405 Arsenal Street

Watertown, MA 02172-0001

D. R. Messier (SLCMT-MCC)

J. J. Swab (SLCMT-EMC)

G. E. Gazza

D. J. Viechnicki (SLCMT-EMC)

R. Katz

21-23. ARMY RESEARCH OFFICE

P. O. Box 12211

Research Triangle Park, NC 27709

E. Chen

A. Crowson

R. Reeber

24. AVCO RESEARCH LABORATORY

2385 Revere Beach Parkway

Everett, MA 02149

R. J. Pollina

25. BABCOCK \& WILCOX

1562 Beeson St.

Alliance, OH 44601

T. I. Johnson 
26. BABCOCK \& WILCOX

Domestic Fossil Operations

20 South Van Buren Avenue

Barberton, OH 44023

M. Gold

27-28. BABCOCK \& WILCOX

Lynchburg Research Center

P. O. Box 11165

Lynchburg, VA 24506

H. M. Moeller

B. Long

29-31. BRITISH COAL CORPORATION

Coal Research Establishment

Stoke Orchard, Cheltenham

Glochester, England GL52 4RZ

M. Arnold

C. Bower

A. Twigg

32. BRITISH GAS CORPORATION

Westfield Development Center

Cardenden, Fife

Scotland KY5OHP

J. E. Scott

33. BROOKHAVEN NATIONAL LABORATORY

Department of Applied Science

Upton, Long Island, NY 11973

T. E. O'Hare

34-35. CANADA CENTER FOR MINERAL AND ENERGY Technology

568 Booth Street

Ottawa, Ontario

Canada K1A OG1

R. Winston Revic

Mahi Sahoo

36-38. CARBORUNDUM COMPANY

1625 Buffalo Avenue, P. O. Box 337

Niagara Falls, NY 14302

Chris Ebel

Roger Storm 
G. V. Srinivasan

39. CERAMATEC, INC.

2425 South 900 West

Salt Lake City, UT 84119

D. W. Richerson

40. DOW CORNING CORPORATION

3901 S. Saginaw Road

Midland, MI 48686-0995

H. Atwell

41. DOW CHEMICAL USA

Ceramics and Advanced Materials

800 Building

Midland, MI 48667

K. A. Epstein

42-43. DUPONT LANXIDE COMPOSITES

1300 Marrows Road

P. O. Box 6077

Newark, DE 19707

B. W. Sorenson

P. A. Craig

44. E. I. DU PONT NEMOURS \& CO., INC.

Pencader Plant, Composites Division

P. O. Box 6100

Newark, DE 19714-6100

M. H. Headinger

45. EC TECHNOLOGIES

3614 Highpoint Drive

San Antonio, TX 78217

D. J. Kenton

46-47. ELECTRIC POWER RESEARCH INSTITUTE

P. O. Box 10412

3412 Hillview Avenue

Palo Alto, CA 94303

W. T. Bakker

j. Stringer 
48. EUROPEAN COMMUNITIES JOINT RESEARCH CENTRE

Petten Establishment

P. O. Box 2

1755 ZG Petten

The Netherlands

M. Van de Voorde

49-50. FORD MOTOR COMPANY

1430 Culver Avenue

\#-2079 SRL Building

Dearborn, MI 48121-4036

G. M. Crosbie

R. K. Govila

51. GA TECHNOLOGIES INC.

P. O. Box 85608

San Diego, CA 92138

T. D. Gulden

52. GENERAL ELECTRIC COMPANY CORPORATE R \& D

Room MB-187

P. O. Box 8

Schenectady, NY 12301

C. A. Johnson

53-54. GEORGIA INSTITUTE OF TECHNOLOGY

Georgia Tech Research Institute

Atlanta, GA 30332

T. L. Starr

W. J. Lackey

55. HAMPTON UNIVERSITY

Office of the VP for Development

Hampton, VA 23668

Joyce E. Taylor

56-57. IDAHO NATIONAL ENGINEERING LABORATORY

P. O. Box 1625

Idaho Falls, ID 83415

D. W. Keefer

B. H. Rabin

58. KENNAMETAL, INC.

Philip McKenna Laboratory 
1011 Old Salem Road

P. O. Box 639

Greensburg, PA 15601

B. North

59. LAVA CRUCIBLE-REFRACTORIES CO.

P. O. Box 278

Zelienople, PA 16063

T. Mulholland

60. LAWRENCE LIVERMORE LABORATORY

P. O. Box 808, L-325

Livermore, CA 94550

W. A. Steele

61-64. LOS ALAMOS NATIONAL LABORATORY

P. O. Box 1663

Los Alamos, NM 87545

J. D. Katz (P. O. Box 1663)

J. J. Petrovic (Group MST-4, MS 6771)

W. Blumenthal (MS E465)

T. E. Mitchell (MS K-765)

65. MASSACHUSETTS INSTITUTE OF TECHNOLOGY

Department of Civil Engineering

Room I-280, 77 Massachusetts Avenue

Cambridge, MA 02139

O. Buyukozturk

66-70. NASA LEWIS RESEARCH CENTER

21000 Brookpark Road

Cleveland, $\mathrm{OH} 44135$

R. T. Bhatt

J. P. Gyekenyesi (MS 6-1)

J. D. Kiser (MS 49-3)

W. A. Sanders (MS 49-3)

S. Levine

71-74. NATIONAL INSTITUTE OF STANDARDS AND TECHNOLOGY Materials Building

Gaithersburg, MD 20899

A. Pechenik

S. M. Hsu

S. M. Weiderhorn (Building 223, Room A329) 
G. Quinn (Inorganic Materials Division, Building 223)

75. NATIONAL MATERIALS ADVISORY BOARD

National Research Council

2101 Constitution Ave.,

Washington, DC 20418

K. M. Zwilsky

76. NATIONAL SCIENCE FOUNATION

1800 G. St., N. W.,

Washington, D. C. 20550

John Hurt

77-78. NAVAL AIR DEVELOPMENT CENTER

Street Road, Warminster, PA 18974-5000

S. Wang (Code 6063)

R. R. Sands

79-80. NEW ENERGY AND INDUSTRIAL TECHNOLOGY DEVELOPMENT

Sunshine 60 Bldg.

P. O. Box 1151

I-1 Higashi-Ikebukuro 3-Chrome

Toshima-Ku, Tokyo, 170

Japan

H. Narita

S. Ueda

81. NISHI TOKYO UNIVERSITY

3-7-19 Seijo, Setagaya

Tokyo 157

Japan

S. Somiya

82-84. NORTH CAROLINA A \& T STATE UNIVERSITY

Dept. of Mechanical Engineering

Greensboro, NC 27411

J. Sankar

A. D. Kelkar

R. Vaidyanathan

85-87. NORTH CAROLINA STATE UNIVERSITY

Materials Science and Engineering Department

P. O. Box 7907

Raleigh, NC 27695-7907 
J. Narayan

R. O. Scattergood

R. F. Davis

88. NORTHWESTERN UNIVERSITY

Department of Materials Science and Engineering

Technological Institute

Evanston, IL 60208

K. T. Faber

89-90. THE NORTON COMPANY

High Performance Ceramics Division

Goddard Road

Northborough, MA 01532-1545

N. Corbin

V. K. Pujari

91-111. OAK RIDGE NATIONAL LABORATORY

P. O. Box 2008

Oak Ridge, TN 37831

P. T. Becher

T. M. Besmann

R. A. Bradley

P. T. Carlson

N. C. Cole

M. K. Ferber

D. R. Johnson

R. R. Judkins

M. A. Karnitz

R. A. Lawson (8 copies)

R. A. Lowden

J. O. Steigler

D. P. Stinton

V. J. Tennery

112. OFFICE OF NAVAL RESEARCH

Code 431, 800 N. Quincy Street

Arlington, VA 22217

S. G. Fishman

113-114. OFFICE OF SCIENTIFIC RESEARCH

Bolling Air Force Base

Washington D. C. 20332-6448

Walter F. Jones 
Harlod S. Rhoads

115. PENNSYLVANIA STATE UNIVERSITY

Ceramic Science and Engineering Department

118, Steidle Building

University Park, PA 16802

D. J. Green

116. ROCKWELL INTERNATIONAL

Science Center

1049 Camino Dos Rios

Thousand Oaks, CA 91360

D. B. Marshall

117-118. RUTGERS UNIVERSITY

Department of Ceramics

P. O. Box 909

Piscataway, NJ 08855-0909

R. M. Cannon

S. C. Danforth

119. RESEARCH TRIANGLE INSTITUTE

P. O. Box 12194

Research Triangle Park, NC 27709

T. W. Sigmon

120. SRI INTERNATIONAL

333 Ravenswood Avenue

Menlo Park, CA 94025

S. Johnson

121. SANDIA NATIONAL LABORATORIES

Department 1840

P. O. Box 5800

Albuquerque, NM 87185

R. J. Eagan

122. SHELL DEVELOPMENT COMPANY

P. O. Box 1380

Houston, TX 77251-1380

L. W. R. Dicks

123. SOLAR TURBINES, INC.

2211 Erie Street 
San Diego, CA 92110

M. S. Laser

124. SOUTHWEST RESEARCH INSTITUTE

Department of Materials Sciences

6220 Culebra Road

San Antonio, TX 78228-0510

J. Lankford

125. SUNDSTRAND POWER SYSTEMS

Division of Sundstrand Corporation

4400 Ruffin Road

P. O. Box 85757

San Diego, CA 92186-5757

R. W. Fawley

126. TENNESSEE VALLEY AUTHORITY

Energy Demonstration \& Technology

MR2N58A

Chattanooga, TN 37402-2801

C. M. Huang

127. TEXTRON SPECIALTY MATERIALS

2 Industrial Avenue

Lowell, MA 01851

T. F. Foltz

128-129. 3M COMPANY

Ceramic Materials Department

201-2C-12 3M Center

St. Paul, MN 55144

L. R. White

B. Weaver

130. THE JOHN HOPKINS UNIVERSITY

Materials Science and Engineering

Maryland Hall

Baltimore, MD 21218

R. E. Green, Jr.

131. THE MATERIALS PROPERTIES COUNCIL, INC.

United Engineering Center

345 E. Forty-Seventh Street

New York, NY 10017 
M. Prager

132. THE TORRINGTON COMPANY

Advanced Technology Center

59 Field Street

Torrington, CT 06790

W. J. Chmura

133. UNION CARBIDE CORPORATION

Linde Division

P. O. Box 44

175 East Park Drive

Tonawanda, NY 14151-0044

Harry Cheung

134-135. UNITED TECHNOLOGIES RESEARCH CENTER

MS24, Silver Lane

East Hartford, CT 06108

K. M. Prewo

J. J. Brennan

136. UNIVERSAL ENERGY SYSTEMS, INC.

Ceramics and Composites Research

4401 Dayton-Xenia Road

Dayton, OH 45432

Tai-il Mah

137-138. UNIVERSITY OF CALIFORNIA AT SANTA BARBARA

College of Engineering

Department of Materials Engineering

Santa Barbara, CA 93106

A. G. Evans

F. F. Lange

139. UNIVERSITY OF CINCINNATI

Department of Materials Science and Engineering Cincinnati, OH 45221-0012

Raj N. Singh

140. UNIVERSITY OF DAYTON RESEARCH INSTITUTE

300 College Park

Dayton, OH 45469-0172

N. L. Hecht 
141. UNIVERSITY OF DELAWARE

Center for Composite Materials

201 Spencer Laboratory

Newark, DE 19716

T. W. Chou

142. UNIVERSITY OF FLORIDA

1712 N. W., 39th Drive

Gainesville, FL 32605

D. E. Clark

143. UNIVERSITY OF ILLINOIS

Materials Research Laboratory

104 South Goodwin Avenue

Urbana, IL 61801

A. Zangvil

144-145. UNIVERSITY OF MASSACHUSETTS

Mechanical Engineering Department

Amherst, MA 01003

J. E. Ritter

S. V. Nair

146-147. UNIVERSITY OF MICHIGAN

Materials Science and Engineering Department

Dow Building

Ann Arbor, MI 48103

T. Y. Tien

J. W. Holmes

148. UNIVERSITY OF MISSOURI-ROLLA

Department of Mechanical Engineering

224 M. E

Rolla, MO 65401

L. R. Dharani

149-151. UNIVERSITY OF WASHINGTON

Department of Materials Science and Engineering

101 Wilson, FB-10

Seattle, WA 98195

T. G. Stoebe

I. A. Aksay

M. G. Jenkins 
152. UNIVERSITY OF WASHINGTON

Department of Mechanical Engineering

MS:FU10

Seattle, WA 98195

A. S. Kobayashi

153-154. VIRGINIA POLYTECHNIC INSTITUTE \& STATE UNIVERSITY

Department of Materials Engineering

Blacksburg, VA 24601

J. J. Brown, Jr.

K. L. Reifsnider

155. WESTERN RESEARCH INSTITUTE

365 N. 9th Street

P. O. Box 3395

University Station

Laramie, WY 82071

V. K. Sethi

156. WESTINGHOUSE ELECTRIC CORPORATION

Research and Development Center

1310 Beulah Road

Pittsburgh, PA 15325

S. C. Singhal

157. W. R. GRACE AND COMPANY

7379 Route 32

Columbus, MD 21044

R. W. Rice

158-161. WRIGHT LABORATORY

Metals and Ceramics Division

WL/MLLM

Wright-Patterson AFB, OH 45433
A. Katz
L. Zawada
T. Nichols
J. Russo

162. DOE

IDAHO OPERATIONS OFFICE

P. O. Box 1625

Idaho Falls, ID 83415

R. B. Loop 
163-164. DOE

DOE OAK RIDGE FIELD OFFICE

P. O. Box 2001

Oak Ridge, TN 37831

Assistant Manager for Energy Research and Development

G. L. Riner

165. DOE

DOE OAK RIDGE FIELD OFFICE

P. O. Box 2008

Building 4500N, MS 6269

Oak Ridge, TN 37831

E. E. Hoffman

166. DOE

OFFICE OF BASIC ENERGY SCIENCES

Materials Sciences Division

ER-131 GTN

Washington, DC 20545

J. B. Darby

167. DOE

OFFICE OF CONSERVATION AND RENEWABLE ENERGY

CE-12 Forrestal Building

Washington, DC 20545

J. J. Eberhart

168. DOE

OFFICE OF ENERGY RESEARCH

ER-131, MS G-236

Washington, DC 20545

R. J. Gottschall

169. DOE

OFFICE OF FOSSIL ENERGY

Washington, DC 20545

J. P. Carr (FE-14) GTN

170. DOE-HQ

OFFICE OF INDUSTRIAL TECHNOLOGY

1000 Independence Avenue, S. W.,

CE-221, SF-035/FORS

Washington, DC 20585

S. L. Richlen 
171. DOE

OFFICE OF VEHICLE AND ENERGY R \& D

CE-151 Forrestal Building

Washington, DC 20545

R. B. Schulz

172-180. DOE

MORGANTOWN ENERGY TECHNOLOGY CENTER

P. O. Box 880

Morgantown, WV 26505

R. A. Bajura

R. C. Bedick

D. C. Cicero

F. W. Crouse, Jr.

N. T. Holcombe

W. J. Huber

M. J. Mayfield

J. E. Notestein

J. S. Wilson

181-184. DOE

PITTSBURGH ENERGY TECHNOLOGY CENTER

P. O. Box 10940

Pittsburgh, PA 15236

A. H. Baldwin

G. V. McGurl

R. Santore

T. M. Torkos 


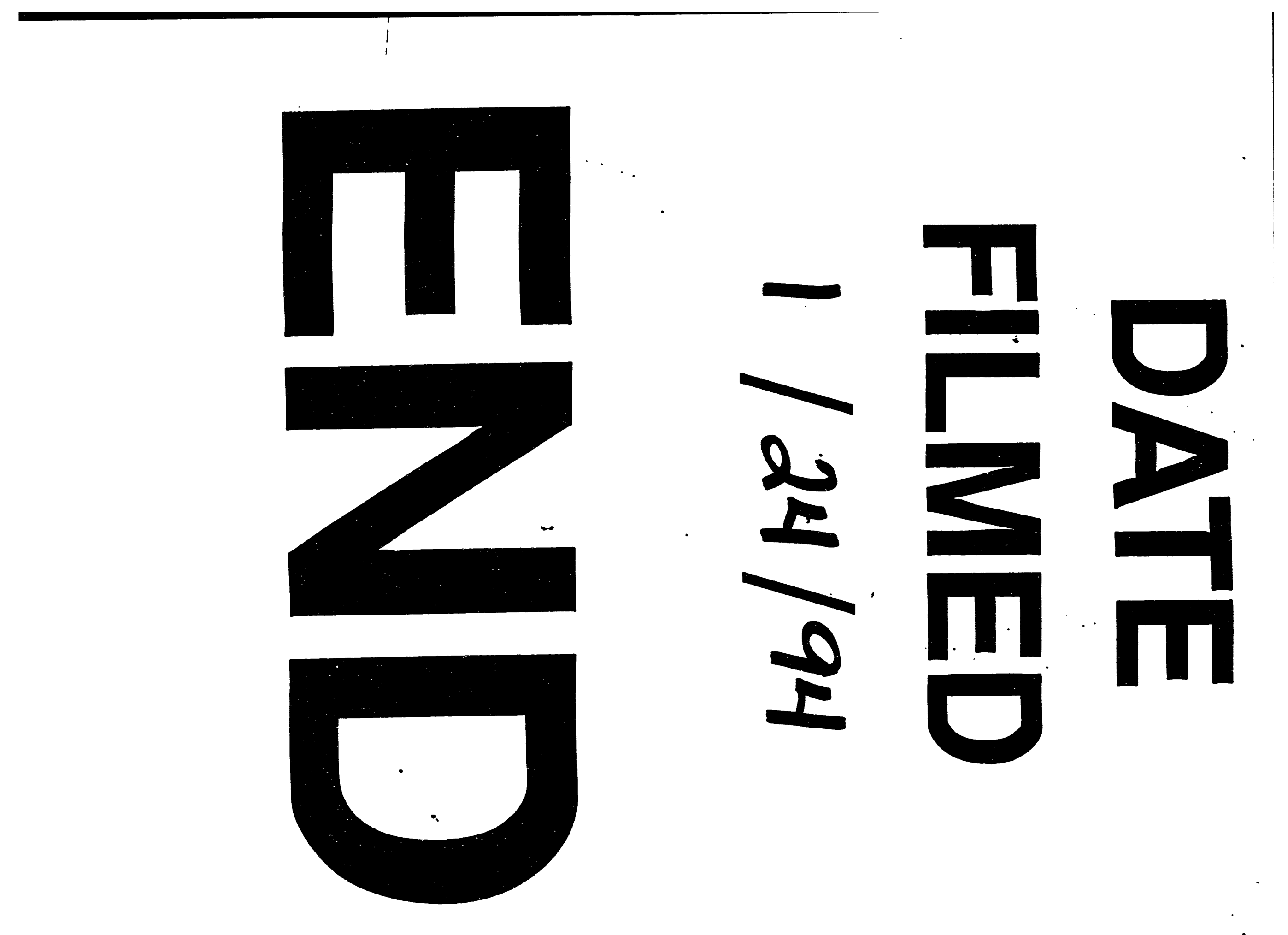


